\author{
UNIVERSIDADE DE SÃO PAULO \\ ESCOLA DE ENGENHARIA DE SÃO CARLOS
}

ISABELA ZULINI

Efeito do confinamento na aderência entre barras de aço e concreto de alta resistência à compressão

São Carlos

2019 

ISABELA ZULINI

\title{
Efeito do confinamento na aderência entre barras de aço e concreto de alta resistência à compressão
}

\author{
VERSÃO CORRIGIDA
}

A versão original encontra-se na Escola de Engenharia de São Carlos

Dissertação apresentada à Escola de Engenharia de São Carlos da Universidade de São Paulo, como parte dos requisitos necessários à obtenção do título de Mestre em Engenharia de Estruturas

Área de Concentração: Estruturas

Orientadora: Profa. Dra. Ana Lúcia Homce de Cresce El Debs

São Carlos 
AUTORIZO A REPRODUÇÃO TOTAL OU PARCIAL DESTE TRABALHO POR QUALQUER MEIO CONVENCIONAL OU ELETRÔNICO, PARA FINS DE ESTUDO E PESQUISA, DESDE QUE CITADA A FONTE.

Ficha catalográfica elaborada pela Biblioteca Prof. Dr. Sérgio Rodrigues Fontes da EESC/USP com os dados inseridos pelo(a) autor(a).

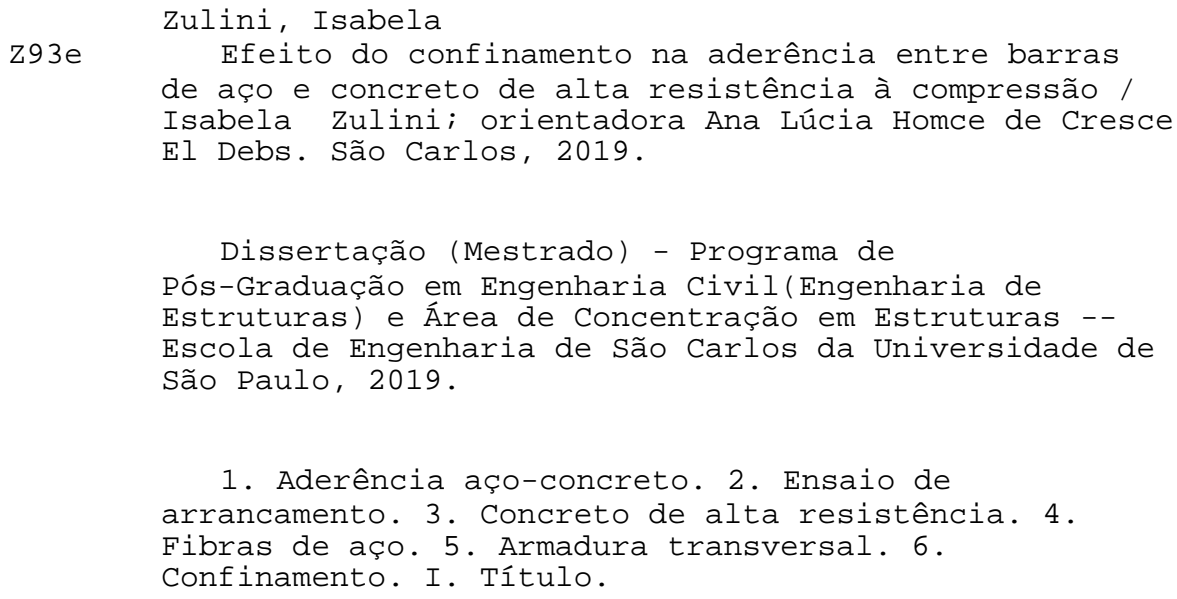

Eduardo Graziosi Silva - CRB - 8/8907 


\section{FOLHA DE JULGAMENTO}

Candidata: Engenheira ISABELA ZULINI.

Título da dissertação: " Efeito do confinamento na aderência entre barras de aço e concreto de alta resistência à compressão".

Data da defesa: 07/08/2019.

Comissão Julgadora:

Resultado:

Profa. Associada Ana Lucia Homce de Cresce El Debs

APROVADA (Orientadora)

(Escola de Engenharia de São Carlos/EESC)

Prof. Dr. Leandro Mouła Trautwein APROVADA

(Universidade Estadual de Campinas/UNICAMP)

Prof. Dr. Fernando Menezes de Almeida Filho APROVADA (Universidade Federal de São Carlos/UFSCar)

Coordenador do Programa de Pós-Graduação em Engenharia Civil (Engenharia de Estruturas):

Prof. Associado Vladimir Guilherme Haach

Presidente da Comissão de Pós-Graduação:

Prof. Titular Murilo Araujo Romero 



\section{AGRADECIMENTOS}

A Deus, pelo dom da vida e por todas as bênçãos alcançadas, por me iluminar e proteger dos perigos.

A toda minha família, em especial meus pais, Neusa e Reginaldo, e minha irmã, Marcela, por todo amor, apoio e incentivo para que fosse possível estudar na EESC-USP.

Ao meu namorado, Danilo, pelo carinho, amor, apoio e companheirismo, por permanecermos unidos mesmo com a distância durante a faculdade e termos superado momento difíceis.

A professora Ana Lúcia, por toda confiança em mim depositada, pela atenção oferecida, pelo incentivo para que eu não desistisse e todo carinho ao longo desses anos.

Aos professores Fernando, Vladimir e Leandro pelas sugestões na qualificação e defesa para aprimorar meu trabalho. Aos professores Ricardo e Vladimir, funcionário Dorival e amigos do Departamento Pablo, Arthur e Carol Rezende, por me auxiliarem com a simulação numérica.

Aos meus amigos e colegas de faculdade e do departamento. Agradeço em especial Aline, Cristina, Gabrielle, Eduardo, Fernanda, Juliana, Jéssica, Juan, Marcos, Raquel e Tatiane pela amizade, companhia, incentivo, ajuda e tantas horas de estudos/trabalhos. Agradeço também Alex, Elias e Gidrão por me ajudarem tantas vezes no laboratório e a professora Alessandra, por me auxiliar na confecção do traço do concreto e me acompanhar nas diversas concretagens, me tranquilizando e ensinando sempre com muita paciência.

Aos técnicos do laboratório, Amaury, Fabiano, Jorge, Mauri, Luiz Vareda e Romeu, por toda dedicação para que fosse possível executar meus ensaios.

Aos funcionários do departamento, pela atenção e dedicação em todos os serviços fornecidos.

À EESC-USP por deixar marcado na minha vida tantos momentos bons, permitir que eu conhecesse pessoas maravilhosas e aprendesse tanto.

Às empresas Grace Construction Products e Tecnosil pelo fornecimento do superplastificante e da sílica ativa utilizados no concreto.

À Coordenação de Aperfeiçoamento de Pessoal de Nível Superior (CAPES), pelo financiamento da bolsa de pesquisa.

Enfim, a todos que, direta ou indiretamente, colaboraram para a realização deste trabalho. 

ZULINI, I (2019). Efeito do confinamento na aderência entre barras de aço e concreto de alta resistência à compressão. 2019. Dissertação (Mestrado em Engenharia Civil (Estruturas)), Escola de Engenharia de São Carlos, Universidade de São Paulo, São Carlos, 2019.

O presente trabalho buscou investigar o efeito do confinamento no comportamento da aderência em concreto de alta resistência, na faixa de $70 \mathrm{MPa}$. Para isso, foram realizados ensaios de arrancamento de carregamento monotônico com um trecho aderente central de comprimento igual a três vezes o diâmetro da barra longitudinal isolado por trechos não aderentes de cinco vezes o diâmetro da barra, variando os seguintes parâmetros: diâmetro da barra longitudinal, de $10 \mathrm{~mm}, 16 \mathrm{~mm}$ e $20 \mathrm{~mm}$; cobrimento de concreto, sendo a relação entre o diâmetro do corpo-de-prova e da barra igual a 8, 9 e 15; adição de fibras de aço, no teor volumétrico de 1\%; e inclusão de armadura transversal helicoidal. A partir da análise experimental, foi possível verificar que o aumento no diâmetro da armadura longitudinal promoveu um aumento na tensão de aderência máxima e no deslizamento último, exceto no caso onde houve a mudança de ruptura de arrancamento para fendilhamento (de $16 \mathrm{~mm}$ para $20 \mathrm{~mm}$ ). Também, constatou-se que a inclusão de fibra metálica no concreto de alta resistência foi o mecanismo mais eficiente de confinamento no âmbito da aderência. Além disso, os resultados obtidos experimentalmente foram comparados com os modelos teóricos de autores da literatura e com as equações para a resistência de aderência descritas nas normas brasileira, americana e europeia. Por fim, concluiu-se que todas as prescrições normativas estão a favor da segurança, com uma grande margem de tolerância para a resistência de aderência.

Palavras-chave: Aderência aço-concreto. Ensaio de arrancamento. Concreto de alta resistência. Fibras de aço. Armadura transversal. Confinamento. 



\section{ABSTRACT}

\section{ZULINI, I (2019). Effects of confinement in bond between reinforcement bar and high}

strength concrete. 2019. Dissertation (M. Sc. in Civil Engineering (Structures)), São Carlos School of Engineering, University of São Paulo, São Carlos, 2019.

The present work investigates the effect of the confinement on the behavior of bond in high strength concrete, around $70 \mathrm{MPa}$. In order to aim this objective, it was made several monotonic pull-out tests with a central bond length equal to three times the rebar diameter isolated by bond-free lengths of five times the rebar diameter, changing the following parameters: rebar diameter, of 10, 16 and $20 \mathrm{~mm}$; concrete cover, with a ratio between the concrete diameter and the rebar diameter of 8,9 and 15; including steel fiber, at a volumetric rate of $1 \%$; and including spiral reinforcement. By the experimental analysis, it was possible to verify that increasing the rebar diameter made the maximum bond stress and slip also increase, except for the case where the rupture changed from splitting to pull-out (from 16 $\mathrm{mm}$ to $20 \mathrm{~mm}$ ). Also, it was found that including steel fiber in high strength concrete showed to be the most efficient confinement's mechanism within the bond behavior. Besides, the experimental results were compared to the theoretical models proposed by authors from the literature and to the equations for bond strength from the Brazilian, American and European model codes. Lastly, it was concluded that all the model codes are in favor of safety, with a large margin of tolerance for bond strength.

Keywords: Bond steel-concrete. Pull-out test. High Strenght Concrete. Steel fiber. Stirrup. Confinement. 



\section{SUMÁRIO}

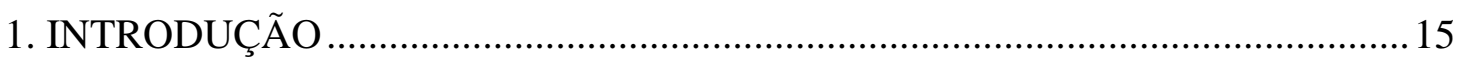

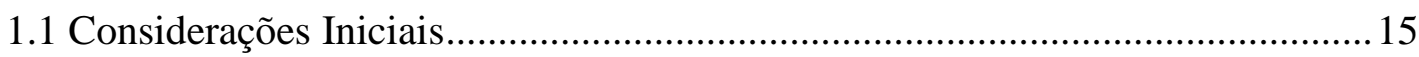

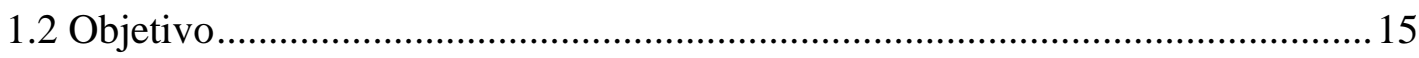

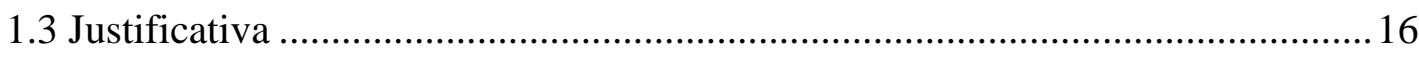

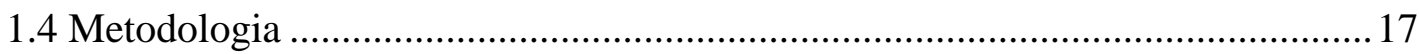

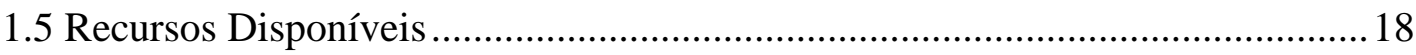

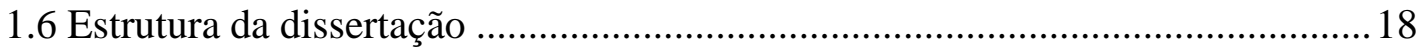

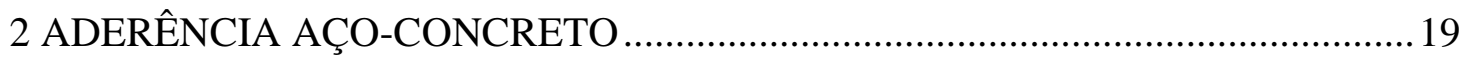

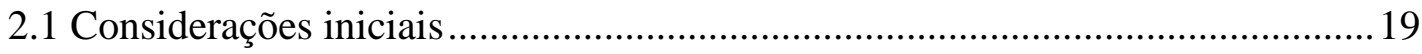

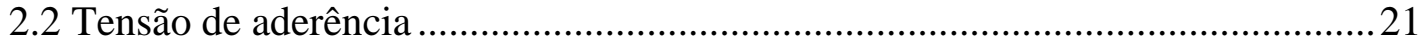

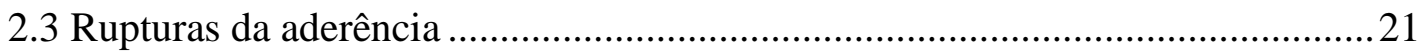

2.4 Ensaio de arrancamento direto (Pull Out Test) ............................................. 22

2.4.1 Ensaio de arrancamento RILEM-CEB-FIP (1973) ...................................24

2.4.2 Ensaio de arrancamento de Rehm e Eligehausen (1979) ............................26

2.5 Parâmetros que influenciam na aderência.........................................................2 27

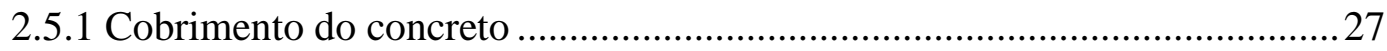

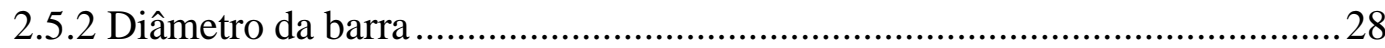

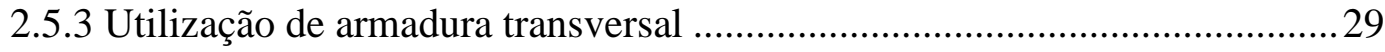

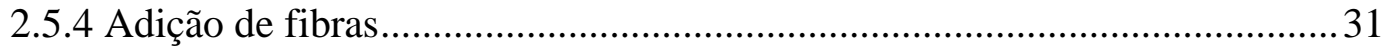

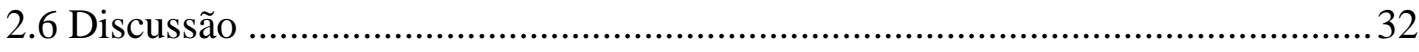

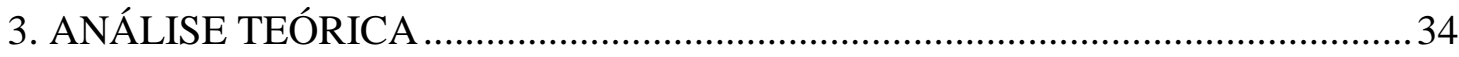

3.1 Prescrições normativas para o cálculo da resistência de aderência...................... 34

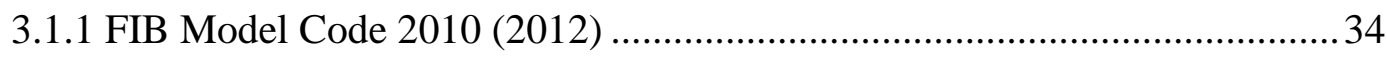

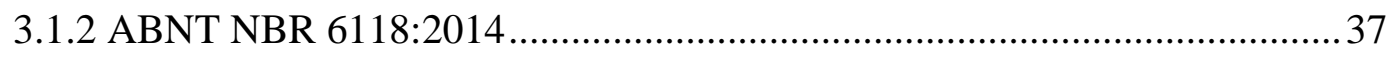

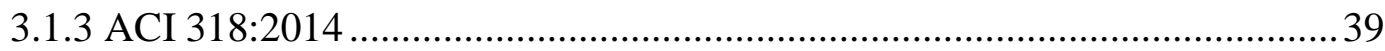


3.2 Previsão da curva tensão de aderência versus deslizamento 41

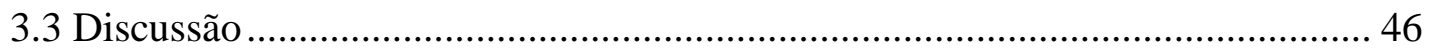

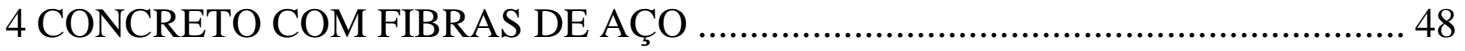

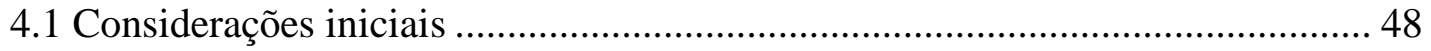

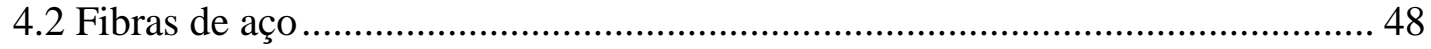

4.3 Características do concreto com fibras ......................................................... 50

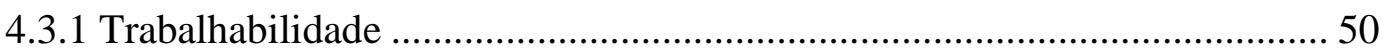

4.3.2 Módulo de elasticidade e coeficiente de Poisson....................................... 50

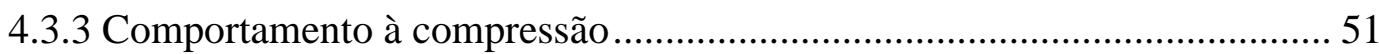

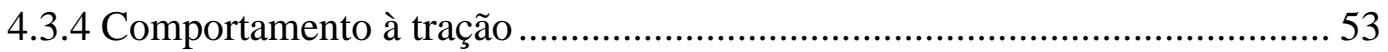

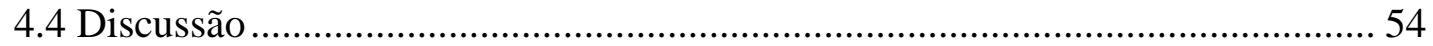

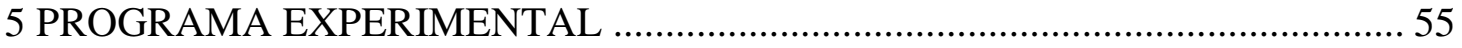

5.1 Caracterização dos materiais constituintes do concreto ................................. 57

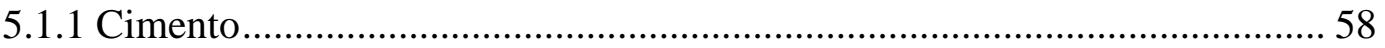

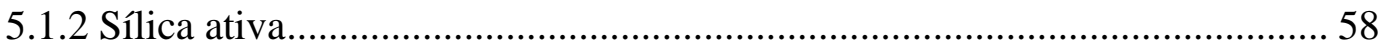

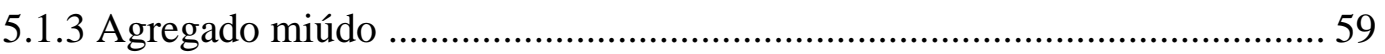

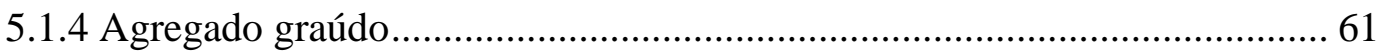

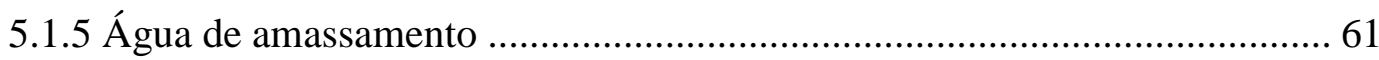

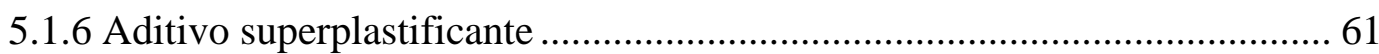

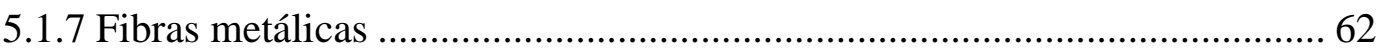

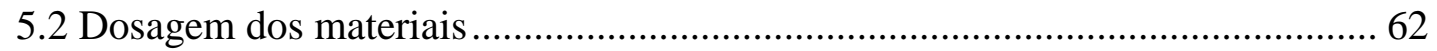

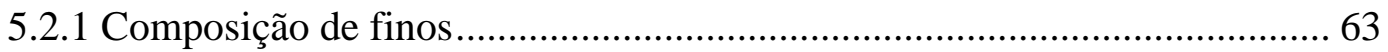

5.2.2 Consumo dos materiais e traço em massa ................................................ 63

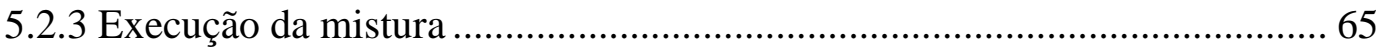

5.3 Ensaios de determinação das propriedades do concreto..................................... 66

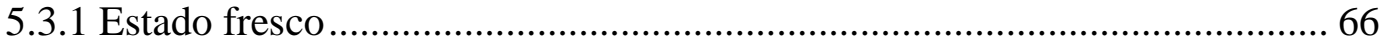

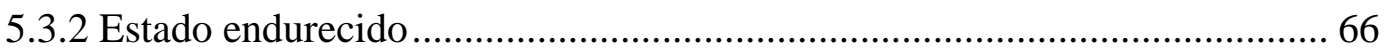


5.4 Ensaios de determinação das propriedades do aço 70

5.5 Ensaio de arrancamento 73

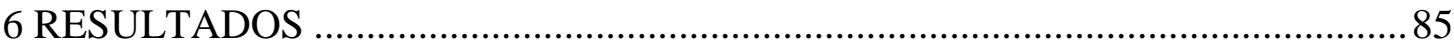

6.1 Ensaios de caracterização do concreto ........................................................... 85

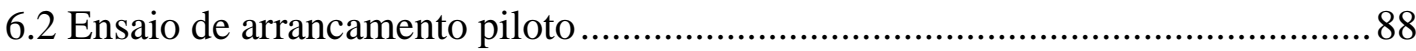

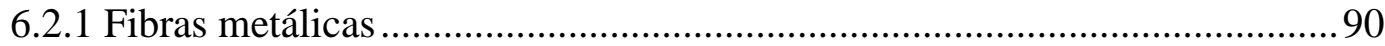

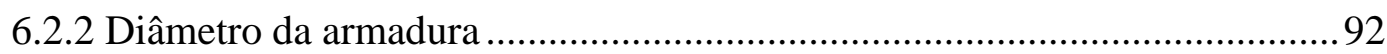

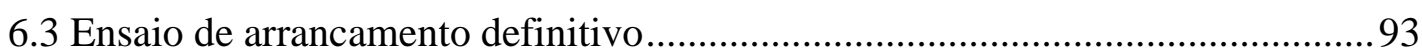

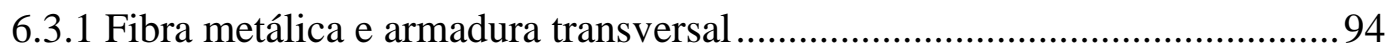

6.3.2 Cobrimento de concreto e armadura transversal .........................................99

6.3.3 Cobrimento de concreto e fibra metálica .................................................99

6.3.4 Cobrimento de concreto, fibra metálica e armadura transversal ................ 100

6.4 Comparações entre os resultados experimentais e prescrições normativas ...... 101

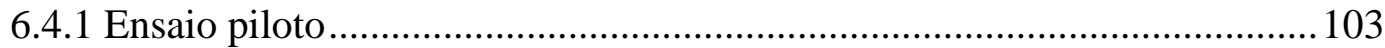

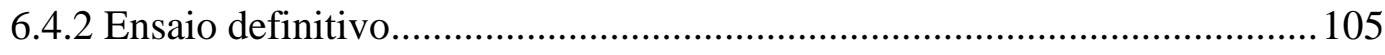

6.5 Comparações entre os resultados experimentais e modelos teóricos................. 108

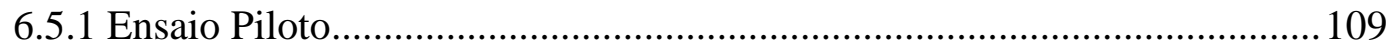

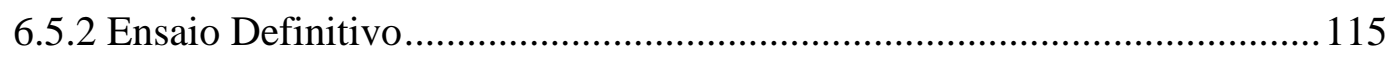

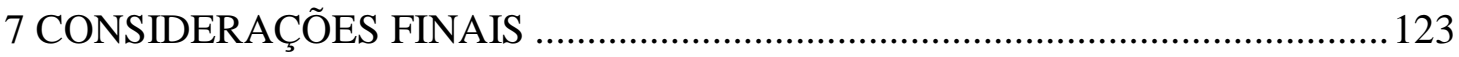

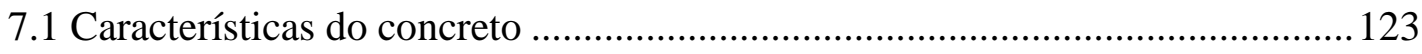

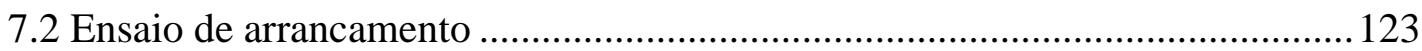

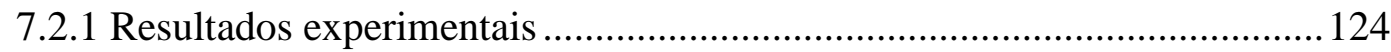

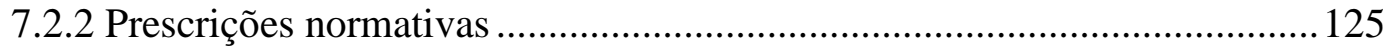

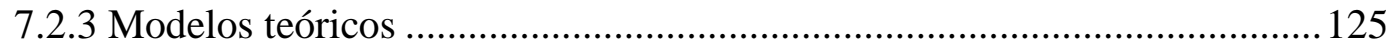

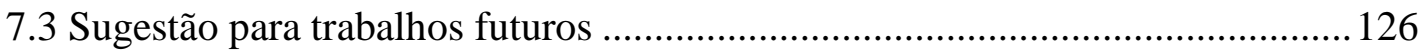

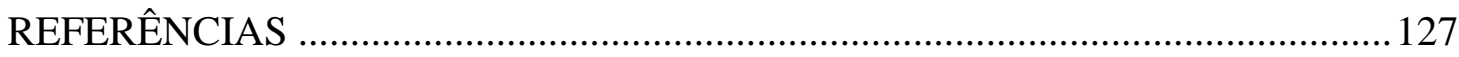

Apêndice A- Curvas de tensão de aderência versus deslizamento .............................. 131 



\section{INTRODUÇÃO}

\subsection{CONSIDERAÇÕES INICIAIS}

$\mathrm{O}$ uso de concreto armado em edificações está relacionado, principalmente, às vantagens do material: excelente resistência à água, adequação a diferentes formas e tamanhos devido à plasticidade no estado fresco e baixo custo, em geral, pois seus componentes básicos estão disponíveis em grande parte do planeta. No entanto, o concreto convencional possui uma relação resistência-peso baixa em relação ao aço (MEHTA; MONTEIRO, 2008).

Com a diminuição da relação água/cimento foi possível aumentar a resistência à compressão do concreto até a faixa de $40 \mathrm{MPa}$ e, consequentemente, diminuir as seções dos elementos, possibilitando a construção de edificações mais elevadas. Nos anos 70, com o avanço na tecnologia dos superplastificantes e aditivos redutores de água, a resistência pôde ser aumentada ainda mais, resultando no concreto de alta resistência, com valores entre 60 e $120 \mathrm{MPa}$. Porém, apesar de possuir uma alta resistência à compressão, ele apresenta algumas limitações como o comportamento de ruptura frágil e a pequena capacidade de deformação. A incorporação de fibras metálicas possibilitou a criação de um material mais dúctil, decorrente da redução da propagação das fissuras e aumento da tenacidade do material, constituindo um novo tipo de concreto: concreto reforçado com fibras ou concreto com fibras (MEHTA; MONTEIRO, 2008).

O concreto armado só existe devido à solidariedade entre a armadura e o concreto, possibilitada pela aderência (FUSCO, 1995). Os fundamentos dessa propriedade foram amplamente estudados no passado para os concretos convencionais e, atualmente, para concretos de alta resistência (SANTANA, 2014). Porém, a influência da armadura transversal e incorporação de fibras metálicas como mecanismos de confinamento, que altera o comportamento da aderência, é uma lacuna importante a ser preenchida para o uso seguro do concreto de alta resistência.

\subsection{OBJETIVO}

O objetivo geral deste trabalho foi estudar o efeito do confinamento na aderência entre o aço e o concreto de alta resistência, na faixa de $70 \mathrm{MPa}$, por meio de uma investigação 
teórico-experimental utilizando ensaios de arrancamento conforme proposto por Rehm e Eligehausen (1979).

Os objetivos específicos foram:

a) Estudar o efeito dos diversos mecanismos de confinamento, por meio do aumento do cobrimento de concreto, adição de fibras de aço e inclusão de armadura transversal, na aderência entre a barra longitudinal e o concreto;

b) Verificar a influência de diferentes diâmetros da barra longitudinal na aderência entre a barra longitudinal e o concreto;

c) Comparar os resultados experimentais com os modelos teóricos propostos por autores da literatura e prescrições normativas.

\subsection{JUSTIFICATIVA}

A propriedade da aderência entre o aço e o concreto é desenvolvida no comprimento de ancoragem, o qual é responsável pela transmissão dos esforços e compatibilidade de deformações entre os materiais. Dessa forma, é necessário que seu valor seja otimizado para garantir que os materiais atinjam sua capacidade de resistência máxima sem torná-lo superdimensionado a ponto de ser antieconômico (SANTANA, 2014).

Existem diversos mecanismos de confinamento passivo que são utilizados no dia-dia da engenharia e que podem impactar positivamente na aderência, entre eles, a introdução de fibras metálicas e de armadura transversal e o aumento no cobrimento de concreto. No entanto, as prescrições normativas não incluem esses fatores no dimensionamento do comprimento de ancoragem, limitando-se, basicamente, à resistência (à compressão ou à tração) do concreto e ao diâmetro da barra.

Nesse contexto, o presente trabalho buscou verificar a influência de alguns mecanismos de confinamento no comportamento da aderência, além de comparar os resultados experimentais com os modelos teóricos propostos por alguns autores e com as prescrições normativas mais usuais. Além disso, a pesquisa buscou dar prosseguimento nos estudos da aderência, contribuindo com novas constatações e reforçando entendimentos anteriores. 


\subsection{METODOLOGIA}

Foi adotada a seguinte metodologia para atingir os objetivos propostos:

a) Revisão Bibliográfica: foi realizada uma pesquisa bibliográfica com o objetivo de aprofundar os conhecimentos sobre o assunto com base em trabalhos desenvolvidos sobre o tema até o momento.

b) Análise Teórica: foi feito um estudo dos modelos teóricos para o comportamento da aderência propostos pelos seguintes pesquisadores: Harajli, Hout e Jalkh (1995), Huang, Engstron e Magnusson (1996), Barbosa (2001), Almeida Filho (2006) e Simplício (2008). Também, foram avaliadas as equações de resistência de aderência sugeridas pelas normas técnicas: FIB Model Code 2010 (2012), ABNT NBR 6118:2014 e ACI 318:2014.

b) Análise Experimental: a análise experimental consistiu em fazer ensaios de arrancamento em concreto de resistência de $70 \mathrm{MPa}$, segundo o modelo proposto por Rehm e Eligehausen (1979), que consiste em um trecho aderente central de três vezes o diâmetro da barra longitudinal isolado por trechos não aderentes de cinco vezes o diâmetro da barra, separada em:

1) Ensaio piloto: realizado com o objetivo de avaliar o comportamento da aderência entre diversos diâmetros e a influência da adição de fibra no concreto na taxa volumétrica de $1 \%$, além de verificar se a geometria dos modelos estava apropriada para o estudo. Dessa forma, foi possível escolher um diâmetro da barra longitudinal para a investigação dos ensaios definitivos.

2) Ensaio de caracterização dos materiais: foram feitos diversos ensaios de caracterização dos materiais envolvidos (concreto, barra de aço e fibras metálicas).

3) Ensaio de arrancamento dos modelos definitivos: com o diâmetro fixado a partir do ensaio piloto e com as alterações necessárias, foram executados ensaios de arrancamento variando os seguintes parâmetros: cobrimento de concreto e inclusão de armadura transversal e fibras metálicas no concreto. 
c) Análise dos Resultados: de posse dos resultados teóricos e experimentais foi realizada uma análise comparativa dos resultados, que permitiu elaborar conclusões pertinentes ao assunto em questão.

\subsection{RECURSOS DISPONÍVEIS}

Os recursos que foram utilizados incluem: materiais das bibliotecas do Campus USPSão Carlos e das bases de dados disponíveis online e infraestrutura do Laboratório de Estruturas do Departamento de Engenharia de Estruturas da EESC-USP para execução dos ensaios de arrancamento e de caracterização dos materiais.

\subsection{ESTRUTURA DA DISSERTAÇÃO}

A dissertação foi composta por sete capítulos, além das referências utilizadas.

O primeiro capítulo inclui as considerações iniciais do estudo: a origem do concreto de alta resistência com fibras e a importância da aderência no concreto armado. Além disso, contém o objetivo e justificativa da pesquisa, a metodologia adotada e recursos disponíveis.

O segundo capítulo apresenta o comportamento da aderência aço-concreto, incluindo as parcelas que a compõe, o conceito de tensão de aderência, formas de ruptura, tipos de ensaios de arrancamento e parâmetros que a influenciam, em especial o cobrimento de concreto, diâmetro da barra e inclusão de armadura transversal e fibras, que foram tópicos avaliados no presente trabalho.

O terceiro capítulo contém as equações para cálculo da resistência de aderência pelas normas. Também, são apresentados os modelos teóricos para previsão do gráfico da tensão de aderência versus deslizamento propostos por autores que abordaram o tema.

O quarto capítulo retrata os tipos de fibras e principais propriedades do concreto com fibras.

O quinto capítulo é composto pelo programa experimental, apresentando as características dos materiais utilizados, a dosagem do concreto, procedimento de concretagem e ensaios, geometria dos modelos e instrumentação utilizada.

O sexto capítulo inclui uma discussão dos resultados do programa experimental.

O sétimo capítulo apresenta uma conclusão do trabalho apresentado e propões tópicos a serem estudados em trabalhos futuros. 


\section{ADERÊNCIA AÇO-CONCRETO}

\subsection{CONSIDERAÇÕES INICIAIS}

A aderência é o termo utilizado para a interação e transferência de força entre a armadura e o concreto, influenciando o desempenho do concreto armado em diversos modos. No estado limite de serviço, a aderência influencia a largura e espaçamento de fissuras transversais, o enrijecimento da tensão e a curvatura. No estado limite último, ela é responsável pela resistência nos dispositivos de ancoragem e influencia a capacidade de rotação das regiões das rótulas plásticas (FIB MODEL CODE 2010, 2012)

A aderência garante solidariedade dos componentes do concreto armado, o aço e o concreto, fazendo com que trabalhem em conjunto. Ela atua controlando o deslocamento relativo entre a barra de aço e o concreto que a envolve, possibilitando a transferência dos esforços e a compatibilidade de deslocamentos entre eles (FUSCO, 1995).

Segundo Fusco (1995) e Leonhardt e Mönnig (1977), a aderência é composta por três parcelas distintas, mas essa separação é meramente didática, visto que não é possível determinar cada uma delas separadamente:

- Aderência por adesão:

É a parcela que corresponde à resistência à separação dos dois materiais oriunda das ligações físico-químicas na interface aço e concreto, que ocorrem durante a pega do cimento. $\mathrm{O}$ efeito de colagem entre os materiais depende da conformação e condição superficial da barra. Essa parcela tem um valor pequeno se comparada às demais e um pequeno deslocamento relativo entre os materiais já é suficiente para rompê-la (FUSCO, 1995).

- Aderência por atrito:

Nos ensaios de arrancamento, verifica-se que a força de aderência desenvolvida é superior à parcela por adesão. Esse incremento ocorre devido às forças de atrito, que decorrem da pressão transversal exercida pelo concreto sobre a barra. Este fenômeno acontece porque a presença da barra no concreto inibe parcialmente as deformações de retração do concreto, mas podem aparecer também devido às tensões de compressão transversais resultantes das cargas. A solidarização dos materiais, e, portanto, a aderência, é maior em barras curvas, devido ao maior atrito, e sob compressão transversal externa, como nos apoios diretos das vigas (FUSCO, 1995). 
- Aderência mecânica:

A terceira parcela da aderência ocorre devido à presença de saliências na superfície da barra, que funcionam como "consolos" e mobilizam tensões de compressão no concreto. Nas barras nervuradas, a aderência ocorre quase que totalmente devido a essa parcela, mas sua intensidade depende da forma e inclinação das nervuras, altura e distância livre entre elas. Mesmo as barras lisas apresentam essa parcela devido às irregularidades superficiais decorrentes do processo de laminação e praticamente se confunde com a parcela por atrito. Este é o tipo de ligação mais efetiva e confiável, pois contribui de maneira significativa para a solidarização dos dois materiais (FUSCO, 1995).

Desse modo, não é possível determinar cada parcela da aderência com precisão, mas pode-se fazer uma avaliação qualitativa por meio da análise do gráfico da Figura 1:

Figura 1-Comportamento esquemático da relação tensão de aderência versus deslizamento para barras lisas e nervuradas

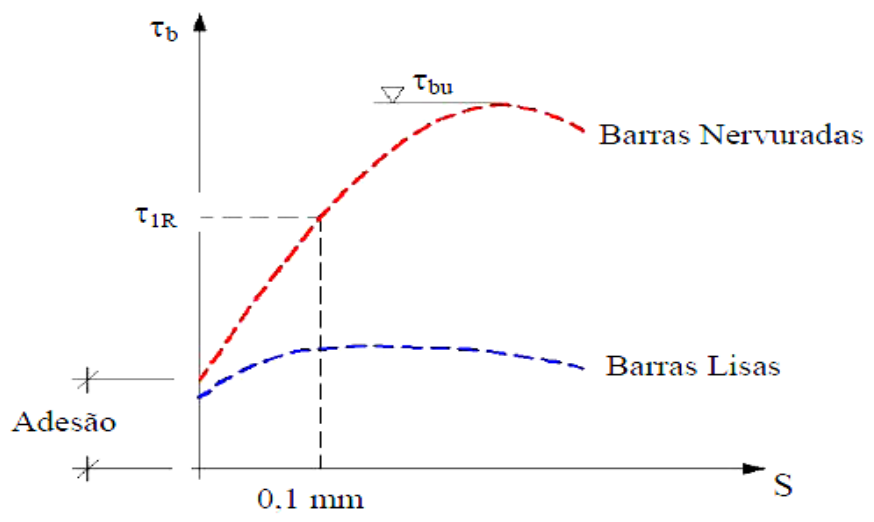

Fonte: Leonhardt e Mönnig (1977), modificado por Santana (2014)

Logo que a barra é solicitada, não ocorrem deslizamentos e se desenvolve a parcela de aderência por adesão. Em seguida, o trecho inclinado da curva corresponde à aderência mecânica, sendo mais acentuado para barras nervuradas. O trecho descendente da curva corresponde à perda de aderência, caracterizada pelo decréscimo da tensão de aderência e aumento do deslizamento. Nas barras lisas, a curva é mais abatida e a perda de aderência ocorre de forma mais suave, devido às características da aderência por atrito (LEONHARDT; MÖNNIG, 1977). 


\subsection{TENSÃO DE ADERÊNCIA}

A tensão de aderência representa a variação da tensão na interface do aço com o concreto, relacionada com a força atuante na barra e a superfície da barra aderente ao concreto. A tensão última de aderência corresponde ao instante em que uma barra de aço imersa em uma peça de concreto está na iminência de ser arrancada. É feita uma aproximação no cálculo dessa tensão, considerando-a uniformemente distribuída ao longo do comprimento da barra (FUSCO, 1995).

De acordo com Leonhardt e Mönnig (1977), a tensão de aderência surge quando há variação de tensões em um trecho da barra de aço, que pode ocorrer devido à presença de:

- Cargas: provocam alterações nas tensões de compressão e tração nas barras da armadura;

- Fissuras: provocam uma concentração localizada na tensão de aderência;

- Forças de ancoragem nas extremidades da barra: a força atuante na barra é transferida ao concreto por meio da aderência;

- Variações de temperatura: a aderência tende a restringir a maior dilatação das barras de aço em relação ao concreto, mas, quando a tensão de aderência atinge valores muito elevados pode ocorrer ruptura do cobrimento de concreto;

- Retração do concreto: a perda da água adsorvida devido às diferenças de umidade entre o concreto e o ambiente causa deformações no concreto e são impedidas pela barra de aço, originando tensões de compressão na armadura e tração no concreto;

- Deformação lenta do concreto em peças comprimidas de concreto armado: a perda da água adsorvida devido à aplicação de tensão provoca um acréscimo nas tensões de compressão das barras e alívio no concreto.

\subsection{RUPTURAS DA ADERÊNCIA}

As rupturas da aderência podem ser: pelo arrancamento, quando a barra é puxada após a ruptura da interface entre o concreto e a barra, com comportamento mais dúctil e ocorre quando existe um bom confinamento, ou fendilhamento do concreto, resultante do efeito de tração circunferencial, típico de situações em que o confinamento é inadequado (FUSCO, 1995; ACI 408R, 2003). 
A Figura 2 apresenta a configuração aproximada do gráfico da tensão de aderência versus deslizamento para cada tipo de ruptura da aderência.

Figura 2-Representação esquemática (curva tensão de aderência versus escorregamento e fissuras típicas) da ruptura da aderência por a) arrancamento e b) fendilhamento

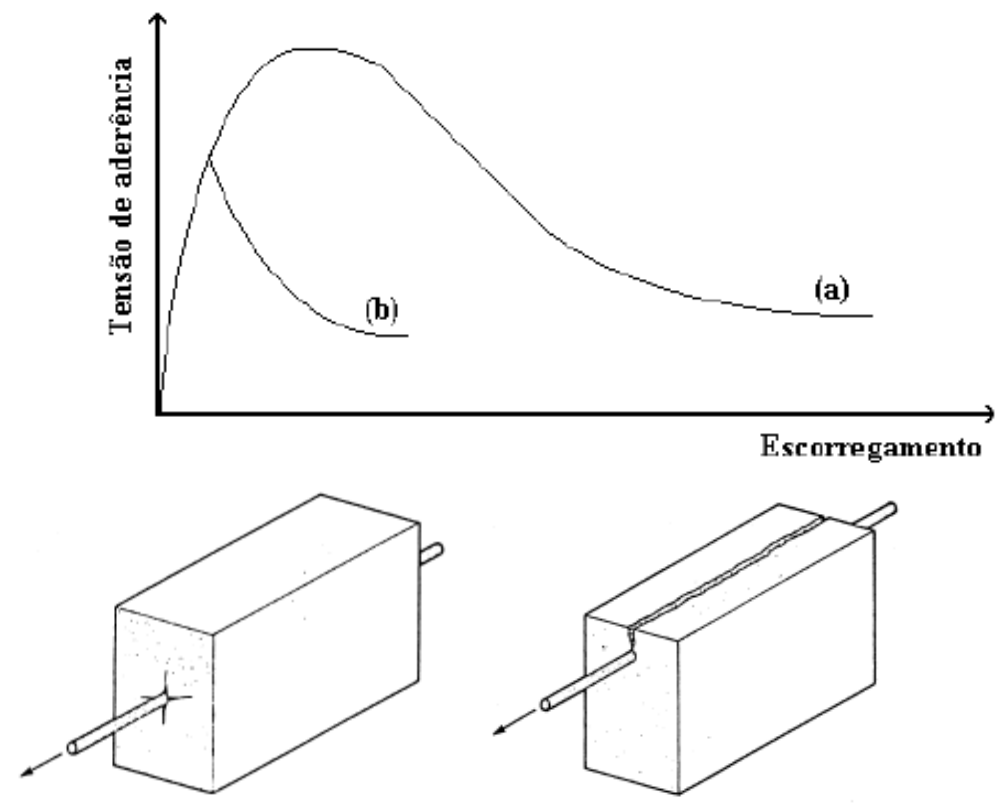

a)

b)

Fonte: Dumêt (2003)

\subsection{ENSAIO DE ARRANCAMENTO DIRETO (PULL OUT} TEST)

O ensaio de arrancamento direto é o ensaio clássico para determinação da resistência de aderência, no qual uma das extremidades da barra é projetada para fora do prisma de concreto e tracionada, com seu deslocamento medido.

Segundo Fusco (1995), a tensão de aderência, $\tau_{\mathrm{b}}$, se relaciona com a tensão $\sigma_{\mathrm{s}}$ decorrente da aplicação da força de tração, conforme a Figura 3: 
Figura 3-Tensões mobilizadas no ensaio de arrancamento

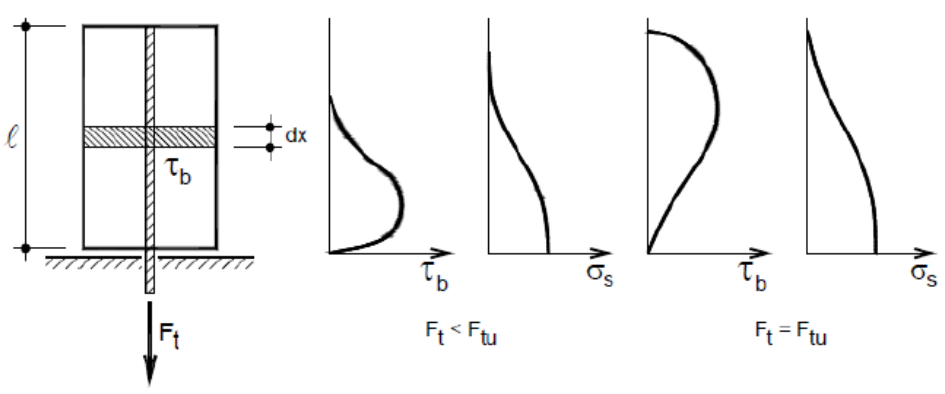

Fonte: Fusco (1995), modificado por Santana (2014)

Pela Figura 4, pode ser observado que, do equilíbrio do elemento infinitesimal de comprimento $\mathrm{d}_{\mathrm{x}}$, área da seção transversal da barra de aço $\mathrm{A}_{\mathrm{s}}$ e diâmetro da barra $\phi$, tem-se:

$$
\tau_{p}=\frac{\phi}{4} \cdot \frac{d \sigma_{s}}{d x}
$$

Figura 4-Forças e tensões atuantes no elemento infinitesimal

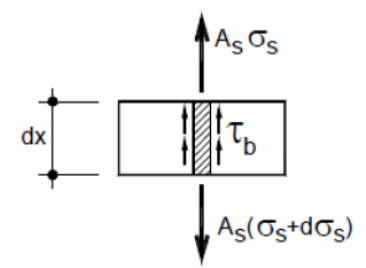

Fonte: Fusco (1995), modificado por Santana (2014)

Verifica-se pela equação analítica da tensão de aderência e pela Figura 3 que a tensão de aderência atinge o valor máximo no ponto de inflexão de $\sigma_{\mathrm{s}}$. Quando a força de tração é menor que última, a aderência é mobilizada em apenas parte da barra, para $d \sigma_{\mathrm{s}} / \mathrm{dx} \neq 0$, ou seja, enquanto $\sigma_{\mathrm{s}}$ não for constante. $\mathrm{O}$ arrancamento ocorre quando a força aplicada $\mathrm{F}_{\mathrm{t}}$, se iguala com a última e toda a capacidade de aderência é mobilizada. Na prática, a força última não é determinada pela carga final de carregamento e sim pela força correspondente a um deslocamento padrão na extremidade da barra, pois normalmente o bloco sofre diversas fissuras antes do arrancamento da barra, em um processo de destruição das ligações entre os materiais (FUSCO, 1995).

Os ensaios de arrancamento resultam em valores médios da tensão de aderência, com a suposição de que todo o comprimento da barra transfere a tensão para o concreto na iminência do arrancamento: 


$$
\tau_{b m}=\frac{\mathrm{R}_{\mathrm{st}}}{\pi \cdot \phi \cdot \mathrm{l}_{\mathrm{b}}}
$$

Sendo:

$\mathrm{R}_{\mathrm{st}}$ : força atuante na barra;

$\phi$ : diâmetro da barra;

$l_{b}$ : comprimento de aderência.

Devido à grande dispersão das medidas para a tensão de aderência, Leonhardt e Mönnig (1977) sugerem o cálculo da resistência de aderência utilizando-se o valor da força atuante na barra que provoca um deslizamento de $0,1 \mathrm{~mm}$ na extremidade oposta. Porém, deve-se estar ciente que o valor da resistência de aderência efetiva é muito maior, já que os deslizamentos podem superar $1 \mathrm{~mm}$.

\subsubsection{ENSAIO DE ARRANCAMENTO RILEM-CEB-FIP (1973)}

Uma das formas de avaliar a aderência entre a barra e o concreto é por meio do ensaio de arrancamento da RILEM-CEB-FIP (1973). O ensaio é composto por um prisma de concreto e uma barra, de diâmetro $\phi$, inserida em seu centro, com apenas metade de seu comprimento aderido ao concreto para evitar a perturbação que ocorre próxima à placa de apoio. Para isso, deve ser utilizada uma mangueira de plástico lisa na região não aderente, que seja o mais rígida possível, e uma cera ou mástique na sua ponta para conectar à barra. Neste ensaio, as duas extremidades da barra são projetadas para fora do prisma de concreto, sendo um trecho menor que o outro, com as dimensões descritas na Figura 5.

Figura 5-Prisma para ensaio de arrancamento RILEM-CEB-FIP
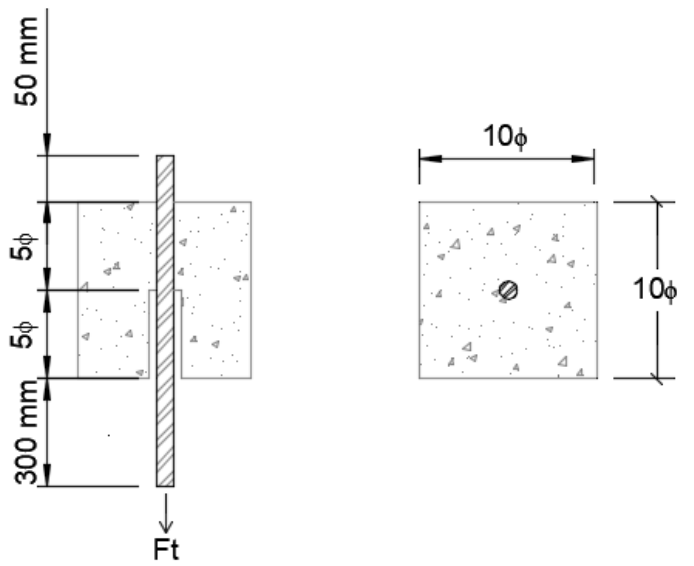

Fonte: RILEM-CEB-FIP (1973), modificado 
A barra é tracionada no extremo maior e os deslocamentos relativos entre a barra e o prisma são medidos no outro extremo. A tensão de aderência é obtida com base em um concreto de resistência de $30 \mathrm{MPa}$ conforme a expressão:

$$
\tau_{p}=0,0637 \cdot \frac{P}{\phi^{2}} \cdot \frac{300}{f_{c m}}
$$

Sendo:

$\tau_{\mathrm{p}}$ : tensão de aderência convertida para uma resistência à compressão do concreto de $30 \mathrm{MPa}$;

P: força de tração aplicada à barra;

$\phi$ : diâmetro da barra;

$\mathrm{f}_{\mathrm{cm}}$ : resistência à compressão média para os corpos-de-prova de $15 / 30 \mathrm{~cm}$.

O modelo tradicional da RILEM-CEB-FIP (1973) não inclui armadura transversal e longitudinal suplementares, o protótipo é concretado na posição horizontal, a compactação é feita por um vibrador de imersão e a resistência à compressão média do concreto do modelo deve estar entre $27 \mathrm{MPa}$ a $33 \mathrm{MPa}$ aos 28 dias, obtida por ensaios em corpos-de-prova de 15/30 cm. Também, é aconselhado utilizar uma velocidade para cada diâmetro da barra que permita um incremento da tensão de aderência constante, que ficaria próximo ao valor obtido pela equação, em kgf/s:

$$
v_{p}=5 . \phi^{2}
$$

Como foi indicado na Figura 5 o modelo tradicional do ensaio é um prisma quadrado de concreto de aresta igual a 10 vezes o diâmetro da barra. No entanto, pesquisadores como Fernandes (2000), Castro (2002), Almeida Filho (2006), Couto (2007) e Santana (2014) optaram por trabalhar com corpos-de-prova cilíndricos por proporcionarem um cobrimento constante, favorecendo uma distribuição uniforme de tensões, além de serem moldados mais facilmente com o uso de tubos de PVC.

Além disso, Simplício (2008) verificou que o comprimento de aderência de $5 \phi$ poderia não ser adequado para concretos de alta resistência, pois pode resultar no escoamento da barra, impedindo a ruptura da aderência por fendilhamento ou arrancamento. $\mathrm{O}$ autor executou diversos ensaios de arrancamento pull-out com comprimento de aderência de $3 \phi$ e o mesmo foi feito nos ensaios de Santana (2014). 


\subsubsection{ENSAIO DE ARRANCAMENTO DE REHM E ELIGEHAUSEN (1979)}

Conforme descrito no ensaio da RILEM-CEB-FIP (1973) e reafirmado por Leonhardt e Mönnig (1977), quando a barra é totalmente aderida ao concreto, a placa de apoio impede a deformação transversal do corpo-de-prova e cria uma compressão pelo efeito arco, provocando uma compressão transversal sobre a barra e, consequentemente, uma aderência por atrito adicional. Eliminando-se alguns trechos de aderência, essas influências são diminuídas. Como é difícil medir diretamente a variação da tensão ao longo do comprimento de aderência, normalmente os cálculos dessa tensão nos ensaios são feitos por meio de valores médios. Verifica-se pela Figura 6, que, utilizando-se valores médios para a tensão de aderência, o modelo proposto por Rehm ${ }^{1}$ (1969 apud LEONHARDT; MÖNNIG, 1977) se aproxima mais do valor limite que o proposto pela RILEM-CEB-FIP (1973).

Figura 6-Modelos para ensaio de arrancamento e suas respectivas variações de tensão de aderência ao longo do comprimento

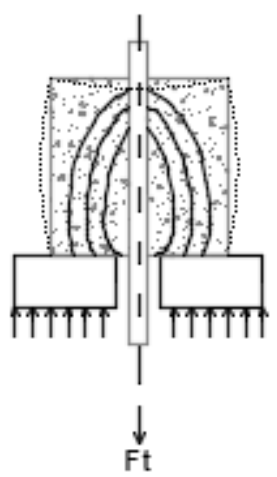

a) Prisma inadequado $c 0 m$ a indicação esquemática da compressão por efe to de arco e de compressão transversal

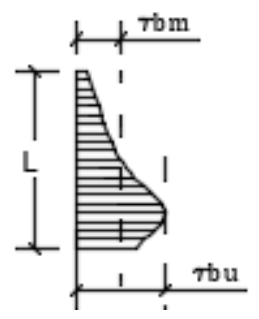

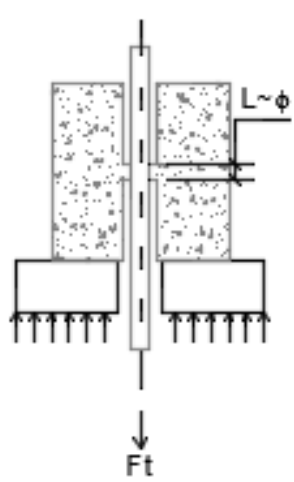

b) Prisma segundo Rehm (1969)

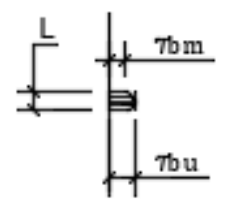

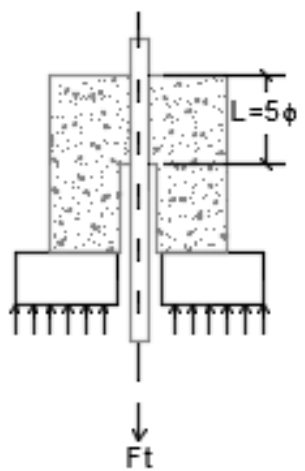

c) Prisma segundo a RILEM-CEB-FIP (1973)

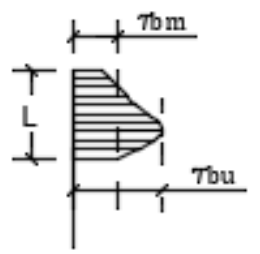

Fonte: Leonhardt e Mönnig (1977), modificado

1 REHM, G. Kriterien zur Beurteilung von Bewehrungsstaben mit hochwetigem Verbund. Stahlbetonbau, Berlin, p.79-96, 1969. 
Rehm e Eligehausen (1979) propuseram um ensaio de arrancamento conforme mostrado na Figura 7, intercalando trechos sem aderência de comprimento $5 \phi$ com um trecho central que permitia a aderência entre o prisma de concreto e a barra. Essa configuração foi proposta a fim de reduzir a influência de uma possível restrição das deformações laterais do concreto por atrito com a placa que aplica o carregamento.

Os autores efetuaram 308 ensaios sob carregamento cíclico com variações no carregamento máximo e amplitude do carregamento, diâmetro da barra $(8,14$ e $28 \mathrm{~mm})$, resistência do concreto (23,5 e $48 \mathrm{MPa}$ ) e comprimento de aderência ( $3 \phi$ e $18 \phi)$.

Figura 7-Esquema do ensaio proposto por Rehm e Eligehausen

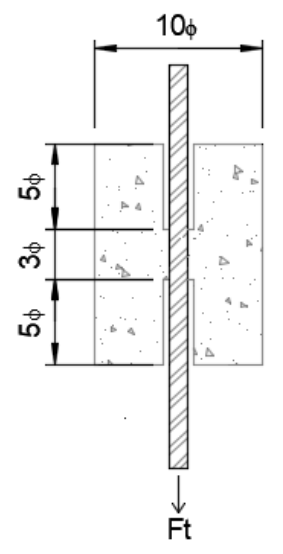

Fonte: Rehm e Eligehausen (1979), modificado

\subsection{PARÂMETROS QUE INFLUENCIAM NA ADERÊNCIA}

Diversos fatores podem interferir na aderência entre a barra da armadura e o concreto. Os seguintes fatores foram destacados, devido à relevância no presente estudo: cobrimento de concreto, diâmetro da barra e inclusão de fibras e de armadura transversal.

\subsubsection{COBRIMENTO DO CONCRETO}

De acordo com o ACI 408R (2003), o aumento do cobrimento do concreto provoca um maior confinamento no elemento estrutural. Com um confinamento adequado, a curva tensão de aderência versus deslizamento tende a ser menos acentuada e a ruptura tende a ocorrer pelo esmagamento do concreto nas nervuras e arrancamento da barra. Porém, no caso de um confinamento pequeno, a ruptura ocorre por fendilhamento, com fissuras originadas das tensões radiais de tração. 
Danin (2010) fez ensaios de arrancamento modificado em corpos-de-prova prismáticos de concreto de $60 \mathrm{MPa}$ variando o diâmetro da barra de 10 a $20 \mathrm{~mm}$. A razão de 3,35 entre o cobrimento e o diâmetro da barra $(\phi)$ foi o limite entre a ruptura por arrancamento e fendilhamento para as barras de $16 \mathrm{~mm}$. Nos corpos-de-prova com barra de 10 e 12,5 mm, o cobrimento de $5,5 \phi$ foi suficiente para provocar o arrancamento da barra. No entanto, todos os modelos de $20 \mathrm{~mm}$ apresentaram fendilhamento por apresentar um cobrimento insuficiente.

\subsubsection{DIÂMETRO DA BARRA}

A tensão de aderência aumenta com o diâmetro da barra. Diâmetros de barras maiores requerem comprimentos de aderência maiores e, consequentemente, promovem uma tensão de aderência maior que para diâmetros menores com o mesmo grau de confinamento. Além disso, o diâmetro da barra longitudinal também influencia no confinamento promovido pela armadura transversal: quando a barra de diâmetro maior desliza, maiores deformações e tensões são mobilizadas na armadura transversal, promovendo maiores tensões de aderência (ACI 408R, 2003).

Barbosa e Filho (2013) analisaram os resultados de ensaios de arrancamento pull-out variando os diâmetros das barras de aço de 16, 20 e $25 \mathrm{~mm}$ e verificaram que ao aumentar o diâmetro da barra houve aumento da tensão de aderência.

Simplício (2008) executou diversos ensaios de arrancamento pull-out com corpos-deprova prismáticos de concreto de alto desempenho reforçado com fibras de aço, com diâmetros da barra de 8, 10, 12,5 e $16 \mathrm{~mm}$. Foi constatado que para um mesmo percentual de fibras e resistência à compressão, houve um acréscimo na tensão última e na ductilidade com o aumento do diâmetro.

Santana (2014) fez ensaios de arrancamento com barras de 10 e $16 \mathrm{~mm}$ para concreto convencional e de alta resistência. Verificou-se que as tensões últimas de aderência cresceram com o aumento do diâmetro da barra de aço.

Rosales (2016) avaliou o comportamento da aderência em concreto de 30 MPa para forma prismática e cilíndrica, com diâmetros da barra de 8, 10 e 12,5 mm. Exceto pelo corpode-prova de $100 \mathrm{~mm}$ com barra de $12 \mathrm{~mm}$, que rompeu por fendilhamento, em todos os outros houve deslizamento da barra. Também, verificou-se que ao aumentar o diâmetro da barra houve um aumento da tensão máxima de aderência. 


\subsubsection{UTILIZAÇÃO DE ARMADURA TRANSVERSAL}

Segundo o ACI 408R (2003), a presença da armadura transversal provoca um confinamento, restringindo o progresso de fraturas de fendilhamento e aumentando a tensão de aderência requerida para causar a falha. Desse modo, o incremento na taxa de armadura transversal, dentro de um certo limite, provoca um aumento na tensão de aderência e, pode inclusive, alterar o modo de ruptura de fendilhamento para arrancamento.

De acordo com Zuo e Darwin (1998,2000), a tensão de aderência pode ser dividida em uma parcela do concreto, desenvolvida sem a presença de armadura transversal, e outra da armadura transversal, a qual está relacionada com o número e área dos estribos, diâmetro da barra e resistência do concreto. Os autores enfatizaram que a tensão de aderência cresce com o aumento da taxa de armadura transversal, pois retarda o processo de fissuração e permite que um maior número de nervuras contribua com a transferência de tensão entre os materiais.

Rao et al (2007) fizeram ensaios de arrancamento pull-out para prismas de concreto com resistência à compressão de 40 e $50 \mathrm{MPa}$, comprimento aderente de 150 e $50 \mathrm{~mm}$, diâmetros das barras de 16 e 20 mm para três condições de confinamento: estribos em espirais e em laço e sem confinamento. A tensão de aderência última nas amostras não confinadas foi cerca de 40 a $50 \%$ menor que os valores obtidos nas amostras com confinamento. O confinamento também promoveu uma maior ductilidade, com um trecho pós-pico mais extenso, em especial nas amostras com espirais, e alterou a forma de ruptura de fendilhamento para arrancamento.

Hosseini e Hahman (2016) realizaram o ensaio de arrancamento direto em modelos compostos por uma barra longitudinal principal, armadura transversal helicoidal, com diferentes aberturas $(25,35$ e $45 \mathrm{~mm})$ e espaçamentos $(15,25$ e $35 \mathrm{~mm})$, e barras de emenda em argamassas de $60 \mathrm{MPa}$. Verificou-se que a diminuição da abertura da armadura transversal helicoidal provocou um aumento na tensão de aderência muito maior que a diminuição do espaçamento da armadura: ao mudar a abertura $45 \mathrm{~mm}$ para $25 \mathrm{~mm}$ aumentou em $34 \%$ a tensão de aderência última, enquanto que ao diminuir o espaçamento de $35 \mathrm{~mm}$ para $15 \mathrm{~mm}$ aumentou apenas 4,8\%. Além disso, o uso da barra helicoidal e barras de emenda aumentou a tensão de aderência da barra principal em 2,8 vezes em relação ao modelo sem esses elementos. 
O confinamento, promovido pelo uso de armadura transversal, pode ser representado pelo modelo de Mander, Prietsley e Park (1988). A região efetivamente confinada ocorre no núcleo, segundo os autores, excluindo-se as áreas decorrentes do efeito de arqueamento. Para pilares de seção circular com estribos circulares ou em espiral, o arqueamento ocorre próximo à armadura transversal, apenas no sentido longitudinal, como pode ser visto nas Figura 8 e Figura 9. Ele se desenvolve como uma parábola do segundo grau, com inclinação inicial de $45^{\circ}$ (CARRAZEDO, 2002).

Figura 8-Efeito do arqueamento em pilares com estribos circulares

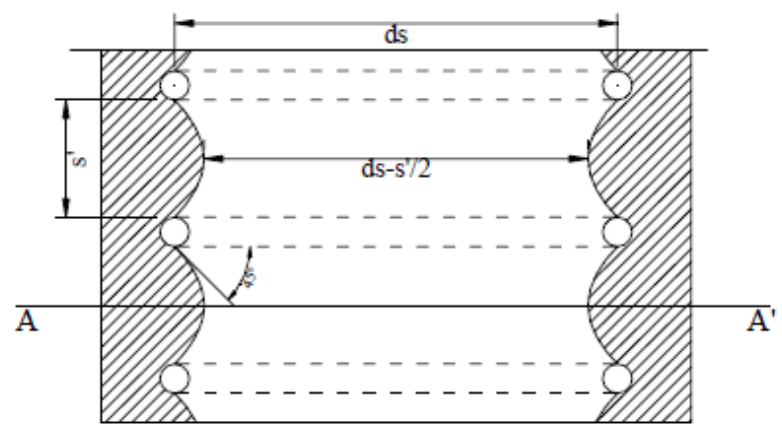

Fonte: Mander, Prietsley e Park (1988), modificado por Carrazedo (2002)

Figura 9-Efeito do arqueamento em pilares com estribos em espiral

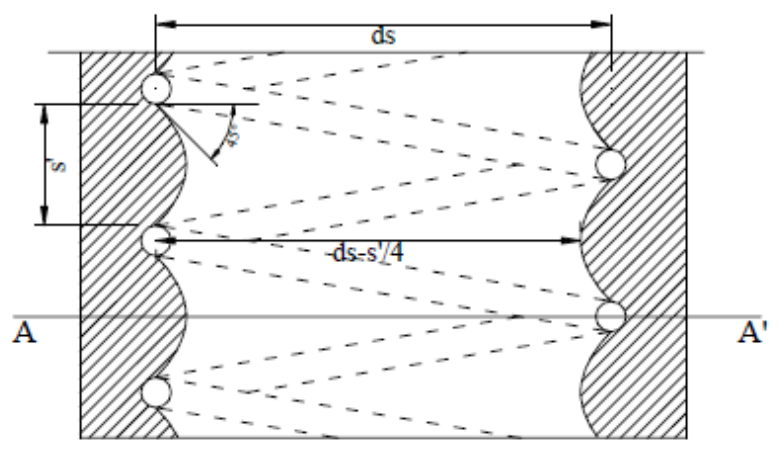

Fonte: Mander, Prietsley e Park (1988), modificado por Carrazedo (2002)

Uma maneira de avaliar o confinamento, proposta por Mander, Prietsley e Park (1988), é pelo coeficiente de efetividade $\left(\mathrm{k}_{\mathrm{e}}\right)$ :

$$
k_{e}=\frac{\left(1-\frac{s^{\prime}}{2 . d_{s}}\right)^{2}}{1-\rho_{c c}} \text { para estribos circulares }
$$




$$
k_{e}=\frac{1-\frac{s^{\prime}}{2 \cdot d_{s}}}{1-\rho_{c c}} \text { para espirais }
$$

Sendo:

$\mathrm{d}_{\mathrm{s}}$ : diâmetro do núcleo confinado (de centro a centro das barras da armadura transversal);

s’: espaçamento da armadura transversal;

$\rho_{c c}$ : taxa de armadura longitudinal em relação à área do núcleo.

\subsubsection{ADIÇÃO DE FIBRAS}

A adição de fibras no concreto tem como principal propósito o aumento da ductilidade e da resistência pós fissuração do concreto, pois é requerida uma maior energia para abrir e propagar fissuras (ACI 408R, 2003).

Ezeldin e Balaguru (1989) testaram corpos-de-prova de concreto simples e concreto de alta resistência com fibras em ensaios pull-out modificado. Variou-se a quantidade de sílica no concreto, a porcentagem de fibras e o diâmetro das barras, de 10, 16, 20 e $25 \mathrm{~mm}$. Concluíram que o volume de $0,25 \%$ de fibras diminuía a tensão de aderência e o de 0,5\% e 0,75\% aumentavam em até $18 \%$, quando comparado com o concreto sem fibras. Os autores concluíram que a inclusão de fibras melhorou a ductilidade e o comportamento pós pico. Também, foi verificado que ao aumentar o volume de fibras o escorregamento das barras na máxima tensão de aderência também cresceu e houve uma contribuição maior das fibras na tensão de aderência nos exemplares com diâmetros maiores.

Harajli e Salloukh (1997) fizeram um programa experimental de vigas de concreto de $35 \mathrm{MPa}$ variando o diâmetro das barras $(16,20$ e $25 \mathrm{~mm})$ e o volume de fibras de polipropileno e aço $(0,45,0,60,1,20$ e $2 \%)$. Notaram que a adição de fibras aumentou a tensão de aderência, além de aumentar a ductilidade. As fibras de polipropileno aumentaram a ductilidade dos modelos, mas não foram tão eficazes como as de aço no aumento da tensão de aderência.

Simplício (2008) variou o volume de fibras de 0,5, 0,75 e 1\%. A presença de fibras aumentou a tensão máxima de aderência em relação ao concreto sem fibras, mas entre os percentuais empregados não houve uma grande variação.

Correia (2012) analisou o comportamento de modelos em concreto de resistência à compressão de $50 \mathrm{MPa}$ com $2 \%$ de fibras e barras de diâmetro de $10 \mathrm{~mm}$ e $16 \mathrm{~mm}$ em ensaios de arrancamento RILEM-CEB-FIP (1973). Também efetuou ensaios para um modelo de 
arrancamento proposto, com inclusão de um estribo e barras com pontas retas e gancho de $90^{\circ}$. Nos ensaios RILEM-CEB-FIP (1973), todos os modelos romperam por arrancamento da barra. Nos ensaios com o modelo proposto, o modo de ruptura passou de fendilhamento nos modelos em concreto simples para predominantemente arrancamento ao incorporar as fibras e estribos. Além disso, as fibras de aço e estribos aumentaram a tensão de aderência nas barras com gancho. Porém, nos modelos com ancoragem reta a tensão foi diminuída com a incorporação de fibras.

Santana (2014) efetuou ensaios de arrancamento em concreto de resistências de 30, 60 e $90 \mathrm{MPa}$ com um volume de fibras de 0,1 e 1,5\% e barras de aço de 10 e $16 \mathrm{~mm}$. Foi constatado que a incorporação de fibras não resultou em uma significativa influência na tensão última de aderência e seu deslizamento, mas foram decisivas para o tipo e a forma da ruptura nos concretos de resistência mais elevada. No concreto de $30 \mathrm{MPa}$, o modo de ruptura permaneceu sendo arrancamento mesmo sem a inclusão de fibras. Para a resistência à compressão de $60 \mathrm{MPa}$, a ruptura passou de fendilhamento no concreto simples para majoritariamente arrancamento da barra no concreto com fibras. Nos corpos-de-prova de 90 $\mathrm{MPa}$, as fibras foram capazes de proporcionar uma ruptura menos frágil, com um quadro de fissuração múltipla.

\subsection{DISCUSSÃO}

Conforme descrito acima, a aderência tem um papel fundamental para o funcionamento do concreto armado. Composta por três parcelas teóricas verifica-se pelo gráfico da tensão de aderência versus deslizamento que no início é desenvolvida a aderência por adesão, oriunda da pega do concreto, seguida da aderência mecânica, com um trecho mais inclinado para as barras nervuradas, e a parcela do atrito, que caracteriza uma curva mais abatida e suave para as barras lisas (FUSCO, 1995).

As formas de ruptura da aderência dependem do grau de confinamento e podem ser por arrancamento, caracterizada por um comportamento mais dúctil, ou por fendilhamento, com ruptura frágil. É desejável que a ruptura ocorra por arrancamento por promover uma maior segurança às pessoas (FUSCO, 1995).

O ensaio de arrancamento é utilizado para analisar o comportamento da aderência. A tensão de aderência atinge seu valor máximo no ponto de inflexão da tensão no aço e enquanto a força de tração do aço for menor que a última a aderência é mobilizada em apenas 
parte da barra. $\mathrm{O}$ arrancamento ocorre quando a força atinge seu valor último. No entanto, na prática, a força última não corresponde ao carregamento final e sim a um valor de deslocamento previsto, pois antes do arrancamento ocorrer, várias fissuras já foram desenvolvidas (FUSCO, 1995).

Nesses ensaios, são admitidos valores médios da tensão de aderência resultantes da relação entre a força no aço e o comprimento aderente total, supondo que todo o comprimento da barra transfere a tensão para o concreto na iminência do arrancamento. Além disso, a barra não pode estar totalmente aderida ao concreto, pois a placa de apoio impede a deformação transversal do corpo-de-prova e cria uma aderência por atrito adicional (LEONHARDT; MÖNNIG, 1977). O ensaio mais conhecido é o da RILEM-CEB-FIP (1973), com aderência em apenas metade do modelo. No entanto, alguns autores (SIMPLÍCIO, 2008; SANTANA, 2014) verificaram que o comprimento proposto de $5 \phi$ pode não ser adequado para concretos de alta resistência, pois resulta no escoamento da barra. O ensaio proposto por Rehm (1969) contém um trecho central aderente, de comprimento $\phi$, promovendo uma maior aproximação entre a tensão de aderência média e a máxima. Também, Rehm e Eligehausen (1979) propuseram que o trecho aderente de $3 \phi$ ficasse no centro do modelo para reduzir a influência de uma possível restrição das tensões laterais de concreto por fricção na placa que aplica o carregamento. Portanto, esse modelo foi escolhido para os ensaios de arrancamento do presente estudo, pois tem a tendência de promover um confinamento causado pela armadura transversal mais eficiente que o da RILEM-CEB-FIP (1973).

$\mathrm{O}$ aumento do cobrimento do concreto e uso de armadura transversal promovem um confinamento no concreto, que pode alterar uma ruptura por fendilhamento para uma por arrancamento. O cobrimento adequado de concreto tende a provocar um esmagamento do concreto nas nervuras e consequente arrancamento da barra. A inclusão de armadura transversal restringe o progresso de fraturas de fendilhamento e aumenta a tensão de aderência requerida para causar a ruptura (ACI 408R, 2003).

O concreto com fibras tende a apresentar uma maior resistência pós fissuração, pois requer uma maior energia para abrir e propagar fissuras. Desse modo, a inclusão de fibras tende a melhorar a ductilidade e o comportamento pós pico, podendo alterar uma ruptura por fendilhamento para arrancamento (ACI 408R, 2003).

Por fim, a tensão de aderência aumenta com o diâmetro da barra, pois diâmetros maiores requerem comprimentos de aderência maiores e, consequentemente, promovem uma tensão de aderência maior (ACI 408R, 2003). 


\section{ANÁLISE TEÓRICA}

\subsection{PRESCRIÇÕES NORMATIVAS PARA O CÁLCULO DA RESISTÊNCIA DE ADERÊNCIA}

\subsubsection{FIB MODEL CODE 2010 (2012)}

Segundo o FIB Model Code 2010 (2012), a tensão de aderência básica, considerada como uma tensão média na superfície que envolve a barra e o concreto, pode ser estimada pela seguinte equação:

$$
f_{b d, 0}=\eta_{1} \cdot \eta_{2} \cdot \eta_{3 .} \cdot \eta_{4 .} \frac{\left(f_{c k} / 25\right)^{0,5}}{\gamma_{c b}}
$$

Sendo:

$\mathrm{f}_{\mathrm{bd}, 0}$ : resistência de aderência básica;

$\eta_{1}$ : coeficiente de conformação superficial da barra (Tabela 1);

$\eta_{2}$ : coeficiente relacionado com a posição da barra na concretagem (Tabela 2);

$\eta_{3}$ : coeficiente relacionado com o diâmetro da barra (Tabela 3);

$\eta_{4}$ : coeficiente relacionado com a tensão de escoamento da barra (Tabela 4);

$\mathrm{f}_{\mathrm{ck}}$ : resistência característica do concreto à compressão;

$\gamma_{\mathrm{cb}}$ : coeficiente de segurança parcial para a aderência, que vale 1,5.

Tabela 1-Coeficiente $\eta_{1}$ para cada tipo de barra

\begin{tabular}{c|c}
\hline Barra & $\eta_{1}$ \\
\cline { 2 - 2 } Lisa & 0,9 \\
\hline Nervuradas revestidas com epóxi & 1,4 \\
\hline Nervuradas & 1,75 \\
\hline
\end{tabular}

Fonte: FIB Model Code 2010 (2012)

Tabela 2-Coeficiente $\eta_{2}$ para cada situação de aderência

\begin{tabular}{c|c}
\hline \multicolumn{1}{c|}{ Situação } & $\eta_{1}$ \\
\hline Boa aderência* & 1 \\
\hline Fonte: FIB Model Code 2010 (2012) & 0,7 \\
\hline Quando a barra lisa é usada & 0,5 \\
\hline
\end{tabular}

Fonte: FIB Model Code 2010 (2012) 
*As situações de boa aderência são: barras com inclinação de $45^{\circ}$ a $90^{\circ}$ em relação à horizontal durante a concretagem e barras com a inclinação menor que $45^{\circ}$ que estão acima de $250 \mathrm{~mm}$ da base ou pelo menos $300 \mathrm{~mm}$ do topo do modelo durante a concretagem.

Tabela 3-Coeficiente $\eta_{3}$ para cada diâmetro da barra

Fonte: FIB Model Code 2010 (2012)

\begin{tabular}{c|c}
\hline Diâmetro da barra & $\eta_{3}$ \\
\hline$\phi \leq 25 \mathrm{~mm}$ & 1 \\
\hline$\phi>25 \mathrm{~mm}$ & $(25 / \phi)^{0,3}$ \\
\hline
\end{tabular}

Tabela 4-Coeficiente $\eta_{4}$ para cada diâmetro da barra

Fonte: FIB Model Code $2010 \overline{(2012)}$

\begin{tabular}{c|c}
\hline $\begin{array}{c}\text { Tensão de escoamento } \\
\text { da barra (MPa) }\end{array}$ & $\eta_{4}$ \\
\hline 400 & 1,2 \\
\hline 500 & 1 \\
\hline 600 & 0,85 \\
\hline 700 & 0,75 \\
\hline 800 & 0,68 \\
\hline
\end{tabular}

Nas situações em que o cobrimento de concreto, o espaçamento da barra ou a taxa de armadura transversal superar o mínimo, a tensão de aderência última de cálculo deve ser utilizada ao invés da tensão de aderência básica:

$$
f_{b d}=\left(\alpha_{2}+\alpha_{3}\right) f_{b d, 0}-2 \cdot p_{t r}<2 . f_{b d, 0}-0,4 \cdot p_{t r}<\left(\frac{1,5}{\gamma_{c b}}\right) \cdot \sqrt{f_{c k}}
$$

Sendo:

$\alpha_{2}$ : representa a influência do confinamento passivo do cobrimento, podendo ser tomado como 1,0 se não houver maiores especificações (Tabela 5);

Tabela 5-Parâmetro $\alpha_{2}$ para cada barra

\begin{tabular}{c|c}
\hline Barra & \multicolumn{1}{c}{$\alpha_{2}$} \\
\hline Nervurada & $\left(\frac{c_{\text {min }}}{\phi}\right)^{0,5} \cdot\left(\frac{c_{S}}{2 \cdot c_{\text {min }}}\right)^{0,15}$ \\
\hline Revestidas com epóxi & $\left(\frac{c_{\text {min }}}{\phi}\right)^{0,7} \cdot\left(\frac{c_{S}}{2 \cdot c_{\text {min }}}\right)^{0,15}$ \\
\hline Lisas & 1 \\
\hline
\end{tabular}

Fonte: FIB Model Code 2010 (2012) 
$\mathrm{c}_{\text {min }}$ : mínimo entre $\mathrm{c}_{\mathrm{s}} / 2, \mathrm{c}_{\mathrm{x}}$ e $\mathrm{c}_{\mathrm{y}}$, conforme a Figura $10, \operatorname{com} 0,5 \leq \frac{c_{\min }}{\phi} \leq 3 e \frac{c_{s}}{2 \cdot c_{\min }} \leq 5$ $c_{\max }$ : máximo entre $\mathrm{c}_{\mathrm{s}} / 2, \mathrm{c}_{\mathrm{x}}$ e $\mathrm{c}_{\mathrm{y}}$, conforme a Figura 10

Figura 10-Representação de $c_{\min }$ e $c_{\max }$

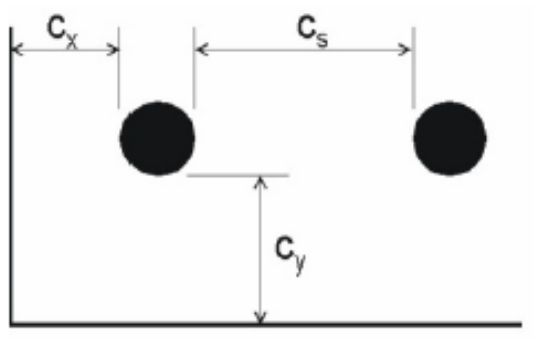

Fonte: FIB Model Code 2010 (2012)

$\alpha_{3}$ : representa a influência do confinamento da armadura transversal, podendo ser tomado como 1,0 se não houver maiores especificações.

$$
\alpha_{3}=k \cdot\left(K_{t r}-\frac{\alpha_{t}}{50}\right) \geq 0, \operatorname{com} K_{t r} \leq 0,05
$$

\section{Sendo:}

$\alpha_{\mathrm{t}}: 0,5$ para barras com diâmetro menores ou iguais a $25 \mathrm{~mm} ; 1,0$ para barras de $50 \mathrm{~mm}$; 0 para armaduras de paredes e lajes;

k: coeficiente de eficiência relacionado com a disposição da armadura de confinamento em relação à barra, conforme a Figura 11 e Tabela 6;

$\mathrm{K}_{\mathrm{tr}}$ : densidade de armadura transversal.

$$
K_{t r}=\frac{n_{1} \cdot A_{s v}}{n_{b} \cdot \phi \cdot s_{v}}
$$

Sendo:

$\mathrm{n}_{1}$ : número de ramos de armadura de confinamento numa região potencial de fendilhamento; $\mathrm{A}_{\text {sv }}$ : seção transversal de um ramo de armadura de confinamento;

Sv: espaçamento longitudinal da armadura de confinamento;

$\mathrm{n}_{\mathrm{b}}$ : número de barras ancoradas;

$\phi$ : diâmetro da barra ancorada. 
Figura 11-Fator k de acordo com a disposição das barras

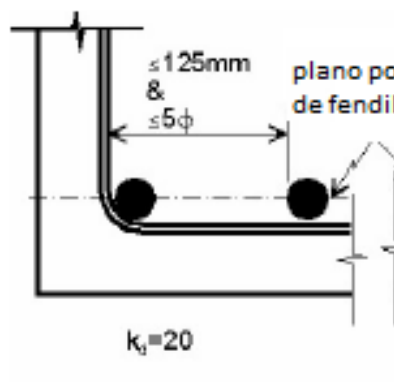

(a)

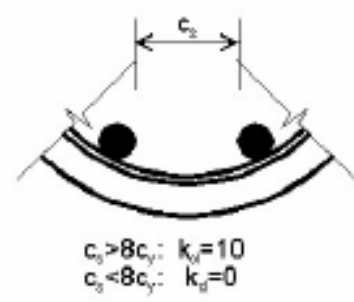

(d)

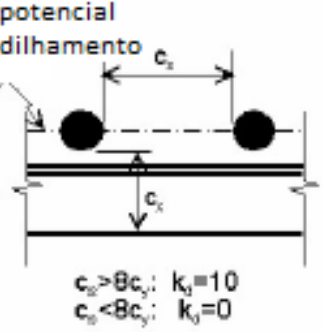

(b)

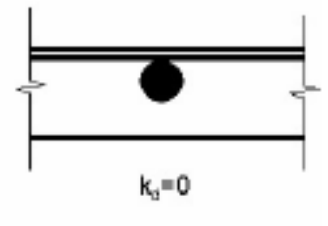

(c)

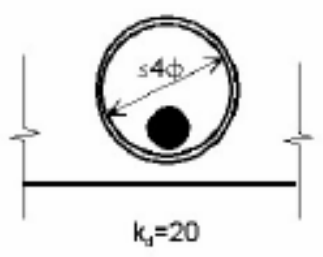

(e)

Tabela 6- Valores de k para cada situação

\begin{tabular}{l|c}
\hline \multicolumn{1}{c|}{ Situação } & $\mathrm{k}$ \\
\hline $\begin{array}{l}\text { Ramos de uma ligação são perpendiculares ao plano de fendilhamento, com outra } \\
\text { barra a uma distância menor que 5 } \phi \text { ou } 125 \mathrm{~mm}\end{array}$ & 20 \\
\hline $\begin{array}{l}\text { Quando barras estão confinadas por uma armadura helicoidal com diâmetro menor } \\
\text { que } 4 \phi\end{array}$ & 20 \\
\hline $\begin{array}{l}\text { Barras contidas por barras retas ou helicoidais no interior da espessura de } \\
\text { cobrimento (c), desde que a distância entre barras seja pelo menos 8c }\end{array}$ & 10 \\
\hline \multicolumn{1}{c}{ Outros casos } & 0 \\
\hline
\end{tabular}

Fonte: FIB Model Code 2010 (2012)

ptr: tensão de compressão média perpendicular à superfície de ruptura potencial por fendilhamento no estado limite último; quando a compressão transversal perpendicular ao eixo da barra atua sobre uma porção do comprimento aderente, a tensão de aderência deve ser

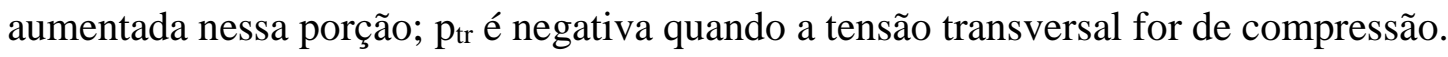

\subsubsection{ABNT NBR 6118:2014}

A norma brasileira de projeto de estruturas de concreto, ABNT NBR 6118:2014, prevê a seguinte equação para estimativa da resistência de aderência de cálculo entre a armadura e o concreto na ancoragem de armaduras passivas: 


$$
f_{b d}=\eta_{1} \cdot \eta_{2} \cdot \eta_{3 \cdot} \cdot f_{c t d}
$$

Sendo:

$\mathrm{f}_{\mathrm{bd}}$ : resistência de aderência de cálculo;

$\eta_{1}$ : coeficiente de conformação superficial da barra (Tabela 7);

$\eta_{2}$ : coeficiente relacionado com a posição da barra na concretagem (Tabela 8);

$\eta_{3}$ : coeficiente relacionado com o diâmetro da barra (Tabela 9);

$\mathrm{f}_{\text {ctd: }}$ : resistência de cálculo do concreto à tração direta (Equação 3).

Tabela 7-Coeficiente $\eta_{1}$ para cada tipo de barra

\begin{tabular}{c|c}
\hline Barra & $\eta_{1}$ \\
\hline Lisa & 1 \\
\hline Entalhada & 1,4 \\
\hline Nervurada & 2,25 \\
\hline
\end{tabular}

Fonte: ABNT NBR 6118:2014

Tabela 8-Coeficiente $\eta_{2}$ para cada situação de aderência

\begin{tabular}{cc|c}
\hline Situação & $\eta_{2}$ \\
\hline Boa aderência* $^{*}$ & 1 \\
\hline Má aderência & 0,7 \\
\hline
\end{tabular}

Fonte: ABNT NBR 6118:2014

*As situações de boa aderência são: barras com inclinação de maior que $45^{\circ}$ em relação à horizontal durante a concretagem; para barras com a inclinação menor que $45^{\circ}$ e com altura total menor que $60 \mathrm{~cm}$ localizado no máximo a $30 \mathrm{~cm}$ acima da face inferior do elemento (ou da junta de concretagem mais próxima), e, se altura total superar $60 \mathrm{~cm}$, localizado no mínimo a $30 \mathrm{~cm}$ abaixo da face superior

Tabela 9-Coeficiente $\eta 3$ para cada diâmetro da barra

Fonte: ABNT NBR 6118:2014

\begin{tabular}{c|c}
\hline Diâmetro da barra & $\eta_{3}$ \\
\hline$\phi<32 \mathrm{~mm}$ & 1 \\
\hline$\phi \geq 32 \mathrm{~mm}$ & $(132-\phi) / 100$ \\
\hline
\end{tabular}




$$
f_{c t d}=\frac{f_{c t k, i n f}}{\gamma_{c}}
$$

Sendo:

$\gamma_{c}$ : coeficiente de ponderação da resistência do concreto (Tabela 10);

$\mathrm{f}_{\mathrm{ctk}, \text { inf: }}$ resistência à tração característica inferior do concreto (Equação 4);

Tabela 10-Coeficiente $\gamma_{c}$ para cada combinação de ações

\begin{tabular}{c|c}
\hline Combinações & $\gamma_{\mathrm{c}}$ \\
\hline Normais & 1,4 \\
\hline Especiais ou de Construção & 1,2 \\
\hline Excepcionais & 1,2 \\
\hline
\end{tabular}

Fonte: ABNT NBR 61 $\overline{18: 2014}$

$$
f_{c t k, i n f}=0,7 . f_{c t, m}
$$

$\mathrm{f}_{\mathrm{ct}, \mathrm{m}}$ : resistência média à tração do concreto.

\subsubsection{ACI 318:2014}

A norma americana não fornece uma fórmula para o cálculo da tensão de aderência, apenas informa o comprimento de aderência necessário:

$$
l_{b}=\frac{f_{y}}{1,1 \cdot \lambda \cdot \sqrt{f_{c}}} \cdot \frac{\Psi_{t} \cdot \Psi_{e} \cdot \Psi_{s}}{\frac{c+K t r}{\phi}} \cdot \phi
$$

Sendo:

$\mathrm{l}_{\mathrm{b}}$ : comprimento de ancoragem básico;

$\mathrm{f}_{\mathrm{y}}$ : tensão de escoamento do aço;

$\lambda$ : fator relativo à densidade do concreto (Tabela 11);

$\mathrm{f}_{\mathrm{c}}$ : resistência à compressão do concreto;

$\Psi_{\mathrm{t}}$ : fator relativo à posição da armadura (Tabela 12);

$\Psi_{\mathrm{e}}$ : fator relativo ao revestimento da armadura (Tabela 13);

$\Psi_{\mathrm{s}}$ : fator relativo ao diâmetro da barra (Tabela 14);

$\phi$ : diâmetro da barra;

c: menor valor entre o centro da barra e a superfície de concreto ou metade do espaçamento entre os centros das barras;

$\mathrm{K}_{\mathrm{tr}}$ : índice de armadura transversal (Equação 15). 
Tabela 11-Fator $\lambda$ para cada densidade do concreto

\begin{tabular}{c|c}
\hline Situação & $\lambda$ \\
\hline Concreto com densidade normal & 1 \\
\hline Concreto com baixa densidade & 0,75 ou $1,8 \cdot \frac{f_{c t}}{\sqrt{f_{c}{ }^{\prime}}} *$ \\
\hline
\end{tabular}

Fonte: ACI 318:2014

*Quando o valor de $\mathrm{f}_{\mathrm{ct}}$ for definido, não podendo ser superior a 1

Tabela 12-Fator $\Psi_{\mathrm{t}}$ para cada posição da armadura

\begin{tabular}{c|c}
\hline Situação & $\Psi_{\mathrm{t}}$ \\
\hline Armadura longitudinal localizada a mais de $300 \mathrm{~mm}$ da face superior da peça & 1,3 \\
\hline Outros casos & 1 \\
\hline
\end{tabular}

Fonte: ACI 318:2014

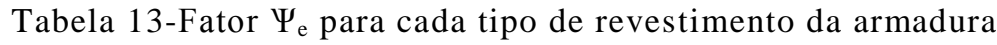

\begin{tabular}{c|c}
\hline Situação & $\Psi_{\mathrm{e}}$ \\
\hline Armaduras sem revestimento & 1 \\
\hline $\begin{array}{c}\text { Barras revestidas com epóxi com o cobrimento menor que 3 } \phi \text { ou com espaçamento } \\
\text { livre menor que } 6 \phi\end{array}$ & 1,5 \\
\hline Outras situações com armaduras revestidas com epóxi & 1,2 \\
\hline
\end{tabular}

Fonte: ACI 318:2014

Tabela 14-Fator $\Psi_{\text {s }}$ para cada diâmetro da armadura

Fonte: ACI 318:2014

\begin{tabular}{c|c}
\hline Situação & $\Psi_{\mathrm{s}}$ \\
\hline$\phi \leq 20 \mathrm{~mm}$ & 0,8 \\
\hline$\phi \geq 25 \mathrm{~mm}$ & 1 \\
\hline
\end{tabular}

$$
K_{t r}=\frac{A_{t r} \cdot f_{y t}}{10,5 \cdot s \cdot n}
$$

Sendo:

$\mathrm{A}_{\mathrm{tr}}$ : área de armadura transversal;

$\mathrm{f}_{\mathrm{yt}}$ : tensão de escoamento do aço da armadura transversal;

s: espaçamento máximo da armadura transversal;

n: número de barras ancoradas ao longo do plano de fendilhamento. 
O ACI 318:2014 recomenda que o termo $\frac{c+K t r}{\phi}$ seja limitado a 2,5. Além disso, esse parâmetro determina o tipo de ruptura esperada: abaixo de 2,5 espera-se que ocorra fendilhamento e acima, arrancamento. Também, o produto $\Psi_{\mathrm{t}}$. $\Psi_{\mathrm{e}}$ não deve ser superior a 1,7.

Como o ACI 318:2014 não fornece uma equação para a resistência de aderência, esta foi calculada considerando-se a força para início de escoamento do aço $\left(R_{s}=f_{y} . \pi \cdot \phi^{2} / 4\right)$ e a definição da equação (2) de tensão de aderência $\left(\tau_{\mathrm{b}}=\mathrm{R}_{\mathrm{st}} / \pi \cdot \phi \cdot \mathrm{l}_{\mathrm{b}}\right)$, incluindo o comprimento de aderência da equação (14). Desse modo, tem-se que:

$$
f_{b d}=\frac{1,1 \cdot \lambda \cdot \sqrt{f_{c}{ }^{\prime}}}{4 \cdot \Psi_{t} \cdot \Psi_{e} \cdot \Psi_{s}} \cdot \frac{c+K t r}{\phi}
$$

\subsection{PREVISÃO DA CURVA TENSÃO DE ADERÊNCIA VERSUS DESLIZAMENTO}

A Tabela 17 apresenta os modelos teóricos propostos por Harajli, Hout e Jalkh (1995), Huang, Engstron e Magnusson (1996), Barbosa (2001), Almeida Filho (2006), Simplício (2008) e FIB Model Code 2010 (2012). A Tabela 15, Tabela 16 e Tabela 18 incluem os valores dos parâmetros utilizados nos modelos teóricos. As seguintes definições foram utilizadas nas fórmulas:

$\tau$ : tensão de aderência para um dado deslizamento $\delta(\mathrm{MPa})$;

$\tau_{\max }$ : tensão de aderência máxima (MPa);

$\tau_{\mathrm{f}}$ : tensão de aderência final (MPa);

$\delta_{1}$ : deslizamento relacionado ao início do patamar, atingindo a máxima tensão de aderência (no caso de Simplício, corresponde ao deslocamento relacionado com a tensão $\tau_{1 \text { ); }}$

$\delta_{2}$ : deslizamento relacionado ao fim do patamar (no caso de Simplício, é o de início do patamar);

$\delta_{3}$ : deslizamento para o qual é atingida a tensão final de aderência (no caso de Simplício, é o de fim de patamar);

$\delta_{4}$ : deslizamento final;

$\mathrm{h}_{\mathrm{r}}$ : altura das nervuras $(\mathrm{mm})$;

s: distância entre nervuras da barra (mm);

$\tau$ : tensão relativa ao deslizamento $\delta(\mathrm{MPa})$ 
$\mathrm{f}_{\mathrm{r}}$ : área relativa das nervuras $=0,5 \cdot \mathrm{h}_{\mathrm{r}} / \mathrm{s}_{\mathrm{r}}$;

$\mathrm{V}_{\mathrm{f}}$ : percentual volumétrico de fibra;

$\mathrm{f}_{\mathrm{c}}$ : resistência à compressão do concreto $(\mathrm{MPa})$;

$\phi$ : diâmetro da barra (mm);

$\mathrm{a}_{1}$ a a7: coeficientes utilizados por Barbosa (2001) que variam para concretos convencionais $\left(f_{c} \leq 50 \mathrm{MPa}\right)$ e de alta resistência $\left(\mathrm{f}_{\mathrm{c}}>50 \mathrm{MPa}\right)$, conforme a Tabela 15 ;

$b_{1}, b_{2}$ e $b_{3}$ : coeficientes utilizados por Almeida Filho (2006) que variam com o diâmetro da barra e tipo de concreto (de alto desempenho ou convencional), conforme a Tabela 16.

Tabela 15-Coeficientes propostos por Barbosa (2001) para determinação da tensão de aderência e deslizamento máximos

\begin{tabular}{c|c|c}
\hline Coeficiente & $\begin{array}{c}\text { Resistência } \\
\text { inferior a 50 MPa }\end{array}$ & $\begin{array}{c}\text { Resistência } \\
\text { superior a 50 MPa }\end{array}$ \\
\hline $\mathrm{a}_{1}$ & 19,36 & 32,58 \\
\hline $\mathrm{a}_{2}$ & 0,51 & 0,48 \\
\hline $\mathrm{a}_{3}$ & 0,25 & 0,52 \\
\hline $\mathrm{a}_{4}$ & 0,68 & 0,42 \\
\hline $\mathrm{a}_{5}$ & 0,104 & 0,08 \\
\hline $\mathrm{a}_{6}$ & 0,027 & 0,003 \\
\hline $\mathrm{a}_{7}$ & 0,93 & 6,68 \\
\hline
\end{tabular}

Fonte: Barbosa (2001)-Adaptado

Tabela 16- Coeficientes propostos por Almeida Filho (2006) para determinação da tensão de aderência em função do deslizamento

\begin{tabular}{c|c|c|c|c}
\hline \multirow{2}{*}{ Coeficiente } & \multicolumn{2}{|c|}{$\begin{array}{c}\text { Resistência à } \\
\text { compressão de } 60 \\
\mathrm{MPa}\end{array}$} & \multicolumn{2}{c}{$\begin{array}{c}\text { Resistência à } \\
\text { compressão de 30 } \\
\mathrm{MPa}\end{array}$} \\
\cline { 2 - 5 } & $\begin{array}{c}\phi=10 \\
\mathrm{~mm}\end{array}$ & $\begin{array}{c}\phi=16 \\
\mathrm{~mm}\end{array}$ & $\begin{array}{c}\phi=10 \\
\mathrm{~mm}\end{array}$ & $\begin{array}{c}\phi=16 \\
\mathrm{~mm}\end{array}$ \\
\hline $\mathrm{b}_{1}$ & 11,522 & 10,583 & 15,73 & 21,31 \\
\hline $\mathrm{b}_{2}$ & 10,138 & 9,165 & 15,79 & 24,23 \\
\hline $\mathrm{b}_{3}$ & 0,2552 & 0,3597 & 0,602 & 0,956 \\
\hline
\end{tabular}

Fonte: Almeida Filho (2006)-Adaptado 
Tabela 17-Resumo dos modelos teóricos para a curva tensão de aderência versus deslizamento-Continua

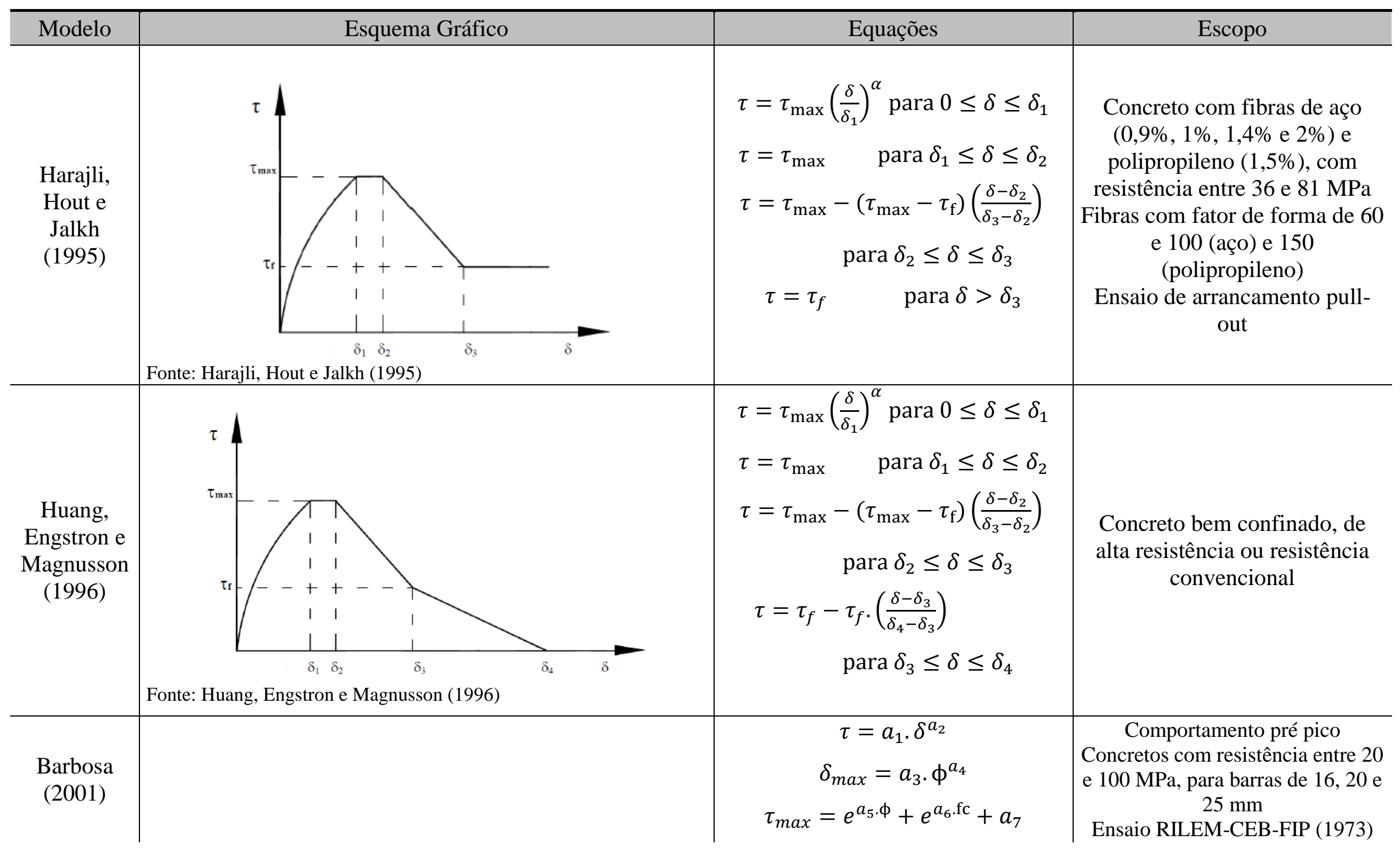


Tabela 17-Resumo dos modelos teóricos para a curva tensão de aderência versus deslizamento-Conclusão

\begin{tabular}{|c|c|c|c|}
\hline $\begin{array}{l}\text { Modelo } \\
\text { Teórico }\end{array}$ & Esquema Gráfico & Equações & Escopo \\
\hline $\begin{array}{l}\text { Almeida } \\
\text { Filho } \\
(2006)\end{array}$ & & $\tau=b_{1}-b_{2} \cdot e^{\frac{-\delta}{b_{3}}}$ & $\begin{array}{c}\text { Comportamento pré-pico } \\
\text { Concretos com resistências de } 30 \text { e } \\
60 \mathrm{MPa} \text { para barras de } 10 \text { e } 16 \mathrm{~mm} \\
\text { Ensaio RILEM-CEB-FIP (1973) } \\
\text { com corpos-de-prova cilíndricos }\end{array}$ \\
\hline $\begin{array}{l}\text { Simplício } \\
\text { (2008) }\end{array}$ & Fonte: Simplício (2008) & $\begin{array}{c}\tau=\tau_{\max }\left(\frac{\delta}{\delta_{1}}\right)^{\alpha} \text { para } 0 \leq \delta \leq \delta_{1} \\
\tau=\left(\tau_{\max }-\tau_{1}\right)\left(\frac{\delta-\delta_{1}}{\delta_{2}-\delta_{1}}\right)+\tau_{1} \\
\operatorname{para} \delta_{1} \leq \delta \leq \delta_{2} \\
\tau=\tau_{\max } \quad \operatorname{para} \delta_{2} \leq \delta \leq \delta_{3} \\
\tau=\left(\tau_{\max }-\tau_{f}\right)\left(\frac{\delta_{4}-\delta}{\delta_{4}-\delta_{3}}\right)+\tau_{f} \\
\operatorname{para} \delta_{3} \leq \delta \leq \delta_{4}\end{array}$ & $\begin{array}{l}\text { Concreto de alto desempenho } \\
\text { com fibras de aço (0 a } 1 \%) \text {, } \\
\text { com resistências à compressão } \\
\text { de } 64 \mathrm{MPa}, 80 \mathrm{MPa} \text { e } 110 \mathrm{MPa} \text {, } \\
\text { e barras de } 8,10,12,5 \text { e } 16 \mathrm{~mm} \\
\text { Ensaio RILEM-CEB-FIP } \\
\text { (1973) com comprimento } \\
\text { aderente de } 3 \phi\end{array}$ \\
\hline $\begin{array}{l}\text { FIB Model } \\
\text { Code } 2010 \\
\quad(2012)\end{array}$ & Fonte: FIB Model Code 2010 (2012)-Adaptado & $\begin{array}{c}\tau=\tau_{\max }\left(\frac{\delta}{\delta_{1}}\right)^{\alpha} \text { para } 0 \leq \delta \leq \delta_{1} \\
\tau=\tau_{\max } \quad \operatorname{para} \delta_{1} \leq \delta \leq \delta_{2} \\
\tau=\tau_{\max }-\left(\tau_{\max }-\tau_{\mathrm{f}}\right)\left(\frac{\delta-\delta_{2}}{\delta_{3}-\delta_{2}}\right) \\
\operatorname{para} \delta_{2} \leq \delta \leq \delta_{3} \\
\tau=\tau_{f} \quad \operatorname{para} \delta_{3} \leq \delta\end{array}$ & $\begin{array}{l}\text { Arrancamento: } \\
\text { confinado: cobrimento maior } \\
\text { que } 5 \phi \text {, espaçamento entre } \\
\text { barras maior que } 10 \phi \text {, ou com } \\
\text { armadura confinante } \\
\text { Fendilhamento: } \phi \text { menor que } 25 \\
\text { mm e comprimento de } \\
\text { ancoragem de } 5 \phi \\
\text { Concreto entre } 15 \text { e } 110 \mathrm{MPa}\end{array}$ \\
\hline
\end{tabular}


Tabela 18-Parâmetros utilizados nos modelos teóricos

\begin{tabular}{|c|c|c|c|c|c|c|c|c|c|c|c|c|}
\hline \multirow{4}{*}{ Par. } & \multirow{4}{*}{$\begin{array}{c}\text { Harajli, } \\
\text { Hout e } \\
\text { Jalkh } \\
\text { (1995) }\end{array}$} & \multirow{2}{*}{\multicolumn{4}{|c|}{ Huang, Engstron e Magnusson (1996) }} & \multirow{4}{*}{ Simplício (2008) } & \multicolumn{6}{|c|}{ FIB Model Code 2010 (2012) } \\
\hline & & & & & & & \multicolumn{2}{|c|}{ Arrancamento } & \multicolumn{4}{|c|}{ Fendilhamento* $^{*}$} \\
\hline & & \multicolumn{2}{|c|}{$\mathrm{CC}$} & \multicolumn{2}{|c|}{ CAR } & & \multirow{2}{*}{$\mathrm{BC}$} & \multirow{2}{*}{$\mathrm{O}$} & \multicolumn{2}{|c|}{$\mathrm{BC}$} & \multicolumn{2}{|c|}{$\mathrm{O}$} \\
\hline & & $\mathrm{BC}$ & $\mathrm{O}$ & $\mathrm{BC}$ & $\mathrm{O}$ & & & & $\mathrm{CNC}$ & $\mathrm{AT}$ & $\mathrm{CNC}$ & AT \\
\hline$\tau_{\max }$ & $2,57 \cdot \sqrt{f_{c}}$ & $0,45 . f_{c}$ & $0,225 . f_{c}$ & $0,45 . f_{c}$ & $0,225 . f_{c}$ & $\left(400 \cdot V_{f}+28\right) \cdot\left(f_{c} \cdot f_{\mathrm{r}}\right)^{0,35}$ & $2,5 \cdot \sqrt{f_{c}}$ & $1,25 \cdot \sqrt{f_{c}}$ & 7. $\left(\frac{f_{c}}{25}\right)^{0,25}$ & 8. $\left(\frac{f_{c}}{25}\right)^{0,25}$ & $5 \cdot\left(\frac{f_{c}}{25}\right)^{0,25}$ & $5,5 \cdot\left(\frac{f_{c}}{25}\right)^{0,25}$ \\
\hline$\delta_{1}$ & $0,15 \cdot s_{r}$ & $1,0 \mathrm{~mm}$ & $1,0 \mathrm{~mm}$ & $0,5 \mathrm{~mm}$ & $0,5 \mathrm{~mm}$ & $0,35 . \delta_{2}$ & $1,0 \mathrm{~mm}$ & $1,8 \mathrm{~mm}$ & $\delta$ & $\delta$ & $\delta$ & $\delta$ \\
\hline$\delta_{2}$ & $0,35 \cdot s_{r}$ & $3,0 \mathrm{~mm}$ & $3,0 \mathrm{~mm}$ & $1,5 \mathrm{~mm}$ & $1,5 \mathrm{~mm}$ & $\frac{30-0,174 \cdot f_{c}}{f_{c}} \cdot\left(s_{r} \cdot h_{r}\right)^{0,28}$ & $2,0 \mathrm{~mm}$ & $3,6 \mathrm{~mm}$ & $\delta_{1}$ & $\delta_{1}$ & $\delta_{1}$ & $\delta_{1}$ \\
\hline$\delta_{3}$ & $\mathrm{~s}_{\mathrm{r}}$ & $\mathrm{Sr}_{\mathrm{r}}$ & $\mathrm{Sr}_{\mathrm{r}}$ & $\mathrm{S}_{\mathrm{r}}$ & $\mathrm{S}_{\mathrm{r}}$ & $\begin{array}{r}- \\
\left(0,0164 \cdot h_{r}-0,0079\right) \cdot f_{c} \\
+0,85\end{array}$ & $\mathrm{~S}_{\mathrm{r}}$ & $\mathrm{S}_{\mathrm{r}}$ & $1,2 . \delta_{1}$ & $0,5 . \mathrm{Sr}_{\mathrm{r}}$ & $1,2 . \delta_{1}$ & $0,5 . \mathrm{S}_{\mathrm{r}}$ \\
\hline$\delta_{4}$ & - & 3.Sr & 3.Sr & $3 . \mathrm{Sr}$ & 3.Sr & 8 & - & - & - & - & - & - \\
\hline$\alpha$ & 0,3 & 0,4 & 0,4 & 0,3 & 0,3 & 0,35 & 0,4 & 0,4 & 0,4 & 0,4 & 0,4 & 0,4 \\
\hline$\tau_{\mathrm{f}}$ & $0,9 \cdot \sqrt{f_{c}}$ & $0,4 \cdot \tau_{\max }$ & $0,4 \cdot \tau_{\max }$ & $0,4 . \tau_{\max }$ & $0,4 . \tau_{\max }$ & $\begin{array}{r}{\left[0,0013 \cdot f_{c}\left(1+h_{r}\right)+0,23 \cdot h_{r}\right.} \\
+0,05] \cdot \tau_{\max }\end{array}$ & $0,4 \cdot \tau_{\max }$ & $0,4 . \tau_{\max }$ & 0 & $0,4 . \tau_{\max }$ & 0 & $0,4 . \tau_{\max }$ \\
\hline
\end{tabular}

Legenda:

CC: Concreto convencional, CAR: Concreto de alta resistência, BC: boas condições de aderência, O: Outros casos, CNC: Concreto não confinado, AT: com armadura transversal 
*Os valores indicados para o fendilhamento foram obtidos substituindo $\mathrm{l}_{\mathrm{b}} / \phi=5$, $\mathrm{c}_{\max } / \mathrm{c}_{\min }=2, \mathrm{c}_{\min }=\mathrm{c}_{\max }$, e $\mathrm{K}_{\mathrm{tr}}=0,02$ (modelo com armadura transversal) na equação abaixo:

$$
\tau_{\text {bu,split }}=\eta_{2} \cdot 6,5 \cdot\left(\frac{f_{c}}{25}\right)^{0,25}\left(\frac{25}{\phi}\right)^{0,2}\left[\left(\frac{c_{\min }}{\phi}\right)^{0,33}\left(\frac{c_{\max }}{\phi}\right)^{0,1}+k_{m} \cdot K_{t r}\right]
$$

Onde:

$\mathrm{k}_{\mathrm{m}}$ : eficiência do confinamento promovido pela armadura transversal, com valor de 12 quando as barras são confinadas por um conjunto de estribos a pelo menos $90^{\circ}$.

\subsection{DISCUSSÃO}

Foram incluídas na pesquisa as seguintes prescrições normativas para cálculo da resistência de aderência: FIB Model Code 2010 (2012), ABNT NBR 6118:2014 e ACI 318:2014.

A proposta da ABNT NBR 6118:2014 é muito próxima ao do FIB Model Code 2010 (2012), representadas nas equações 7 e 11, respectivamente, exceto por ser proporcional à resistência à tração do concreto, enquanto o segundo é a resistência à compressão do concreto. O mesmo ocorre com o ACI 318:2014 (equação 16), com uma relação direta com a resistência à compressão do concreto.

Em todas as normas existem um fator para considerar a superfície da barra (conformação superficial ou o revestimento), região de boa/má aderência (ou posição da barra) e o diâmetro da barra. O FIB Model Code 2010 (2012) inclui ainda um quarto coeficiente para a tensão de escoamento da barra. O ACI 318:2014 fornece um quarto fator para considerar a densidade do concreto e um quinto com a relação entre o cobrimento (c) somado à taxa de armadura transversal $\left(\mathrm{K}_{\text {tr }}\right)$ e o diâmetro da barra longitudinal $(\phi)$.

A inclusão de fibras metálicas seria considerada indiretamente por meio do incremento na resistência à compressão do concreto, no caso do FIB Model Code 2010 (2012) e ACI 318:2014, e da resistência à tração do concreto, para a ABNT NBR 6118:2014.

O cobrimento do concreto e a taxa de armadura transversal apenas são considerados no modelo do ACI 318:2014 (equação 16), mas sua relação com o diâmetro é limitada a 2,50, o que extrapola as geometrias sugeridas pelos ensaios de arrancamento de Rehm e 
Eligehausen (1979) e pela RILEM-CEB-FIP (1973), pois sugerem um corpo-de-prova de 10 $\phi$, retornando um valor de $\mathrm{c} / \phi$ de 5 .

Os modelos teóricos utilizados para comparação com os resultados experimentais foram: Harajli, Hout e Jalkh (1995), Huang, Engstron e Magnusson (1996), Barbosa (2001), Almeida Filho (2006), Simplício (2008) e FIB Model Code 2010 (2012).

Nota-se, a partir da Tabela 15 a Tabela 18, as seguintes observações:

1) O único modelo teórico que retrata o trecho pós-pico para a ruptura por fendilhamento é o do FIB Model Code 2010 (2012);

2) Os modelos teóricos não incluem a influência do cobrimento de concreto ou da armadura transversal, exceto no caso de fendilhamento para o modelo do FIB Model Code 2010 (2012), contribuindo apenas para tornar o concreto bem confinado e causar a ruptura por arrancamento;

3) A adição de fibras é considerada no modelo de Simplício (2008), por meio do volume de fibras, para cálculo direto da tensão de aderência máxima e final, e é incluso indiretamente no modelo de Harajli, Hout e Jalkh (1995) por meio do incremento na resistência à compressão do concreto;

4) A tensão de aderência máxima e final nos modelos propostos por Harajli, Hout e Jalkh (1995), Huang, Engstron e Magnusson (1996) e FIB Model Code 2010 (2012) são proporcionais à resistência à compressão do concreto $\left(f_{c}\right)$ e o deslizamento final é igual ao espaçamento entre nervuras da barra $\left(\mathrm{s}_{\mathrm{r}}\right)$, sendo que o deslizamento último tem um valor fixo para os modelos de Huang, Engstron e Magnusson (1996) e FIB Model Code 2010 (2012) e é proporcional a sr no modelo de Harajli, Hout e Jalkh (1995);

5) Além das variáveis $f_{c}$ e $s_{r}$, o modelo de Simplício (2008) compreende a altura das nervuras e o volume de fibras;

6) Barbosa (2001) divide o modelo em resistência à compressão inferior ou superior a $50 \mathrm{MPa}$, sendo que o diâmetro da barra e a resistência à compressão do concreto apenas influenciam os valores máximos de deslizamento e tensão de aderência;

7) Almeida Filho (2006) divide o modelo para diâmetros de barra de $10 \mathrm{~mm}$ ou 16 $\mathrm{mm}$, para concreto convencional (30 MPa) ou de alta resistência (60 MPa);

8) Os modelos teóricos escolhidos foram resultantes de ensaios experimentais com características diferentes do proposto na pesquisa, seja pelo método de ensaio, na sua maioria seguindo o RILEM-CEB-FIP (1973), diâmetros da barra ou faixa de resistência à compressão do concreto. 


\section{CONCRETO COM FIBRAS DE AÇO}

\subsection{CONSIDERAÇÕES INICIAIS}

As fibras são utilizadas como reforço de materiais frágeis desde a antiguidade. Os egípcios acrescentavam a palha na produção de tijolos de barro para melhorar seu comportamento à flexão. Crinas de cavalo e palhas foram utilizadas em diversos momentos como reforço nas construções, a fim de evitar fissuras de retração. Tranças de bambu também foram incorporadas em forros de gesso armado. A partir de 1910, foram feitos estudos envolvendo a utilização de alguns elementos em aço, como pregos e arames, para melhorar as características do concreto. No entanto, apenas a partir dos anos 50/60 que surgiu o estudo do potencial das fibras no concreto (SANTANA, 2014).

A adição da armadura no concreto simples permitiu a absorção das tensões de tração que o concreto não resistiria. Porém, a armadura tem uma localização específica, enquanto que as fibras são distribuídas ao longo da massa de concreto, constituindo um reforço tridimensional e permitindo a absorção das tensões em todas as direções (ACI 544.1R, 1996).

Existem diversos tipos de fibra. Para que ela possa ser utilizada no concreto, a resistência à tração deve ser superior à da matriz de concreto e deve apresentar uma ductilidade adequada. As fibras de polipropileno, nylon e polietileno são de baixo módulo de elasticidade, restringindo sua aplicação como reforço da matriz, mas são apropriadas para proteção contra incêndios, pois criam um caminho livre para a saída do vapor d'água e aliviam as pressões internas. As fibras de aço, carbono e vidro apresentam maior resistência à tração, sendo que as de aço apresentam baixo custo em relação às demais e as fibras de vidro são mais resistentes aos álcalis (SIMPLÍCIO, 2008).

\subsection{FIBRAS DE AÇO}

A incorporação de fibras de aço no concreto tem como objetivo melhorar as seguintes características: tenacidade, controle de fissuras, resistência à flexão, resistência ao impacto e fadiga (ACI 544.1R, 1996). 
Diversas geometrias estão disponíveis no mercado: seção circular ou retangular, ondulada, com extremidade reta ou com ganchos ou pinos. Também, podem ser classificadas conforme seu comprimento em curtas ou longas (SIMPLÍCIO, 2008).

Um parâmetro muito utilizado na caracterização de fibras metálicas é o fator de forma, que corresponde à relação entre seu comprimento e diâmetro. Também, utiliza-se o índice de reforço, que corresponde ao produto da taxa volumétrica de fibras pelo fator de forma (SIMPLÍCIO, 2008).

Normalmente, os tipos de aço utilizado na fabricação das fibras são: o aço carbono e o aço liga, que resulta em fibras resistentes à corrosão, indicadas para estruturas refratárias ou marítimas (SIMPLÍCIO,2008).

Existe em vigor a norma ABNT NBR 15530:2007, que classifica as fibras de aço de baixo teor de carbono e apresenta os requisitos mínimos para a forma geométrica, tolerância dimensional, defeito de fabricação, resistência à tração e dobramento. A Figura 12 apresenta as formas para as classes e tipos especificados na norma brasileira.

Figura 12-Formas geométricas para cada classe e tipo de fibra de aço segundo a

ABNT NBR 15530:2007

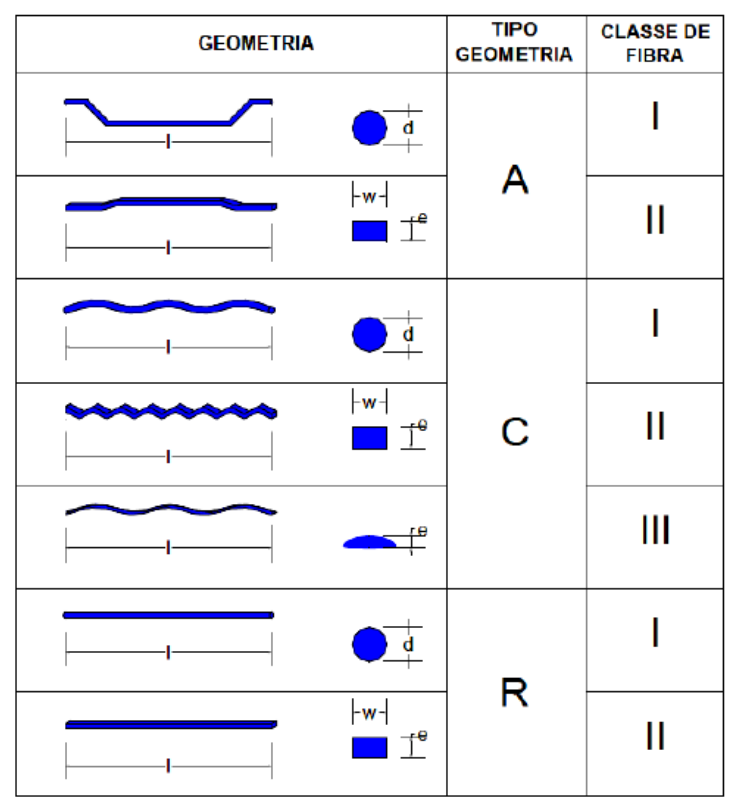

Fonte: ABNT NBR 15530:2007, modificado por Santana (2014)

Ela divide as fibras de aço em:

- $\quad$ Tipos: quanto à conformação da fibra: com ancoragem nas extremidades (tipo A), corrugada (tipo C), reta ou sem ancoragem nas extremidades (tipo R). 
- $\quad$ Classes: quanto ao processo de produção: oriunda de arame trefilado a frio (classe I), oriunda de chapa laminada cortada a frio (classe II), oriunda de arame trefilado e escarificado (classse III).

\subsection{CARACTERÍSTICAS DO CONCRETO COM FIBRAS}

O concreto com fibras de aço pode ser simplificado por um compósito influenciado pelas características da fibra, do concreto e da interface entre ambos. A atuação das fibras de aço no concreto pode ser no controle de fissuras ou no acréscimo de carga (ACI 544.1R, 1996).

O concreto submetido às tensões de tração ou compressão apresenta microfissuras, que podem existir antes mesmo da aplicação de carregamento devido à retração. Conforme o carregamento aumenta, essas microfissuras se juntam, formando uma macrofissura, e se propagam, levando à ruptura do concreto. As fibras de aço atuam nesse processo de formação das fissuras, costurando as microfissuras e diminuindo sua propagação, o que contribui para a ductilidade e capacidade de carga da estrutura. As fibras curtas são indicadas para o controle da microfissuração e as longas para a macrofissuração (SIMPLÍCIO, 2008).

\subsubsection{TRABALHABILIDADE}

A trabalhabilidade do concreto é influenciada pelos seguintes fatores: fator de forma, geometria e volume da fibra, dosagem da matriz e aderência entre a fibra e a matriz. A perda da trabalhabilidade é proporcional ao volume e fator de forma das fibras, sendo sugerida uma quantidade máxima de fibras de $2 \%$ em relação ao volume e fator de forma máximo de 100 , a fim de não comprometer a homogeneidade da mistura (MEHTA; MONTEIRO, 2008).

\subsubsection{MÓDULO DE ELASTICIDADE E COEFICIENTE DE POISSON}

Para volumes de fibra inferiores a $2 \%$, os valores de módulo de elasticidade e coeficiente de Poisson não são alterados em relação ao concreto sem fibras (ACI 544.1R, 1996). 


\subsubsection{COMPORTAMENTO À COMPRESSÃO}

Não há um consenso a respeito da influência da adição de fibras sobre a resistência à compressão do concreto. Para volumes de fibra de 1,5\%, o ACI 544.1R (1996) afirma haver um ganho de até $15 \%$ na resistência à compressão do concreto, mas pode haver um comprometimento na resistência à compressão devido à compactação malfeita decorrente da diminuição da trabalhabilidade.

De qualquer forma, o fato é que as fibras formam uma ponte para a transferência de tensões e reduzem a abertura e crescimento das fissuras, contribuindo na tenacidade do concreto (SIMPLÍCIO, 2008).

Figura 13-Curva tensão versus deformação na compressão do concreto com diversos porcentuais de fibra

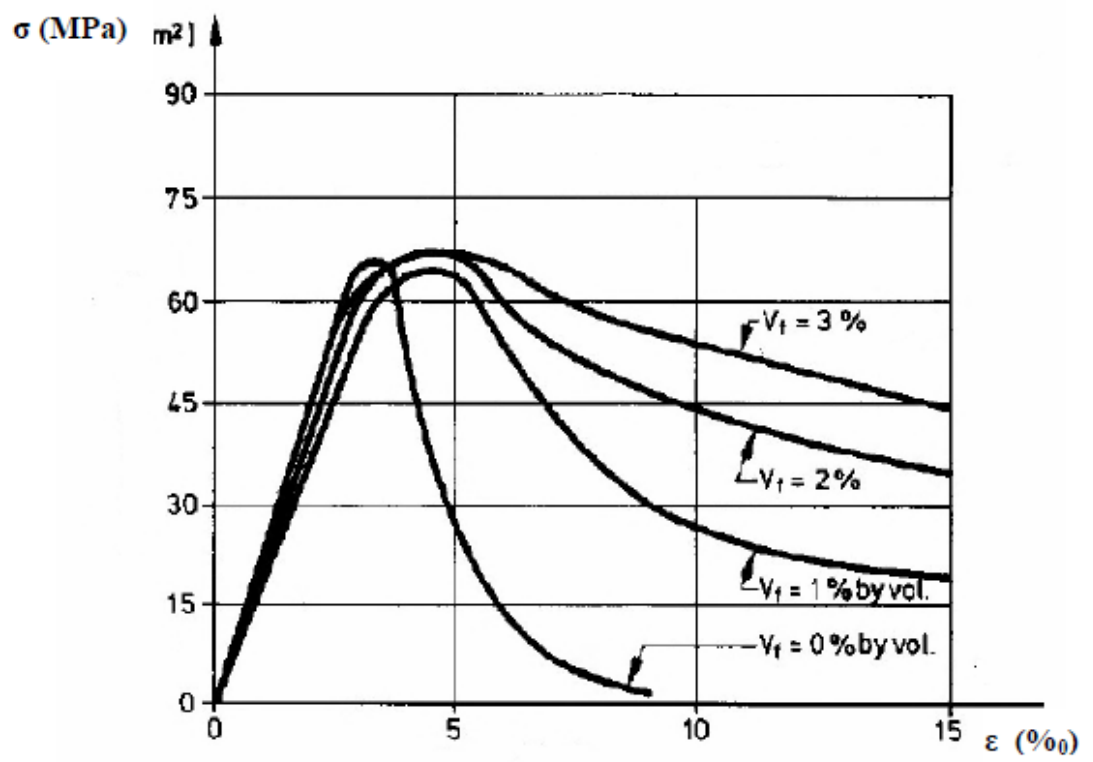

Fonte: Markovic (2006), modificado por Simplício (2008)

Verifica-se pela Figura 13 que a incorporação de fibras não acarreta em um ganho na resistência à compressão muito significativo, mas contribui na ductilidade pós-fissuração mesmo para baixos volumes. O trecho ascendente do diagrama tensão versus deformação do concreto não sofre alterações, mas há uma diminuição na inclinação do trecho descendente (LIMA JR, 2003).

Normalmente, altos índices de reforço das fibras resultam em uma maior ductilidade e capacidade de absorção de energia do compósito, mas podem prejudicar a trabalhabilidade (LIMA JR, 2003). 
Lima Jr e Giongo (2002) apresentam duas equações para simular o comportamento do concreto com fibras submetido à compressão. As equações são válidas para taxas de fibra de 0 a 2\%, fator de forma de 50 a 120 e resistência do concreto de 20 a $100 \mathrm{MPa}$.

Para o trecho ascendente, a equação é:

$$
\frac{\sigma}{f_{c f}}=\frac{\beta \cdot\left(\frac{\varepsilon_{c}}{\varepsilon_{c f}}\right)}{(\beta-1)+\left(\frac{\varepsilon_{c}}{\varepsilon_{c f}}\right)^{\beta}}
$$

Sendo:

$\mathrm{f}_{\mathrm{cf}}$ : resistência do concreto com fibras

$\sigma:$ tensão em um ponto qualquer do diagrama

$\varepsilon$ : deformação em um ponto qualquer do diagrama

$\beta$ : parâmetro que determina a inclinação da curva

Tabela 19- Equações para determinação dos parâmetros do trecho ascendente do comportamento do concreto com fibras submetido à compressão

\begin{tabular}{c|c}
\hline Autor & Equação \\
\hline Popovics (1973) & $\beta=\frac{E_{c}}{E_{c}-\frac{f_{c f}}{\varepsilon_{c f}}}$ \\
\hline Ezeldin e Balaguru (1992) & $\beta=1,093+0,7132 \cdot R^{-0,926}$ para fibras com extremidades com \\
ancoragem \\
Nataraja et al. (1999) & $\beta=1,093+7,4818 \cdot R^{-1,387}$ para fibras retas \\
\hline
\end{tabular}

Fonte: Lima Jr e Giongo (2002)-Adaptado

$\varepsilon_{\mathrm{cf}}:$ deformação correspondente à resistência do concreto

$$
\varepsilon_{c f}=-0,0017-0,0010\left(\frac{f_{c f}}{70}\right)-0,00032 . R
$$

$\mathrm{R}$ : índice de reforço

$$
R=V_{f} \cdot \frac{l}{D}
$$


$\mathrm{V}_{\mathrm{f}}$ : fração volumétrica de fibras

1: comprimento da fibra

D: diâmetro da fibra

Para o trecho descendente, a equação é:

$$
\frac{\sigma}{f_{c f}}=\exp \left(k_{1} \cdot\left(\varepsilon_{c}-\varepsilon_{c f}\right)^{k_{2}}\right)
$$

Sendo:

$$
\begin{gathered}
k_{1}=-0,207-8,786 \cdot 10^{-4} \cdot f_{c}+0,141 \cdot \ln (0,902+3,783 \cdot R) \\
k_{2}=-0,148-3,827 \cdot k_{1}+0,935 \cdot R+4,690 \cdot 10^{-3} \cdot f_{c}
\end{gathered}
$$

$\mathrm{f}_{\mathrm{c}}$ : resistência do concreto sem fibras

Figura 14-Comparação entre o modelo de Ezeldin e Balaguru (1992) e dados experimentais para o concreto com e sem fibras submetido à compressão

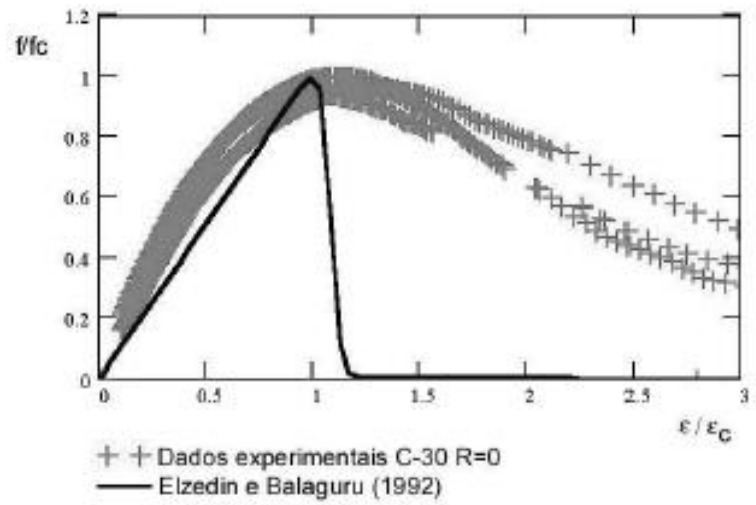

Fonte: Lima Jr (2003)

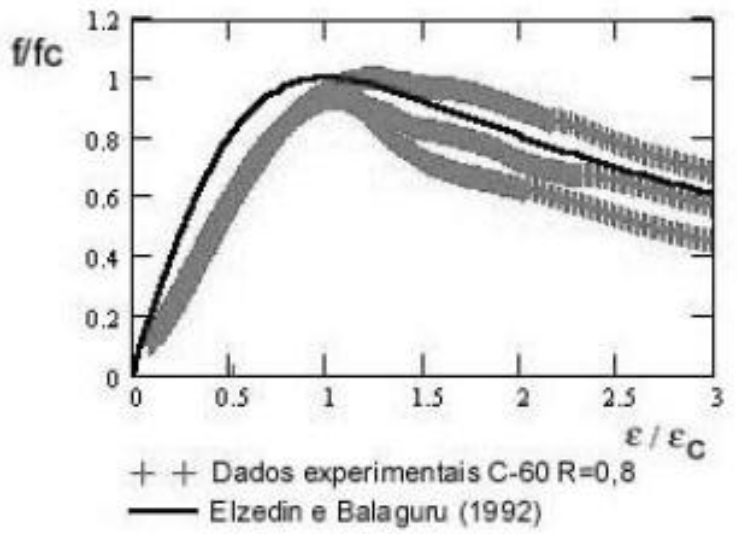

\subsubsection{COMPORTAMENTO À TRAÇÃO}

A incorporação de fibras no concreto impacta diretamente na resistência à tração, sendo possível ocorrer um aumento entre $30 \%$ e $40 \%$ para cada incremento no teor volumétrico de fibras de 1,5\% (ACI 544.1R, 1996). Sua principal contribuição encontra-se no comportamento pós-fissuração, com uma diminuição da inclinação do trecho descendente do diagrama tensão versus deformação do concreto (LIMA JR, 2003). 
Balaguru e Shah (1992) apresentam um modelo simples para o comportamento à tração do concreto com fibras, no qual o trecho ascendente é linear até a máxima tensão, correspondente à deformação de $0,2 \%$.

Figura 15-Modelo proposto por Balaguru e Shah (1992) para o comportamento do concreto com fibras submetido à tração

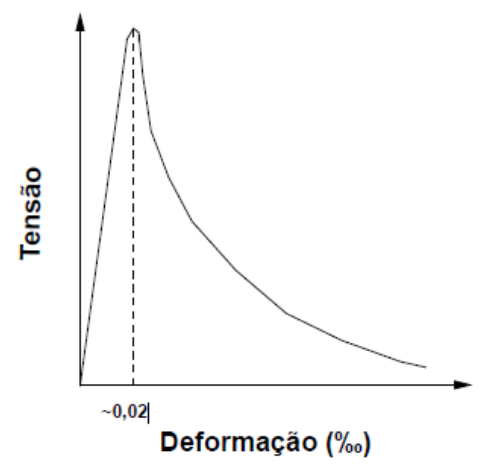

Fonte: Lima Jr (2003)

\subsection{DISCUSSÃO}

A adição de fibras no concreto tem como objetivos melhorar sua tenacidade, controle de fissuras, resistência à flexão, resistência ao impacto e fadiga. Sua principal vantagem com relação à armadura de aço é formar um reforço tridimensional, absorvendo as tensões de tração em todas as direções. Isso é possível, pois as fibras atuam costurando as microfissuras e diminuindo sua propagação, contribuindo diretamente no comportamento pós-pico do concreto, aumentando sua ductilidade (ACI 544.1R, 1996).

Para teores volumétricos inferiores a $2 \%$, como foi utilizado na presente pesquisa, a adição de fibras ao concreto não diminui consideravelmente a trabalhabilidade, que poderia comprometer a resistência à compressão do concreto por dificultar a compactação, além de não alterar o módulo de elasticidade ou o coeficiente de Poisson. Já a resistência à tração é influenciada positivamente com a incorporação de fibras, podendo sofrer aumentos entre $30 \%$ e $40 \%$ (ACI 544.1R, 1996). 


\section{PROGRAMA EXPERIMENTAL}

O estudo experimental foi desenvolvido no Laboratório de Estruturas do Departamento de Engenharia de Estruturas da EESC/USP e consistiu em:

a) Caracterização dos materiais:

- Caracterização dos materiais constituintes do concreto (cimento, sílica ativa, superplastificante, areia fina, areia média, brita 0 )

- Ensaio de resistência à compressão do concreto conforme ABNT NBR 5739:2007

- Ensaio de resistência à tração por compressão diametral do concreto conforme ABNT NBR 7222:2011

- Determinação do módulo de elasticidade via técnica de excitação por impulso

- Ensaio de tração do aço conforme ABNT NBR 7480:2007 e ABNT NBR ISO 6892$1: 2013$

- Determinação das propriedades físicas da barra conforme ABNT NBR 7480:2007

b) Ensaio de arrancamento: foram realizados ensaios de arrancamento, com três exemplares para cada modelo, baseados nos ensaios de Rehm e Eligehausen (1979), com algumas alterações, divididos em duas etapas:

1) Ensaio Piloto: foram estabelecidos os seguintes parâmetros:

- Diâmetros da armadura longitudinal: $10 \mathrm{~mm}, 16 \mathrm{~mm}$ e $20 \mathrm{~mm}$

- Resistência do concreto à compressão aos 28 dias: $70 \mathrm{MPa}$

- Volume de fibras: $1 \%$

- Carregamento monotônico

- Relação entre o diâmetro do corpo-de-prova e diâmetro da barra: 10ф para barra de $10 \mathrm{~mm}$ e $20 \mathrm{~mm}$ e $9 \phi$ para as de $16 \mathrm{~mm}$

- Comprimento de aderência: $3 \phi$

- Realizado aos 33 dias 
2) Ensaio Definitivo: foram estabelecidos os seguintes parâmetros:

- Diâmetro da armadura longitudinal: $16 \mathrm{~mm}$

- Diâmetro e espaçamento da armadura transversal: $5 \mathrm{~mm}$ e $20 \mathrm{~mm}$

- Resistência do concreto à compressão aos 28 dias: $70 \mathrm{MPa}$

- Volume de fibras: $1 \%$

- Carregamento monotônico

- Relação entre o diâmetro do corpo-de-prova e diâmetro da barra: $8 \phi, 9 \phi, 15 \phi$

- Comprimento de aderência: $3 \phi$

- Realizado aos 28 dias

A nomenclatura utilizada para os modelos dos ensaios de arrancamento foi dividida em duas formas:

1) Para o ensaio piloto: inclusão ou não de fibras metálicas (sem fibras $-\mathrm{C}$, com fibras-CF) e diâmetro da barra $(10,16$ ou $20 \mathrm{~mm})$

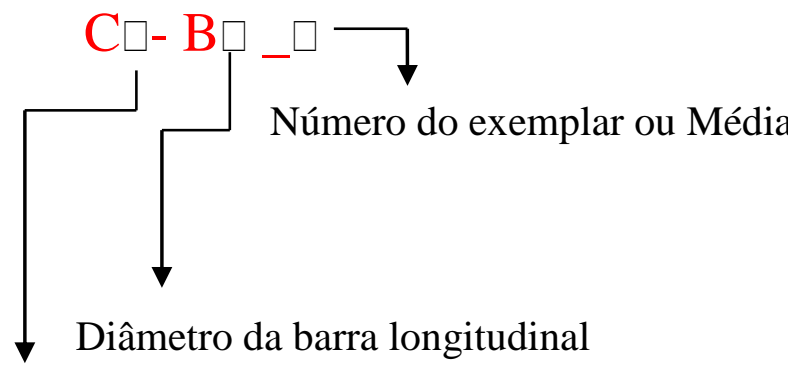

Tipo de concreto (sem fibras ou com fibras)

2) Para o ensaio definitivo: inclusão ou não de fibras metálicas (sem fibras $-\mathrm{C}$, com fibras$\mathrm{CF})$, relação entre o diâmetro do corpo-de-prova e o diâmetro da barra $(8,9$, ou 15) e armadura transversal (sem armadura transversal-“"” ou com armadura transversal-S).

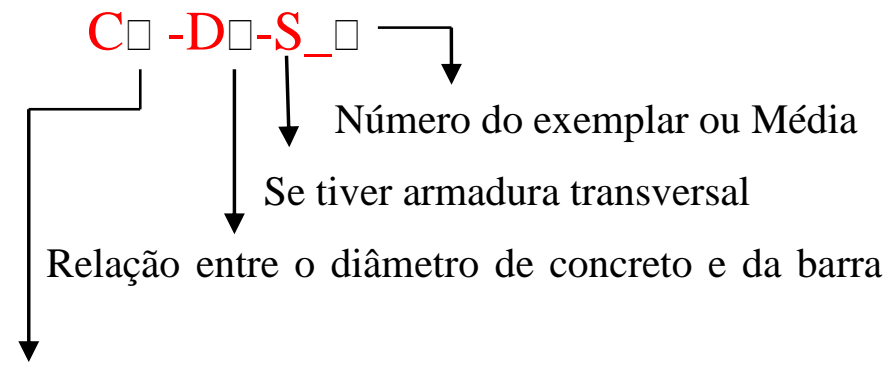

Tipo de concreto (sem fibras ou com fibras) 
Tabela 20- Nomenclatura dos modelos e parâmetros avaliados

\begin{tabular}{|c|c|c|c|c|c|c|}
\hline Etapa & Nomenclatura & $\begin{array}{c}\mathrm{N}^{\mathbf{0}} \\
\text { exemplares } \\
\end{array}$ & \begin{tabular}{|c|} 
Fibras \\
metálicas
\end{tabular} & $\begin{array}{c}\text { Diâmetro da } \\
\text { Barra (mm) } \\
\end{array}$ & $\begin{array}{l}\text { Relação entre o diâmetro } \\
\text { de concreto e da barra }\end{array}$ & $\begin{array}{l}\text { Armadura } \\
\text { transversal }\end{array}$ \\
\hline Piloto & C-B10 & 3 & - & 10 & 10 & - \\
\hline Piloto & CF-B10 & 3 & $\checkmark$ & 10 & 10 & - \\
\hline Piloto & C-B16 & 3 & - & 16 & 9 & - \\
\hline Piloto & CF-B16 & 3 & $\checkmark$ & 16 & 9 & - \\
\hline Piloto & C-B20 & 3 & - & 20 & 10 & - \\
\hline Piloto & CF-B20 & 3 & $\checkmark$ & 20 & 10 & - \\
\hline Definitivo & C- D9 & 3 & - & 16 & 9 & - \\
\hline Definitivo & CF-D9 & 3 & $\checkmark$ & 16 & 9 & - \\
\hline Definitivo & C-D9-S & 3 & - & 16 & 9 & $\checkmark$ \\
\hline Definitivo & CF-D9-S & 3 & $\checkmark$ & 16 & 9 & $\checkmark$ \\
\hline Definitivo & C-D15 & 3 & - & 16 & 15 & - \\
\hline Definitivo & CF-D15 & 3 & $\checkmark$ & 16 & 15 & - \\
\hline Definitivo & C-D15-S & 3 & - & 16 & 15 & $\checkmark$ \\
\hline Definitivo & CF-D15-S & 3 & $\checkmark$ & 16 & 15 & $\checkmark$ \\
\hline Definitivo & C-D8 & 3 & - & 16 & 8 & - \\
\hline Definitivo & CF-D8 & 3 & $\checkmark$ & 16 & 8 & - \\
\hline Definitivo & C-D8-S & 3 & - & 16 & 8 & $\checkmark$ \\
\hline Definitivo & CF-D8-S & 3 & $\checkmark$ & 16 & 8 & $\checkmark$ \\
\hline
\end{tabular}

Fonte: Autoria própria

\subsection{CARACTERIZAÇÃO DOS MATERIAIS CONSTITUINTES} DO CONCRETO

A diminuição da relação água-cimento promove um aumento na resistência à compressão do concreto, mas diminui a trabalhabilidade do mesmo, que pode ser ajustada com o acréscimo de superplastificante (MEHTA; MONTEIRO, 2008). No estudo do traço do concreto utilizado na pesquisa, notou-se que o uso do superplastificante tornava a mistura plástica, como um "chiclete", que acabava interferindo na trabalhabilidade do concreto a ponto de tornar inviável a moldagem dos modelos. Além disso, o excesso de superplastificante era visível nas bordas do concreto ao ser realizado o ensaio de tronco de cone, sendo fixada uma porcentagem inferior para as concretagens definitivas.

Tendo em mente todas essas considerações, foi desenvolvido um traço que resultasse em uma alta resistência à compressão e uma trabalhabilidade adequada, sem segregação dos componentes nem exsudação excessiva da água.

A fim de obter uma maior resistência à compressão do concreto, foi feito um empacotamento de partículas entre a areia fina e média, baseado no proposto por Helene e 
Terzian (1992), de modo que os grãos da areia fina preenchessem, até certo nível, os vazios da areia média, minimizando o índice de vazios da mistura final.

Utilizou-se o cimento CP-II-Z pela baixa liberação de calor, se comparado ao CPVARI que produz uma rápida evaporação da água. Além disso, a reação pozolânica, caracterizada pela reação da pozolana com o hidróxido de cálcio, resulta em um produto similar ao silicato de cálcio hidratado e reduz o volume e tamanho dos poros capilares, conferindo uma maior resistência à pasta de cimento (MEHTA; MONTEIRO, 2008).

\subsubsection{CIMENTO}

O cimento utilizado na dosagem do concreto foi o CPII Z32 (Cimento Portland Composto com Pozolana) com o nome comercial Itaú ${ }^{\circledR}$ Todas as Obras, fabricado pela empresa Votorantim, ilustrado na Figura 16.

Figura 16-Cimento utilizado

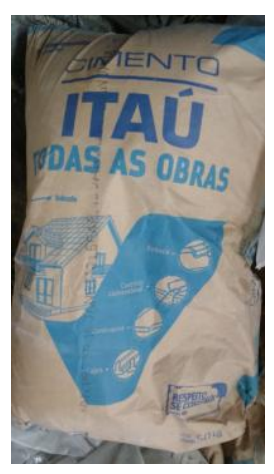

Fonte: Autoria própria

\subsubsection{SÍLICA ATIVA}

A sílica ativa utilizada foi a Silmix ${ }^{\circledR}$, da fabricante Dow Corning, com as propriedades indicadas na Tabela 21 e ilustrada na Figura 17:

Tabela 21-Propriedades da sílica ativa

\begin{tabular}{c|c}
\hline Parâmetro & Valor \\
\hline Diâmetro médio: & $0,40 \mu \mathrm{m}$ \\
\hline Resíduo na peneira $45 \mu \mathrm{m}:$ & $\leq 10,0 \%$ \\
\hline Aparência: & Pó de dimensões micrométricas \\
\hline Densidade aparente: & $150-700 \mathrm{~kg} / \mathrm{m}^{3}$ \\
\hline Área específica B.E.T.: & $\geq 15.000 \mathrm{e} \leq 30.000 \mathrm{~m}^{2} / \mathrm{kg}$ \\
\hline
\end{tabular}

Fonte: Fabricante (Dow Corning) 
Figura 17-Sílica ativa

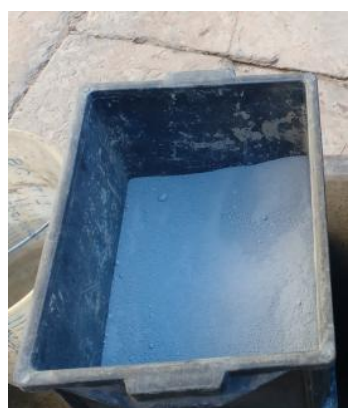

Fonte: Autoria própria

\subsubsection{AGREGADO MIÚDO}

Foram utilizados dois tipos de areia, fina e média, na dosagem do concreto, de modo que houvesse um preenchimento maior dos vazios ("empacotamento") e fosse obtida uma maior massa unitária compactada na composição das amostras. A areia média encontrava-se disposta em baias do Laboratório de Estruturas, enquanto a areia fina foi encomendada de um fornecedor. As Figura 18 e Figura 19 apresentam os materiais utilizados, já separados para a dosagem do concreto.

A análise granulométrica, com a dimensão máxima característica, módulo de finura e massa específica das areias, extraídas de Leite (2018), encontram-se na Tabela 22 e Tabela 23, além da curva granulométrica representada na Figura 20:

Tabela 22-Análise granulométrica da areia fina

\begin{tabular}{c|c|c}
\hline Abertura da peneira $(\mathrm{mm})$ & Porcentagem retida & Porcentagem retida acumulada \\
\hline 0,6 & 0,00 & 0,00 \\
\hline 0,3 & 50,49 & 50,49 \\
\hline 0,15 & 43,10 & 93,59 \\
\hline Fundo & 6,41 & 100 \\
\hline \multicolumn{2}{c|}{ Dimensão máxima característica $(\mathrm{mm})$} & 0,6 \\
\hline \multicolumn{2}{c}{ Massa específica $\left(\mathrm{g} / \mathrm{cm}^{3}\right)$} & 2,57 \\
\hline \multicolumn{2}{r}{ Absorção $(\%)$} & 0,15 \\
\hline \multicolumn{2}{r}{ Módulo de finura } & 1,44 \\
\hline
\end{tabular}

Fonte: Leite (2018) 
Tabela 23-Análise granulométrica da areia média

\begin{tabular}{c|c|c}
\hline Abertura da peneira $(\mathrm{mm})$ & Porcentagem retida & Porcentagem retida acumulada \\
\hline 4,75 & 0,00 & 0,00 \\
\hline 2,36 & 0,03 & 0,03 \\
\hline 1,18 & 7,94 & 7,97 \\
\hline 0,6 & 21,51 & 29,48 \\
\hline 0,3 & 36,64 & 66,12 \\
\hline 0,15 & 29,71 & 95,83 \\
\hline Fundo & 4,17 & 100 \\
\hline Dimensão máxima característica $(\mathrm{mm})$ & 2,36 \\
\hline \multicolumn{2}{c}{ Massa específica (g/cm $\left.{ }^{3}\right)$} & 2,58 \\
\hline \multicolumn{2}{c}{ Absorção $(\%)$} & 0,63 \\
\hline \multicolumn{2}{c}{ Módulo de finura } & 2,00 \\
\hline
\end{tabular}

Fonte: Leite (2018)

Figura 18-Areia fina

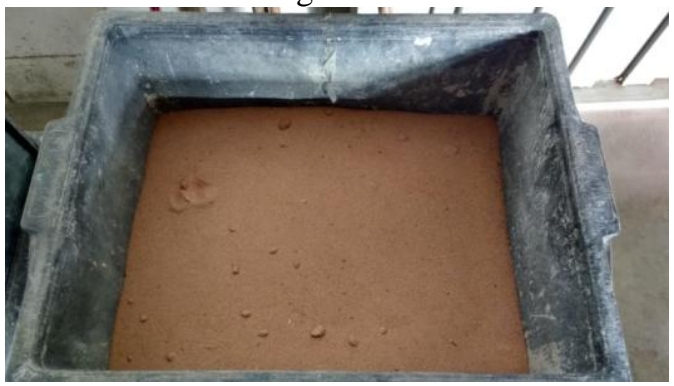

Fonte: Autoria própria
Figura 19-Areia média

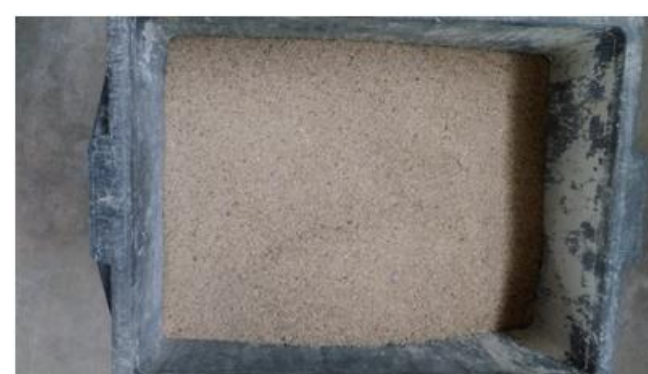

Fonte: Autoria própria

Figura 20-Curva granulométrica da areia fina e média

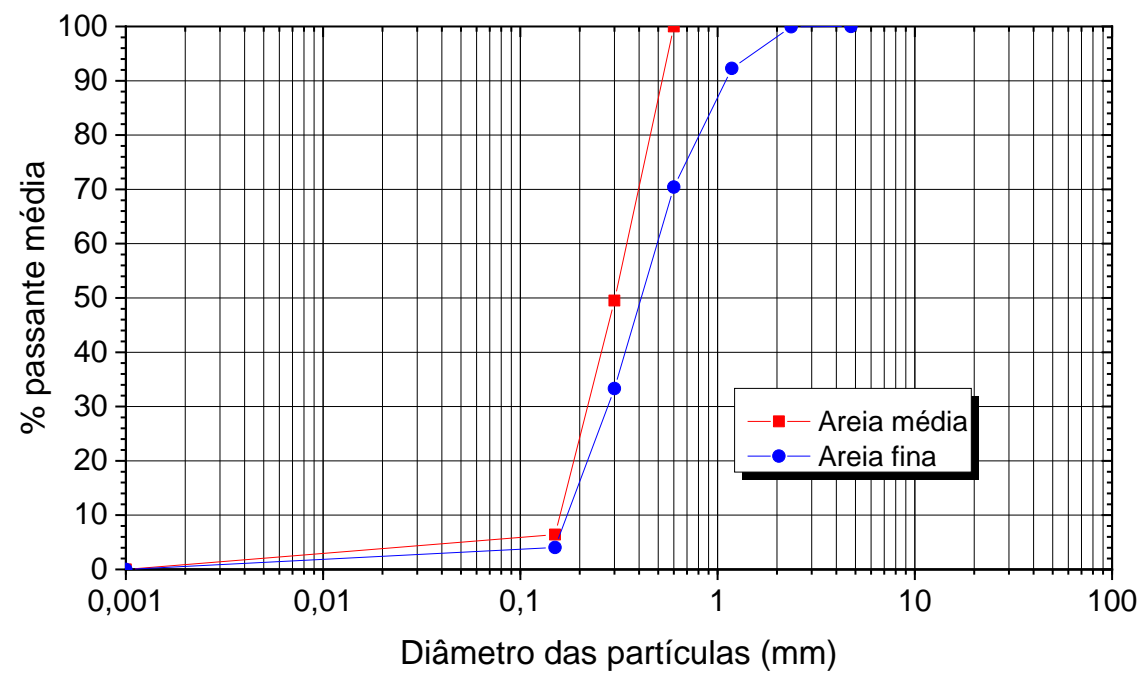

Fonte: Leite (2018)-Adaptado 


\subsubsection{AGREGADO GRAÚDO}

Utilizou-se brita 0 (ou pedrisco), ilustrada na Figura 21, como agregado graúdo na dosagem do concreto por apresentar uma dimensão máxima de 9,5 mm, menor que a brita 1 , facilitando a moldagem dos modelos do ensaio de arrancamento.

O agregado graúdo foi obtido de um fornecedor e apresentava massa específica de $2,85 \mathrm{~g} / \mathrm{cm}^{3}$ (SILVA, 2017).

Figura 21-Agregado graúdo

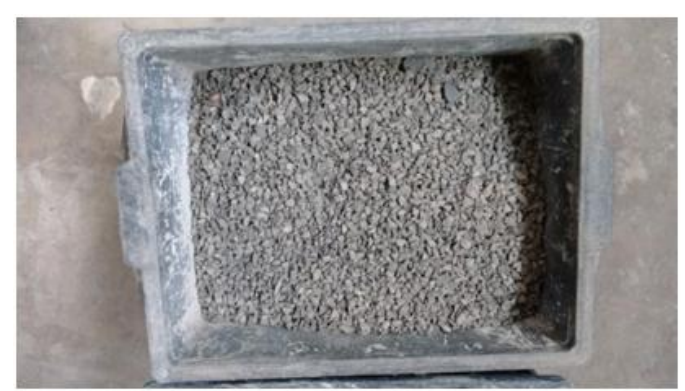

Fonte: Autoria própria

\subsection{5 ÁGUA DE AMASSAMENTO}

A água de amassamento era proveniente da rede pública de abastecimento da cidade de São Carlos (SP).

\subsubsection{ADITIVO SUPERPLASTIFICANTE}

Utilizou-se o aditivo superplastificante ADVATM CAST 525, da fabricante GRACE Construction Products. Ele possui aspecto líquido e densidade de 1,06 kg/m³ (AEC WEB). A Figura 22 ilustra o aditivo utilizado.

Figura 22-Aditivo superplastificante

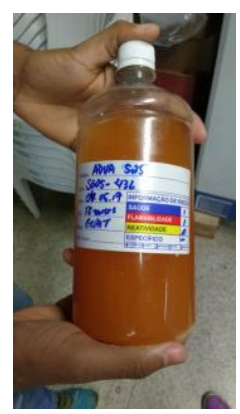

Fonte: Autoria própria 


\subsubsection{FIBRAS METÁLICAS}

As fibras de aço eram conhecidas como Wirand ${ }^{\circledR}$ FS8, da fabricante Maccaferri, com comprimento nominal de $25 \mathrm{~mm}$ e diâmetro de $0,75 \mathrm{~mm}$, sendo os valores obtidos por paquímetro digital iguais a 24,60 $\mathrm{mm}$ e $0,77 \mathrm{~mm}$, respectivamente, conforme Figura 23.

A massa específica foi extraída do trabalho de Silva (2017), obtida pelo ensaio frasco de Chapman: $7,43 \mathrm{~g} / \mathrm{cm}^{3}$.

Figura 23- Caracterização da fibra metálica

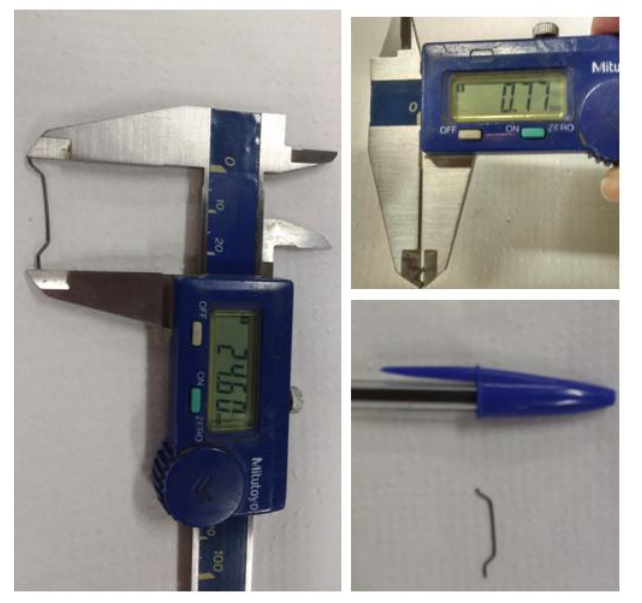

Fonte: Autoria própria

\subsection{DOSAGEM DOS MATERIAIS}

A dosagem dos materiais foi feita com base no traço pobre proposto por Silva (2017), alterando-se o teor água/materiais secos (h) de 7,5\% para 8,87\%, a fim de obter uma mistura menos seca e com um maior período de trabalhabilidade adequada. Fixaram-se os seguintes parâmetros:

- Teor água/materiais secos: $8,87 \%$

- Teor de argamassa: $63 \%$

- Substituição de $10 \%$ de cimento por sílica ativa (em relação ao volume de cimento)

- Teor de aditivo superplastificante (em relação à massa de cimento): $1 \%$ nos concretos sem fibras e $1,1 \%$ nos concretos com fibras

- Volume de fibras: $1 \%$ do volume de concreto.

Para obter um menor índice de vazios foi feita a determinação da composição de finos, conforme descrito a seguir. 


\subsubsection{COMPOSIÇÃO DE FINOS}

A areia média, que se encontrava na baia do Laboratório de Estruturas, foi peneirada grosseiramente para retirada de materiais estranhos, enquanto a areia fina estava ensacada. As areias foram secas ao sol, colocando-se uma fina camada no chão em área de ventilada e recolhendo depois de aproximadamente 3 horas, quando apresentavam uma aparência esbranquiçada. Foi feito um ensaio de combinação ótima, conforme descrito por Helene e Terzian (1992). Segundo os autores, apenas a areia média é disposta em um corpo-de-prova em três camadas, sendo que em cada uma são aplicados 25 golpes. O corpo-de-prova é pesado e a massa de areia média é aferida. Então, são obtidas diversas proporções para a areia média e fina, sendo que a massa de areia média é sempre fixada e o mesmo procedimento é repetido. Ao final, com a maior massa unitária compactada, obtém-se a composição de finos para o menor índice de vazios.

A Tabela 24 indica os valores da massa unitária no estado compactado obtidos para as diversas composições entre a areia média e fina, sendo que a proporção de $45 \%$ de areia média e 55\% de areia fina resultou na proporção ideal.

Tabela 24-Determinação da composição de finos para uma maior massa unitária

\begin{tabular}{c|c|c|c|c|c}
\hline $\begin{array}{c}\text { Composição entre } \\
\text { os agregados } \\
\text { médio/fino (\%) }\end{array}$ & $\begin{array}{c}\text { Quantidade } \\
\text { de Médio } \\
(\mathrm{kg})\end{array}$ & $\begin{array}{c}\text { Quantidade } \\
\text { de Fino (kg) }\end{array}$ & $\begin{array}{c}\text { Acréscimo de } \\
\text { Fino para a } \\
\text { composição } \\
\text { desejada (kg) }\end{array}$ & $\begin{array}{c}\text { Massa total recipiente } \\
\text { Agregados + Tara) } \\
(\mathrm{kg})\end{array}$ & $\begin{array}{c}\text { Massa Unitária no } \\
\text { estado compactado } \\
(\mathrm{kg} / \mathrm{dm})^{3}\end{array}$ \\
\hline $100 / 0$ & 8,525 & -- & - & 14,590 & 1,608 \\
\hline $90 / 10$ & 8,525 & 0,947 & 0,947 & 14,732 & 1,635 \\
\hline $80 / 20$ & 8,525 & 2,131 & 1,184 & 14,816 & 1,651 \\
\hline $70 / 30$ & 8,525 & 3,654 & 1,522 & 14,836 & 1,655 \\
\hline $60 / 40$ & 8,525 & 5,683 & 2,030 & 14,863 & 1,669 \\
\hline $50 / 50$ & 8,525 & 8,525 & 2,842 & 1,915 & 1,670 \\
\hline $45 / 55$ & 8,525 & $\mathbf{1 0 , 4 1 9}$ & $\mathbf{1 , 8 9 4}$ & $\mathbf{1 4 , 9 2 0}$ & 1,666 \\
\hline $40 / 60$ & 8,525 & 12,788 & 2,368 & 14,899 & 1,650 \\
\hline
\end{tabular}

Fonte: Autoria própria

\subsubsection{CONSUMO DOS MATERIAIS E TRAÇO EM MASSA}

A Tabela 25 indica as proporções dos materiais para obtenção do traço analisado, já considerando a devida substituição de cimento por sílica ativa. 
Tabela 25-Consumo e traço do concreto sem fibra

\begin{tabular}{c|c}
\hline Material & Consumo por $\mathrm{m}^{3}$ de concreto \\
\hline Cimento $(\mathrm{kg})$ & 458,41 \\
\hline Areia fina $(\mathrm{kg})$ & 515,45 \\
\hline Areia média $(\mathrm{kg})$ & 421,73 \\
\hline Brita 0 $(\mathrm{kg})$ & 850,60 \\
\hline Água $(\mathrm{kg})$ & 182,98 \\
\hline Superplastificante $(\mathrm{kg})$ & 4,58 \\
\hline Sílica $(\mathrm{kg})$ & 36,15 \\
\hline Traço em massa & $1: 1,84: 1,67: 0,4: 0,01: 0,07$ \\
\hline Fonte: Autoria própria
\end{tabular}

A Figura 24 apresenta o concreto a) sem fibras e b) com $1 \%$ de fibras.

Figura 24-Concreto sem fibras e concreto com fibras

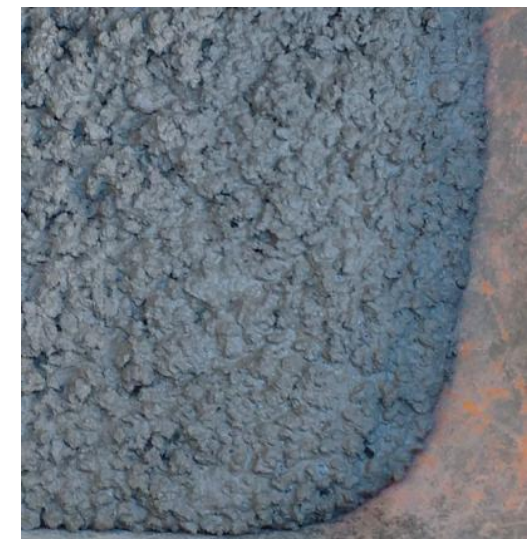

a)

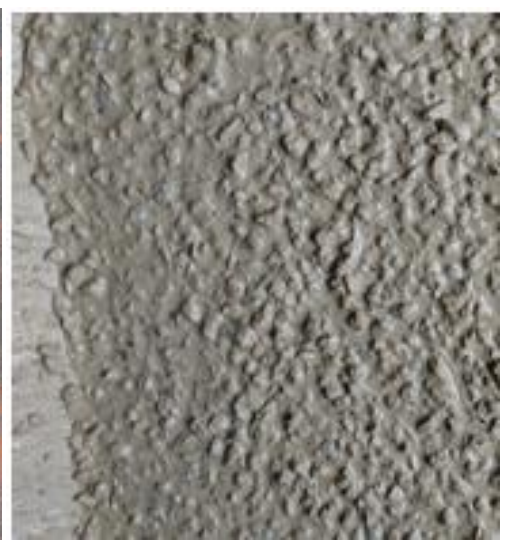

b)

Fonte: Autoria própria

O consumo de fibra, em $\mathrm{kg}$, foi obtido da seguinte forma:

1) Determinação da densidade do concreto sem fibras por meio de um corpo-de-prova de $100 \mathrm{~mm}$ x $200 \mathrm{~mm}$;

2) Cálculo do volume real de concreto a partir da divisão da massa de todos os componentes pela densidade do concreto;

3) Multiplicação do volume de concreto por 0,01 a fim de obter o volume de fibras;

4) Obtenção da massa de fibras ao multiplicar o volume de fibras pela sua densidade. 


\subsubsection{EXECUÇÃO DA MISTURA}

Os materiais foram separados, conforme Figura 25, e inseridos na betoneira na seguinte ordem:

1) Agregados miúdos e graúdos acrescidos de metade da água, misturados por cerca de 1 minuto;

2) Sílica ativa, cimento e o restante da água, misturados por cerca de 5 minutos;

3) Superplastificante, misturado por cerca de 5 minutos;

4) Para o concreto com fibras metálicas, estas foram inseridas aos poucos, para evitar a formação de "ouriços" ou empelotamento e misturadas por cerca de 2 minutos (Figura 26).

Figura 25-Separação dos materiais para concretagem

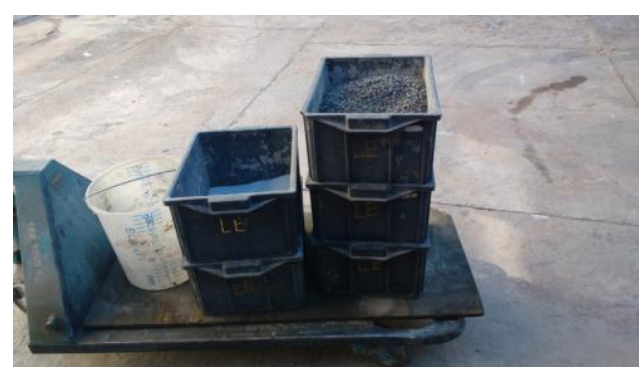

Fonte: Autoria própria

Figura 26-Mistura dos materiais na betoneira e inserção da fibra metálica no concreto

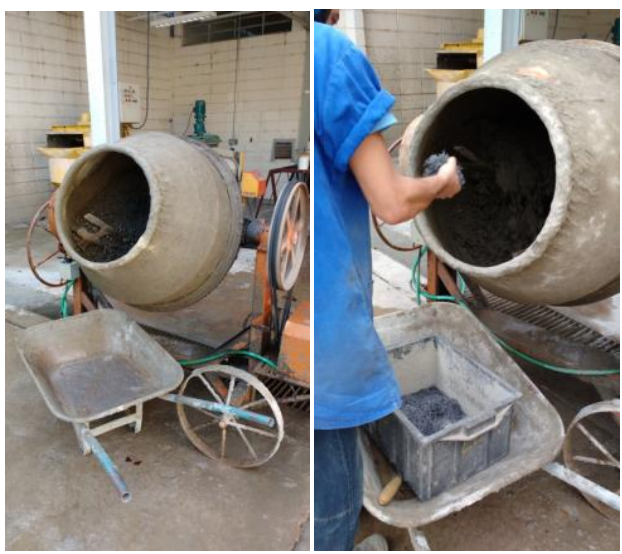

Fonte: Autoria própria 


\subsection{ENSAIOS DE DETERMINAÇÃO DAS PROPRIEDADES DO} CONCRETO

\subsubsection{ESTADO FRESCO}

A consistência do concreto foi avaliada por meio do ensaio de tronco de cone (slump), de acordo com o NM 67:1996. Para facilitar o preenchimento dos modelos, foi adicionada uma quantidade de superplastificante ao concreto que o tornasse bastante fluido e, portanto, foi avaliado o espalhamento do mesmo, além do abatimento, conforme a Tabela 26 e Figura 27:

Tabela 26- Propriedades do estado fresco

\begin{tabular}{c|c}
\hline Abatimento médio $(\mathrm{mm})$ & Espalhamento médio $(\mathrm{mm})$ \\
\hline Fonte: Autoria própria & 436 \\
\hline
\end{tabular}

Figura 27- Ensaio de adensamento do concreto a) sem fibras b) com fibras
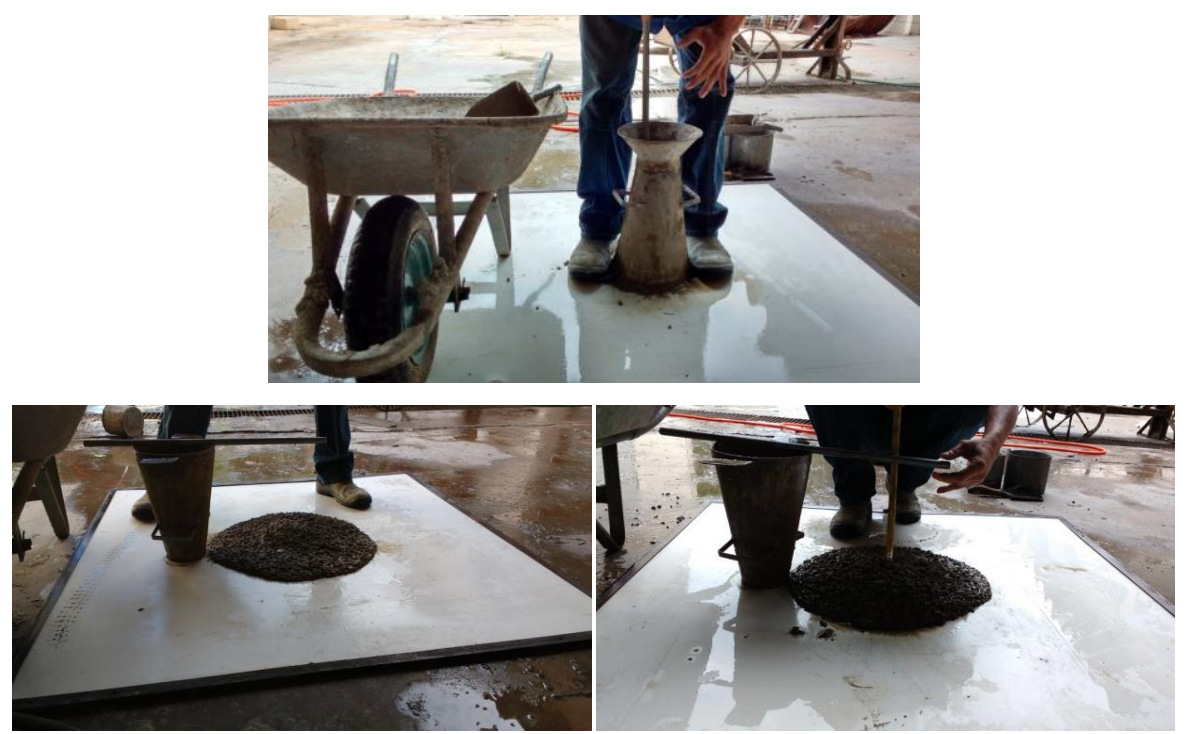

a)

b)

Fonte: Autoria própria

\subsubsection{ESTADO ENDURECIDO}

Foram moldados corpos-de-prova nas dimensões $100 \mathrm{~mm}$ x $200 \mathrm{~mm}$ a fim de determinar as propriedades mecânicas e adensados em mesa vibratória, conforme Figura 28: 
Figura 28- Moldagem e adensamento dos corpos-de-prova em mesa vibratória

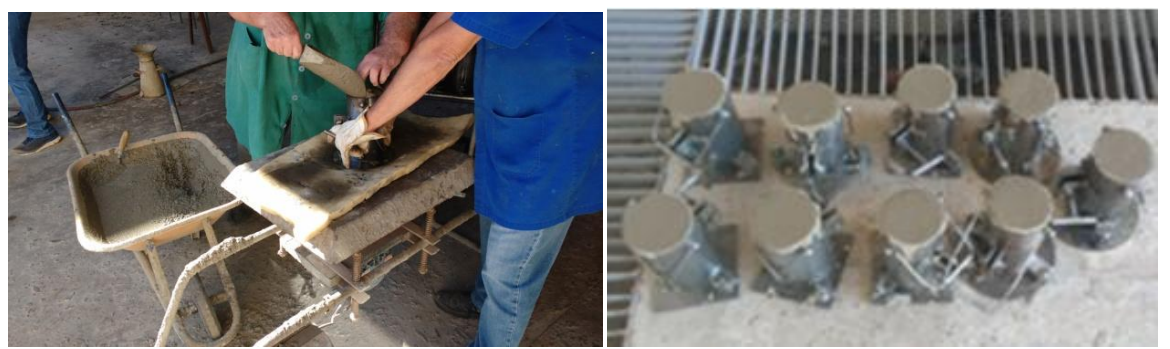

Fonte: Autoria própria

No dia posterior à concretagem, os corpos-de-prova foram desmoldados (Figura 29) e armazenados na câmara úmida para iniciar o processo de cura úmida (Figura 30).

Figura 30-Corpos-de-prova de concreto com fibras armazenados na câmara

Figura 29-Desforma dos corpos-deprova de concreto sem fibras

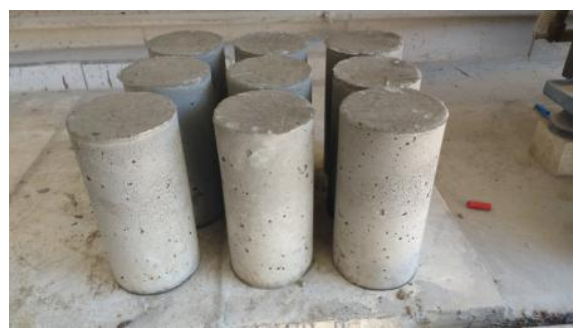

Fonte: Autoria própria úmida

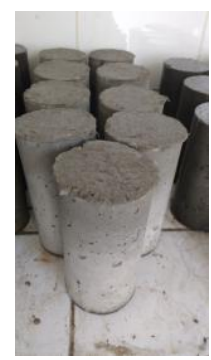

Fonte: Autoria própria

Após 28 dias, os corpos-de-prova foram retificados e suas resistências à compressão, tração e módulo de elasticidade foram medidos, conforme procedimentos descritos a seguir.

\subsubsection{RESISTÊNCIA À COMPRESSÃO}

A resistência à compressão por compressão uniaxial foi obtida por meio de uma prensa hidráulica, indicada na Figura 31, com velocidade de carregamento de 2,4 kN/s, conforme descrito na ABNT NBR 5739:2007.

Para todas as concretagens foram ensaiados três corpos-de-prova, sendo que a Figura 32 ilustra o resultado do teste para os modelos do ensaio piloto. 
Figura 31-Aplicação do carregamento uniaxial para determinação da resistência à

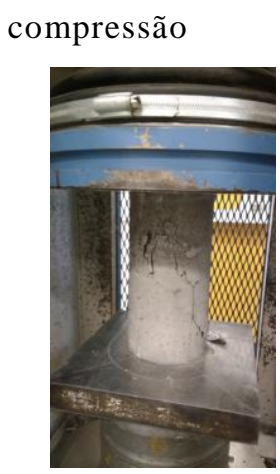

Fonte: Autoria própria

Figura 32-Corpos-de-prova de concreto após o ensaio de resistência à compressão, sendo a) sem fibras e b) com fibras

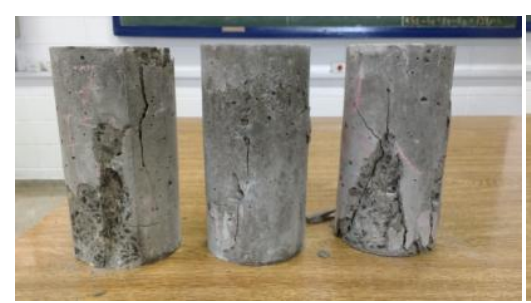

a)

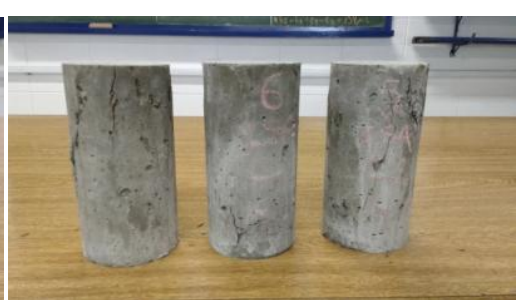

b)

Fonte: Autoria própria

\subsubsection{RESISTÊNCIA À TRAÇÃO}

A resistência à tração foi obtida por ensaio de compressão diametral, conforme ABNT NBR 7222:2011, utilizando-se a mesma prensa hidráulica do ensaio de resistência à compressão, mas com velocidade de carregamento de $0,94 \mathrm{kN} / \mathrm{s}$ e um aparato para aplicação da carga ao longo da longitudinal, indicado na Figura 33 e Figura 34.

Para todas as concretagens foram ensaiados três corpos-de-prova, sendo que a Figura 35 ilustra o resultado do teste para os modelos do ensaio piloto.

Figura 33-Aparato utilizado para determinação da resistência à tração

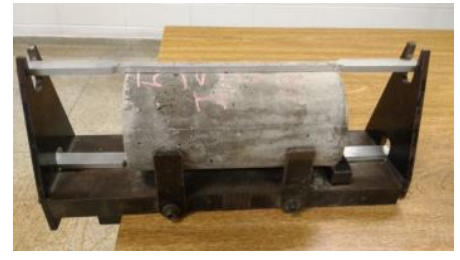

Fonte: Autoria própria 
Figura 34-Aplicação do carregamento para determinação da resistência à tração

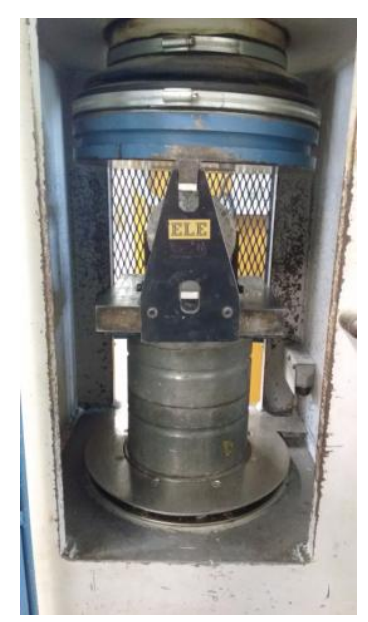

Fonte: Autoria própria

Figura 35-Corpos-de-prova de concreto após o ensaio de resistência à tração, sendo a) sem fibras e b) com fibras

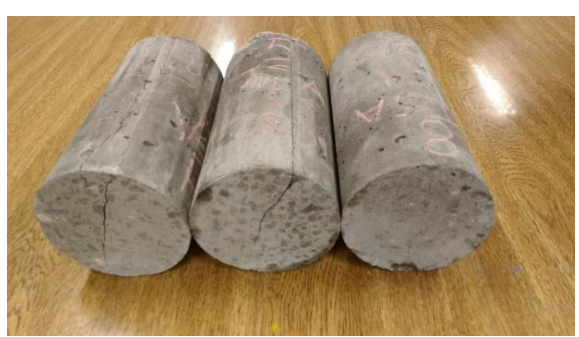

a)

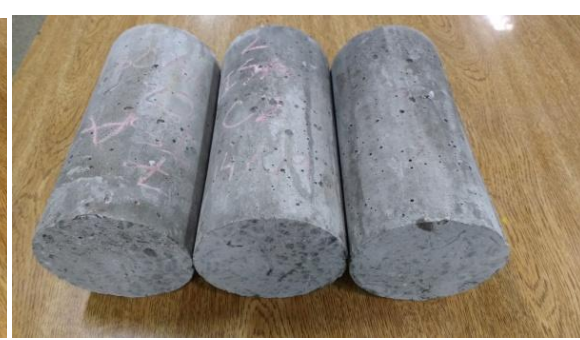

b)

Fonte: Autoria própria

Segundo Lobo Carneiro² (1949 apud FUSCO, 1995), o plano de fratura do ensaio de tração por compressão diametral não é obrigatoriamente o plano de menor resistência, fornecendo resultados maiores que os obtidos por tração pura. Assim, os valores obtidos nesse ensaio devem ser multiplicados por 0,85 .

\subsubsection{MÓDULO DE ELASTICIDADE}

Optou-se por utilizar o aparelho Sonelastic ${ }^{\circledR}$, da fabricante ATCP Engenharia Física, a fim de determinar o módulo de elasticidade dinâmico, devido à facilidade na execução do ensaio.

${ }^{2}$ LOBO CARNEIRO, F.L. Résistence à la traction des bétons. Rio de Janeiro, Instituto Nacional de Tecnologia, 1949 
A técnica consiste em aplicar um pequeno golpe mecânico no corpo-de-prova e o microfone do aparelho capta o sinal (Figura 36). A partir da obtenção da frequência natural e das características do corpo-de-prova (dimensões e massa), o software converte a resposta acústica em módulo de elasticidade dinâmico.

Foram ensaiados três corpos-de-prova, sem fibra e com fibra, extraídos da concretagem dos modelos do ensaio piloto, sendo medidos em cada um os módulos de elasticidade dinâmico longitudinal e flexional.

Figura 36- Ensaio de determinação do módulo de elasticidade dinâmico com o Sonelastic

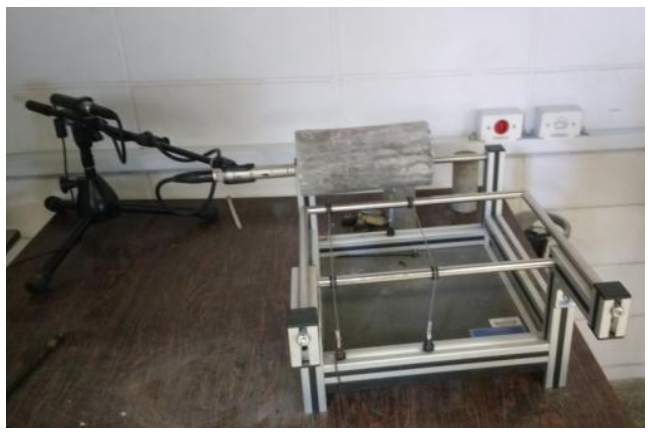

Fonte: Autoria própria

\subsection{ENSAIOS DE DETERMINAÇÃO DAS PROPRIEDADES DO} $\mathrm{AÇO}$

As barras de aço utilizadas como armadura longitudinal e transversal nos ensaios de aderência foram fabricadas em CA-50 pela empresa Udiaço, localizada no município de São Carlos (SP).

As propriedades mecânicas e físicas foram determinadas conforme ABNT NBR 7480:2007 e ABNT NBR ISO 6892-1:2013.

O ensaio de tração foi feito por meio da máquina servo-hidráulica Instron, sistema de aquisição de dados System 5000 e extensômetros do tipo clipgage. Definiu-se uma velocidade de carregamento de $0,02 \mathrm{~mm} / \mathrm{s}$ até o deslocamento do extensômetro atingir uma deformação de $1,8 \%$, a fim de determinar a tensão de escoamento. Em seguida, o clipgage era retirado para não sofrer danos e o ensaio continuava com velocidade de carregamento de $0,2 \mathrm{~mm} / \mathrm{s}$ até a ruptura da barra. A Figura 37 ilustra o início e fim do ensaio de tração das barras. 
Figura 37-Ensaio de resistência à tração das barras

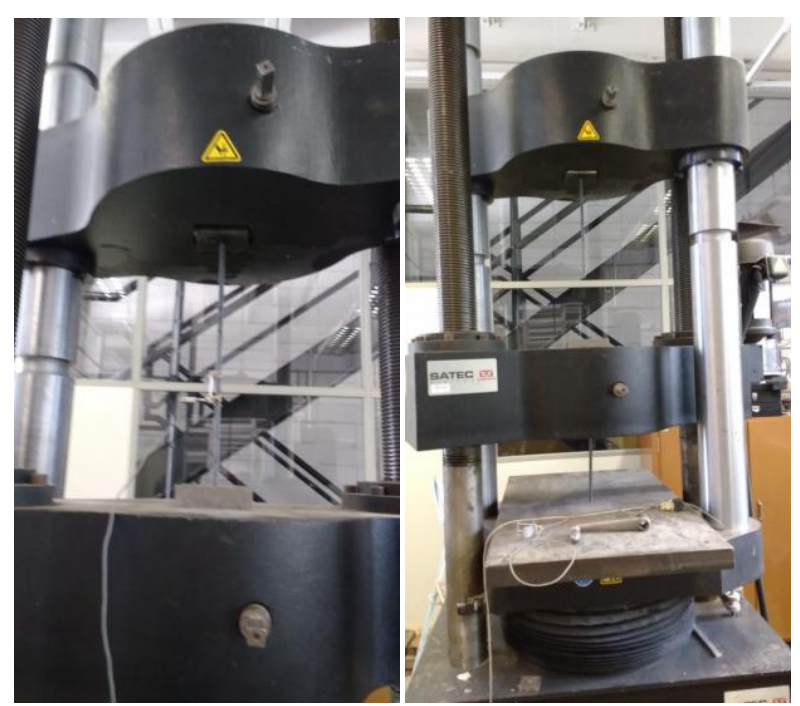

Fonte: Autoria própria

As propriedades físicas das barras foram determinadas com o uso de paquímetro digital, trena e balança de precisão, conforme Figura 38 e Figura 39.

Figura 38-Determinação do espaçamento entre nervuras e altura das nervuras
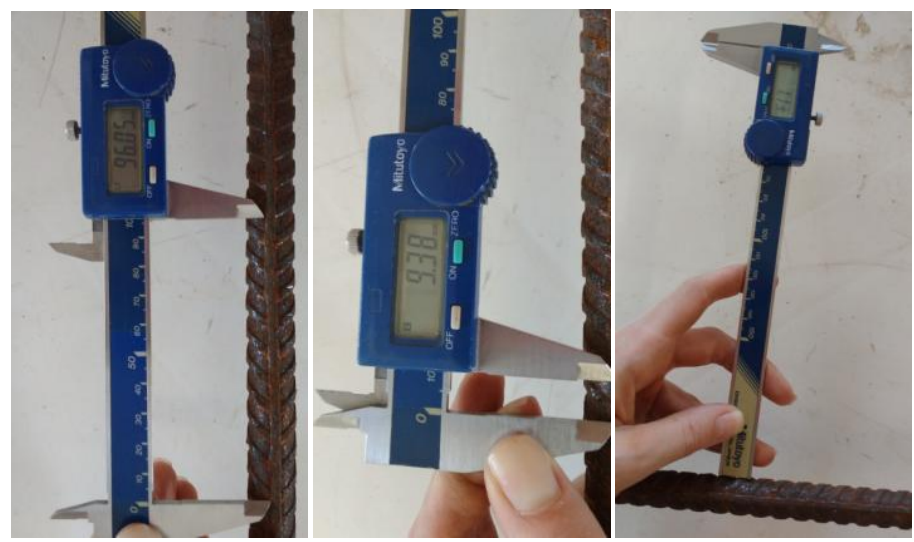

Fonte: Autoria própria

Figura 39-Aferição do comprimento e massa da barra

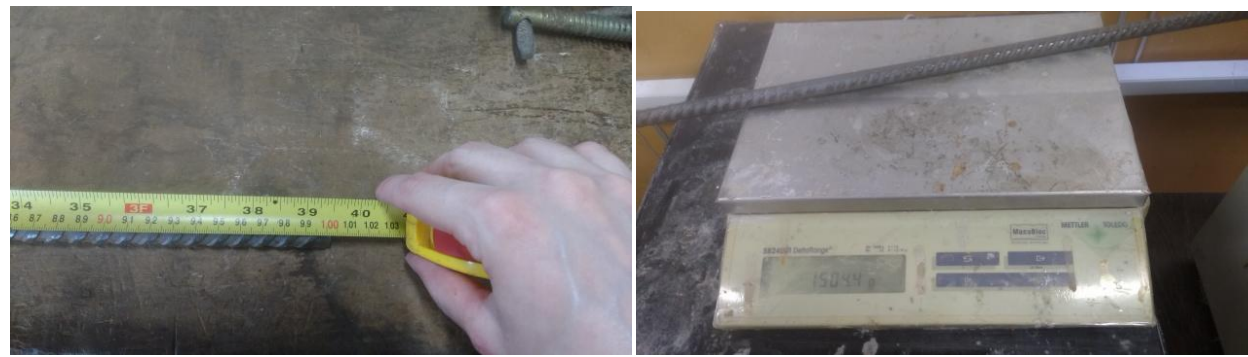

Fonte: Autoria própria 
A altura das nervuras foi obtida diretamente pela medida do paquímetro digital. O espaçamento entre nervuras foi medido de duas formas: tomando dois inícios de nervuras e entre um início e a décima primeira nervura, sendo o espaçamento adotado como sendo a média entre os dois métodos. A partir dos valores de força do ensaio de tração obteve-se os valores de tensão correspondentes ao diâmetro calculado por meio da massa linear e densidade do material, padronizada em $7850 \mathrm{~kg} / \mathrm{m}^{3}$.

O módulo de elasticidade $\left(E_{s}\right)$ foi obtido a partir do intervalo entre duas tensões e deformações, no início do ensaio. Para os diâmetros de $10 \mathrm{~mm}$ e $16 \mathrm{~mm}$, sem patamar de escoamento, obteve-se a tensão de escoamento $\left(f_{\mathrm{y}}\right)$ projetando-se a reta, com mesma inclinação do início (regime elástico), a partir da deformação de $0,2 \%$. Já para a barra de 20 $\mathrm{mm}$, a tensão de escoamento estava claramente definida. A tensão de ruptura $\left(\mathrm{f}_{\mathrm{u}}\right)$ foi calculada a partir do último valor de força medido.

As propriedades físicas encontram-se na Tabela 27 e o diagrama tensão-deformação com os valores de $f_{y}, E_{s}$ e $f_{u}$ encontram-se na Tabela 28 e Figura 40:

Tabela 27-Propriedades físicas das barras

\begin{tabular}{c|c|c|c|c}
\hline $\begin{array}{c}\text { Diâmetro } \\
\text { nominal }(\mathrm{mm})\end{array}$ & $\begin{array}{c}\text { Altura das nervuras } \\
\text { média }(\mathrm{mm})\end{array}$ & $\begin{array}{c}\text { Espaçamento médio } \\
\text { entre nervuras }(\mathrm{mm})\end{array}$ & $\begin{array}{c}\text { Massa linear } \\
(\mathrm{kg} / \mathrm{m})\end{array}$ & $\begin{array}{c}\text { Diâmetro } \\
\text { calculado }(\mathrm{mm})\end{array}$ \\
\hline 10 & 0,87 & 6,34 & 0,59 & 9,751 \\
\hline 16 & 1,02 & 9,59 & 1,51 & 15,670 \\
\hline 20 & 1,54 & 13,43 & 2,47 & 20,007 \\
\hline
\end{tabular}

Fonte: Autoria própria

Tabela 28- Propriedades mecânicas das barras

\begin{tabular}{c|c|c|c}
\hline Diâmetro $(\mathrm{mm})$ & $\mathrm{f}_{\mathrm{y}}(\mathrm{MPa})$ & $\mathrm{f}_{\mathrm{u}}(\mathrm{MPa})$ & $\mathrm{E}_{\mathrm{s}}(\mathrm{MPa})$ \\
\hline 10 & 549 & 793 & 203201 \\
\hline 16 & 540 & 807 & 201786 \\
\hline 20 & 521 & 633 & 200226 \\
\hline
\end{tabular}

Fonte: Autoria própria 
Figura 40- Tensão versus deformação das barras de diâmetro 10, 16 e $20 \mathrm{~mm}$

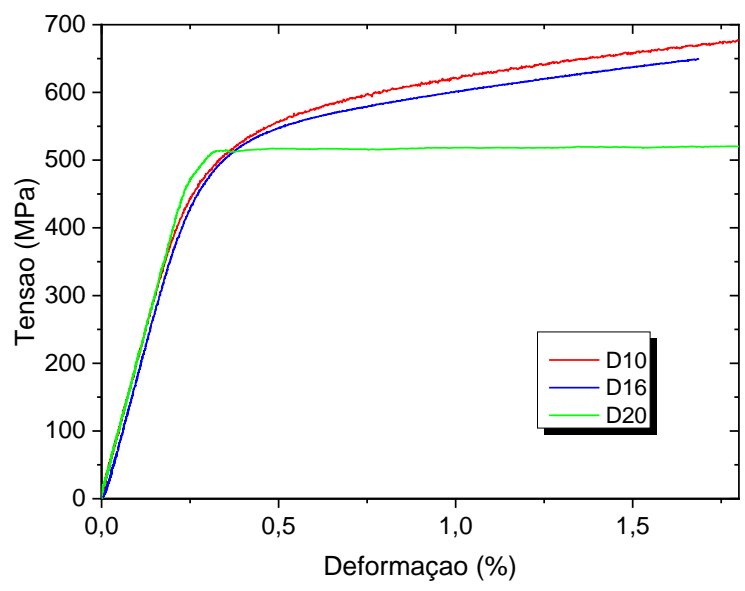

Fonte: Autoria própria

\subsection{ENSAIO DE ARRANCAMENTO}

O ensaio de arrancamento consiste em extrair a barra de aço de um corpo-de-prova de concreto. O modelo utilizado na pesquisa foi baseado na proposta de Rehm e Eligehausen (1979): possui um trecho central com aderência entre a barra de aço e o concreto, enquanto que o restante é isolado por uma mangueira plástica para criar os trechos não aderentes.

\subsubsection{GEOMETRIA DOS MODELOS}

Seguindo o modelo de Rehm e Eligehausen (1979), os corpos-de-provas eram cilíndricos com comprimento aderente igual a $3 \phi$ e o restante igual a $5 \phi$. O trecho superior e inferior da barra foram dimensionados de modo que fosse possível prender nas garras da máquina Instron.

No ensaio piloto, o diâmetro do corpo-de-prova foi igual ao proposto pelos autores (10申 ou $9 \phi$, devido à indisponibilidade de tubo de PVC, que foi utilizado como forma, no diâmetro equivalente), enquanto que nos ensaios definitivos foram feitos também modelos com diâmetro de $8 \phi$ e $15 \phi$ para avaliar a influência do cobrimento de concreto no comportamento da aderência.

As geometrias dos modelos usadas no ensaio piloto e definitivo encontram-se a seguir: 


\section{a) Ensaio Piloto}

O ensaio piloto tinha como objetivo verificar o comportamento da interação entre diferentes diâmetros da barra de aço com o concreto sem fibras e com fibras, avaliando se as geometrias dos modelos estavam apropriadas e se a proposta de Rehm e Eligehausen (1979) seria adequada para o estudo em questão. Com os resultados, foi possível fixar um diâmetro para ser melhor investigado nos ensaios definitivos.

Foram moldados corpos-de-prova para concreto com e sem fibras de aço, sem armadura transversal e diâmetro de concreto de $10 \phi$ para barra de $10 \mathrm{~mm}$ e $20 \mathrm{~mm}$ e $9 \phi$ para as de $16 \mathrm{~mm}$, com três exemplares para cada modelo, totalizando 18 corpos-de-prova. Buscou-se respeitar a relação igual a 10 entre o diâmetro de concreto e o diâmetro da barra, conforme Rehm e Eligehausen (1979), mas não havia disponibilidade de tubos de PVC de $160 \mathrm{~mm}$, apenas no diâmetro de $150 \mathrm{~mm}$ (diâmetro interno de $140 \mathrm{~mm}$ ), equivalendo a $9 \phi$. A Tabela 29 apresenta os parâmetros avaliados no ensaio piloto.

Tabela 29-Parâmetros avaliados no ensaio piloto

\begin{tabular}{|c|c|c|c|c|}
\hline $\begin{array}{c}\text { Diâmetro da barra } \\
\text { longitudinal }(\phi), \mathrm{mm}\end{array}$ & $\begin{array}{l}\text { Cobrimento de } \\
\text { concreto }(\mathrm{c} / \phi)\end{array}$ & Teor de fibras $\left(V_{f}\right)$ & $\begin{array}{l}\text { Número de } \\
\text { exemplares }\end{array}$ & Modelo \\
\hline \multirow{2}{*}{10} & \multirow{2}{*}{4,40} & 0 & 3 & C-B10 \\
\hline & & $1 \%$ & 3 & CF-B10 \\
\hline \multirow{2}{*}{16} & \multirow{2}{*}{3,88} & 0 & 3 & C-B16 \\
\hline & & $1 \%$ & 3 & CF-B16 \\
\hline \multirow{2}{*}{20} & \multirow{2}{*}{4,25} & 0 & 3 & C-B20 \\
\hline & & $1 \%$ & 3 & CF-B20 \\
\hline
\end{tabular}

Fonte: Autoria própria

A Figura 41 indica as dimensões dos corpos-de-prova utilizados no ensaio piloto. 
Figura 41-Dimensões dos corpos-de-prova das barras de 10, 16 e $20 \mathrm{~mm}$ do ensaio piloto
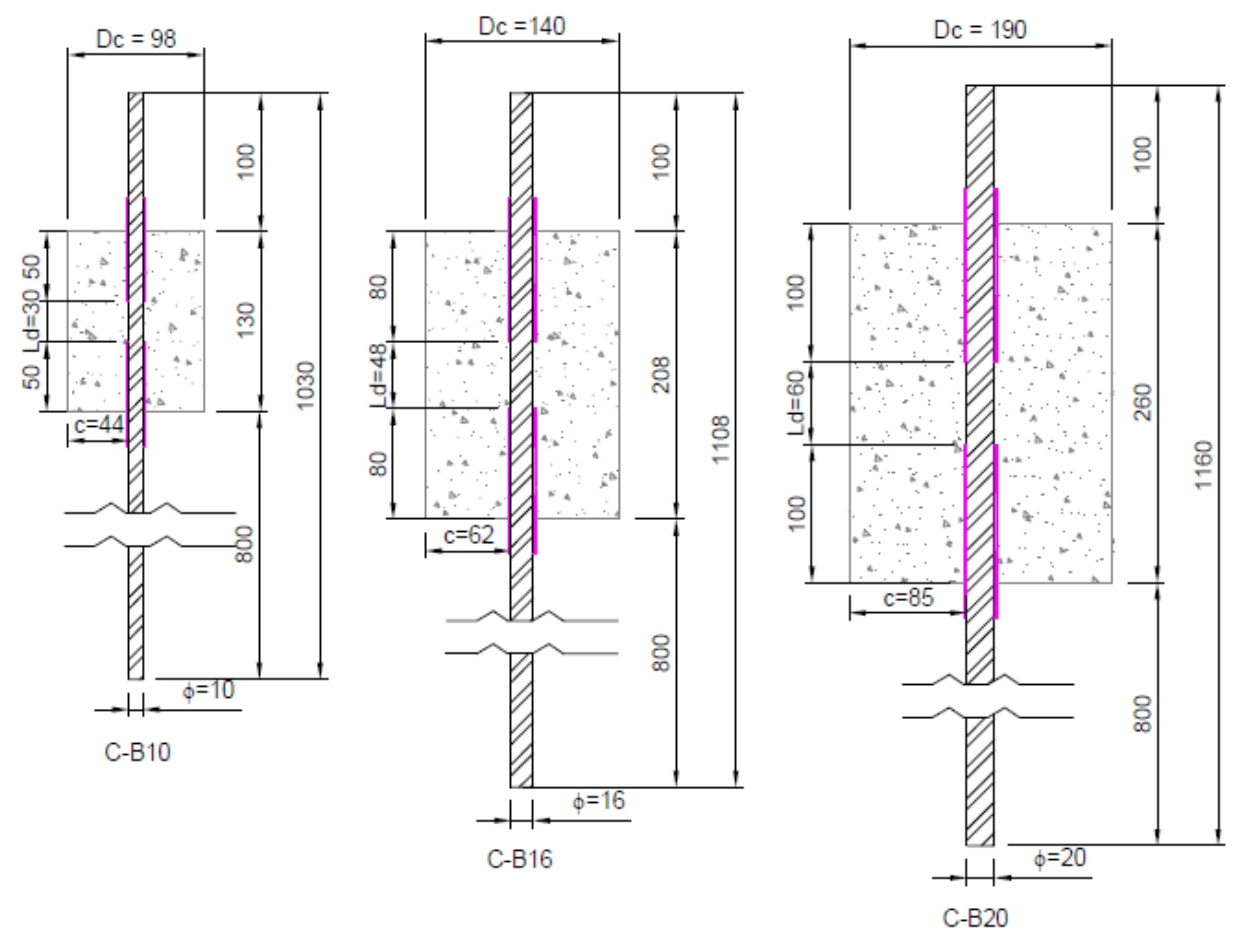

Fonte: Autoria própria

\section{b) Ensaio Definitivo}

Todos os modelos do ensaio definitivo foram feitos com barra longitudinal de $16 \mathrm{~mm}$ $(\phi)$, variando:

- Cobrimento de concreto

- Inclusão ou não de fibras metálicas

- Inclusão ou não de armadura transversal

Novamente, utilizou-se a relação entre o diâmetro do concreto e a barra igual a 9, pois correspondia ao diâmetro do tubo de PVC disponível e que melhor se aproximava às dimensões propostas por Rehm e Eligehausen (1979). Também, o diâmetro do concreto foi aumentado para uma relação de 15, a fim de avaliar se haveria uma contribuição adicional no confinamento promovido pelo aumento do cobrimento. Por fim, utilizou-se um diâmetro menor de concreto, com relação de 8, para atingir o fendilhamento e verificar se a inclusão de fibras e armadura transversal seriam suficientes para alterar a forma de ruptura para arrancamento, ou promover um aumento da ductilidade. A Figura 42 indica as dimensões utilizadas no ensaio definitivo. 
Figura 42-Dimensões dos corpos-de-prova de diâmetro $8 \phi, 9 \phi$ e $15 \phi$ do ensaio definitivo (com armadura transversal)
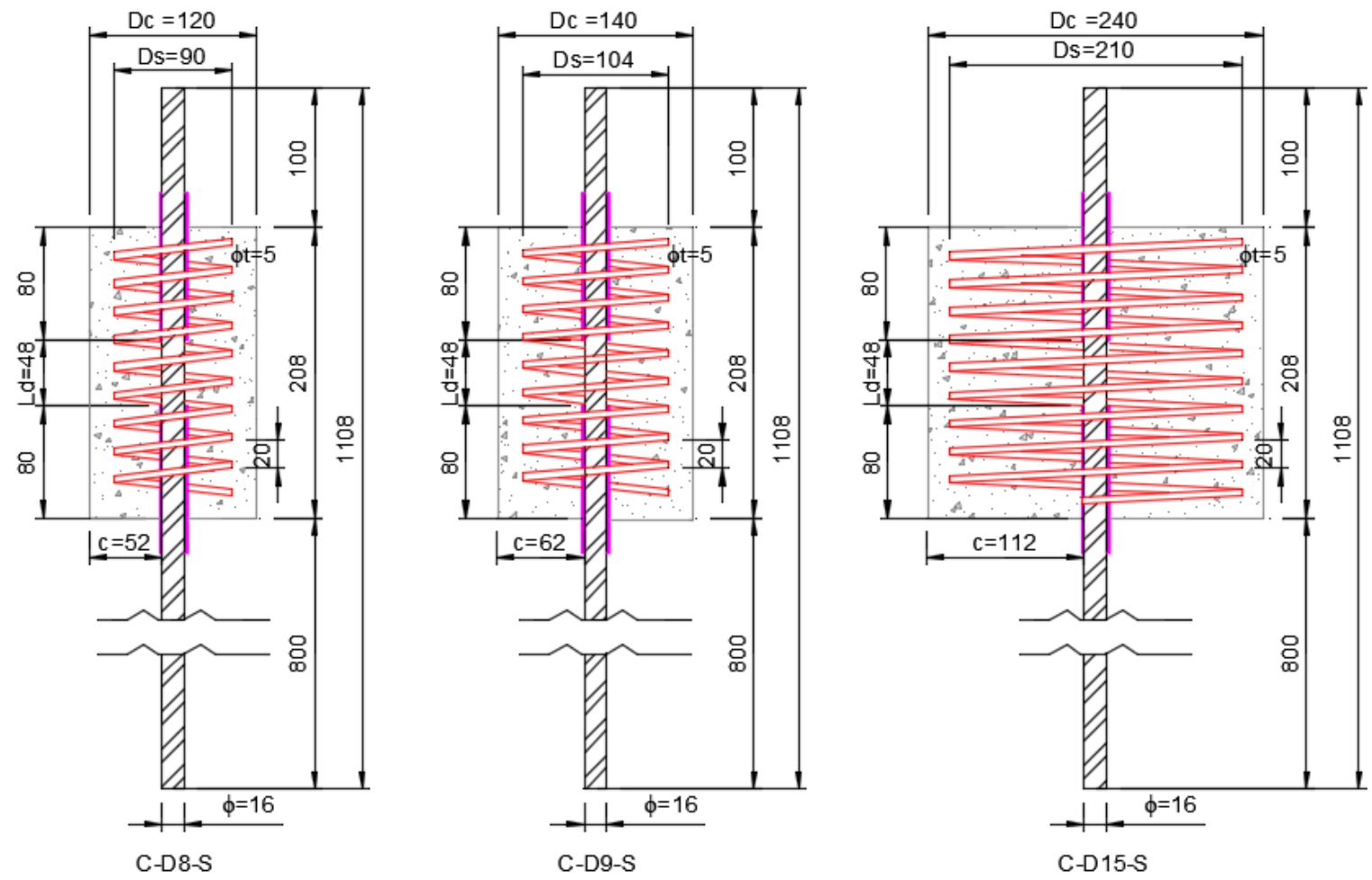

Fonte: Autoria própria

Variando-se os parâmetros descritos acima e moldando-se três corpos-de-prova para cada modelo, foram feitos 36 ensaios de arrancamento, conforme descrito na Tabela 30.

Tabela 30- Resumo dos ensaios discretizando os parâmetros avaliados

\begin{tabular}{|c|c|c|c|c|c|c|}
\hline $\begin{array}{c}\text { Diâmetro de } \\
\text { concreto }\left(\mathrm{D}_{\mathrm{c}}\right), \mathrm{mm}\end{array}$ & $\mathrm{D}_{\mathrm{c}} / \phi$ & $\mathrm{c} / \phi$ & $\begin{array}{c}\text { Teor de } \\
\text { fibras (Vf) }\end{array}$ & $\begin{array}{c}\text { Diâmetro da } \\
\text { espiral (Ds), } \mathrm{mm}\end{array}$ & $\begin{array}{c}\mathrm{N}^{\mathrm{o}} \mathrm{de} \\
\text { exemplares }\end{array}$ & Modelo \\
\hline \multirow{4}{*}{120} & \multirow{4}{*}{8} & \multirow{4}{*}{3,25} & \multirow{2}{*}{0} & - & 3 & C-D8 \\
\hline & & & & 90 & 3 & C-D8-S \\
\hline & & & \multirow{2}{*}{$1 \%$} & - & 3 & CF-D8 \\
\hline & & & & 90 & 3 & CF-D8-S \\
\hline \multirow{4}{*}{140} & \multirow{4}{*}{9} & \multirow{4}{*}{3,88} & \multirow{2}{*}{0} & - & 3 & C-D9 \\
\hline & & & & 104 & 3 & C-D9-S \\
\hline & & & \multirow{2}{*}{$1 \%$} & - & 3 & CF-D9 \\
\hline & & & & 104 & 3 & CF-D9-S \\
\hline \multirow{4}{*}{250} & \multirow{4}{*}{15} & \multirow{4}{*}{7,00} & \multirow{2}{*}{0} & - & 3 & C-D15 \\
\hline & & & & 210 & 3 & C-D15-S \\
\hline & & & \multirow{2}{*}{$1 \%$} & - & 3 & CF-D15 \\
\hline & & & & 210 & 3 & CF-D15-S \\
\hline
\end{tabular}




\subsubsection{PREPARAÇÃO DAS FORMAS E MONTAGEM DOS MODELOS}

Tendo em vista que o modelo proposto por Rehm e Eligehausen (1979) era um cilindro de concreto de diâmetro $10 \phi$, foram utilizados tubos de PVC para confecção das fôrmas, com um corte longitudinal para facilitar a desforma do corpo-de-prova.

Para garantir o posicionamento da barra longitudinal no centro do corpo-de-prova foi introduzido um gabarito de madeira na parte superior com um sarrafo.

A extremidade inferior, com um orifício central, foi fechada de dois modos: no ensaio piloto, com uma forma quadrada, externa ao tubo de PVC (Figura 43 e Figura 44), enquanto que no ensaio definitivo foi feito um fundo, interno ao tubo de PVC, preso por parafusos no próprio tubo (Figura 45 e Figura 46). A primeira solução foi adotada para contornar o problema do fundo não coincidir exatamente com o contorno do tubo, provocando vazamentos durante a concretagem. No entanto, foram necessárias quatro barras roscáveis para travar cada modelo, presas na fôrma do fundo e no sarrafo, além de abraçadeiras envoltas aos tubos para impedir que os mesmos abrissem na concretagem, que dificultavam a montagem e desmontagem do sistema. Além disso, o problema de vazamento na concretagem não foi totalmente solucionado, pois o travamento do sistema dependia do aperto correto das barras roscáveis. Desse modo, optou-se por utilizar a segunda solução nos modelos definitivos e colocar fita isolante nos trechos em que a abertura entre o fundo e o tubo eram consideráveis.

Figura 43- Fôrmas para os modelos do ensaio piloto

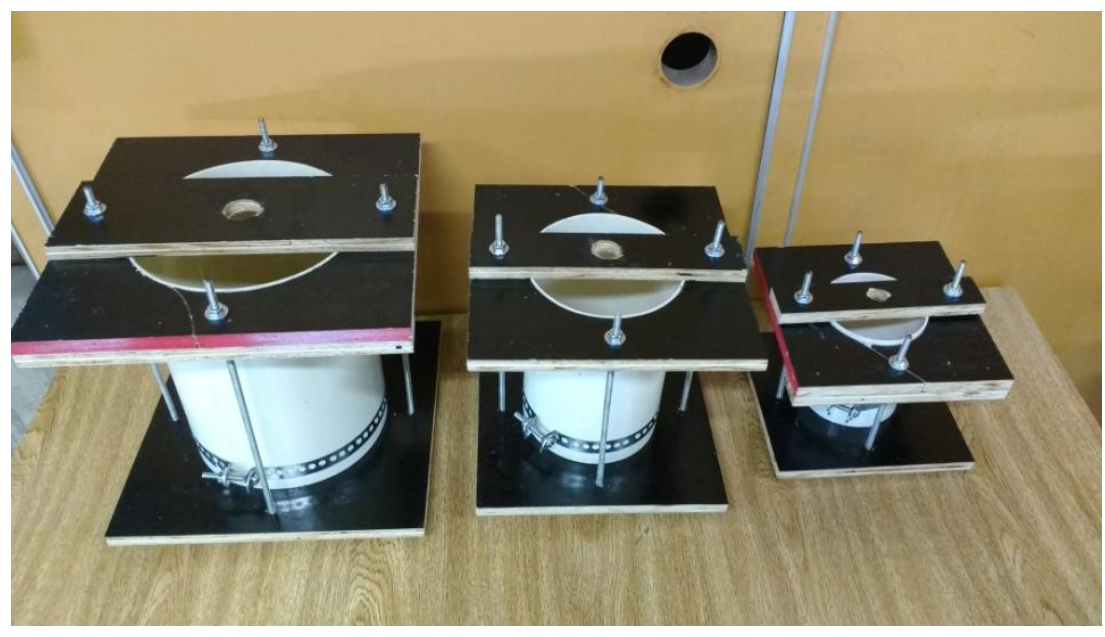

Fonte: Autoria própria 
Figura 44-Esquema das fôrmas dos modelos do ensaio piloto

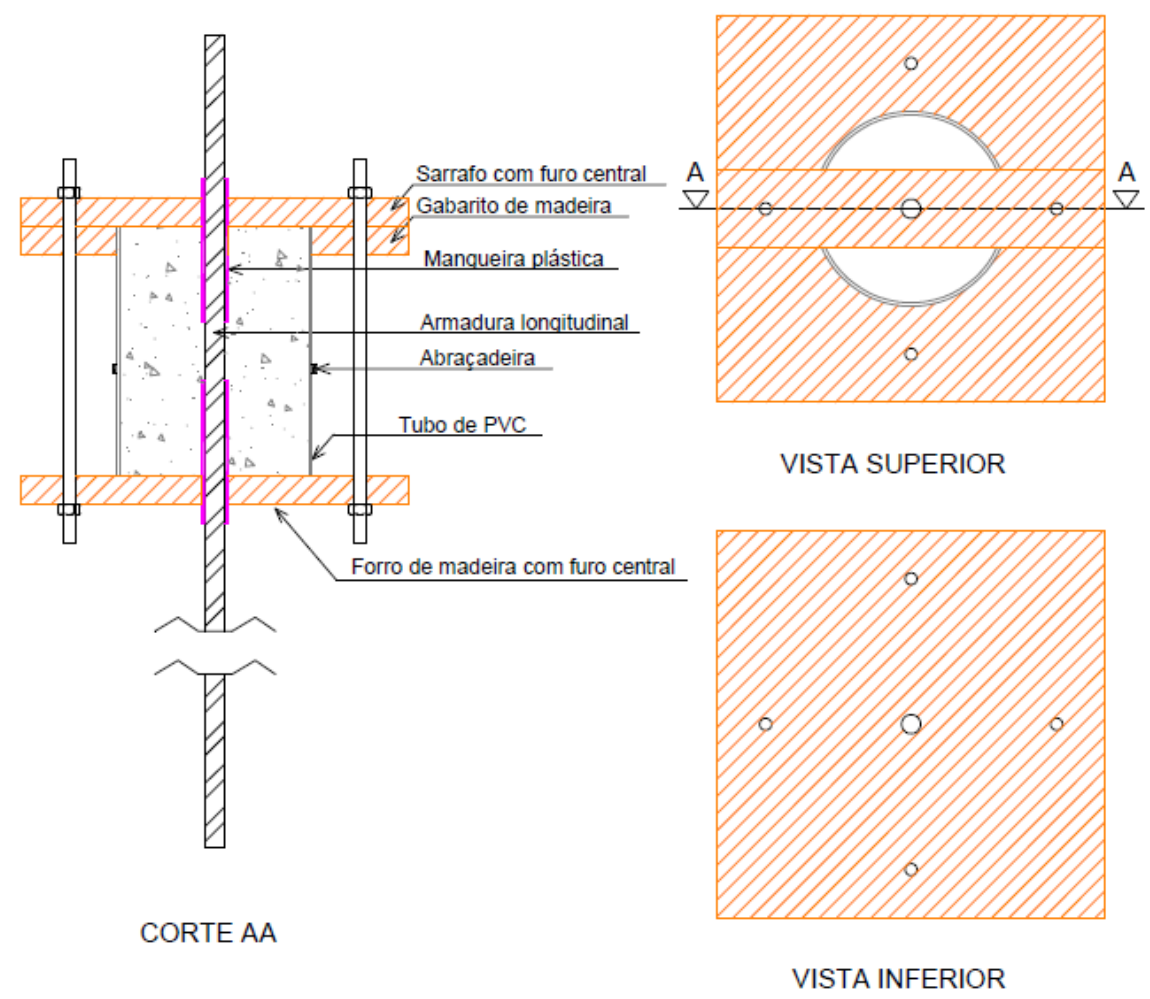

Fonte: Autoria própria

Figura 45-Fôrmas para os modelos do ensaio definitivo

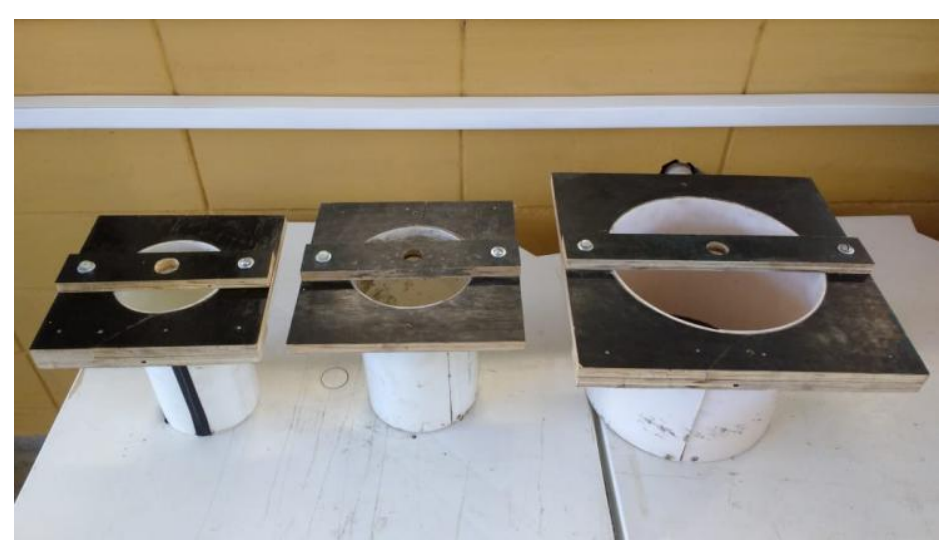

Fonte: Autoria própria 
Figura 46-Esquema das fôrmas dos modelos do ensaio definitivo (sem armadura transversal)

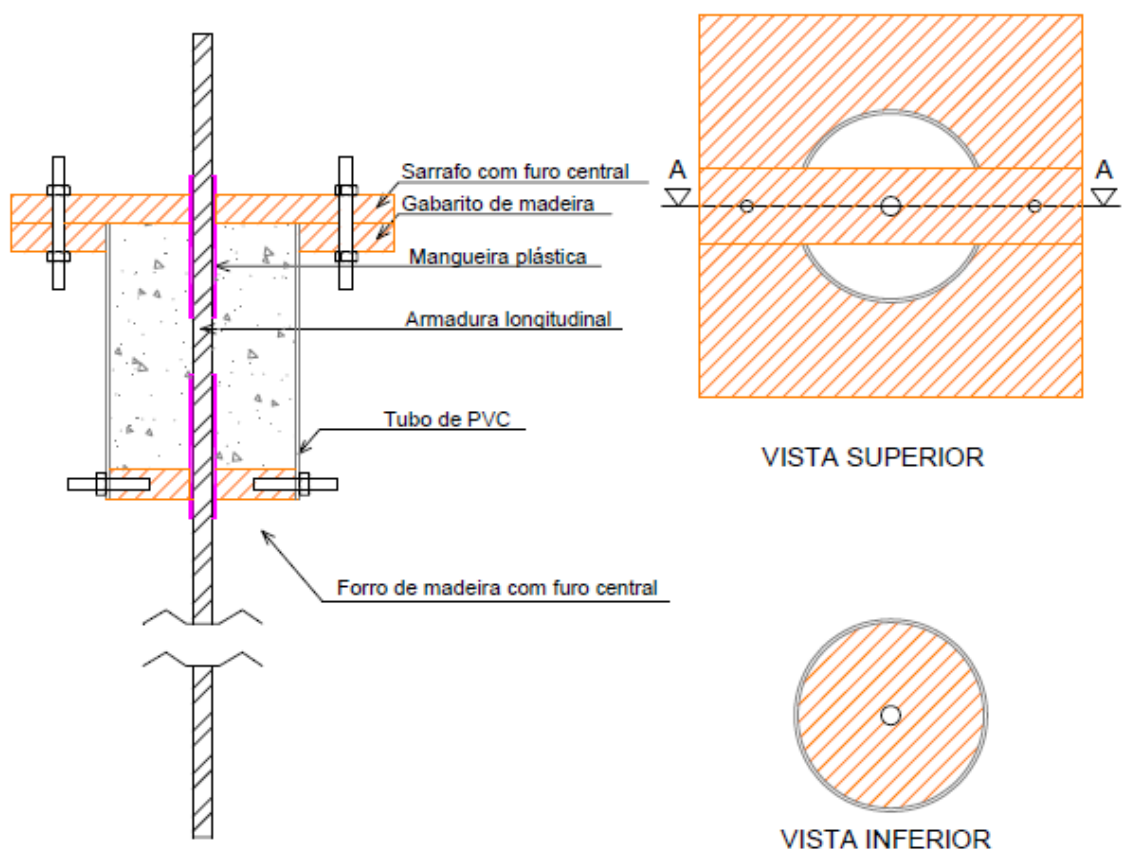

CORTE AA

Fonte: Autoria própria

Os trechos não aderentes, superior e inferior, foram obtidos por meio da utilização de uma mangueira plástica (Figura 47). Tanto o início quanto o fim do trecho não aderente eram marcados com fita isolante, com um número de voltas suficiente para preencher o espaço vazio entre a barra e a mangueira plástica.

Figura 47- Marcação das barras e posicionamento das mangueiras plásticas

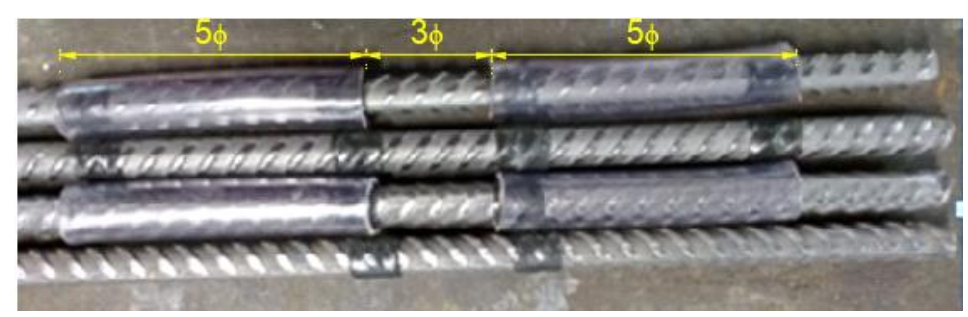

Fonte: Autoria própria

As armaduras transversais dos modelos do ensaio definitivo foram feitas a partir de três moldes: dois tubos de metal (para as de abertura menor) e um toco de madeira (para a de abertura maior), os quais foram presos ao torno. Ao pressionar o vergalhão de aço sobre o molde, com o torno girando, formava-se uma mola, conforme Figura 48. 
Figura 48-Confeccção das armaduras com auxílio do torno

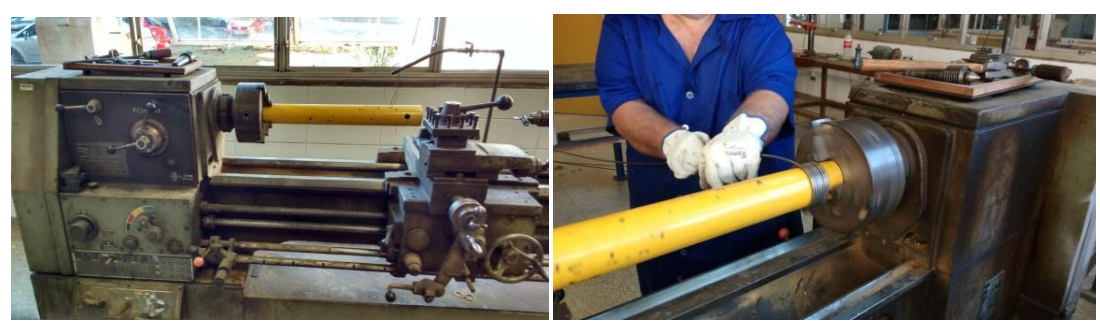

Fonte: Autoria própria

Nas armaduras para os modelos de $8 \phi$ o espaçamento foi garantido apenas ao puxar a mola após retirá-la do torno, dispondo espaçadores plásticos no fundo e topo para assegurar o cobrimento lateral e de topo/fundo. Nas destinadas aos corpos-de-prova de diâmetro $9 \phi$ foram dispostos espaçadores circulares ao longo de toda hélice para garantir o espaçamento e o

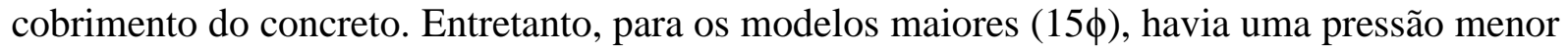
entre os ramos da armadura, então os espaçadores não ficavam fixos na posição. Desse modo, para facilitar a montagem e garantir o espaçamento correto, foram fixadas três barras no mesmo diâmetro da armadura transversal, presa por arames. As armaduras prontas encontramse na Figura 49. Como não foram colocados espaçadores nos modelos de $15 \phi$, segurou-se a armadura transversal durante a concretagem para garantir o cobrimento lateral (Figura 50). A Figura 51 indica o posicionamento da armadura transversal nos corpos-de-prova.

Figura 49-Armadura transversal para os corpos-de-prova de diâmetro a) $8 \phi$, b) $9 \phi$ e c) $15 \phi$

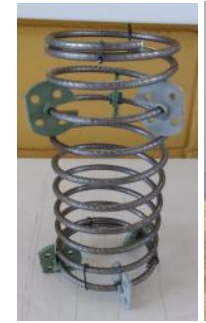

a)

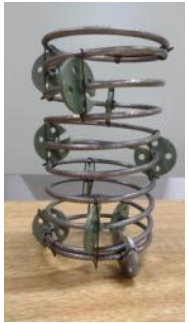

b)

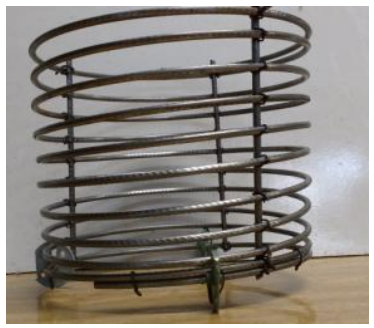

c)

Fonte: Autoria própria

Figura 50-Controle da posição da armadura transversal durante a concretagem

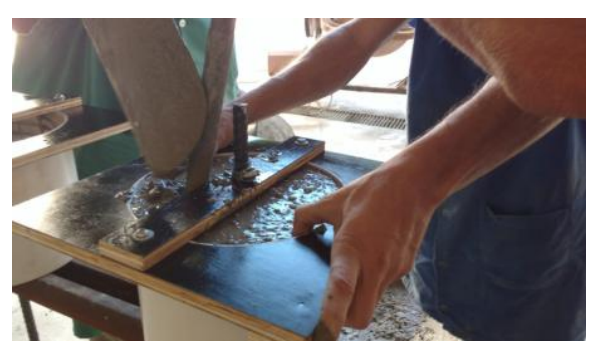

Fonte: Autoria própria 
Figura 51-Posicionamento da armadura transversal dentro da fôrma para os corpos-de-prova de diâmetro a) $8 \phi$, b) $9 \phi$ e c) $15 \phi$

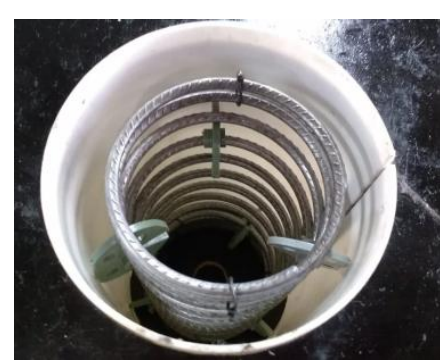

a)

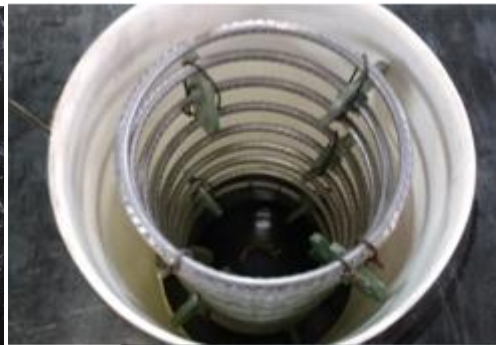

b)

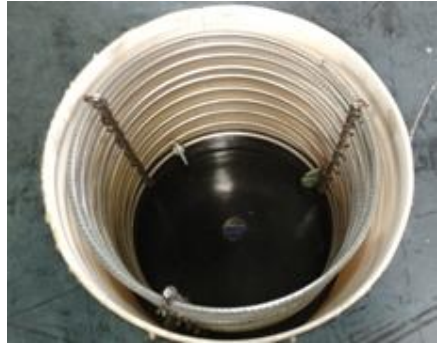

c)

Fonte: Autoria própria

Para garantir que a mangueira e as barras ficassem nas posições corretas foi feito o travamento do conjunto por meio de abraçadeiras metálicas na parte superior e inferior da fôrma, conforme Figura 52.

Figura 52-Modelos travados pela abraçadeira metálica

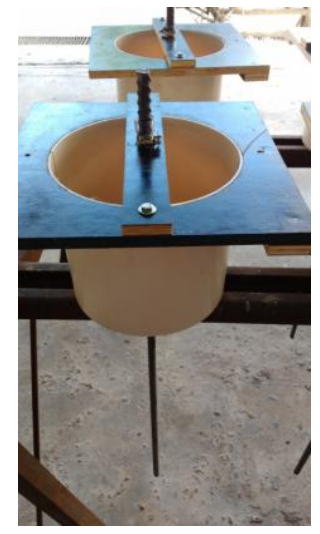

Fonte: Autoria própria

\subsubsection{MOLDAGEM E CURA DOS MODELOS}

A concretagem dos modelos do ensaio piloto e definitivo foi feita com os corpos-de-prova na direção vertical, apoiados em um suporte metálico que permitia a passagem da barra longitudinal, conforme Figura 53 e Figura 54.

O concreto foi adensado por meio de vibrador de imersão, inserindo dentro das formas (Figura 55) e encostando na parte exterior.

No dia posterior à concretagem, os corpos-de-prova foram desformados (Figura 56 e Figura 57) e levados à câmara úmida (Figura 58), onde permaneciam até o dia do ensaio de arrancamento. 
Figura 53-Modelos do ensaio piloto posicionados para serem concretados

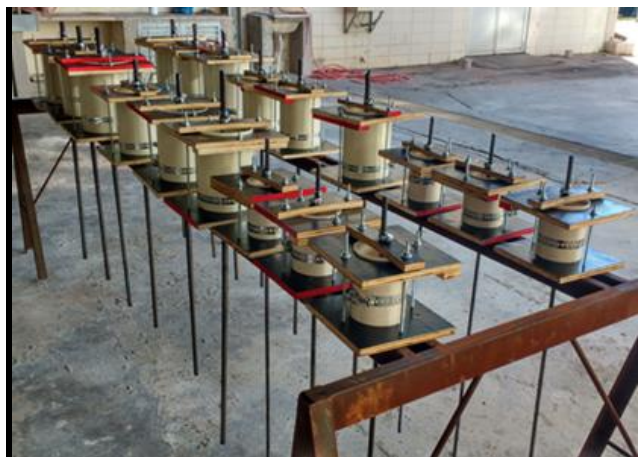

Fonte: Autoria própria
Figura 54- Parte dos modelos do ensaio definitivo posicionados para serem concretados

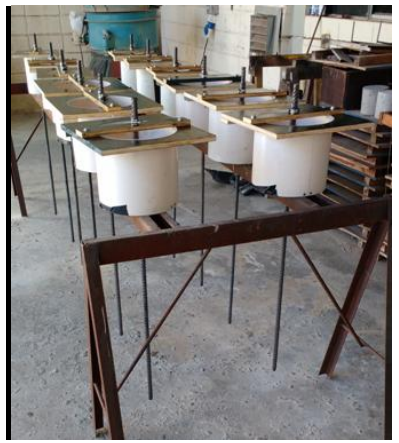

Fonte: Autoria própria

Figura 55-Adensamento dos modelos feito com vibrador de imersão

Fonte: Autoria própria

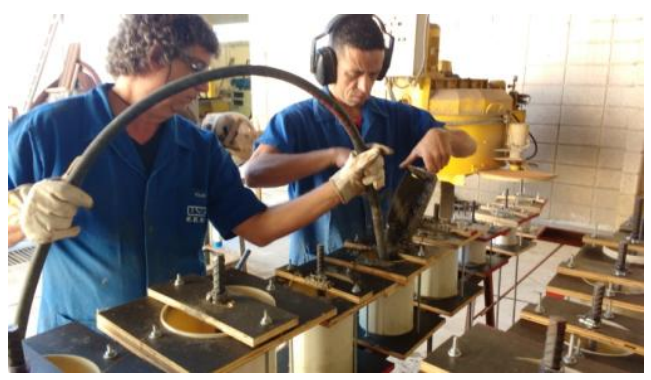

Figura 56- Modelos já concretados e parte desformados

Fonte: Autoria própria

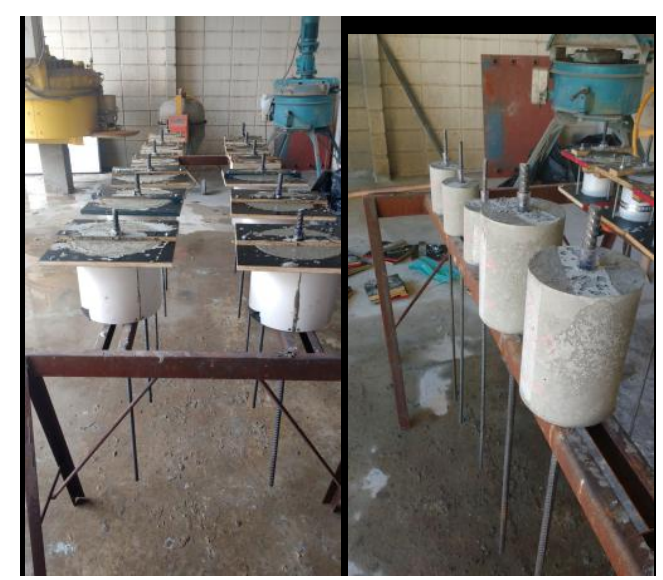

Figura 57- Modelos do ensaio piloto e ensaio definitivos desformados
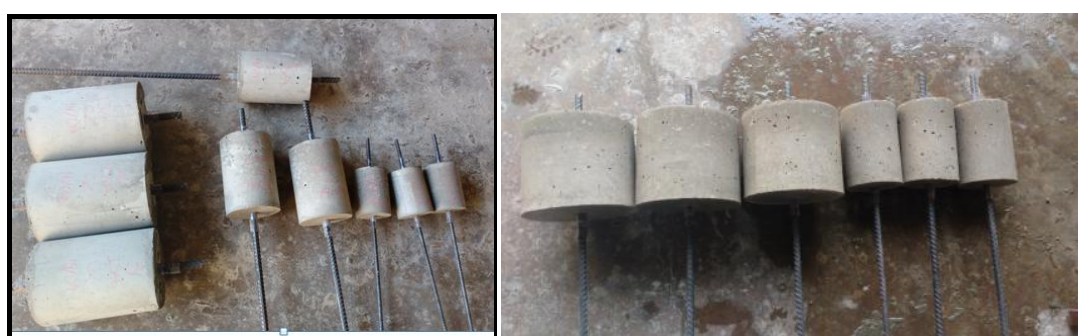

Fonte: Autoria própria 
Figura 58-Cura dos modelos na câmara úmida

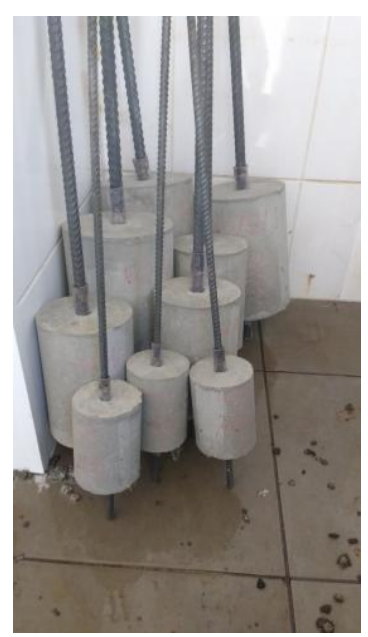

Fonte: Autoria própria

\subsubsection{EXECUÇÃO DO ENSAIOS}

Os ensaios de arrancamento foram realizados na máquina servohidráulica do fabricante Instron, modelo $300 \mathrm{HVL}$, com capacidade de $1500 \mathrm{kN}$, disponível no Laboratório de Estruturas (LE) do Departamento de Engenharia de Estruturas. Também foi utilizado um sistema de aquisição de dados no modelo System 5000 da marca Vishay.

O corpo-de-prova foi posicionado em uma placa metálica com um orifício central, para passagem do trecho inferior da barra, sendo os deslizamentos medidos por um transdutor posicionado na extremidade superior da barra. A extremidade do trecho inferior da barra foi presa à garra da máquina e a aplicação do deslocamento foi feita na base da chapa metálica, conforme esquema da Figura 59 e indicado na Figura 60:

Figura 59-Esquema do ensaio de arrancamento

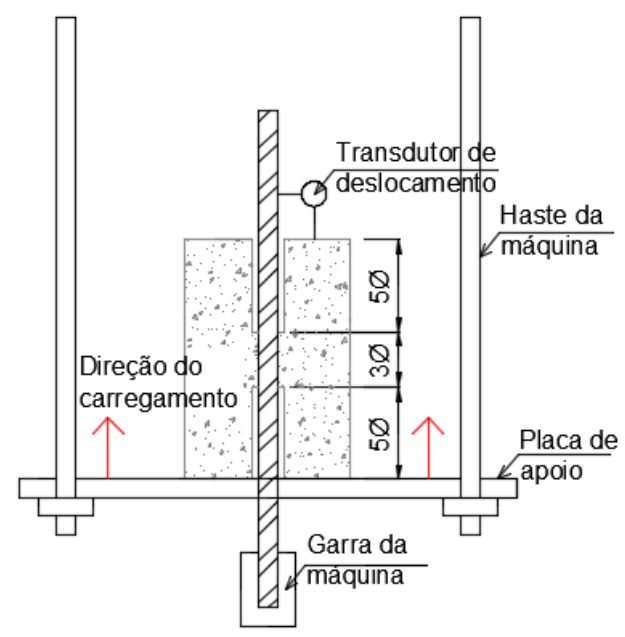

Fonte: Couto (2007)-Adaptado 
Figura 60-Ensaio de arrancamento

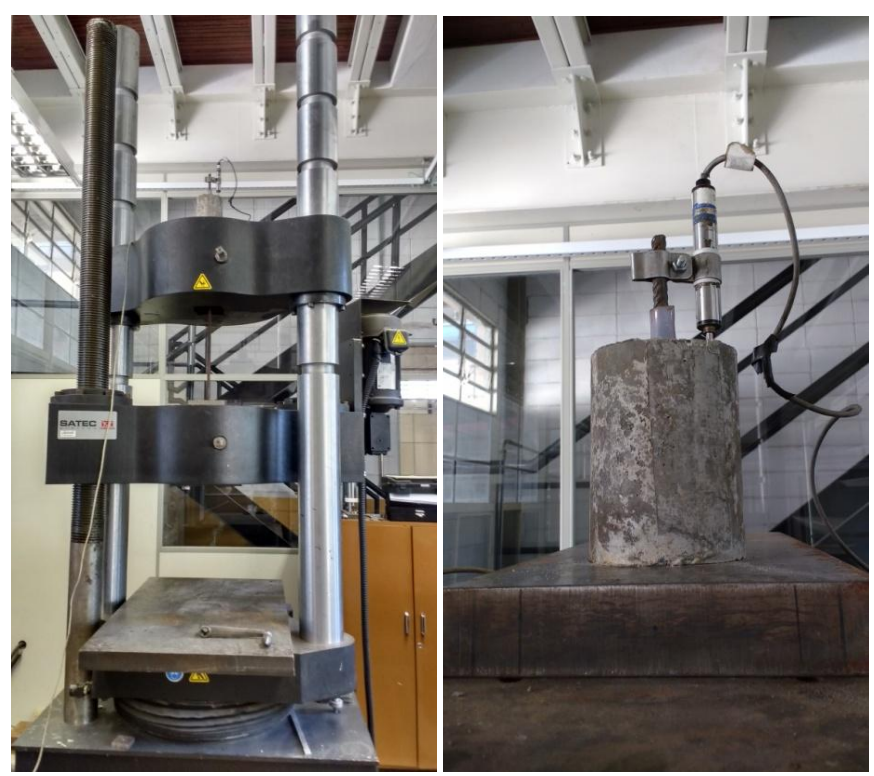

Fonte: Autoria própria

A aplicação do carregamento foi feita com controle de deslocamento, a fim de obter o comportamento da aderência após a sua ruptura. A velocidade aplicada pela máquina variava de acordo com o diâmetro da barra: $0,010 \mathrm{~mm} / \mathrm{s}$ para barra de $10 \mathrm{~mm}, 0,016 \mathrm{~mm} / \mathrm{s}$ para barra de $16 \mathrm{~mm}$ e 0,020 mm/s para barra de $20 \mathrm{~mm}$, conforme indicação de Santana (2014).

Os ensaios de arrancamento ocorreram aos 33/ 34 dias para o ensaio piloto, por problemas operacionais, e aos 28 dias para o ensaio definitivo. 


\section{RESULTADOS}

Os resultados dos ensaios de caracterização do concreto no estado endurecido e dos ensaios de arrancamento (piloto e definitivo) estão descritos a seguir.

Como dispositivos de análise estatística dos dados foram utilizados: a média aritmética (M), o desvio padrão (DP) e o coeficiente de variação (CV). O primeiro é uma forma de medida de tendência central, enquanto os dois últimos fornecem o grau de dispersão dos resultados, sendo que o $\mathrm{CV}$ apresenta como vantagem o fato de não depender da magnitude da propriedade medida (ALMEIDA FILHO, 2006).

$$
\begin{gathered}
M=\frac{\sum_{i}^{n} x_{i}}{n} \\
D P=\sqrt{\frac{\sum_{i}^{n}\left(x_{i}-M\right)^{2}}{n-1}} \\
C V=\frac{D P}{M}
\end{gathered}
$$

O critério de qualidade dos valores obtidos foi definido como sendo CV inferior a 25\%, assim como autores como Barbosa (2001) e Santana (2014). Este grau de tolerância elevado é justificado pela grande variação nos resultados devido ao trecho aderente ser muito pequeno.

\subsection{ENSAIOS DE CARACTERIZAÇÃO DO CONCRETO}

Os ensaios de caracterização do concreto no estado endurecido incluíram a obtenção da resistência à compressão, resistência à tração por compressão diametral e módulo de elasticidade dinâmico.

Os dois primeiros parâmetros foram obtidos dos corpos-de-prova extraídos de todas as concretagens, de modo a haver um maior controle sobre o traço e eliminar possíveis interferências desses parâmetros no comportamento da aderência. Já o módulo de elasticidade dinâmico foi avaliado apenas para as concretagens referentes ao ensaio piloto, por não haver grande dispersão nos resultados. As concretagens foram divididas de acordo com a Tabela 31: 
Tabela 31-Concretagens realizadas

\begin{tabular}{c|c|c|c}
\hline Concretagem & Ensaio & Concreto & Modelo \\
\hline 1 & Piloto & Sem fibras & C-B10, C-B16, C-B20 \\
\hline 2 & Piloto & Com fibras & CF-B10, CF-B16, CF-B20 \\
\hline 3 & Definitivo & Sem fibras & C-D9 e C-D15 \\
\hline 4 & Definitivo & Com fibras & CF-D9 e CF-D15 \\
\hline 5 & Definitivo & Sem fibras & C-D9-S e C-D15-S \\
\hline 6 & Definitivo & Com fibras & CF-D9-S e CF-D16-S \\
\hline 7 & Definitivo & Sem fibras & C-D8 e C-D8-S \\
\hline 8 & Definitivo & Com fibras & CF-D8 e CF-D8-S \\
\hline
\end{tabular}

Fonte: Autoria própria

Os valores médios aos 28 dias de resistência à compressão $\left(f_{c, \text { medio,28 }}\right)$, resistência à tração por compressão diametral $\left(f_{c t, m e d i o, 28}\right)$ e seu valor corrigido pelo fator de 0,85 indicado

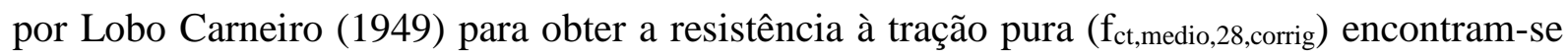
na Tabela 32 e Tabela 33, além do desvio padrão e coeficiente de variação entre os corpos-deprova.

Tabela 32-Resistência à compressão e tração do concreto sem fibras

\begin{tabular}{|c|c|c|c|c|c|c|c|}
\hline Concretagem & $\begin{array}{l}\mathrm{f}_{\mathrm{c}, \text { medio, } 28} \\
(\mathrm{MPa})\end{array}$ & DP & $\mathrm{CV}(\%)$ & $\begin{array}{c}\mathrm{f}_{\mathrm{ct} \text {,medio, } 28} \\
(\mathrm{MPa})\end{array}$ & $\mathrm{DP}$ & $\mathrm{CV}(\%)$ & $\begin{array}{c}\mathrm{f}_{\mathrm{ct}, \text { medio, } 28, \text { corrig }} \\
(\mathrm{MPa})\end{array}$ \\
\hline 1 & 69,36 & 6,64 & 9,58 & 4,51 & 0,52 & 11,60 & 3,83 \\
\hline 3 & 67,44 & 7,64 & 11,34 & 4,87 & 1,58 & 32,39 & 4,14 \\
\hline 5 & 62,92 & 4,73 & 7,52 & 5,32 & 0,32 & 5,96 & 4,52 \\
\hline 7 & 68,89 & 2,70 & 3,92 & 4,24 & 0,11 & 2,62 & 3,60 \\
\hline $\mathrm{M}$ & 67,15 & & & & & $\mathrm{M}$ & 4,02 \\
\hline DP & 2,94 & & & & & DP & 0,40 \\
\hline $\mathrm{CV}$ & 4,38 & & & & & $\mathrm{CV}$ & 9,88 \\
\hline
\end{tabular}

Fonte: Autoria própria

Tabela 33- Resistência à compressão e tração do concreto com fibras

\begin{tabular}{|c|c|c|c|c|c|c|c|}
\hline Concretagem & $\begin{array}{c}\mathrm{f}_{\mathrm{c}, \text { medio, } 28} \\
(\mathrm{MPa})\end{array}$ & DP & $\mathrm{CV}(\%)$ & $\begin{array}{c}\mathrm{f}_{\text {ct,medio,28 }} \\
(\mathrm{MPa})\end{array}$ & DP & $\mathrm{CV}(\%)$ & $\begin{array}{c}\mathrm{f}_{\mathrm{ct}, \text { medio, } 28, \text { corrig }} \\
(\mathrm{MPa})\end{array}$ \\
\hline 2 & 72,49 & 0,88 & 1,21 & 5,77 & 0,45 & 7,84 & 4,91 \\
\hline 4 & 68,06 & 4,97 & 7,30 & 5,18 & 0,21 & 3,97 & 4,41 \\
\hline 6 & 68,98 & 4,05 & 5,87 & 5,67 & 0,83 & 14,68 & 4,82 \\
\hline 8 & 68,87 & 2,73 & 3,97 & 5,56 & 0,08 & 1,47 & 4,72 \\
\hline $\mathrm{M}$ & 69,60 & & & & & $\mathrm{M}$ & 4,71 \\
\hline DP & 1,97 & & & & & DP & 0,22 \\
\hline $\mathrm{CV}$ & 2,83 & & & & & $\mathrm{CV}$ & 4,62 \\
\hline
\end{tabular}

Fonte: Autoria própria 
Verifica-se que não houve alterações significativas nos valores de resistência à compressão e à tração, com CV inferior a 15\%, exceto na concretagem do primeiro ensaio definitivo sem fibras (concretagem 3) com CV de 32\%, o que permite concluir que a execução do traço foi qualificada. Nota-se também que houve um incremento tanto na resistência à compressão quanto à tração ao introduzir fibras metálicas no concreto, de 3,65\% (de 67,15 MPa no concreto sem fibras para 69,60 MPa para o concreto com fibras) e 17,18\% (de 4,02 MPa para 4,71 MPa), respectivamente. O ganho na resistência à tração era esperado, tendo em vista que as fibras tendem a "costurar" as fissuras e aumentar a ductilidade do concreto. O ganho na resistência à compressão é previsto pelo ACI 544.1R (1996) para volumes baixos de fibras, pois as fibras agem como ponte de transferência de tensões entre as fissuras, mas também pode provocar uma má compactação e criar zonas de fragilidade, diminuindo a resistência (FIGUEIREDO, 2000).

O módulo de elasticidade é influenciado por diversos fatores, entre eles: relação água/cimento, propriedades elásticas do agregado graúdo, maturidade e condição de cura (GIDRÃO, 2015). Gidrão (2015) efetuou testes para comparação entre o módulo de elasticidade dinâmico e estático com concreto de resistência entre 20 e $90 \mathrm{MPa}$ e relação a/c de 0,3 a 0,5 .

A Tabela 34 fornece o módulo de elasticidade dinâmico longitudinal $\left(E_{\text {dlong,28 }}\right)$ e

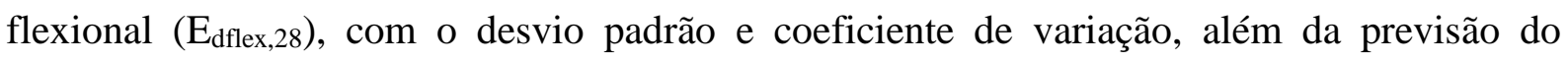
módulo de elasticidade estático $\left(\mathrm{E}_{\mathrm{ci}, 28}\right)$, obtido por meio da equação proposta por Gidrão (2015), invertida, utilizando o módulo de elasticidade dinâmico longitudinal:

$$
E_{c i}=\left(\frac{E_{d}}{4,365}\right)^{\frac{1}{0,649}}
$$

Tabela 34-Módulo de elasticidade dinâmico e estático do concreto sem fibras e com fibras

\begin{tabular}{c|c|c|c|c|c|c|c|c}
\hline Concreto & $\mathrm{E}_{\mathrm{dlong}, 28}(\mathrm{GPa})$ & $\mathrm{DP}$ & $\mathrm{CV}(\%)$ & $\mathrm{E}_{\mathrm{dflex}, 28}(\mathrm{GPa})$ & $\mathrm{DP}$ & $\mathrm{CV}(\%)$ & $\mathrm{E}_{\mathrm{ci}, 28}(\mathrm{GPa})$ & $\begin{array}{c}\text { Variação } \\
(\%)\end{array}$ \\
\hline $\mathrm{C}$ & 48,73 & 0,81 & 1,66 & 49,02 & 1,01 & 2,06 & $\mathbf{4 1 , 1 6}$ & 15,53 \\
\hline $\mathrm{CF}$ & 48,76 & 0,43 & 0,89 & 49,62 & 1,02 & 2,06 & $\mathbf{4 1 , 2 1}$ & 15,50 \\
\hline
\end{tabular}

Fonte: Autoria própria

Nota-se que os coeficientes de variação tanto do módulo de elasticidade longitudinal quanto flexional são muito baixos, o que aumenta a confiabilidade da determinação do módulo de elasticidade dinâmico por técnica de impulso. Além disso, os valores obtidos para o módulo longitudinal e flexional são bem próximos, mas o longitudinal apresentou um 
coeficiente de variação inferior ao flexional e, portanto, foi usado no cálculo do módulo de elasticidade estático pela equação 26.

A variação entre o módulo de elasticidade dinâmico e estático está coerente com o previsto (MEHTA; MONTEIRO, 2008): 20\% para concreto de alta resistência.

\subsection{ENSAIO DE ARRANCAMENTO PILOTO}

Os ensaios de arrancamento forneceram duas variáveis: força de reação da barra presa à máquina e deslocamento relativo (deslizamento) entre o topo do concreto e parte superior da barra de aço. Admitindo-se que todo o comprimento aderente da barra transfere a tensão para o concreto, foi possível calcular a tensão média de aderência pela equação (2).

A fim de atenuar o efeito da resistência do concreto $\left(\mathrm{f}_{\mathrm{c}, \text { medio }}\right)$ nos resultados dos ensaios de arrancamento, tendo em vista que os corpos de prova foram moldados em diferentes concretagens, a tensão de aderência foi normalizada utilizando a equação (27), seguindo a recomendação do ACI 408R (2003), para permitir uma análise independentemente do valor de $f_{c, \text { medio. }}$

$$
\tau_{\text {norm }}=\left(\frac{70}{f_{c, \text { medio }}}\right)^{1 / 4} \cdot \tau
$$

O ensaio piloto foi realizado aos 33 dias, devido à impossibilidade de ensaiar aos 28 dias, resultando em uma variação na resistência à compressão (Tabela 35):

Tabela 35-Valores de resistência à compressão dos corpos-de-prova do ensaio piloto

\begin{tabular}{c|c|c|c}
\hline Idade (dias) & Concreto & $\mathrm{f}_{\mathrm{c}, \text { medio }}(\mathrm{MPa})$ & Variação $(\%)$ \\
\hline 28 & $\mathrm{C}$ & 69,36 & - \\
\hline 33 & $\mathrm{C}$ & $\mathbf{7 7 , 4 6}$ & 10,46 \\
\hline 28 & $\mathrm{CF}$ & 72,49 & - \\
\hline 33 & $\mathrm{CF}$ & $\mathbf{7 9 , 1 5}$ & 8,42 \\
\hline
\end{tabular}

Fonte: Autoria própria

Dessa forma, adotou-se para $\mathrm{f}_{\mathrm{c} \text {,medio }}$ os valores médios (entre os três corpos de prova de cada concretagem) de resistência do concreto obtidos na data do ensaio, sendo aos 33 dias para o ensaio piloto e aos 28 dias para o definitivo, indicados na Tabela 36, de modo a normalizar a tensão de aderência (equação 27) e avaliar apenas os efeitos dos confinamentos promovidos pela inclusão de fibras metálicas, armadura transversal e cobrimento do concreto: 
Tabela 36-Resistência à compressão para cada modelo

\begin{tabular}{c|c|c|c|c}
\hline Concretagem & Ensaio & Concreto & Modelo & $\mathrm{f}_{\mathrm{c}, \text { medio }}(\mathrm{MPa})$ \\
\hline 1 & Piloto & Sem fibras & C-B10, C-B16, C-B20 & 77,46 \\
\hline 2 & Piloto & Com fibras & CF-B10, CF-B16 CF-B20 & 79,15 \\
\hline 3 & Definitivo & Sem fibras & C- D9 e C -D15 & 67,44 \\
\hline 4 & Definitivo & Com fibras & CF -D9 e CF- D15 & 68,06 \\
\hline 5 & Definitivo & Sem fibras & C- D9-S e C- D15-S & 62,92 \\
\hline 6 & Definitivo & Com fibras & CF- D9-S e CF- D15-S & 68,98 \\
\hline 7 & Definitivo & Sem fibras & C-D8 e C-D8-S & 68,89 \\
\hline 8 & Definitivo & Com fibras & CF-D8 e CF-D8-S & 68,87 \\
\hline
\end{tabular}

Fonte: Autoria própria

Para cálculo da tensão de aderência máxima $\left(\tau_{\max }\right)$ e deslizamento último $\left(\delta_{\mathrm{u}}\right)$, que se referem à tensão de aderência máxima e seu correspondente deslizamento, foram descartados os resultados dos corpos-de-prova que apresentaram comportamentos diferentes do esperado. No caso do ensaio piloto, foi descartado um espécime do C-20 por ter apresentado ruptura por arrancamento. Como não havia nenhum mecanismo de confinamento, além do próprio cobrimento de concreto, a ruptura esperada era de fendilhamento, como ocorreu com os outros dois espécimes. Dessa forma, a curva não foi contabilizada para cálculo da curva média, pois resultaria em uma curva mista, de fendilhamento com arrancamento, que poderia levar a conclusões equivocadas. Porém, todos os gráficos de tensão de aderência versus deslizamento dos corpos-de-prova podem ser verificados no Apêndice do presente trabalho.

As curvas médias de tensão de aderência versus deslizamento foram obtidas por meio do recurso "Analysis" -> "Signal Processing" -> "Smooth" do software Origin 8, utilizandose o método "Adjacent-Averaging", que realiza a média entre as tensões de aderência dos exemplares para cada valor de deslizamento.

A Tabela 37 apresenta o resultado das médias (entre os exemplares iguais) dos modelos do ensaio piloto para a tensão de aderência máxima e deslizamento último, além do desvio padrão e coeficiente de variação.

Tabela 37-Resultado dos modelos do ensaio piloto

\begin{tabular}{c|c|c|c|c|c|c}
\hline Corpo-de-prova & $\tau_{\max }(\mathrm{MPa})$ & $\mathrm{DV}$ & $\mathrm{CV}(\%)$ & $\delta_{\mathrm{u}}(\mathrm{mm})$ & $\mathrm{DV}$ & $\mathrm{CV}(\%)$ \\
\hline C-B10_Media & 34,10 & 2,99 & 8,78 & 0,40 & 0,04 & 10,59 \\
\hline CF-B10_Media & 32,15 & 5,94 & 18,49 & 0,47 & 0,20 & 43,27 \\
\hline C-B16_Media & 35,82 & 1,57 & 4,38 & 0,47 & 0,16 & 34,25 \\
\hline CF-B16_Media & 38,59 & 0,82 & 2,13 & 0,63 & 0,17 & 26,23 \\
\hline C-B20_Media & 40,37 & 6,52 & 16,14 & 0,29 & 0,08 & 26,36 \\
\hline CF-B20_Media & 41,84 & 1,67 & 4,00 & 1,31 & 0,54 & 41,28 \\
\hline
\end{tabular}

Fonte: Autoria própria 
Conforme pode ser visto na Tabela 37, não houve grandes variações na tensão de aderência entre os espécimes ensaiados, com valores de coeficiente de variação (CV) inferiores a 25\%, dentro do limite de tolerância indicado por Barbosa (2001). Por outro lado, o deslizamento último apresentou uma alta dispersão, entre $25 \%$ e $40 \%$, sendo maior nos modelos com fibra. Isso pode ser justificado pelo fato de que a mínima diferença na disposição da barra ou da fibra entre os modelos pode provocar um aumento ou diminuição no deslizamento e, como este é baixo, essa diferença pode ser mais significativa.

Os itens a seguir apresentam a análise dos resultados obtidos no ensaio piloto, divididos entre inclusão ou não de fibra de aço no concreto e diâmetro da barra longitudinal. Para avaliar o efeito de cada um dos mecanismos de confinamento, os valores de tensões de aderência máxima e os de deslizamento último obtidos no modelo chamado "destino" foram divididos pelos valores do modelo denominado "origem", resultando em acréscimos (valores positivos) ou decréscimos (negativos) percentuais indicados como $\tau_{\max \text {, relativo }}$ e $\delta_{\mathrm{u} \text {, relativo. }}$

\subsubsection{FIBRAS METÁLICAS}

A Figura 61, Figura 62 e Figura 63 apresentam a curva tensão de aderência versus arrancamento para os modelos do ensaio piloto com diâmetro de $10 \mathrm{~mm}, 16 \mathrm{~mm}$ e $20 \mathrm{~mm}$, respectivamente, a fim de analisar a influência da adição de fibras metálicas.

Figura 61- Tensão de aderência versus deslizamento para os modelos com diâmetro de $10 \mathrm{~mm}$

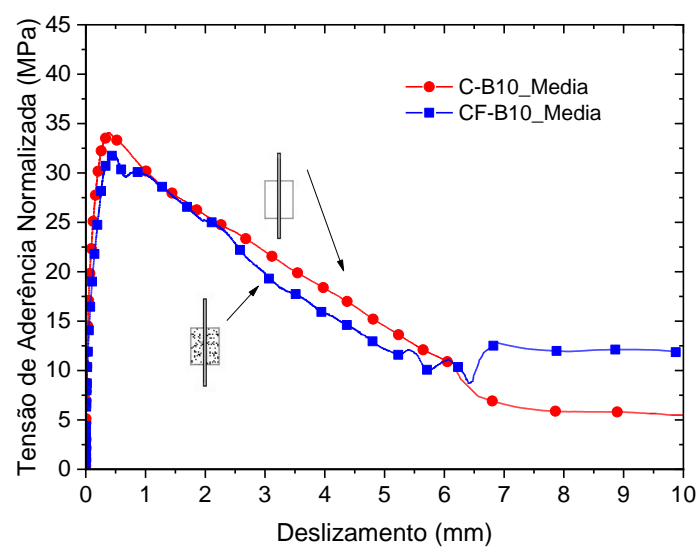

Fonte: Autoria própria
Figura 62-Tensão de aderência versus deslizamento para os modelos com diâmetro de $16 \mathrm{~mm}$

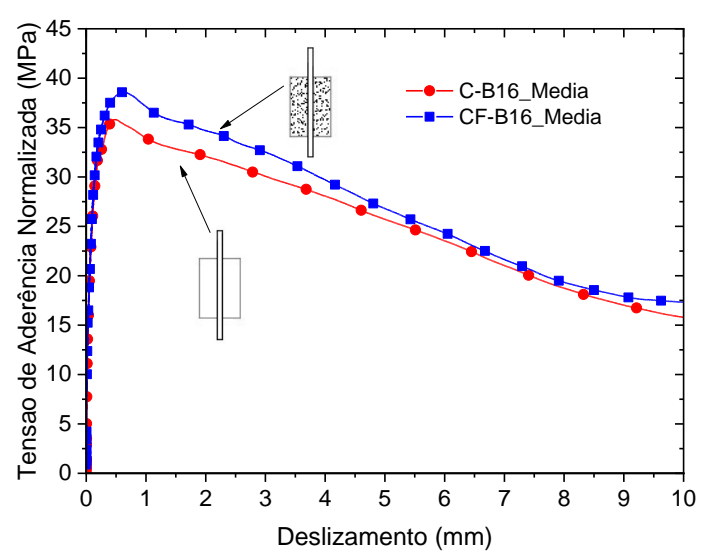

Fonte: Autoria própria 
Figura 63-Tensão de aderência versus deslizamento para os modelos com diâmetro de 20 $\mathrm{mm}$

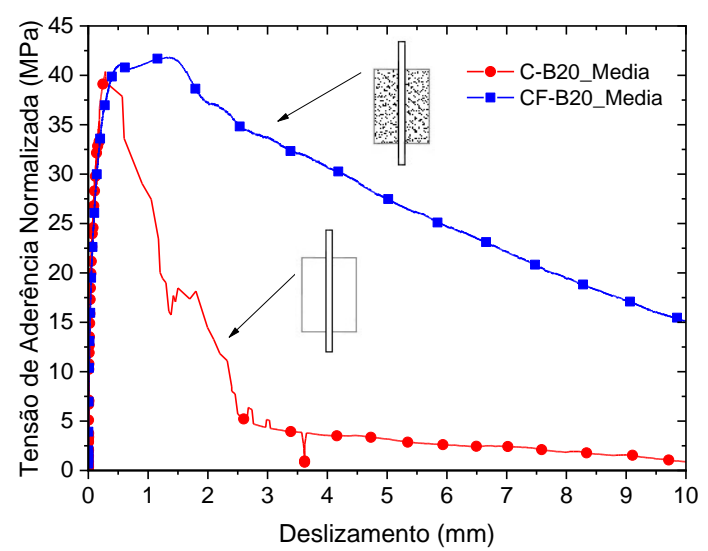

Fonte: Autoria própria

Todos os modelos apresentaram o arrancamento como modo de ruptura, exceto pelo de barra de $20 \mathrm{~mm}$ sem fibras (C-B20), caracterizado pela ruptura por fendilhamento. A Figura 64 ilustra o estado após o ensaio, sendo que, nos modelos cujo modo de ruptura ocorreu por arrancamento (como o da Figura 64a), as fissuras são ausentes ou imperceptíveis, enquanto que na ruptura por fendilhamento a fissura é bem pronunciada ao longo da longitudinal do elemento (Figura 64b). Dessa forma, a inclusão de fibras permitiu a alteração do modo de ruptura de fendilhamento para arrancamento no modelo de $20 \mathrm{~mm}$.

Figura 64- Modo de ruptura: a) Arrancamento (modelos CF-B20-1, 2e 3)

b)Fendilhamento (modelo C-B20-2)

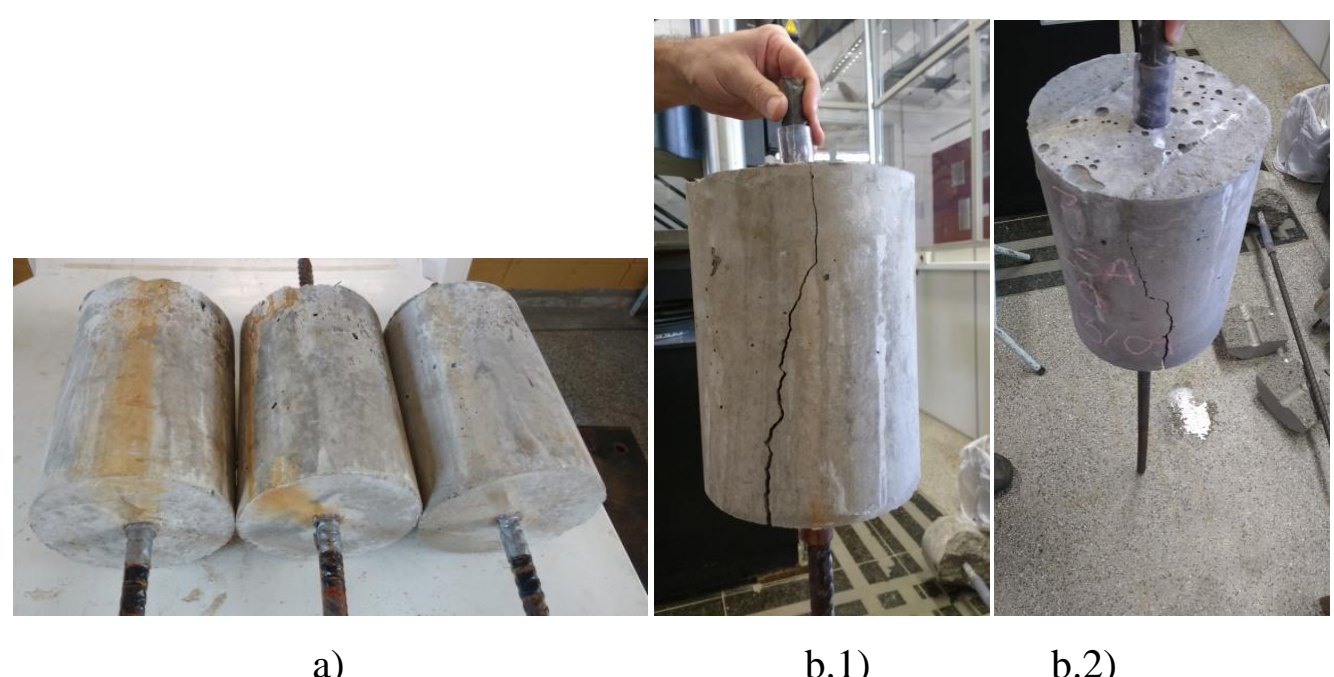

Fonte: Autoria própria 
Conforme pode ser verificado nas figuras acima e na Tabela 38, houve um pequeno aumento na tensão de aderência ao incluir fibras nos modelos com barra de $16 \mathrm{~mm}$ e $20 \mathrm{~mm}$, ocorrendo um decréscimo no modelo com barra de $10 \mathrm{~mm}(-5,73 \%)$. O deslizamento aumentou consideravelmente em todos os casos, sendo mais pronunciado no modelo de barra de $20 \mathrm{~mm}$, pois o modo de ruptura passou a ser arrancamento, deixando de haver um pico no início do carregamento.

Tabela 38- Comparação entre os modelos do ensaio piloto ao acrescentar fibras

\begin{tabular}{c|c|c|c}
\hline Origem & Destino & $\tau_{\max , \text { relativo }}(\%)$ & $\delta_{\mathrm{u}, \text { relativo }}(\%)$ \\
\hline C-B10_Media & CF-B10_Media & $-5,73$ & 19,14 \\
\hline C-B16_Media & CF-B16_Media & 7,73 & 33,69 \\
\hline C-B20_Media & CF-B20_Media & 3,63 & 356,10 \\
\hline
\end{tabular}

Fonte: Autoria própria

\subsubsection{DIÂMETRO DA ARMADURA}

Ao dividir os modelos em concreto sem fibras (Figura 65) e com fibras (Figura 66) foi possível analisar a influência do diâmetro da armadura no comportamento da aderência.

Figura 65- Tensão de aderência versus deslizamento para os modelos sem fibra metálica

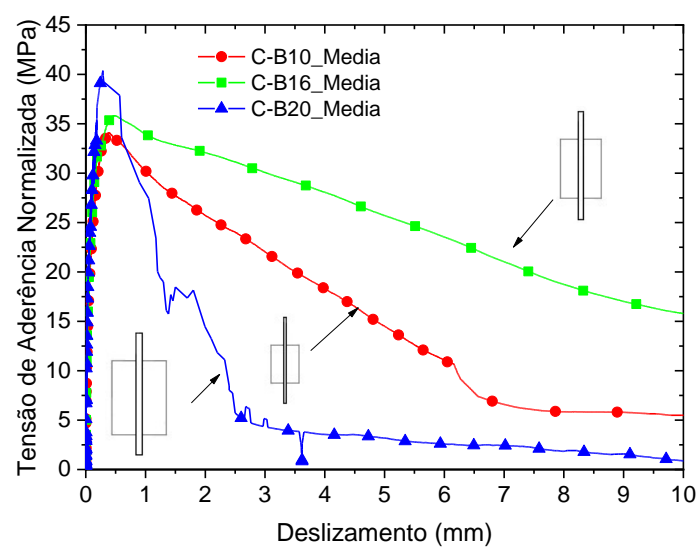

Fonte: Autoria própria
Figura 66- Tensão de aderência versus deslizamento para os modelos com fibra metálica

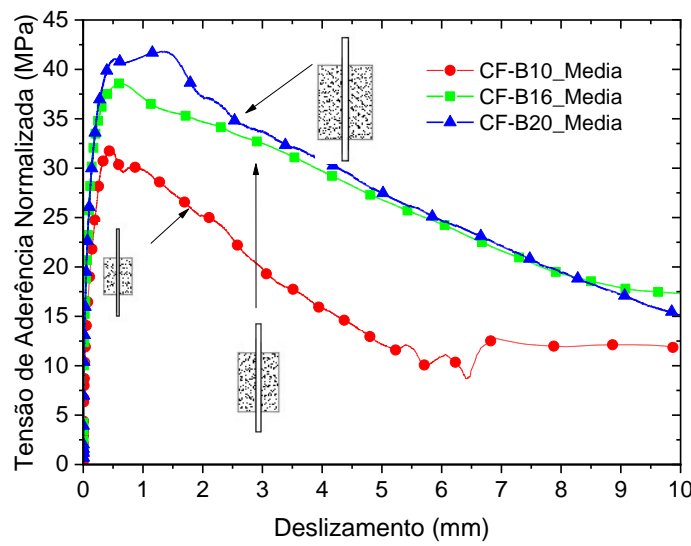

Fonte: Autoria própria

Nota-se pelas figuras acima e pela Tabela 39 e Tabela 40, que o aumento do diâmetro da armadura longitudinal promoveu um aumento na tensão de aderência, tanto para os modelos sem quanto com fibra. Para os modelos sem fibra, este acréscimo foi mais 
pronunciado ao alterar de $16 \mathrm{~mm}$ para $20 \mathrm{~mm}$ do que de $10 \mathrm{~mm}$ para $16 \mathrm{~mm}$, tendo em vista que o modo de ruptura para barra de $20 \mathrm{~mm}$ foi de fendilhamento. Nos modelos com fibra ocorreu o inverso, sendo mais impactante ao aumentar de $10 \mathrm{~mm}$ para $16 \mathrm{~mm}$. Também, ao aumentar o diâmetro da barra, houve um aumento no deslizamento último, exceto para o modelo sem fibra ao alterar de $16 \mathrm{~mm}$ para $20 \mathrm{~mm}$, situação em que houve um decréscimo no valor do deslizamento, pois a ruptura passou de arrancamento para fendilhamento.

Tabela 39-Comparação entre os modelos sem fibras do ensaio piloto ao aumentar o diâmetro

\begin{tabular}{c|c|c|c}
\hline Origem & Destino & $\tau_{\max , \text { relativo }}(\%)$ & $\delta_{\text {u, relativo }}(\%)$ \\
\hline C-B10_Media & C-B16_Media & 5,05 & 18,89 \\
\hline C-B16_Media & C-B20_Media & 12,70 & $-39,19$ \\
\hline
\end{tabular}

Fonte: Autoria própria

Tabela 40-Comparação entre os modelos com fibras do ensaio piloto ao aumentar o diâmetro

\begin{tabular}{c|c|c|c}
\hline Origem & Destino & $\tau_{\max , \text { relativo }}(\%)$ & $\delta_{\text {u, relativo }}(\%)$ \\
\hline CF-B10_Media & CF-B16_Media & 20,05 & 33,40 \\
\hline CF-B16_Media & CF-B20_Media & 8,41 & 107,45 \\
\hline
\end{tabular}

Fonte: Autoria própria

\subsection{ENSAIO DE ARRANCAMENTO DEFINITIVO}

O mesmo procedimento para cálculo da tensão de aderência no ensaio piloto, pela equação (2), foi adotado para os resultados do ensaio definitivo, apresentados na Tabela 41. Os valores de tensão de aderência obtidos também foram normalizados utilizando-se a equação (27).

Tabela 41-Resultado dos modelos do ensaio definitivo

\begin{tabular}{c|c|c|c|c|c|c}
\hline Corpo-de-prova & $\tau_{\max }(\mathrm{MPa})$ & DV & CV $(\%)$ & $\delta_{\mathrm{u}}(\mathrm{mm})$ & $\mathrm{DV}$ & $\mathrm{CV}(\%)$ \\
\hline C-D8_Media & 29,41 & 0,89 & 3,01 & 0,39 & 0,04 & 9,40 \\
\hline CF-D8_Media & $\mathbf{2 8 , 9 6}$ & $\mathbf{0 , 5 2}$ & $\mathbf{1 , 8 0}$ & $\mathbf{0 , 5 3}$ & $\mathbf{0 , 0 2}$ & $\mathbf{4 , 0 3}$ \\
\hline C-D9_Media & 30,78 & 1,32 & 4,30 & 0,66 & 0,03 & 5,25 \\
\hline CF-D9_Media & $\mathbf{2 9 , 5 1}$ & $\mathbf{2 , 0 5}$ & $\mathbf{6 , 9 6}$ & $\mathbf{1 , 1 9}$ & $\mathbf{0 , 5 4}$ & $\mathbf{4 5 , 4 4}$ \\
\hline C-D15_Media & 30,36 & 1,89 & 6,24 & 1,46 & 0,20 & 13,64 \\
\hline CF-D15_Media & $\mathbf{3 2 , 6 8}$ & $\mathbf{3 , 7 2}$ & $\mathbf{1 1 , 3 7}$ & $\mathbf{0 , 6 6}$ & $\mathbf{0 , 0 7}$ & $\mathbf{1 0 , 9 5}$ \\
\hline C-D8-S_Media & 25,07 & 1,51 & 6,01 & 0,55 & 0,02 & 3,42 \\
\hline CF-D8-S_Media & $\mathbf{2 6 , 8 8}$ & $\mathbf{2 , 2 6}$ & $\mathbf{8 , 4 1}$ & $\mathbf{0 , 6 9}$ & $\mathbf{0 , 0 3}$ & $\mathbf{4 , 3 4}$ \\
\hline C-D9-S_Media & 27,38 & 1,44 & 5,25 & 1,32 & 0,25 & 19,08 \\
\hline CF-D9-S_Media & $\mathbf{3 3 , 8 5}$ & $\mathbf{5 , 1 3}$ & $\mathbf{1 5 , 1 4}$ & $\mathbf{0 , 9 6}$ & $\mathbf{0 , 2 0}$ & $\mathbf{2 0 , 7 5}$ \\
\hline C-D15-S_Media & 27,25 & 3,74 & 13,73 & 1,20 & 0,45 & 37,26 \\
\hline CF-D15-S_Media & $\mathbf{2 9 , 6 4}$ & $\mathbf{1 , 3 4}$ & $\mathbf{4 , 5 4}$ & $\mathbf{1 , 2 6}$ & $\mathbf{0 , 0 6}$ & $\mathbf{4 , 7 4}$ \\
\hline
\end{tabular}

Fonte: Autoria própria 
Os coeficientes de variação da Tabela 41 indicam uma boa consistência nos resultados, em sua maioria inferiores a $10 \%$ para a tensão de aderência, e inferiores a $20 \%$ para o deslizamento último, exceto pelo modelo CF-D9 e C-D15-S, com valores de 45,44\% e $37,26 \%$, respectivamente, mas que também foram tolerados devido à grande possibilidade de alteração nos valores de deslizamento decorrente de pequenas diferenças nas características dos modelos.

Para construção da curva média, em dois modelos foi feita a exclusão do resultado de um exemplar: C-D8 e CF-D9. No primeiro caso, a ruptura esperada seria por fendilhamento, por não haver nenhum mecanismo de confinamento e pelo baixo cobrimento de concreto. Então, o corpo-de-prova que apresentou ruptura por arrancamento foi excluído da curva média, sendo apresentado apenas no Apêndice do presente trabalho. No segundo caso, por ter um cobrimento de concreto suficiente e incluir fibras metálicas, a ruptura esperada era arrancamento. Porém, por já existir uma fissura anterior ao ensaio, esta promoveu um caminho para alivio das tensões, resultando em uma ruptura mista de arrancamento com fendilhamento. Dessa forma, para não levar a conclusões equivocadas a respeito da inclusão de fibras, o resultado também foi excluído da curva média.

\subsubsection{FIBRA METÁLICA E ARMADURA TRANSVERSAL}

A Figura 67 a Figura 69 apresentam os gráficos de tensão de aderência versus arrancamento dos modelos do ensaio definitivo, fixando a relação entre o diâmetro de concreto e o diâmetro da armadura longitudinal $\left(\mathrm{D}_{\mathrm{c}} / \phi\right)$ em 8,9 e 15, respectivamente, permitindo a análise do efeito da inclusão de fibras metálicas e/ou armadura transversal.

Figura 67- Tensão de aderência versus deslizamento para $D_{\mathcal{c}} / \phi=8$.

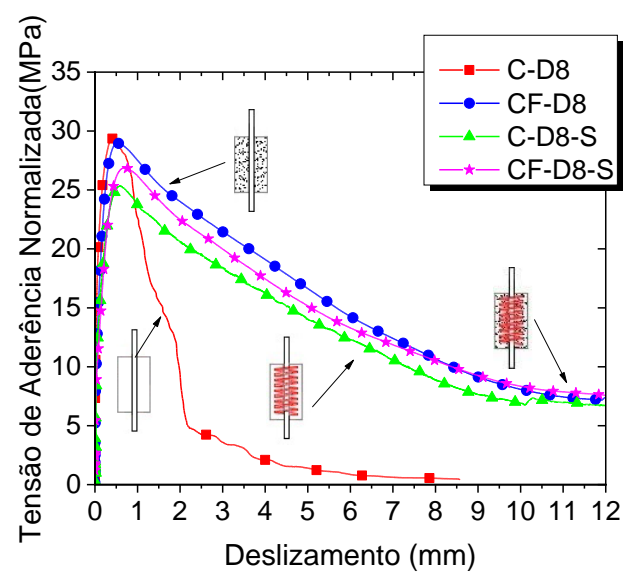

Fonte: Autoria própria 
Figura 68- Tensão de aderência versus deslizamento para $\mathrm{D}_{\mathrm{c}} / \phi=9$

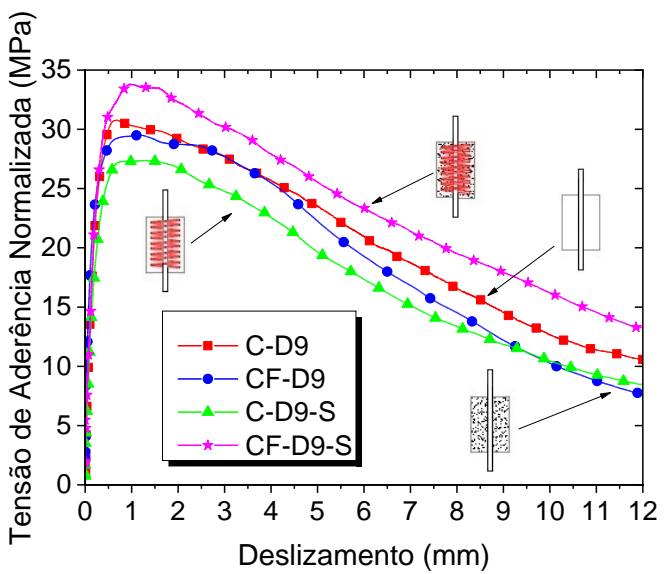

Fonte: Autoria própria
Figura 69- Tensão de aderência versus deslizamento para $\mathrm{D}_{\mathrm{c}} / \phi=15$.

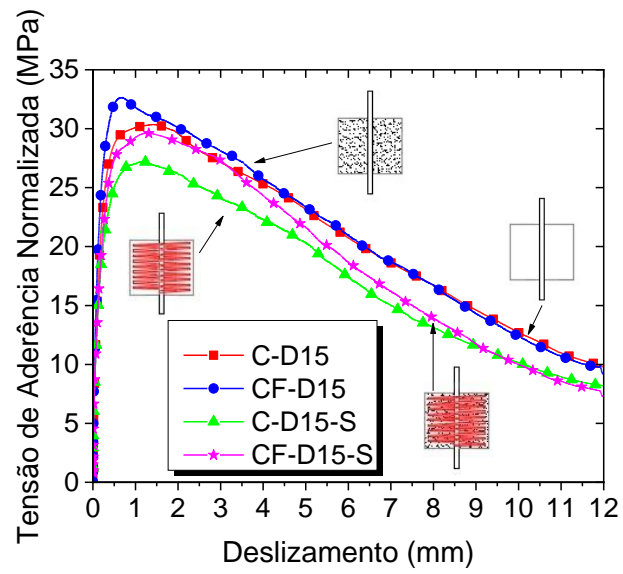

Fonte: Autoria própria

Apenas no modelo sem nenhum tipo de confinamento (C-D8) o modo de ruptura foi o fendilhamento, conforme apresentado na Figura 70a), enquanto os demais apresentaram o arrancamento da barra, exemplificado na Figura 70b).

Figura 70-Tipos de ruptura: a) Fendilhamento (modelo C-D8)

b)Arrancamento (modelo CF-D8)

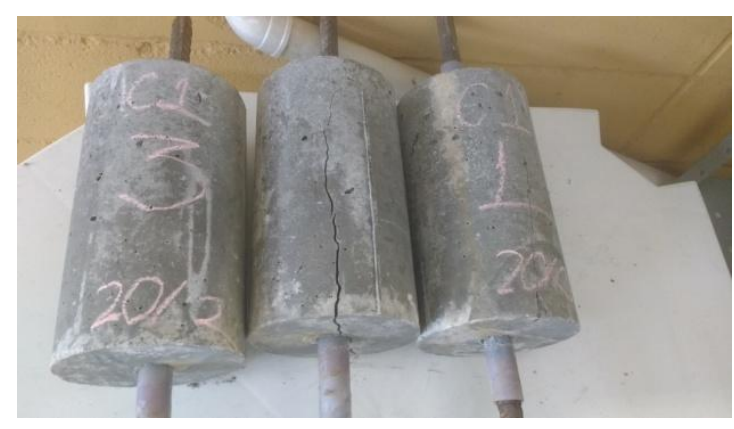

a)

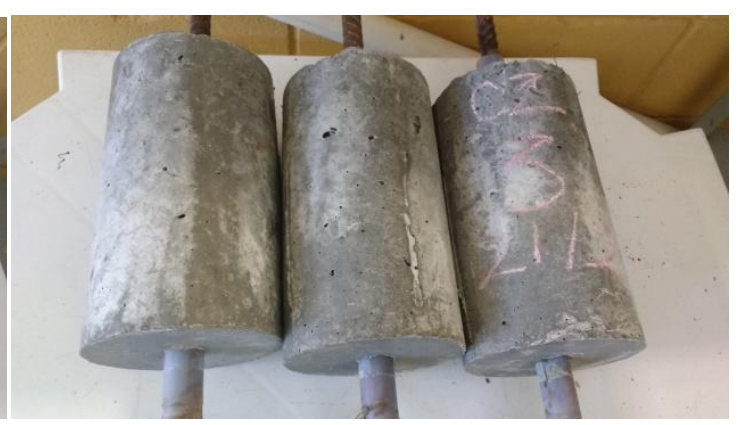

b)

Fonte: Autoria própria

Os incrementos e decréscimos na tensão de aderência (e seu respectivo deslizamento) ao incluir a fibra metálica na composição do concreto estão relacionados na Tabela 42. Os valores relativos de tensão de aderência máxima e deslizamento último foram obtidos pela relação entre os valores de $\tau_{\max } \mathrm{e} \delta_{\mathrm{u}}$ dos modelos com fibras (destino) em comparação com os modelos sem fibras (origem).

No modelo com $D_{c} / \phi=8$ sem confinamento (C-D8), a presença da fibra metálica alterou o modo de rutura de fendilhamento para arrancamento e a tensão de aderência máxima 
praticamente não foi alterada (diminuiu 1,54\%). Nesse caso, as fibras metálicas contribuíram no trecho pós-pico, tornando o comportamento mais dúctil. Isso também pode ser verificado no deslizamento último: houve um aumento considerável $(35,55 \%)$ devido à alteração do modo de ruptura de fendilhamento para arrancamento.

O modelo C-D9 já possuía confinamento suficiente promovido pelo cobrimento de concreto, então, seu modo de ruptura foi arrancamento. A inclusão de fibras metálicas praticamente não produziu efeitos no comportamento da curva com relação à tensão de aderência máxima, mas praticamente dobrou (aumento de 80,61\%) o valor do deslizamento último.

O modelo com maior cobrimento de concreto (C-15) apresentou um incremento considerável $(7,64 \%)$ na tensão de aderência máxima ao incluir as fibras metálicas, mas com um decréscimo de $54,46 \%$ no deslizamento último.

Nos modelos com armadura transversal houve um aumento da tensão de aderência máxima ao incluir fibras (7,21\% no C-D8-S, 23,63\% no C-D9-S e 8,77\% no C-D15-S), com decréscimo no deslizamento último apenas no modelo com $\mathrm{D}_{\mathrm{c}} / \phi=9$.

Tabela 42-Comparação entre os modelos do ensaio definitivo ao acrescentar fibra

\begin{tabular}{c|c|c|c}
\hline Origem & Destino & $\tau_{\text {max, relativo }}(\%)$ & $\delta_{\mathrm{u}, \text { relativo }}(\%)$ \\
\hline C-D8 & CF-D8 & $-1,54$ & $\mathbf{3 5 , 5 5}$ \\
\hline C-D9 & CF-D9 & $-4,12$ & $\mathbf{8 0 , 6 1}$ \\
\hline C-D15 & CF-D15 & $\mathbf{7 , 6 4}$ & $-54,46$ \\
\hline C-D8-S & CF-D8-S & $\mathbf{7 , 2 1}$ & $\mathbf{2 5 , 0 9}$ \\
\hline C-D9-S & CF-D9-S & $\mathbf{2 3 , 6 3}$ & $-27,09$ \\
\hline C-D15-S & CF-D15-S & $\mathbf{8 , 7 7}$ & $\mathbf{5 , 2 6}$ \\
\hline
\end{tabular}

Fonte: Autoria própria

Ao contrário do comportamento obtido com a adição de fibras metálicas, a inclusão de armadura transversal diminuiu a tensão de aderência máxima em todos os modelos, entre $7,18 \%$ a $14,75 \%$, exceto pelo CF-D9 que apresentou um aumento de $14,72 \%$, conforme apresentado na Tabela 43. Isso provavelmente ocorreu porque o aumento do cobrimento de concreto ao passar de $D_{\mathcal{c}} / \phi=8$ para $D_{\mathcal{c}} / \phi=9$ tornou possível a ruptura por arrancamento e, a partir do momento que isso ocorreu, a tensão de aderência não pode ser aumentada, conforme observado também por Eligehausen, Popov e Bertero (1983). Além disso, as fibras metálicas mostraram ser mais efetivas em resistir às fissuras de fendilhamento que a armadura em espiral, tendo em vista que esta só é mobilizada a partir do momento que as fissuras apresentam um comprimento e abertura considerável (LIN; OSTERTAG, 2017). 
No entanto, a inclusão de armadura transversal promoveu um aumento no deslizamento último, que chegou a quase o dobro no modelo C-D9, com diminuição nos modelos C-D15 e CF-D9.

Tabela 43-Comparação entre os modelos do ensaio definitivo ao acrescentar armadura transversal

\begin{tabular}{cc|c|c|c}
\hline Origem & Destino & $\tau_{\text {max, relativo }}(\%)$ & $\delta_{\mathrm{u}, \text { relativo }}(\%)$ \\
\hline C-D8 & C-D8-S & $-14,75$ & $\mathbf{4 1 , 6 9}$ \\
\hline C-D9 & C-D9-S & $-11,03$ & $\mathbf{9 9 , 7 0}$ \\
\hline C-D15 & C-D15-S & $-10,26$ & $-17,79$ \\
\hline CF-D8 & CF-D8-S & $-7,18$ & $\mathbf{3 0 , 7 5}$ \\
\hline CF-D9 & CF-D9-S & $\mathbf{1 4 , 7 2}$ & $-19,38$ \\
\hline CF-D15 & CF-D15-S & $-9,32$ & $\mathbf{9 0 , 0 5}$ \\
\hline
\end{tabular}

Fonte: Autoria própria

O efeito combinado da fibra metálica e armadura transversal (Tabela 44) só foi efetivo no modelo C-D9, com aumento de 9,99\% na tensão de aderência máxima, diminuição $(8,61 \%)$ no modelo C-D8 e sem efeito significante no modelo C-D15.

Com relação ao deslizamento último, este sofreu um aumento no modelo com $D_{c} / \phi=8$, tendo em vista que o modo de ruptura passou de fendilhamento para arrancamento, e no modelo $\mathrm{D}_{\mathrm{c}} / \phi=9$, havendo uma diminuição no modelo com $\mathrm{D}_{\mathrm{c}} / \phi=15$.

Tabela 44-Comparação entre os modelos do ensaio definitivo ao acrescentar fibra e armadura transversal

\begin{tabular}{c|c|c|c}
\hline Origem & Destino & $\tau_{\max , \text { relativo }}(\%)$ & $\delta_{\mathrm{u}, \text { relativo }}(\%)$ \\
\hline C-D8 & CF-D8-S & $-8,61$ & $\mathbf{7 7 , 2 4}$ \\
\hline C-D9 & CF-D9-S & $\mathbf{9 , 9 9}$ & $\mathbf{4 5 , 6 1}$ \\
\hline C-D15 & CF-D15-S & $-2,39$ & $-13,46$ \\
\hline
\end{tabular}

Fonte: Autoria própria

\subsubsection{COBRIMENTO DE CONCRETO E ARMADURA TRANSVERSAL}

A Figura 71 e Figura 72 apresentam a influência proporcionada pelo aumento do cobrimento de concreto e/ou adição de armadura transversal, sendo fixado o volume de fibras $(0$ e $1 \%)$. 
Figura 71- Tensão de aderência versus deslizamento sem fibras

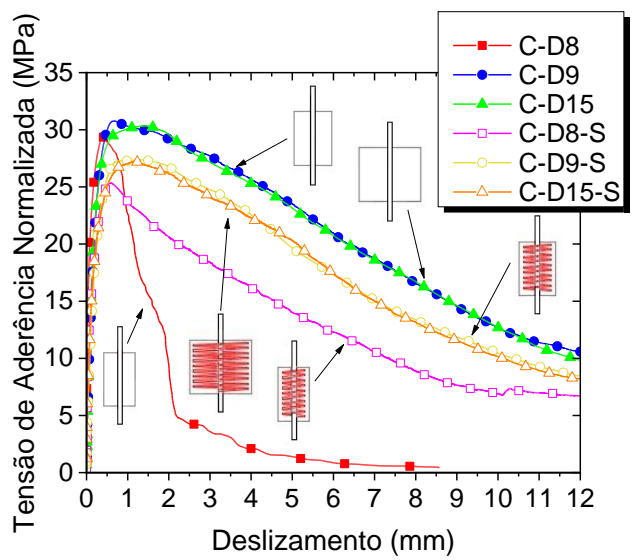

Fonte: Autoria própria
Figura 72- Tensão de aderência versus deslizamento com fibras

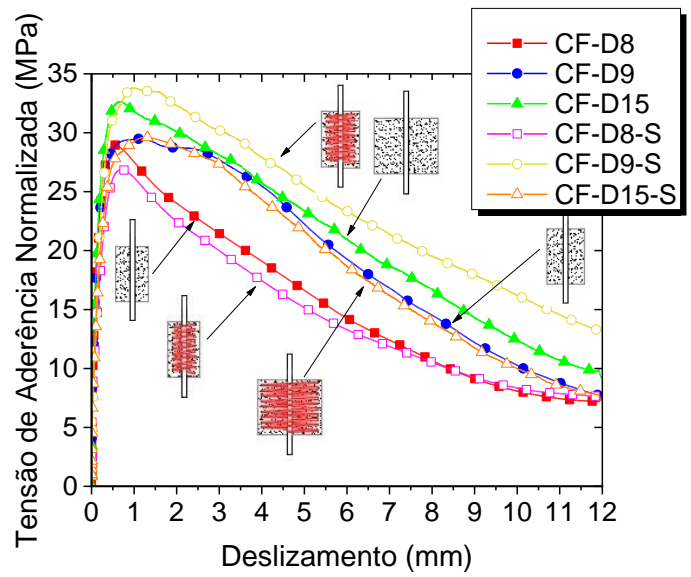

Fonte: Autoria própria

O impacto proporcionado pelo aumento do cobrimento de concreto na tensão de aderência máxima e no deslizamento último é apresentado na Tabela 45.

Todos os modelos com relação $\mathrm{D}_{\mathrm{c}} / \phi=8$ tiveram um aumento na tensão de aderência ao aumentar o cobrimento para $\mathrm{D}_{\mathrm{c}} / \phi=9$ (de $4,65 \%$ no modelo C-D8 e $25,94 \%$ no modelo CF-D8S). No entanto, ao alterar a relação $\mathrm{D}_{\mathrm{c}} / \phi$ de 9 para 15 não houve ganho na tensão de aderência, exceto pelo modelo CF-D9 que apresentou um aumento de 10,75\%. Com relação ao deslizamento último houve uma queda apenas nos modelos CF-D9 e C-D9-S. Tal fato confirma que a relação $D_{c} / \phi=9$ apresenta um cobrimento suficiente para permitir a ruptura por arrancamento, sendo pouco efetivo aumentar para 15 com a intenção de impactar positivamente na tensão de aderência.

Tabela 45- Comparação entre os modelos do ensaio definitivo ao aumentar o cobrimento

\begin{tabular}{c|c|c|c}
\hline Origem & Destino & $\tau_{\max , \text { relativo }}(\%)$ & $\delta_{\mathrm{u}, \text { relativo }}(\%)$ \\
\hline C-D8 & C-D9 & $\mathbf{4 , 6 5}$ & $\mathbf{6 8 , 8 0}$ \\
\hline C-D9 & C-D15 & $-1,35$ & $\mathbf{1 2 0 , 6 1}$ \\
\hline CF-D8 & CF-D9 & $\mathbf{1 , 9 0}$ & $\mathbf{1 2 4 , 9 1}$ \\
\hline CF-D9 & CF-D15 & $\mathbf{1 0 , 7 5}$ & $-44,38$ \\
\hline C-D8-S & C-D9-S & $\mathbf{9 , 2 1}$ & $\mathbf{1 3 7 , 9 1}$ \\
\hline C-D9-S & C-D15-S & $-0,49$ & $-9,18$ \\
\hline CF-D8-S & CF-D9-S & $\mathbf{2 5 , 9 4}$ & $\mathbf{3 8 , 6 7}$ \\
\hline CF-D9-S & CF-D15-S & $-12,46$ & $\mathbf{3 1 , 1 1}$ \\
\hline
\end{tabular}

Fonte: Autoria própria

A Tabela 46 apresenta o efeito combinado do aumento de cobrimento e inclusão de armadura transversal. Os modelos sem fibra apresentaram um decréscimo na tensão de 
aderência (6,90\% no C-D8 e 11,47\% no C-D9) ao adicionar este tipo de confinamento combinado, enquanto os espécimes com fibra tiveram um acréscimo no modelo CF-D8 $(16,90 \%)$ e não houve grandes alterações no modelo CF-D9.

Em todos os casos houve um aumento no deslizamento último ao aumentar o cobrimento e incluir a armadura transversal.

Tabela 46- Comparação entre os modelos do ensaio definitivo ao aumentar o cobrimento e acrescentar armadura transversal

\begin{tabular}{c|c|c|c}
\hline Origem & Destino & $\tau_{\text {max, relativo }}(\%)$ & $\delta_{\mathrm{u}, \text { relativo }}(\%)$ \\
\hline C-D8 & C-D9-S & $-6,90$ & $\mathbf{2 3 7 , 0 8}$ \\
\hline C-D9 & C-D15-S & $-11,47$ & $\mathbf{8 1 , 3 6}$ \\
\hline CF-D8 & CF-D9-S & $\mathbf{1 6 , 9 0}$ & $\mathbf{8 1 , 3 2}$ \\
\hline CF-D9 & CF-D15-S & $\mathbf{0 , 4 3}$ & $\mathbf{5 , 7 0}$ \\
\hline
\end{tabular}

Fonte: Autoria própria

\subsubsection{COBRIMENTO DE CONCRETO E FIBRA METÁLICA}

A curva tensão de aderência versus deslizamento para os modelos sem armadura transversal e com armadura helicoidal é apresentada na Figura 73 e Figura 74, respectivamente.

Figura 73- Tensão de aderência versus deslizamento sem armadura transversal

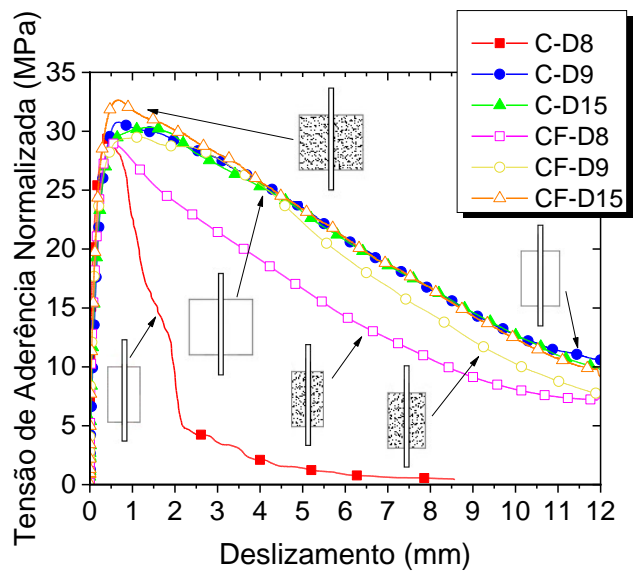

Fonte: Autoria própria
Figura 74- Tensão de aderência versus deslizamento com armadura transversal

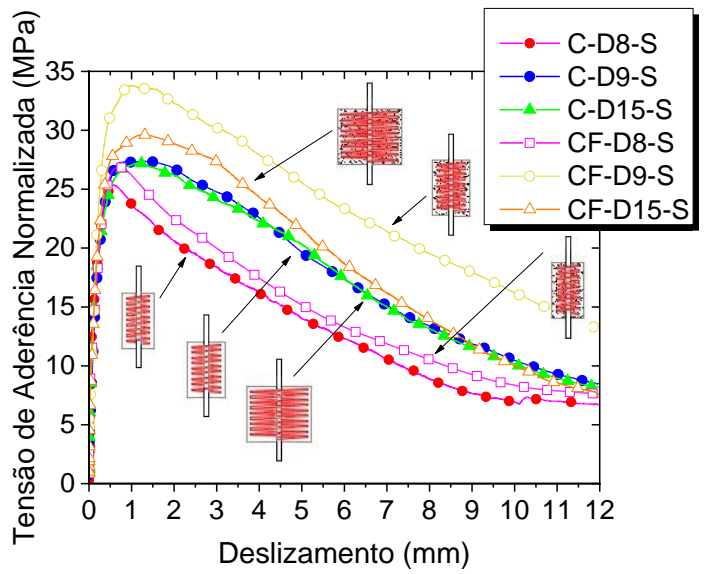

Fonte: Autoria própria 
$\mathrm{Na}$ Tabela 47 é possível observar que o aumento simultâneo do cobrimento de concreto com a inclusão de fibras metálicas promoveu um aumento na tensão de aderência em todos os casos (de 0,33\% no C-D8 a 35,01\% no C-D8-S), com um ligeiro decréscimo $(4,40 \%)$ no deslizamento último apenas no modelo com armadura e $\mathrm{D}_{\mathrm{c}} / \phi=9$ (C-D9-S).

Tabela 47-Comparação entre os modelos do ensaio definitivo ao aumentar o cobrimento e acrescentar fibra

\begin{tabular}{c|c|c|c}
\hline Origem & Destino & $\tau_{\max , \text { relativo }}(\%)$ & $\delta_{\mathrm{u}, \text { relativo }}(\%)$ \\
\hline C-D8 & CF-D9 & $\mathbf{0 , 3 3}$ & $\mathbf{2 0 4 , 8 6}$ \\
\hline C-D9 & CF-D15 & $\mathbf{6 , 1 9}$ & $\mathbf{0 , 4 5}$ \\
\hline C-D8-S & CF-D9-S & $\mathbf{3 5 , 0 1}$ & $\mathbf{7 3 , 4 7}$ \\
\hline C-D9-S & CF-D15-S & $\mathbf{8 , 2 3}$ & $-4,40$ \\
\hline
\end{tabular}

Fonte: Autoria própria

\subsubsection{COBRIMENTO DE CONCRETO, FIBRA METÁLICA E ARMADURA}

\section{TRANSVERSAL}

A Figura 75 apresenta a curva dos modelos sem nenhum tipo de confinamento e com os três parâmetros analisados conjuntamente: cobrimento de concreto, fibras metálicas e armadura transversal.

Figura 75-Tensão de aderência versus deslizamento dos modelos sem confinamento e com confinamento (incluindo fibra metálica e armadura transversal e aumento do cobrimento de concreto)

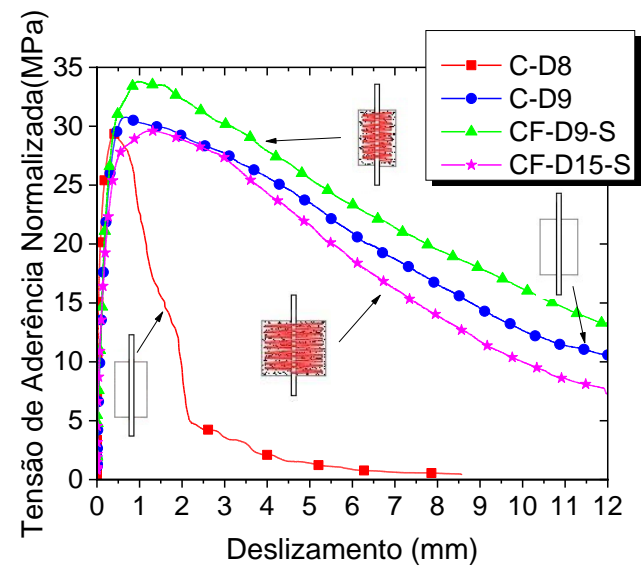

Fonte: Autoria própria 
Conforme a Tabela 48 indica, o modelo $\mathrm{D}_{\mathrm{c}} / \phi=8$ apresentou um aumento de $15,10 \%$ na tensão de aderência máxima ao incluir os mecanismos de confinamento, enquanto que o modelo $\mathrm{D}_{\mathrm{c}} / \phi=9$ apresentou um pequeno decréscimo (3,71\%). Em ambos os casos houve um aumento do deslizamento último. Esse resultado indica que o confinamento foi mais importante para o modelo C-D8, tendo em vista que seu modo de ruptura era fendilhamento, que para o modelo C-D9, cuja ruptura já era arrancamento.

Tabela 48- Comparação entre os modelos do ensaio definitivo ao aumentar o cobrimento e acrescentar fibra e armadura transversal

\begin{tabular}{c|c|c|c}
\hline Origem & Destino & $\tau_{\text {max, relativo }}(\%)$ & $\delta_{\mathrm{u}, \text { relativo }}(\%)$ \\
\hline C-D8 & CF-D9-S & $\mathbf{1 5 , 1 0}$ & $\mathbf{1 4 5 , 7 8}$ \\
\hline C-D9 & CF-D15-S & $-3,71$ & $\mathbf{9 0 , 9 1}$ \\
\hline
\end{tabular}

Fonte: Autoria própria

\subsection{COMPARAÇÕES ENTRE OS RESULTADOS}

\section{EXPERIMENTAIS E PRESCRIÇÕES NORMATIVAS}

Foi feita a comparação dos valores da resistência de aderência obtidos experimentalmente e segundo as equações fornecidas pelo FIB Model Code 2010 (2012), ABNT NBR 6118:2014 e ACI 318:2014.

A resistência de aderência dos ensaios de arrancamento foi definida como a tensão de aderência para um deslizamento de 0,1 mm, como prescrito por Leonhardt e Mönnig (1977).

Para efeito de comparação foram desprezados os coeficientes ponderadores da resistência do concreto, utilizando-se a resistência à compressão e tração média.

Os modelos do ensaio piloto foram moldados em duas concretagens, sendo uma com fibra e outra sem. Tendo em vista que os modelos foram ensaiados aos 33 dias, foram adotados os valores de resistência à compressão do concreto na data do ensaio.

Já para os modelos do ensaio definitivo, que foram ensaiados aos 28 dias, não houve grande discrepância nos valores de resistência à compressão e tração entre as concretagens. Então, utilizou-se valores médios (calculados separadamente para o concreto com fibras e sem fibras) aos 28 dias para caracterizar os valores prescritos pelas normas. A Tabela 49 resume os valores de resistência à tração e compressão do ensaio piloto e definitivo para concreto sem fibras e com fibras, utilizados nas prescrições normativas da resistência de aderência. 
Tabela 49-Valores de resistência à compressão e tração dos corpos-de-prova do ensaio piloto e definitivo

\begin{tabular}{c|c|c|c}
\hline Ensaio & Concreto & $\mathrm{f}_{\mathrm{c}, \text { medio }}(\mathrm{MPa})$ & $\mathrm{f}_{\mathrm{ct}, \text { medio }}(\mathrm{MPa})$ \\
\hline \multirow{2}{*}{ Piloto } & $\mathrm{C}$ & 77,46 & 3,83 \\
\cline { 2 - 4 } & $\mathrm{CF}$ & 79,15 & 4,91 \\
\hline \multirow{2}{*}{ Definitivo } & $\mathrm{C}$ & 66,41 & 4,09 \\
\cline { 2 - 4 } & $\mathrm{CF}$ & 68,64 & 4,65 \\
\hline
\end{tabular}

Fonte: Autoria própria

As seguintes considerações foram feitas para o cálculo da resistência de aderência de cada código normativo:

- FIB Model Code 2010 (2012): barras nervuradas, em regiões de boa aderência (inclinação de $90^{\circ}$ em relação à horizontal) e diâmetro inferior a $25 \mathrm{~mm}$, obtendo-se os valores dos coeficientes da Tabela 1 a Tabela 3, que, substituídos na equação (7) resultou na seguinte equação para a resistência de aderência, sendo o coeficiente $\eta_{4}$ segundo a Tabela 50:

$$
f_{b}=1,75 \cdot 1 \cdot 1 \cdot \eta_{4 .}\left(f_{c, \text { medio }} / 25\right)^{0,5}
$$

Tabela 50- Coeficiente $\eta_{4}$ para cada diâmetro da barra

Fonte: Autoria própria

\begin{tabular}{c|c|c}
\hline$\phi(\mathrm{mm})$ & $\mathrm{f}_{\mathrm{y}}(\mathrm{MPa})$ & $\eta_{4}$ \\
\hline 10 & 549,03 & 0,9265 \\
\hline 16 & 540,37 & 0,9395 \\
\hline 20 & 521,32 & 0,9680 \\
\hline
\end{tabular}

- ABNT NBR 6118:2014: barras nervuradas, de diâmetro inferior a 20 mm e em regiões de boa aderência (inclinação superior a $45^{\circ}$ sobre a horizontal), obtendo-se os coeficientes da Tabela 7 a Tabela 9, que, substituídos na equação (11) resultaram na seguinte equação para a resistência de aderência:

$$
f_{b}=2,25.1 .1 . f_{c t, \text { medio }}=2,25 . f_{c t, \text { medio }}
$$

- ACI 318:2014: densidade do concreto normal, barra longitudinal localizada abaixo de $300 \mathrm{~mm}$ da face superior da peça e armadura sem revestimento, obtendo-se os coeficientes da Tabela 11 a Tabela 14, que, substituídos na equação (16) com relação c+Ktr/ $\phi$ igual ao valor limite de 2,5 , tendo em vista 
que em todas as situações esse valor foi ultrapassado $(3,25 ; 3,88$ e 7,00 para as relações de $D_{c} / \phi=8, D_{c} / \phi=9$ e $D_{c} / \phi=15$, respectivamente), obteve-se a seguinte equação:

$$
f_{b}=\frac{1,1 \cdot 1 \cdot \sqrt{f_{c, \text { medio }}}}{4 \cdot 1 \cdot 1 \cdot 0,8} \cdot 2,5=0,859375 \cdot \sqrt{f_{c, \text { medio }}}
$$

\subsubsection{ENSAIO PILOTO}

A média dos valores experimentais da resistência de aderência, tomada para um valor de deslizamento de $0,1 \mathrm{~mm}$, para cada um dos modelos do ensaio piloto, foi comparada com os valores obtidos pelas equações das normas, conforme descrito acima (equações 28 a 30). A Figura 76 apresenta essa comparação para os modelos sem fibra e a Figura 77 os valores para os espécimes com fibra, além do resumo na Tabela 51.

Figura 76-Resistência de aderência conforme prescrições normativas e resultados obtidos pelo ensaio piloto para concreto sem fibra

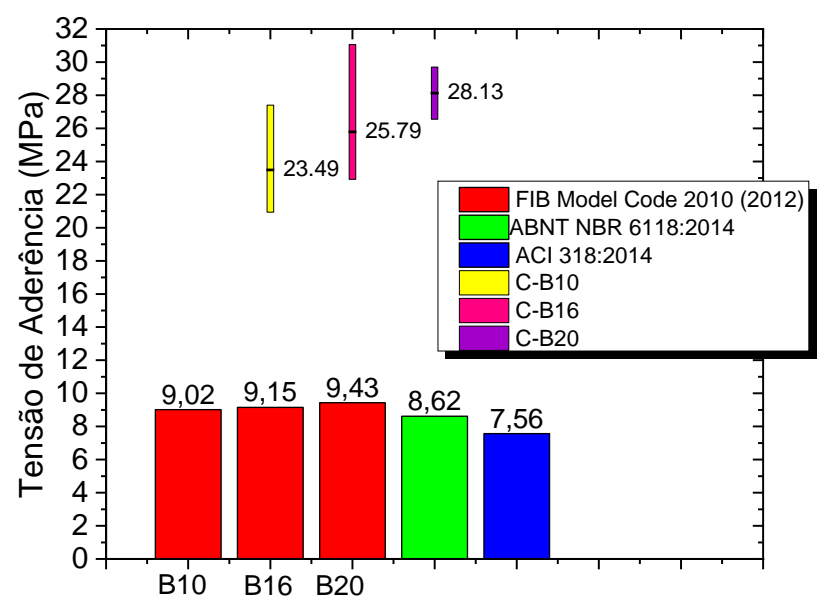

Fonte: Autoria própria 
Figura 77-Resistência de aderência conforme prescrições normativas e resultados obtidos pelo ensaio piloto para concreto com fibra

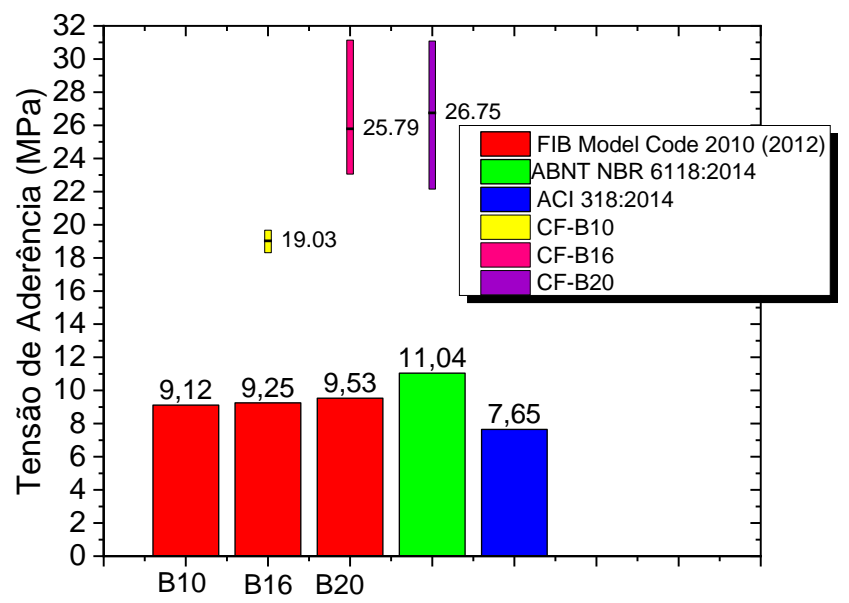

Fonte: Autoria própria

Conforme pode ser observado, todas as prescrições normativas estão a favor da segurança, com uma margem de tolerância grande para a resistência de aderência. O ACI 318:2014 demonstrou ser o mais conservador, com uma diminuição de 73,11\% (equivalente a $26,89 \%$ da tensão obtida experimentalmente) e 59,82\% no caso mais crítico (representando $40,18 \%$ do valor experimental). A norma brasileira também apresentou uma margem grande, correspondendo a $30,63 \%$ do valor experimental no caso mais crítico (decréscimo de 69,37\%). Os valores da ABNT NBR 6118:2014 se aproximaram dos da norma europeia, FIB Model Code 2010 (2012), a qual apresentou uma resistência de aderência equivalente a $33,52 \%$ do valor experimental no caso mais crítico. 
Tabela 51-Valores de resistência de aderência obtidos no ensaio de arrancamento piloto e nas prescrições normativas

\begin{tabular}{|c|c|c|c|}
\hline Diâmetro da barra & Corpo-de-prova & $\mathrm{fb}(\mathrm{MPa})$ & Variação (\%) \\
\hline \multirow{8}{*}{10} & C-B10_Media & 23,49 & - \\
\hline & FIB Model Code 2010 (2012) & 9,02 & $-61,58$ \\
\hline & ABNT NBR 6118:2014 & 8,62 & $-63,32$ \\
\hline & ACI 318:2014 & 7,56 & $-67,80$ \\
\hline & CF-B10_Media & 19,03 & - \\
\hline & FIB Model Code 2010 (2012) & 9,12 & $-52,06$ \\
\hline & ABNT NBR 6118:2014 & 11,04 & $-41,97$ \\
\hline & ACI 318:2014 & 7,65 & $-59,82$ \\
\hline \multirow{8}{*}{16} & C-B16_Media & 25,79 & - \\
\hline & FIB Model Code 2010 (2012) & 9,15 & $-64,52$ \\
\hline & ABNT NBR 6118:2014 & 8,62 & $-66,59$ \\
\hline & ACI 318:2014 & 7,56 & $-70,67$ \\
\hline & CF-B16_Media & 25,79 & - \\
\hline & FIB Model Code 2010 (2012) & 9,25 & $-64,13$ \\
\hline & ABNT NBR 6118:2014 & 11,04 & $-57,18$ \\
\hline & ACI 318:2014 & 7,65 & $-70,35$ \\
\hline \multirow{8}{*}{20} & C-B20_Media & 28,13 & - \\
\hline & FIB Model Code 2010 (2012) & 9,43 & $-66,48$ \\
\hline & ABNT NBR 6118:2014 & 8,62 & $-69,37$ \\
\hline & ACI 318:2014 & 7,56 & $-73,11$ \\
\hline & CF-B20_Media & 26,75 & - \\
\hline & FIB Model Code 2010 (2012) & 9,53 & $-64,37$ \\
\hline & ABNT NBR 6118:2014 & 11,04 & $-58,72$ \\
\hline & ACI 318:2014 & 7,65 & $-71,42$ \\
\hline
\end{tabular}

Fonte: Autoria própria

\subsubsection{ENSAIO DEFINITIVO}

Os valores de resistência de aderência para o ensaio definitivo foram obtidos pelo mesmo procedimento do ensaio piloto. Para facilitar a visualização, os resultados foram separados em modelos sem fibras e com fibras, sendo apresentados na Figura 78 e Figura 79, respectivamente, e na Tabela 52 e Tabela 53, respectivamente. 
Figura 78-Resistência de aderência conforme prescrições normativas e resultados obtidos pelo ensaio definitivo para concreto sem fibra

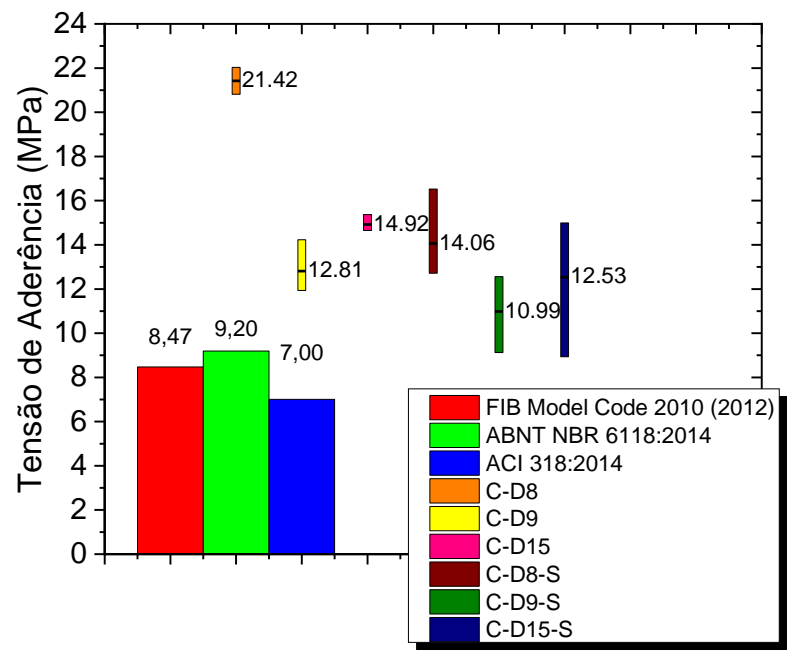

Fonte: Autoria própria

Figura 79-Resistência de aderência conforme prescrições normativas e resultados obtidos pelo ensaio definitivo para concreto com fibra

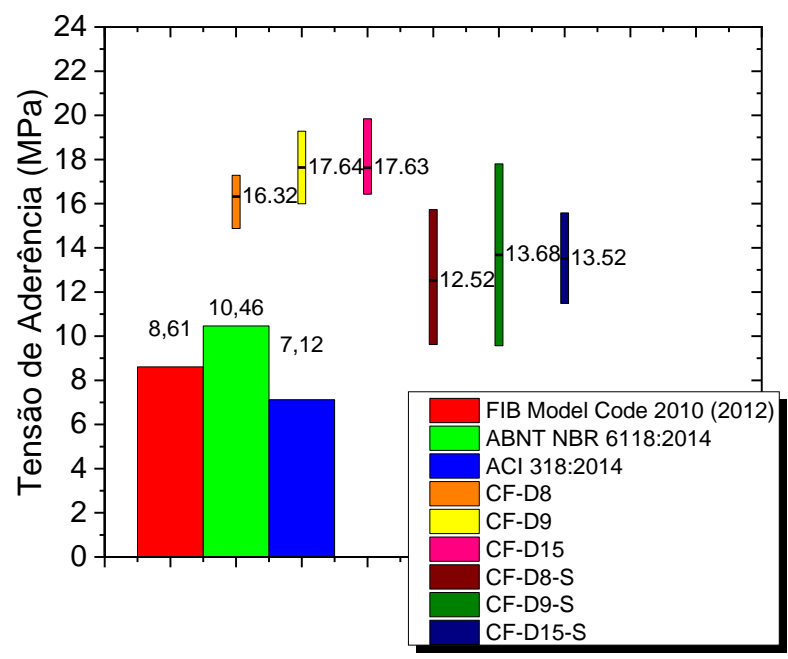

Fonte: Autoria própria

Novamente pode ser verificada uma grande margem de segurança entre os valores de resistência de aderência obtidos experimentalmente e pelas prescrições normativas. O ACI 318:2014 permanece sendo mais conservador que as demais normas, com decréscimos entre $67,30 \%$ e $36,27 \%$ (representando $32,70 \%$ e $63,73 \%$ do valor experimental). A norma 
brasileira (valores entre $42,93 \%$ e $83,67 \%$ da resistência experimental) e europeia (entre $39,56 \%$ e $77,10 \%$ ) tiveram comportamentos semelhantes.

Tabela 52-Valores de resistência de aderência obtidos no ensaio de arrancamento definitivo e nas prescrições normativas para os exemplares sem fibras metálicas

\begin{tabular}{|c|c|c|c|}
\hline Diâmetro do Concreto & Corpo-de-prova & $\mathrm{f}_{\mathrm{b}}(\mathrm{MPa})$ & Variação (\%) \\
\hline \multirow{8}{*}{8} & C-D8_Media & 21,42 & - \\
\hline & FIB Model Code 2010 (2012) & 8,47 & $-60,44$ \\
\hline & ABNT NBR 6118:2014 & 9,20 & $-57,07$ \\
\hline & ACI 318:2014 & 7,00 & $-67,30$ \\
\hline & C-D8-S_Media & 14,06 & - \\
\hline & FIB Model Code 2010 (2012) & 8,47 & $-39,73$ \\
\hline & ABNT NBR 6118:2014 & 9,20 & $-34,60$ \\
\hline & ACI 318:2014 & 7,00 & $-50,19$ \\
\hline \multirow{8}{*}{9} & C-D9_Media & 12,81 & - \\
\hline & FIB Model Code 2010 (2012) & 8,47 & $-33,85$ \\
\hline & ABNT NBR 6118:2014 & 9,20 & $-28,22$ \\
\hline & ACI 318:2014 & 7,00 & $-45,33$ \\
\hline & C-D9-S_Media & 10,99 & - \\
\hline & FIB Model Code 2010 (2012) & 8,47 & $-22,90$ \\
\hline & ABNT NBR 6118:2014 & 9,20 & $-16,33$ \\
\hline & ACI 318:2014 & 7,00 & $-36,27$ \\
\hline \multirow{8}{*}{15} & C-D15_Media & 14,92 & - \\
\hline & FIB Model Code 2010 (2012) & 8,47 & $-43,21$ \\
\hline & ABNT NBR 6118:2014 & 9,20 & $-38,37$ \\
\hline & ACI 318:2014 & 7,00 & $-53,06$ \\
\hline & C-D15-S_Media & 12,53 & - \\
\hline & FIB Model Code 2010 (2012) & 8,47 & $-32,37$ \\
\hline & ABNT NBR 6118:2014 & 9,20 & $-26,61$ \\
\hline & ACI 318:2014 & 7,00 & $-44,11$ \\
\hline
\end{tabular}

Fonte: Autoria própria 
Tabela 53-Valores de resistência de aderência obtidos no ensaio de arrancamento definitivo e nas prescrições normativas para os exemplares com fibras metálicas

\begin{tabular}{|c|c|c|c|}
\hline Diâmetro do Concreto & Corpo-de-prova & $\mathrm{f}_{\mathrm{b}}(\mathrm{MPa})$ & Variação (\%) \\
\hline \multirow{8}{*}{ 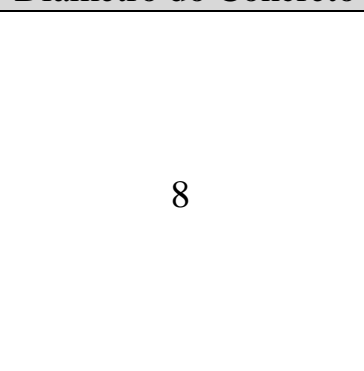 } & CF-D8 Media & 16,32 & - \\
\hline & FIB Model Code 2010 (2012) & 8,61 & $-47,22$ \\
\hline & ABNT NBR 6118:2014 & 10,46 & $-35,91$ \\
\hline & ACI 318:2014 & 7,12 & $-56,37$ \\
\hline & CF-D8-S_Media & 12,52 & - \\
\hline & FIB Model Code 2010 (2012) & 8,61 & $-31,20$ \\
\hline & ABNT NBR 6118:2014 & 10,46 & $-16,45$ \\
\hline & ACI 318:2014 & 7,12 & $-43,13$ \\
\hline \multirow{8}{*}{9} & CF-D9_Media & 17,64 & - \\
\hline & FIB Model Code 2010 (2012) & 8,61 & $-51,17$ \\
\hline & ABNT NBR 6118:2014 & 10,46 & $-40,70$ \\
\hline & ACI 318:2014 & 7,12 & $-59,64$ \\
\hline & CF-D9-S_Media & 13,68 & - \\
\hline & FIB Model Code 2010 (2012) & 8,61 & $-37,03$ \\
\hline & ABNT NBR 6118:2014 & 10,46 & $-23,54$ \\
\hline & ACI $318: 2014$ & 7,12 & $-47,96$ \\
\hline \multirow{8}{*}{15} & CF-D15_Media & 17,63 & - \\
\hline & FIB Model Code 2010 (2012) & 8,61 & $-51,14$ \\
\hline & ABNT NBR 6118:2014 & 10,46 & $-40,67$ \\
\hline & ACI 318:2014 & 7,12 & $-59,62$ \\
\hline & CF-D15-S_Media & 13,52 & - \\
\hline & FIB Model Code 2010 (2012) & 8,61 & $-36,28$ \\
\hline & ABNT NBR 6118:2014 & 10,46 & $-22,63$ \\
\hline & ACI 318:2014 & 7,12 & $-47,34$ \\
\hline
\end{tabular}

Fonte: Autoria própria

\subsection{COMPARAÇÕES ENTRE OS RESULTADOS}

\section{EXPERIMENTAIS E MODELOS TEÓRICOS}

Com base nas equações da Tabela 17, nos coeficientes da Tabela 15 e Tabela 16 e características do concreto e da barra longitudinal utilizados nos ensaios de arrancamento piloto e definitivo, foi possível construir as curvas dos modelos teóricos.

Este item contém os gráficos e tabelas comparando as curvas tensão de aderência versus deslizamento obtidas pelos modelos teóricos e pelos ensaios experimentais de arrancamento.

Tendo em vista as limitações de cada modelo, as seguintes considerações foram feitas: os modelos propostos por Huang, Engstron e Magnusson (1996), Simplício (2008) e FIB Model Code 2010 (2012) foram empregados para todas as situações; os modelos de Barbosa 
(2001) e de Almeida Filho (2006) foram utilizados para os modelos sem fibras e o modelo de Harajli, Hout e Jalkh (1995) foi empregado para concreto com fibras.

É importante ressaltar que os ensaios de arrancamento realizados pelos autores não continham as mesmas geometrias e parâmetros considerados no presente trabalho. Os modelos de Barbosa (2001), Almeida Filho (2006) e Simplício (2008) seguiram o método de ensaio proposto pela RILEM-CEB-FIP (1973), realizando algumas alterações como corposde-prova cilíndricos ou diminuindo o comprimento aderente para $3 \phi$. Alguns modelos foram baseados em corpos-de-prova com barras longitudinais de diâmetros diferentes da presente pesquisa: os modelos de Barbosa (2001) não incluem as barras de $10 \mathrm{~mm}$ e os de Almeida Filho (2006) e Simplício (2008) não continham barras de $20 \mathrm{~mm}$. As fibras metálicas utilizadas por Harajli, Hout e Jalkh (1995) apresentavam fator de forma de 60 e 100, enquanto a da pesquisa foi de 32. O modelo do FIB Model Code 2010 (2012) limita a relação entre o cobrimento de concreto e o diâmetro da barra a 2,5 enquanto os modelos utilizados ultrapassavam 3,25. Dessa forma, as divergências entre os modelos teóricos e os resultados experimentais são justificáveis, tendo em vista essas diferenças nas geometrias dos corpos-deprova e características do concreto/barra de aço.

Os valores de resistência à compressão utilizados nos modelos teóricos foram correspondentes aos obtidos na idade do concreto na data do ensaio, portanto, 33 dias para o ensaio piloto e 28 dias para o ensaio definitivo, conforme a Tabela 36.

\subsubsection{ENSAIO PILOTO}

- Sem fibras

Figura 80-Tensão de aderência versus deslizamento comparativo entre o modelo teórico e experimental com diâmetro da barra de $10 \mathrm{~mm}$ sem fibras

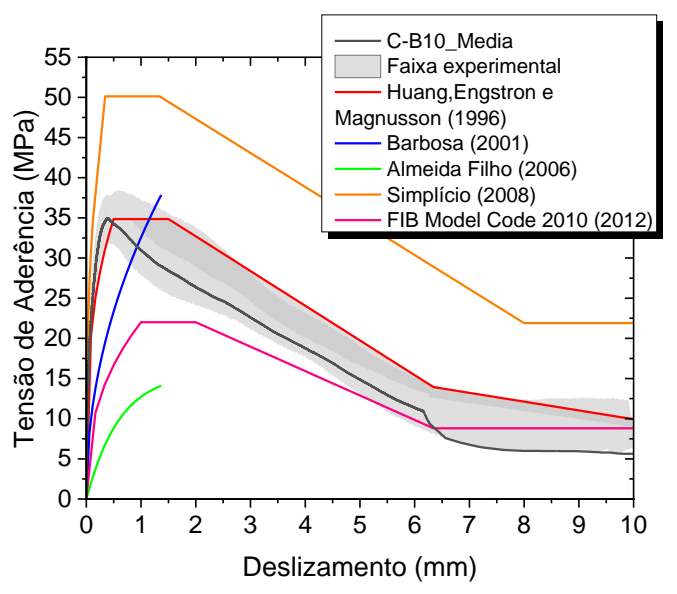

Fonte: Autoria própria 
Figura 81-Tensão de aderência versus deslizamento comparativo entre o modelo teórico e experimental com diâmetro da barra de $16 \mathrm{~mm}$ sem fibras

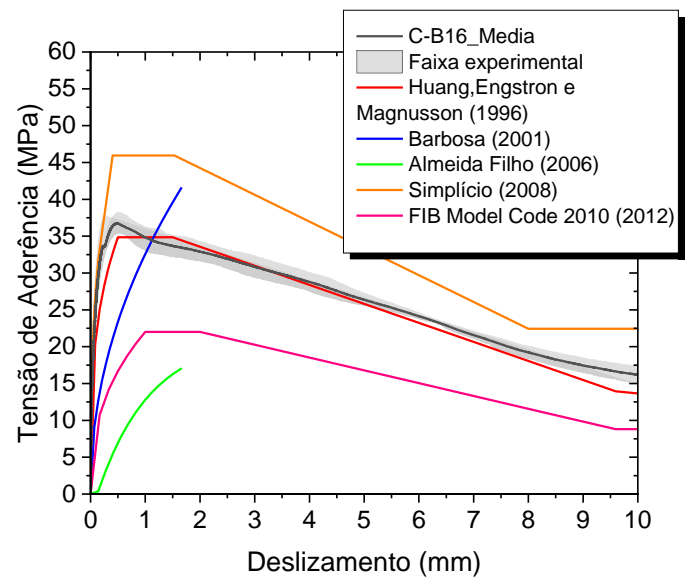

Fonte: Autoria própria
Figura 82-Tensão de aderência versus deslizamento comparativo entre o modelo teórico e experimental com diâmetro da barra de $20 \mathrm{~mm}$ sem fibras

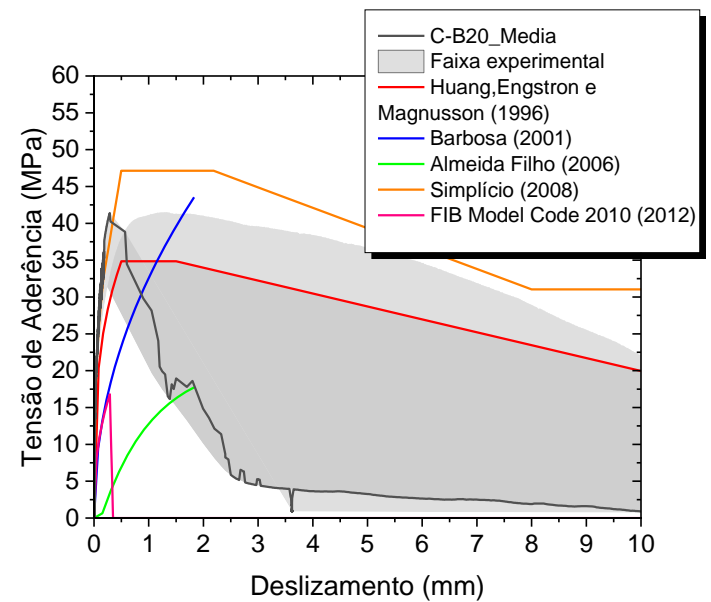

Fonte: Autoria própria

Com base nas equações propostas para os modelos teóricos, foram construídas a Figura 80, Figura 81 e Figura 82 para os espécimes do ensaio de arrancamento piloto, com barras de diâmetro de 10, 16 e $20 \mathrm{~mm}$, respectivamente. Os valores de $\tau_{\max }$ e $\delta_{\text {u }}$ propostos pelos autores e sua comparação (variação percentual) com os obtidos no ensaio experimental são apresentados na Tabela 54.

Os modelos teóricos de Huang, Engstron e Magnusson (1996) e FIB Model Code 2010 (2012) definem o valor de tensão máxima em função apenas da resistência à compressão do concreto $\left(f_{c}\right)$ e o deslizamento final $\left(\delta_{3}\right)$ em função do espaçamento entre nervuras da barra, sendo o deslizamento último $\left(\delta_{1}\right)$ um valor fixo $(0,5$ e $1 \mathrm{~mm}$, respectivamente). Tendo em vista que a concretagem dos corpos-de-prova foi dividida em apenas duas etapas (concreto sem fibras e com fibras), os corpos-de-prova C-B10 e C-B16 possuem o mesmo valor de $\mathrm{f}_{\mathrm{c}}$, e, portanto, resultam no mesmo valor de $\tau_{\max }$ segundo esses modelos teóricos. No entanto, observa-se pelos valores experimentais que houve um aumento tanto na tensão de aderência máxima quanto no deslizamento último ao aumentar o diâmetro da barra de $10 \mathrm{~mm}$ para 16 $\mathrm{mm}$, ocorrendo, portanto, uma discrepância (entre o modelo teórico e experimental) maior no valor de $\tau_{\max }$ para o modelo C-B16, com variação de 5,13\% no modelo teórico de Huang, Engstron e Magnusson (1996) e 40,12\%, do FIB Model Code 2010 (2012), que para o modelo C-B10 (0,34\% e 37,09\%, respectivamente). O valor de deslizamento último segundo o modelo de Huang, Engstron e Magnusson (1996) ficou próximo do real para o espécime C- 
B16 (variação de 5,93\%), enquanto o valor definido pelo FIB Model Code 2010 (2012) foi praticamente o dobro do obtido experimentalmente tanto para o C-B10 quanto para o C-B16.

O modelo C-B20 também foi concretado juntamente com os demais, mas por ter sofrido majoritariamente a ruptura por fendilhamento, a equação para cálculo da tensão máxima do FIB Model Code 2010 (2012) sofre uma correção, obtendo-se um valor ligeiramente inferior se comparado ao C-B10 e C-B16. Porém, devido à ruptura por fendilhamento, o valor experimental da tensão de aderência foi o maior entre os três diâmetros, ocorrendo uma variação entre o modelo teórico e experimental de 59,43\%. Como não é fornecido nenhum valor ou equação para o deslizamento último no modelo do FIB Model Code (2012) submetido à fendilhamento, este foi suposto como sendo igual ao obtido experimentalmente. Pelo modelo de Huang, Engstron e Magnusson (1996), a tensão máxima teria valor igual aos demais diâmetros (já que todos possuem mesmo $\mathrm{f}_{\mathrm{c}}$ ), o que não ocorreu experimentalmente, obtendo-se a maior variação entre os espécimes $(15,82 \%)$. Também, o valor de deslizamento último proposto, de $0,5 \mathrm{~mm}$, divergiu em $74,22 \%$ do valor real.

Os valores de tensão de aderência previstos pelo modelo de Simplício (2008) foram superiores aos experimentais em todos os casos, mesmo para o C-B16 que possuía menor área relativa entre as nervuras $\left(f_{r}\right)$. Os valores de deslizamento último previstos pelo modelo aumentaram com o incremento do diâmetro da barra, tendo em vista o valor fixo de $f_{c}$ e aumento na altura e espaçamento entre nervuras. Porém, foram abaixo do real para os espécimes C-B10 $(13,46 \%)$ e C-B16 $(14,41 \%)$ e acima do real para o C-B20 $(73,40 \%)$.

As equações de Barbosa (2001) propõem um aumento no deslizamento último e na tensão de aderência máxima com o incremento do diâmetro. Entretanto, a forma da curva se mantém a mesma, independentemente do diâmetro, pois os valores dos parâmetros são definidos para resistência à compressão do concreto abaixo ou acima de $50 \mathrm{MPa}$. Pelas equações, verificou-se um deslizamento último teórico bem superior ao experimental, entre 3 e 6 vezes maior. Porém, os valores de tensão máxima se aproximaram do real, com variação de $5,15 \%$ a $13,29 \%$.

O modelo de Almeida Filho (2016) prevê um aumento na tensão de aderência máxima e no deslizamento último com o incremento do diâmetro de $10 \mathrm{~mm}$ para $16 \mathrm{~mm}$. Para a estimativa do comportamento da barra de $20 \mathrm{~mm}$ o modelo foi extrapolado, supondo uma proporção direta para os valores das constantes. Como não é fornecido uma equação para cálculo da tensão ou deslizamento últimos, foi utilizado o mesmo valor de deslizamento último obtido por Barbosa (2001). Foi verificada que a taxa de crescimento da curva tensão de 
aderência versus deslizamento é abaixo da experimental, obtendo-se valores teóricos inferiores para a tensão de aderência e valores superiores para o deslizamento último.

Entre todos os modelos teóricos, o que mais se aproximou do comportamento experimental no trecho pré-pico foi o de Huang, Engstron e Magnusson (1996). O espécime C-B10 apresentou uma discrepância maior no trecho pós-pico devido ao patamar muito prolongado, com uma sobrevalorização de $\delta_{2}$. Já o modelo C-B16 obteve uma certa semelhança tanto no trecho pré-pico quanto no pós-pico. O corpo-de-prova C-B20 se assemelhou apenas no trecho pré-pico, sendo divergente no pós-pico devido à ruptura por fendilhamento, que não era descrita pelo modelo teórico.

Tabela 54- Valores de tensão de aderência obtidos no ensaio de arrancamento piloto e nos modelos teóricos para os exemplares sem fibra metálica

\begin{tabular}{|c|c|c|c|c|c|}
\hline $\begin{array}{c}\text { Diâmetro } \\
\text { da barra }\end{array}$ & Modelo & $\begin{array}{c}\tau_{\max } \\
(\mathrm{MPa}) \\
\end{array}$ & $\begin{array}{l}\text { Variação } \\
(\%)\end{array}$ & $\delta_{\mathrm{u}}(\mathrm{mm})$ & $\begin{array}{l}\text { Variação } \\
(\%)\end{array}$ \\
\hline \multirow{6}{*}{10} & C-B10_Media & 34,98 & - & $\mathbf{0 , 4 0}$ & - \\
\hline & $\begin{array}{l}\text { Huang, Engstron e Magnusson } \\
\text { (1996) }\end{array}$ & 34,86 & $-0,34$ & 0,50 & 25,94 \\
\hline & Barbosa (2001) & 37,86 & 8,26 & 1,37 & 244,52 \\
\hline & Almeida Filho (2006) & 14,10 & $-59,68$ & 1,37 & 244,52 \\
\hline & Simplício (2008) & 50,13 & 43,33 & 0,34 & $-13,46$ \\
\hline & FIB Model Code 2010 (2012) & 22,00 & $-37,09$ & 1,00 & 151,89 \\
\hline \multirow{6}{*}{16} & C-B16_Media & 36,74 & - & 0,47 & - \\
\hline & $\begin{array}{c}\text { Huang, Engstron e Magnusson } \\
(1996)\end{array}$ & 34,86 & $-5,13$ & 0,50 & 5,93 \\
\hline & Barbosa (2001) & 41,63 & 13,29 & 1,67 & 253,01 \\
\hline & Almeida Filho (2006) & 17,07 & $-53,54$ & 1,67 & 253,01 \\
\hline & Simplício (2008) & 45,95 & 25,06 & 0,40 & $-14,41$ \\
\hline & FIB Model Code 2010 (2012) & 22,00 & $-40,12$ & 1,00 & 111,86 \\
\hline \multirow{6}{*}{20} & C-B20_Media & 41,41 & - & 0,29 & - \\
\hline & $\begin{array}{c}\text { Huang, Engstron e Magnusson } \\
\text { (1996) }\end{array}$ & 34,86 & $-15,82$ & 0,50 & 74,22 \\
\hline & Barbosa (2001) & 43,54 & 5,15 & 1,83 & 537,61 \\
\hline & Almeida Filho (2006) & 17,74 & $-57,17$ & 1,83 & 537,61 \\
\hline & Simplício (2008) & 47,13 & 13,82 & 0,50 & 73,40 \\
\hline & FIB Model Code 2010 (2012) & 16,80 & $-59,43$ & 0,29 & - \\
\hline
\end{tabular}

Fonte: Autoria própria 


\section{- Com fibras}

A faixa experimental, com a curva média da tensão de aderência versus deslizamento, juntamente com os modelos teóricos para os espécimes com fibras do ensaio piloto são apresentados na Figura 83, Figura 84 e Figura 85, para os diâmetros de 10, 16 e $20 \mathrm{~mm}$, respectivamente. Assim como nos modelos sem fibras, os valores de tensão de aderência e deslizamento últimos são apresentados na Tabela 55.

Figura 83-Tensão de aderência versus deslizamento comparativo entre o modelo teórico e experimental com diâmetro da barra de $10 \mathrm{~mm}$ com fibras

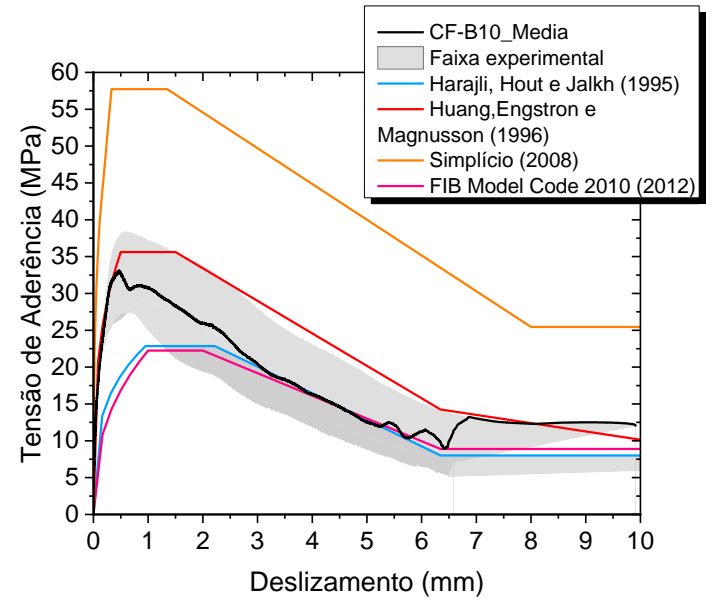

Fonte: Autoria própria

Figura 84-Tensão de aderência versus deslizamento comparativo entre o modelo teórico e experimental com diâmetro da barra de $16 \mathrm{~mm}$ com fibras

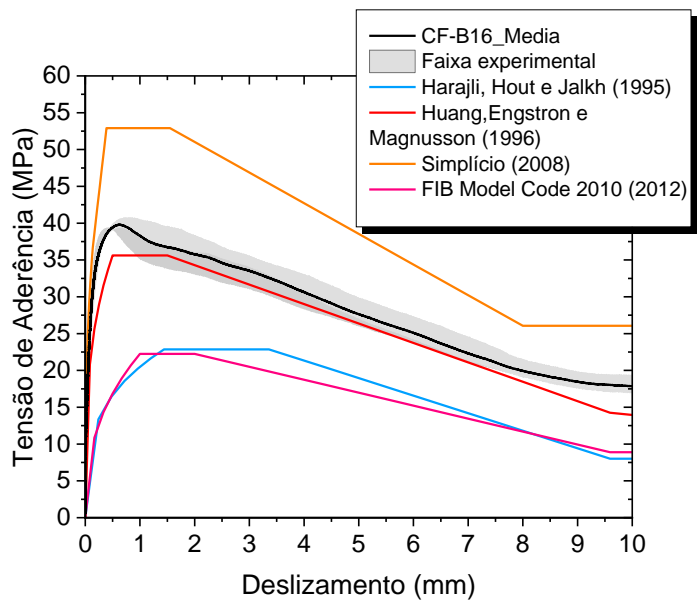

Fonte: Autoria própria
Figura 85-Tensão de aderência versus deslizamento comparativo entre o modelo teórico e experimental com diâmetro da barra de $20 \mathrm{~mm}$ com fibras

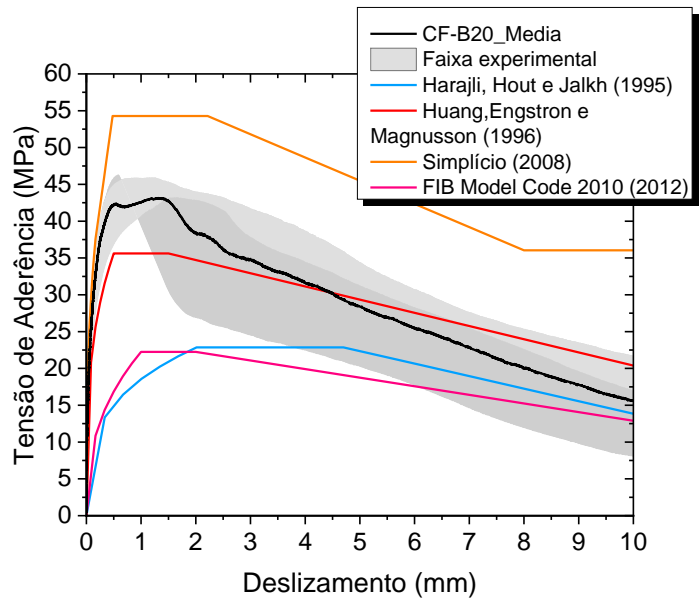

Fonte: Autoria própria 
O modelo teórico de Harajli, Hout e Jalkh (1995) foi dimensionado para concreto com fibras, mas a influência destas é descrita apenas pelo possível aumento na resistência à compressão do concreto $\left(f_{c}\right)$, afetando a tensão de aderência máxima e final. Os deslizamentos são definidos em função do espaçamento entre nervuras das barras. Dessa forma, como foi utilizada a mesma concretagem para os três espécimes com fibras, as tensões de aderência máxima e final teóricas resultaram igual para CF-10, CF-16 e CF-20, com variação apenas nos deslizamentos. Os valores de tensão de aderência máxima teóricos foram menores do que os obtidos experimentalmente, variando de 31,03 a 47,00\%, e os deslizamentos máximos foram maiores, entre $53,87 \%$ e $128,07 \%$.

O modelo de Harajli, Hout e Jalkh (1995) se aproxima do modelo proposto pelo FIB Model Code 2010 (2012), em especial nas constantes (que multiplicam $f_{c}$ ) das equações de tensão de aderência máxima e final, sendo diferentes no cálculo de $\delta_{1}$ e $\delta_{2}$ : enquanto Harajli, Hout e Jalkh (1995) diferencia os valores de deslizamento para cada diâmetro de barra (em função da nervura), o modelo do FIB Model Code 2010 (2012) propõe valores constantes. Então, seguindo o modelo do FIB Model Code 2010 (2012), tanto a tensão de aderência quanto o deslizamento foram iguais para os três diâmetros de barra, resultando em valores abaixo do experimental para a tensão de aderência e acima para o deslizamento, exceto para o modelo de $20 \mathrm{~mm}$, que resultou em um deslizamento último abaixo do experimental.

Assim como no caso sem fibras, o modelo de Simplício (2008) resultou em valores de tensão de aderência acima dos valores experimentais e de deslizamento último abaixo do experimental.

Novamente, o modelo de Huang, Engstron e Magnusson (1996) melhor se aproximou do comportamento experimental, em especial para o espécime C-B16 (com variação de $10,50 \%$ na tensão de aderência máxima e 20,76\% no deslizamento correspondente), divergindo no trecho pós-pico para a barra de $10 \mathrm{~mm}$ e no trecho pré-pico para a barra de 20 $\mathrm{mm}$. 
Tabela 55-Valores de tensão de aderência obtidos no ensaio de arrancamento piloto e nos modelos teóricos para os exemplares com fibra metálica

\begin{tabular}{|c|c|c|c|c|c|}
\hline $\begin{array}{c}\text { Diâmetro } \\
\text { da barra }\end{array}$ & Modelo & $\begin{array}{c}\tau_{\max } \\
(\mathrm{MPa})\end{array}$ & $\begin{array}{c}\text { Variação } \\
(\%)\end{array}$ & $\delta_{\mathrm{u}}(\mathrm{mm})$ & $\begin{array}{c}\text { Variação } \\
(\%)\end{array}$ \\
\hline \multirow{5}{*}{10} & CF-B10 Media & 33,15 & - & 0,47 & - \\
\hline & Harajli, Hout e Jalkh (1995) & 22,86 & $-31,03$ & 0,95 & 101,17 \\
\hline & Huang, Engstron e Magnusson (1996) & 35,62 & 7,45 & 0,50 & 5,71 \\
\hline & Simplício (2008) & 57,73 & 74,14 & 0,33 & $-30,19$ \\
\hline & FIB Model Code 2010 (2012) & 22,24 & $-32,90$ & 1,00 & 111,42 \\
\hline \multirow{5}{*}{16} & CF-B16_Media & 39,80 & - & $\mathbf{0 , 6 3}$ & - \\
\hline & Harajli, Hout e Jalkh (1995) & 22,86 & $-42,55$ & 1,44 & 128,07 \\
\hline & Huang, Engstron e Magnusson (1996) & 35,62 & $-10,50$ & 0,50 & $-20,76$ \\
\hline & Simplício (2008) & 52,91 & 32,96 & 0,39 & $-38,47$ \\
\hline & FIB Model Code 2010 (2012) & 22,24 & $-44,11$ & 1,00 & 58,48 \\
\hline \multirow{5}{*}{20} & CF-B20_Media & 43,14 & - & 1,31 & - \\
\hline & Harajli, Hout e Jalkh (1995) & 22,86 & $-47,00$ & 2,01 & 53,87 \\
\hline & Huang, Engstron e Magnusson (1996) & 35,62 & $-17,44$ & 0,50 & $-61,80$ \\
\hline & Simplício (2008) & 54,27 & 25,80 & 0,48 & $-63,46$ \\
\hline & FIB Model Code 2010 (2012) & 22,24 & $-48,45$ & 1,00 & $-23,61$ \\
\hline
\end{tabular}

Fonte: Autoria própria

\subsubsection{ENSAIO DEFINITIVO}

O ensaio definitivo foi realizado para avaliar a influência do confinamento provocado pela inclusão de fibras e armadura transversal e aumento do cobrimento.

Entretanto, os modelos teóricos apresentados não possuem um equacionamento específico para considerar a influência da armadura transversal, sendo esta utilizada apenas para enquadrar o caso como "bem confinado" e, portanto, sujeito a ruptura por arrancamento. O único modelo a incluir a influência do estribo é o do FIB Model Code 2010 (2012) para a ruptura por fendilhamento, no qual a tensão de aderência sofre um acréscimo com a taxa de armadura (Ktr). Entretanto, o espécime que teve ruptura por fendilhamento foi o C-D8, sem armadura e, portanto, com Ktr=0.

Também, os modelos não consideram o efeito passivo do confinamento provocado pelo aumento no cobrimento de concreto, sendo apenas uma contribuição para a ruptura ocorrer por arrancamento.

Além disso, o ensaio definitivo foi feito com o diâmetro da barra fixo em $16 \mathrm{~mm}$ e, portanto, os modelos teóricos de Barbosa (2001) e Almeida Filho (2006) resultou igual para todos os casos.

Por fim, os modelos teóricos de Harajli, Hout e Jalkh (1995), Huang, Engstron e Magnusson (1996) e FIB Model Code 2010 (2012) propõem uma equação para a tensão máxima em função da resistência à compressão do concreto, que variou conforme os grupos 
de concretagem. Porém, os valores de deslizamento permaneceram iguais entre os modelos, pois ou era definido pelo modelo teórico como um valor constante ou em função da nervura da barra (igual para todos os casos).

A previsão dos modelos teóricos e sua comparação com o ensaio experimental foram divididas segundo a relação Dc/ $\phi$. A Figura 86 e Figura 87 apresentam os modelos para Dc/ $\phi=8$ para concreto sem fibras e com fibras, respectivamente, com os valores máximos de tensão de aderência e deslizamento na Tabela 56.

Figura 86- Tensão de aderência versus deslizamento comparativo entre o modelo teórico e experimental com Dc/ $\phi=8$ sem fibras: a) Sem estribo b) Com estribo

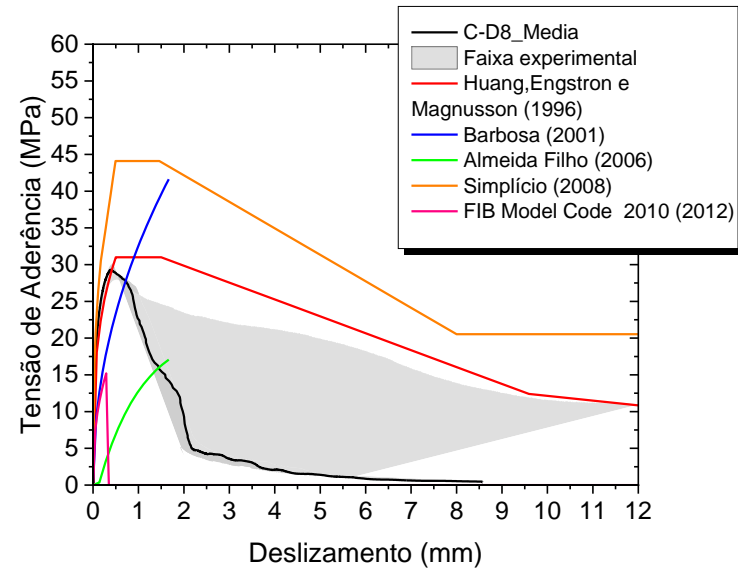

a)

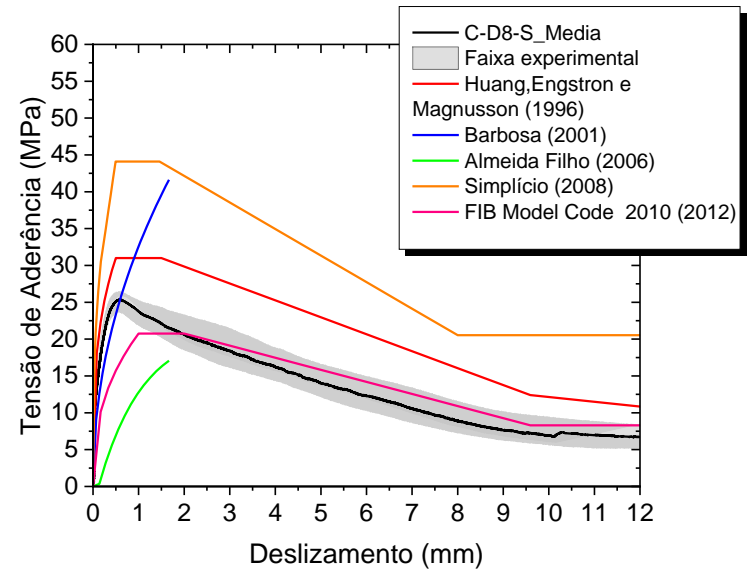

b)

Fonte: Autoria própria

Figura 87-Tensão de aderência versus deslizamento comparativo entre o modelo teórico e experimental com Dc $/ \phi=8$ com fibras: a) Sem estribo b) Com estribo

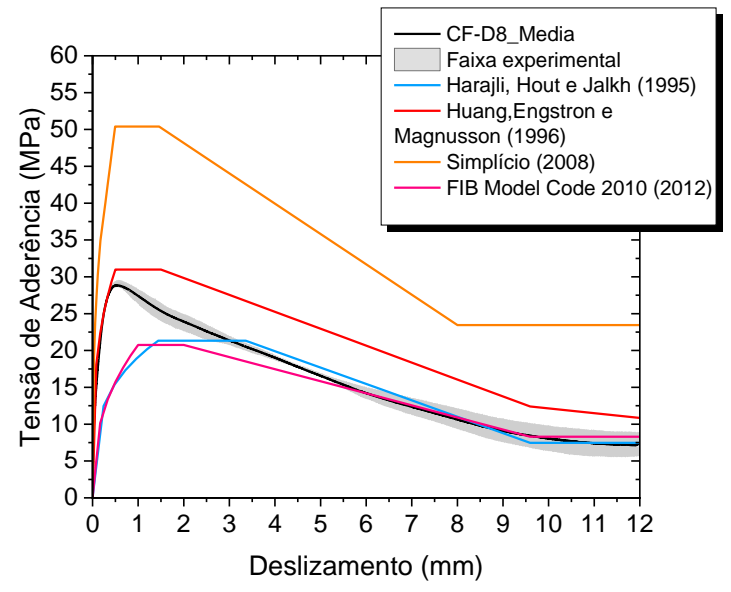

a)

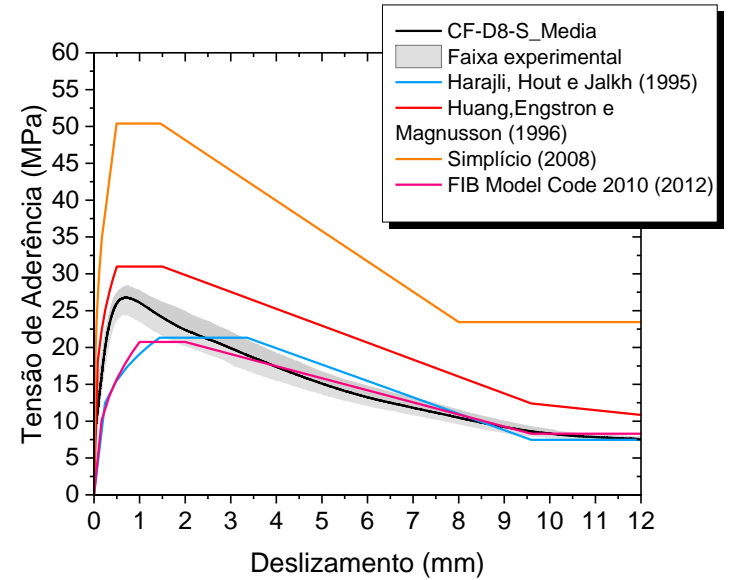

b)

Fonte: Autoria própria 
A resistência à compressão do concreto dos espécimes com $\mathrm{Dc} / \phi=8$ resultou em valores muito próximos $(68,89 \mathrm{MPa}$ para concreto sem fibras e $68,87 \mathrm{MPa}$ para concreto com fibras, conforme Tabela 32 e Tabela 33Tabela 49). Dessa forma, os valores propostos por Huang, Engstron e Magnusson (1996) e FIB Model Code 2010 (2012) foram iguais para todos os espécimes, exceto para o C-D8 devido à ruptura por fendilhamento, no qual foi utilizado o modelo específico do FIB Model Code 2010 (2012). Este modelo resultou em valores de tensão de aderência inferiores ao obtido experimentalmente (variação de 48,11\%) e, diante da falta de equação para cálculo do deslizamento último, este foi suposto como sendo igual ao experimental.

O modelo de Huang, Engstron e Magnusson (1996) não poderia ser aplicado para o espécime C-D8, por não apresentar um confinamento adequado, mas este foi calculado e incluído na proposta para análise dos seus resultados. Mesmo não sendo apropriado por não caracterizar uma ruptura por fendilhamento, o modelo foi o mais próximo do comportamento experimental no trecho pré-pico, com uma variação no cálculo da tensão de aderência de $5,82 \%$.

No modelo sem fibras e com armadura transversal (C-D8-S), o valor de tensão máxima obtido experimentalmente ficou entre o obtido por Huang, Engstron e Magnusson (1996) e pelo FIB Model Code (2012), mas o deslizamento último se aproximou mais do primeiro modelo.

Em todos os casos o modelo de Simplício (2008) superestimou o valor da tensão de aderência máxima e subestimou o valor do deslizamento último.

Nos espécimes sem fibras, os modelos de Almeida Filho (2006) e Barbosa (2001) resultaram em valores iguais, independentemente da inclusão de armadura transversal, por depender apenas do diâmetro da barra. Tanto a tensão de aderência máxima quanto o deslizamento último propostos por Barbosa (2001) resultaram em valores acima do experimental. O mesmo deslizamento último foi utilizado para o limite da curva de Almeida Filho (2006), resultando em uma tensão de aderência abaixo da experimental em ambos os casos (variação de 41,73\% para o C-D8 e 31,65\% para o C-D8-S).

A tensão de aderência máxima proposta por Harajli, Hout e Jalkh (1995), com valores muito próximos da proposta pelo FIB Model Code 2010 (2012), teve uma variação de 26,05\% no CF-D8 e 20,33\% no CF-D8-S, com o deslizamento correspondente muito acima do obtido experimentalmente, ultrapassando a variação de $100 \%$. 
Em ambos os casos com fibras (com e sem armadura transversal) o modelo de Huang, Engstron e Magnusson (1996) se aproximou mais do experimental, em especial no trecho prépico.

Tabela 56-Valores de tensão de aderência obtidos no ensaio de arrancamento definitivo e nos modelos teóricos para os exemplares com $\mathrm{D}_{\mathrm{c}} / \phi=8$

\begin{tabular}{|c|c|c|c|c|}
\hline Modelo & $\begin{array}{c}\tau_{\max } \\
(\mathrm{MPa})\end{array}$ & $\begin{array}{c}\text { Variação } \\
(\%)\end{array}$ & $\delta_{\mathrm{u}}(\mathrm{mm})$ & $\begin{array}{c}\text { Variação } \\
(\%)\end{array}$ \\
\hline C-D8_Media & 29,29 & - & $\mathbf{0 , 3 9}$ & - \\
\hline Huang, Engstron e Magnusson (1996) & 31,00 & 5,82 & 0,50 & 27,88 \\
\hline Barbosa (2001) & 41,63 & 42,10 & 1,67 & 326,14 \\
\hline Almeida Filho (2006) & 17,07 & $-41,73$ & 1,67 & 326,14 \\
\hline Simplício (2008) & 44,10 & 50,55 & 0,50 & 26,66 \\
\hline FIB Model Code 2010 (2012) & 15,20 & $-48,11$ & 0,39 & - \\
\hline C-D8-S_Media & 24,97 & - & $\mathbf{0 , 5 5}$ & - \\
\hline Huang, Engstron e Magnusson (1996) & 31,00 & 24,13 & 0,50 & $-9,75$ \\
\hline Barbosa (2001) & 41,63 & 66,69 & 1,67 & 200,76 \\
\hline Almeida Filho (2006) & 17,07 & $-31,65$ & 1,67 & 200,76 \\
\hline Simplício (2008) & 44,10 & 76,59 & 0,50 & $-10,61$ \\
\hline FIB Model Code 2010 (2012) & 20,75 & $-16,91$ & 1,00 & 80,51 \\
\hline CF-D8_Media & 28,84 & - & $\mathbf{0 , 5 3}$ & - \\
\hline Harajli, Hout e Jalkh (1995) & 21,33 & $-26,05$ & 1,44 & 171,53 \\
\hline Huang, Engstron e Magnusson (1996) & 30,99 & 7,45 & 0,50 & $-5,66$ \\
\hline Simplício (2008) & 50,40 & 74,74 & 0,50 & $-6,52$ \\
\hline FIB Model Code 2010 (2012) & 20,75 & $-28,07$ & 1,00 & 88,68 \\
\hline CF-D8-S_Media & 26,77 & - & 0,69 & - \\
\hline Harajli, Hout e Jalkh (1995) & 21,33 & $-20,33$ & 1,44 & 107,66 \\
\hline Huang, Engstron e Magnusson (1996) & 30,99 & 15,76 & 0,50 & $-27,85$ \\
\hline Simplício (2008) & 50,40 & 88,25 & 0,50 & $-28,50$ \\
\hline FIB Model Code 2010 (2012) & 20,75 & $-22,50$ & 1,00 & 44,30 \\
\hline
\end{tabular}

Fonte: Autoria própria

O mesmo procedimento foi adotado para $D c / \phi=9$, cujo resultado é apresentado na Figura 88 e Figura 89 para concreto sem fibras e com fibras, respectivamente, e que estão resumidos na Tabela 57.

Em todos os casos, o modelo de Simplício (2008) resultou em valores de tensão de aderência máxima superiores ao experimental e deslizamentos últimos inferiores.

Os modelos de Barbosa (2001) e Almeida Filho (2006), utilizados para os casos sem fibras, resultaram em valores de deslizamentos últimos acima do experimental, com valores de tensão de aderência máxima acima do experimental para o caso de Barbosa (2001) e abaixo para o modelo de Almeida Filho (2006). 
O modelo de Harajli, Hout e Jalkh (1995) teve um comportamento muito parecido com o do FIB Model Code 2010 (2012), com valores de tensão de aderência máximos abaixo do obtido experimentalmente.

Huang, Engstron e Magnusson (1996) propuseram um modelo que se adequou melhor aos resultados experimentais, tanto para os espécimes sem fibras quanto com fibras, com armadura transversal ou sem, com variações da tensão de aderência entre $0,48 \%$ e 7,97\% e do deslizamento último entre $24,24 \%$ e $62,06 \%$.

Figura 88- Tensão de aderência versus deslizamento comparativo entre o modelo teórico e experimental com $D_{c} / \phi=9$ sem fibras: a) Sem estribo b) Com estribo

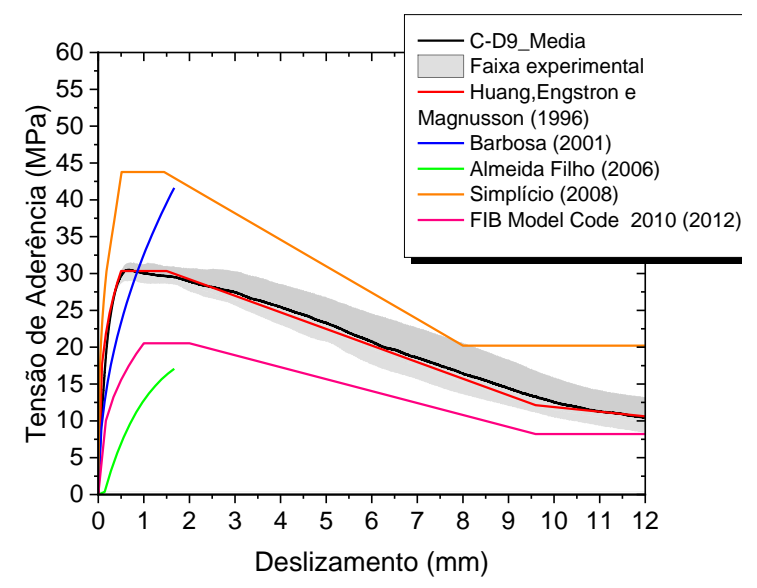

a)

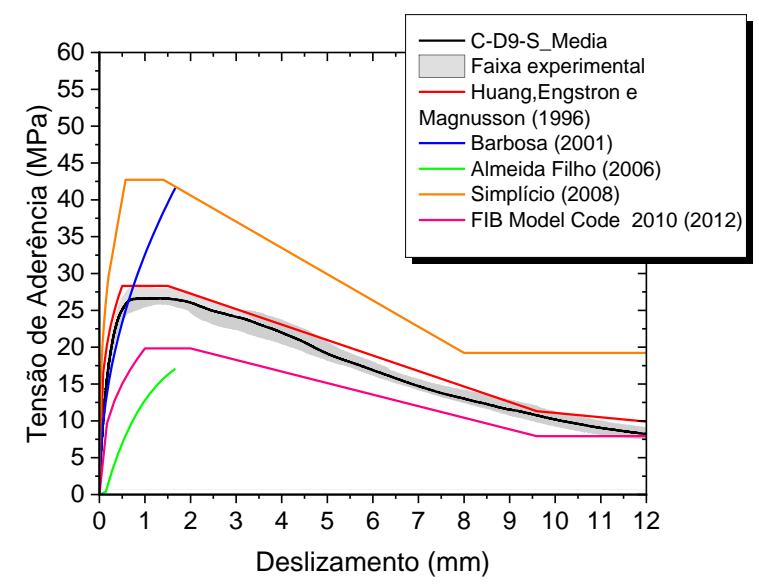

b)

Fonte: Autoria própria

Figura 89- Tensão de aderência versus deslizamento comparativo entre o modelo teórico e experimental com Dc/ $\phi=9$ com fibras: a) Sem estribo b) Com estribo

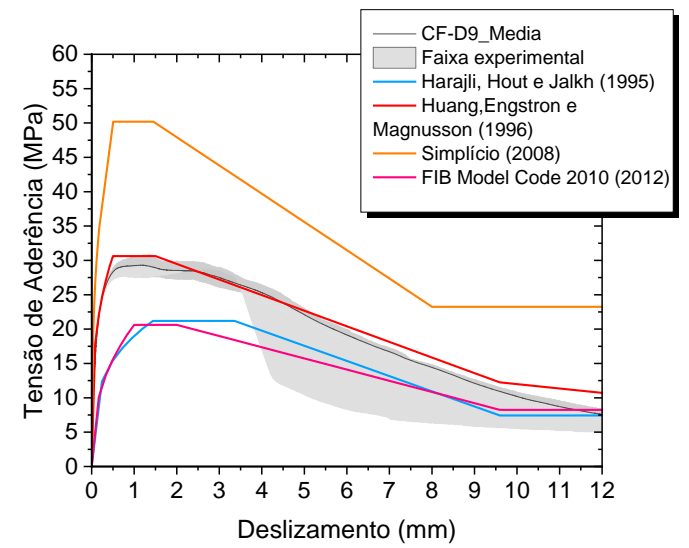

a)

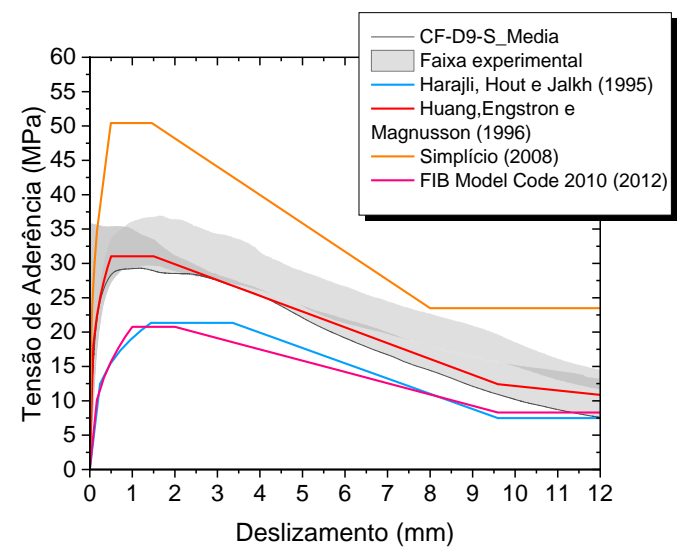

b)

Fonte: Autoria própria 
Tabela 57-Valores de tensão de aderência obtidos no ensaio de arrancamento definitivo e nos modelos teóricos para os exemplares com Dc/ $\phi=9$

\begin{tabular}{|c|c|c|c|c|}
\hline Modelo & $\begin{array}{c}\tau_{\max } \\
(\mathrm{MPa})\end{array}$ & $\begin{array}{l}\text { Variação } \\
(\%)\end{array}$ & $\delta_{\mathrm{u}}(\mathrm{mm})$ & $\begin{array}{c}\text { Variação } \\
(\%)\end{array}$ \\
\hline C-D9_Media & 30,49 & - & 0,66 & - \\
\hline $\begin{array}{l}\text { Huang, Engstron e Magnusson } \\
\text { (1996) }\end{array}$ & 30,35 & $-0,48$ & 0,50 & $-24,24$ \\
\hline Barbosa (2001) & 41,63 & 36,52 & 1,67 & 152,46 \\
\hline Almeida Filho (2006) & 17,07 & $-44,02$ & 1,67 & 152,46 \\
\hline Simplício (2008) & 43,77 & 43,56 & 0,51 & $-22,27$ \\
\hline FIB Model Code 2010 (2012) & 20,53 & $-32,67$ & 1,00 & 51,52 \\
\hline C-D9-S_Media & 26,66 & - & 1,32 & - \\
\hline $\begin{array}{c}\text { Huang, Engstron e Magnusson } \\
\text { (1996) }\end{array}$ & 28,31 & 6,19 & 0,50 & $-62,06$ \\
\hline Barbosa (2001) & 41,63 & 56,13 & 1,67 & 26,42 \\
\hline Almeida Filho (2006) & 17,07 & $-35,98$ & 1,67 & 26,42 \\
\hline Simplício (2008) & 42,72 & 60,24 & 0,57 & $-56,49$ \\
\hline FIB Model Code 2010 (2012) & 19,83 & $-25,62$ & 1,00 & $-24,13$ \\
\hline CF-D9_Media & 29,30 & - & 1,19 & - \\
\hline Harajli, Hout e Jalkh (1995) & 21,20 & $-27,65$ & 1,44 & 20,73 \\
\hline $\begin{array}{l}\text { Huang, Engstron e Magnusson } \\
\text { (1996) }\end{array}$ & 30,63 & 4,52 & 0,50 & $-58,05$ \\
\hline Simplício (2008) & 50,19 & 71,28 & 0,51 & $-57,61$ \\
\hline FIB Model Code 2010 (2012) & 20,62 & $-29,62$ & 1,00 & $-16,11$ \\
\hline CF-D9-S_Media & 33,73 & - & 0,96 & - \\
\hline Harajli, Hout e Jalkh (1995) & 21,34 & $-36,72$ & 1,44 & 49,75 \\
\hline $\begin{array}{l}\text { Huang, Engstron e Magnusson } \\
\text { (1996) }\end{array}$ & 31,04 & $-7,97$ & 0,50 & $-47,97$ \\
\hline Simplício (2008) & 50,43 & 49,50 & 0,49 & $-48,58$ \\
\hline FIB Model Code 2010 (2012) & 20,76 & $-38,44$ & 1,00 & 4,06 \\
\hline
\end{tabular}

Fonte: Autoria própria

Por fim, os modelos teóricos para Dc/ $\phi=15$ são apresentados na Figura 90 e Figura 91, para concreto sem fibras e com fibras, respectivamente, com os valores máximos resumidos na Tabela 58.Os resultados dos espécimes com $\mathrm{Dc} / \phi=15$ foram muito parecidos com o $\mathrm{Dc} / \phi=9$.

Novamente, o modelo de Huang, Engstron e Magnusson (1996) foi o que mais se aproximou do comportamento experimental, com variações da tensão de aderência entre $0,89 \%$ e $17,00 \%$ e do deslizamento último entre $24,59 \%$ e $65,66 \%$. 
Figura 90-Tensão de aderência versus deslizamento comparativo entre o modelo teórico e experimental com $\mathrm{D}_{\mathrm{c}} / \phi=15$ sem fibras: a) Sem estribo b) Com estribo

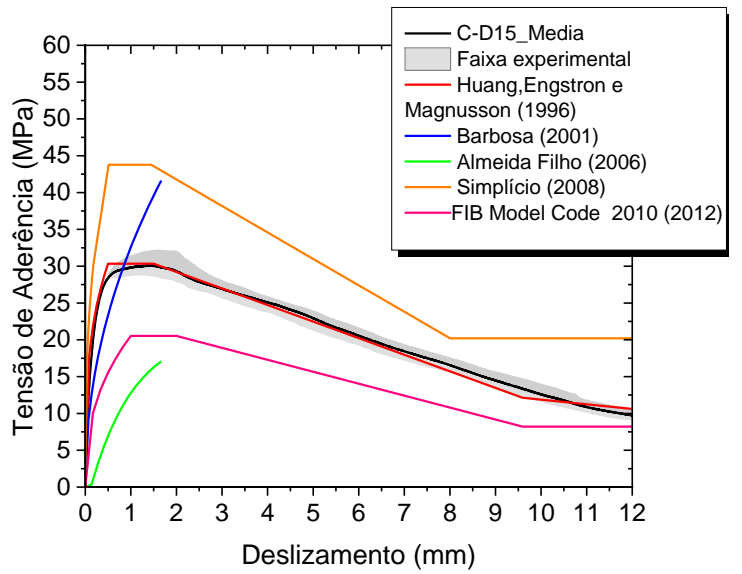

a)

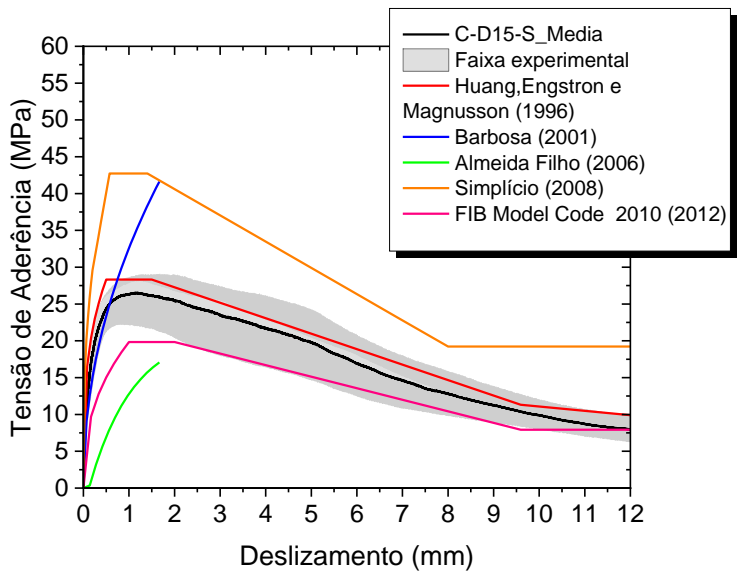

b)

Fonte: Autoria própria

Figura 91-Tensão de aderência versus deslizamento comparativo entre o modelo teórico e experimental com $\mathrm{Dc} / \phi=15$ com fibras: a) Sem estribo b) Com estribo

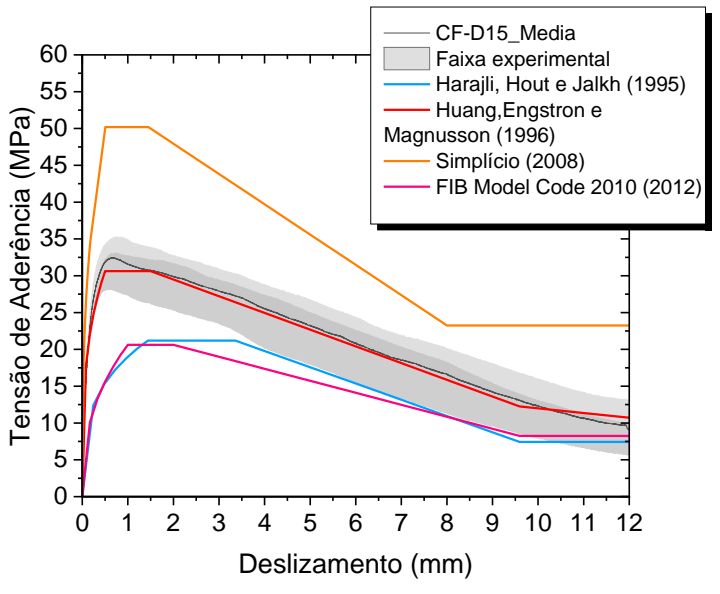

a)

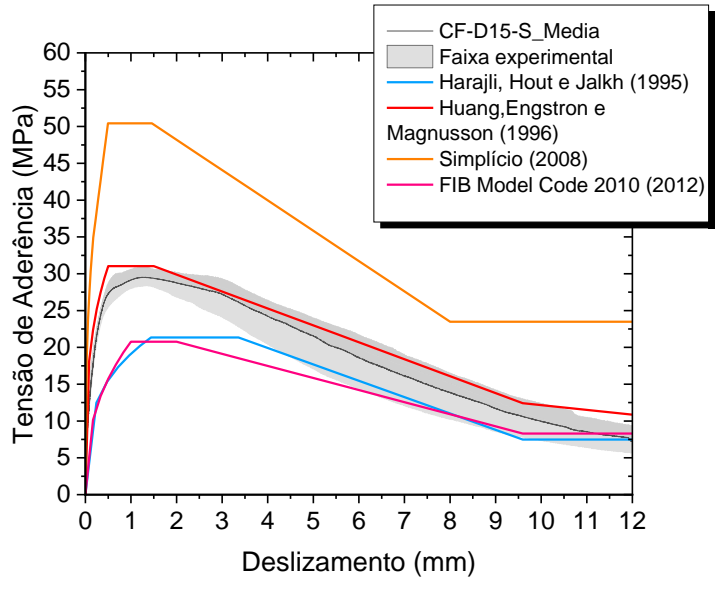

b)

Fonte: Autoria própria 
Tabela 58-Valores de tensão de aderência obtidos no ensaio de arrancamento definitivo e nos modelos teóricos para os exemplares com Dc/ $\phi=15$

\begin{tabular}{|c|c|c|c|c|}
\hline Modelo & $\begin{array}{c}\tau_{\max } \\
(\mathrm{MPa})\end{array}$ & $\begin{array}{c}\text { Variação } \\
(\%)\end{array}$ & $\delta_{\mathrm{u}}(\mathrm{mm})$ & $\begin{array}{l}\text { Variação } \\
(\%)\end{array}$ \\
\hline C-D15_Media & $\mathbf{3 0 , 0 8}$ & - & 1,46 & - \\
\hline $\begin{array}{l}\text { Huang, Engstron e Magnusson } \\
(1996)\end{array}$ & 30,35 & 0,89 & 0,50 & $-65,66$ \\
\hline Barbosa (2001) & 41,63 & 38,39 & 1,67 & 14,44 \\
\hline Almeida Filho (2006) & 17,07 & $-43,25$ & 1,67 & 14,44 \\
\hline Simplício (2008) & 43,77 & 45,53 & 0,51 & $-64,77$ \\
\hline FIB Model Code 2010 (2012) & 20,53 & $-31,75$ & 1,00 & $-31,32$ \\
\hline C-D15-S_Media & 26,53 & - & 1,20 & - \\
\hline $\begin{array}{c}\text { Huang, Engstron e Magnusson } \\
\text { (1996) }\end{array}$ & 28,31 & 6,72 & 0,50 & $-58,23$ \\
\hline Barbosa (2001) & 41,63 & 56,91 & 1,67 & 39,20 \\
\hline Almeida Filho (2006) & 17,07 & $-35,66$ & 1,67 & 39,20 \\
\hline Simplício (2008) & 42,72 & 61,04 & 0,57 & $-52,09$ \\
\hline FIB Model Code 2010 (2012) & 19,83 & $-25,25$ & 1,00 & $-16,46$ \\
\hline CF-D15_Media & 32,45 & - & 0,66 & - \\
\hline Harajli, Hout e Jalkh (1995) & 21,20 & $-34,67$ & 1,44 & 117,06 \\
\hline $\begin{array}{l}\text { Huang, Engstron e Magnusson } \\
\text { (1996) }\end{array}$ & 30,63 & $-5,63$ & 0,50 & $-24,59$ \\
\hline Simplício (2008) & 50,19 & 54,65 & 0,51 & $-23,78$ \\
\hline FIB Model Code 2010 (2012) & 20,62 & $-36,45$ & 1,00 & 50,83 \\
\hline CF-D15-S_Media & 26,53 & - & 1,26 & - \\
\hline Harajli, Hout e Jalkh (1995) & 21,34 & $-19,54$ & 1,44 & 14,21 \\
\hline $\begin{array}{l}\text { Huang, Engstron e Magnusson } \\
\text { (1996) }\end{array}$ & 31,04 & 17,00 & 0,50 & $-60,32$ \\
\hline Simplício (2008) & 50,43 & 90,07 & 0,49 & $-60,78$ \\
\hline FIB Model Code 2010 (2012) & 20,76 & $-21,74$ & 1,00 & $-20,63$ \\
\hline
\end{tabular}

Fonte: Autoria própria 


\section{CONSIDERAÇÕES FINAIS}

Neste capítulo, são apresentados os principais apontamentos obtidos com o estudo, tanto nas características do concreto quanto nos resultados dos ensaios de arrancamento piloto e definitivo, a fim de obter conclusões sobre o efeito do confinamento promovido pelas fibras metálicas, armadura transversal e cobrimento do concreto, nas condições utilizadas.

Além disso, também são apresentadas propostas para trabalhos futuros, envolvendo parâmetros que não foram avaliados nesta pesquisa.

\subsection{CARACTERÍSTICAS DO CONCRETO}

Foram realizados ensaios à compressão, à tração por compressão diametral e módulo de elasticidade dinâmico aos 28 dias para corpos-de-prova sem fibras e com fibras à taxa de $1 \%$ em volume, apresentando os seguintes resultados:

- Resistência à compressão média de 67,15 MPa para o concreto sem fibras e 69,60 MPa para o concreto com fibras, indicando um acréscimo de 3,65\%;

- Resistência à tração pura (convertida a partir do ensaio por compressão diametral pelo fator de 0,85) de 4,02 $\mathrm{MPa}$ e 4,71 $\mathrm{MPa}$, para concreto sem fibras e com fibras, respectivamente, correspondendo a um incremento de $17,18 \%$;

- Módulo de elasticidade estático, obtido pela equação de Gidrão (2015) a partir do módulo de elasticidade dinâmico, de 41,16 GPa nos modelos sem fibras e 41,21 GPa nos modelos com fibras;

- As fibras agiram como uma ponte de transferência de tensões entre as fissuras, as "costurando", impactando diretamente na resistência à tração e sem influências significativas na resistência à compressão e módulo de elasticidade.

\subsection{ENSAIO DE ARRANCAMENTO}

O ensaio de arrancamento seguiu a proposta de Rehm e Eligehausen (1979), contendo uma barra de diâmetro $\phi$ inserida em um corpo-de-prova cilíndrico de concreto de diâmetro de $10 \phi$, com um trecho central aderente de comprimento $3 \phi$, intercalado por dois trechos sem aderência de comprimento $5 \phi$. 
Os ensaios forneceram curvas de tensão de aderência versus deslizamento, sendo analisada a influência do confinamento promovido por três parâmetros: fibras metálicas, armadura transversal e cobrimento de concreto. As curvas experimentais também foram comparadas com os modelos teóricos de autores da literatura e as resistências de aderência foram comparadas com os valores normativos, conforme apresentado a seguir.

\subsubsection{RESULTADOS EXPERIMENTAIS}

A partir da geometria proposta, com barras de 10,16 e $20 \mathrm{~mm}$ e fibras a taxa de $1 \%$, e condições adotadas no ensaio piloto, foi possível concluir que:

- O aumento do diâmetro da armadura longitudinal promoveu um aumento na tensão de aderência máxima e no deslizamento último (exceto na mudança da ruptura de arrancamento para fendilhamento), tanto nos modelos com fibras quanto nos sem;

- Houve um aumento na tensão de aderência ao incluir fibras nos modelos com barra de 16 e $20 \mathrm{~mm}$, ocorrendo um pequeno decréscimo no modelo com barra de $10 \mathrm{~mm}$ (-5,73\%);

- O deslizamento último aumentou consideravelmente ao adicionar as fibras metálicas em todos os casos, sendo mais pronunciado no modelo de barra de $20 \mathrm{~mm}$, pois o modo de ruptura passou a ser arrancamento, deixando de haver um pico no início do carregamento.

Já a geometria adotada no ensaio definitivo, com diâmetro da barra de $16 \mathrm{~mm}$, variação na relação entre o diâmetro do corpo-de-prova (Dc) e o diâmetro da barra $(\phi)$ de 8,9 e 15, inclusão de fibra e armadura transversal, possibilitou inferir as seguintes conclusões:

- O aumento do cobrimento de concreto de $\mathrm{Dc} / \phi=8$ para $\mathrm{Dc} / \phi=9$ foi suficiente para mudar o modo de ruptura de fendilhamento para arrancamento, mesmo para os modelos de concreto sem fibras metálicas e sem a armadura transversal;

- A partir do momento em que foi atingido o modo de ruptura de arrancamento (nos modelos com Dc/ $\phi=9$ ), a inclusão da armadura transversal e/ou o aumento do cobrimento de concreto para $\mathrm{Dc} / \phi=15$ não foram tão eficazes como a fibra metálica no comportamento da aderência;

- A inclusão de fibra metálica foi o mecanismo de confinamento mais eficiente, possibilitando o aumento na tensão de aderência máxima e/ou alterando o modo de ruptura de fendilhamento para arrancamento. 


\subsubsection{PRESCRIÇÕES NORMATIVAS}

Comparando-se os valores experimentais da resistência de aderência (referente a um deslizamento de $0,1 \mathrm{~mm}$ ) e os prescritos pelas referências normativas ACI 318:2014, ABNT NBR 6118:2014 e FIB Model Code 2010 (2012), pode-se concluir o seguinte:

- Todas as prescrições normativas estão a favor da segurança, com uma margem de tolerância grande para a resistência de aderência;

- O ACI 318:2014 demonstrou ser o mais conservador, representando valores entre $26,89 \%$ e $40,18 \%$ do valor experimental para os dados do ensaio piloto e entre $32,70 \%$ e $63,73 \%$ dos valores do ensaio definitivo.

\subsubsection{MODELOS TEÓRICOS}

Por fim, comparando-se os valores de tensão de aderência máxima $\left(\tau_{\max }\right)$ e deslizamento último $\left(\delta_{\mathrm{u}}\right)$ experimentais com os modelos teóricos verificou-se que:

- O modelo de Simplício (2008) resultou em $\tau_{\max }$ superiores aos experimentais em todos os casos, com respectivos $\delta_{\mathrm{u}}$ menores (exceto para o espécime C-B20 e C-D8);

- O modelo de Barbosa (2001) resultou em $\tau_{\max }$ e $\delta_{\mathrm{u}}$ acima dos experimentais;

- O modelo de Almeida Filho (2006) forneceu $\tau_{\max }$ inferiores e $\delta_{u}$ superiores aos experimentais;

- A equação proposta pelo FIB Model Code 2010 (2012) para $\tau_{\max }$ sob ruptura por fendilhamento resultou em valores inferiores ao obtido experimentalmente (modelos C-B20 e C-D8). O equacionamento para a ruptura por arrancamento forneceu valores de $\tau_{\max }$ abaixo do obtido experimentalmente e $\delta_{\mathrm{u}}$, no valor de $1,00 \mathrm{~mm}$, acima do experimental (exceto para CFB20, C-D9-S, CF-D9, C-D15, C-D15-S e CF-D15-S);

- O modelo de Harajli, Hout e Jalkh (1995) é semelhante ao do FIB Model Code 2010 (2012), resultando em $\tau_{\max }$ inferiores ao experimental e $\delta_{\mathrm{u}}$ superiores ao experimental;

- Em todos os casos, o modelo teórico que mais se aproximou do experimental foi o de Huang, Engstron e Magnusson (1996), em especial no trecho pré-pico. 


\subsection{SUGESTÃO PARA TRABALHOS FUTUROS}

A variação dos parâmetros estudados foi limitada devido ao custo com a execução dos ensaios e tempo para conclusão da pesquisa. Dessa forma, alguns trabalhos futuros podem ser realizados para obter novas conclusões a respeito da influência do confinamento na aderência entre o concreto e a armadura longitudinal:

- Moldagem de corpos-de-prova com concreto com resistência à compressão mais elevada, entre 90 e $100 \mathrm{MPa}$;

- Utilização de outras porcentagens de fibra, inclusive misturando dois tipos diferentes;

- Variação na taxa de armadura transversal, diminuindo o espaçamento, aumentando o diâmetro da barra e/ou o cobrimento da mesma;

- Repetição dos parâmetros analisados com outro tipo de ensaio de arrancamento, entre eles o clássico proposto pela RILEM-CEB-FIP (1973), com apenas um trecho superior não aderente;

- Execução de simulação numérica do ensaio de arrancamento e comparação com os resultados experimentais, a fim de validar um modelo numérico e expandir o estudo para outros valores dos parâmetros analisados.

É importante salientar que a dificuldade em executar a simulação numérica encontrase em ter que obter previamente a forma da curva tensão de aderência versus deslizamento para determinar os parâmetros de entrada do modelo numérico. Dessa forma, só é possível validar o modelo numérico e fazer uma análise paramétrica, a fim de extrapolar os parâmetros, dentro de certos limites. 


\title{
REFERÊNCIAS
}

\author{
AEC WEB. Disponível em: \\ $\langle$ https://www.aecweb.com.br/cls/catalogos/grace/adva_cast525.pdf $>$. Acesso em: 10 mar. \\ 2018.
}

ALMEIDA FILHO, F. M. Contribuição ao estudo da aderência entre barras de aço e concreto auto-adensáveis. 2006. Tese de Doutorado - Escola de Engenharia de São Carlos, Universidade de São Paulo, São Carlos, 2006.

AMERICAN CONCRETE INSTITUTE. ACI 544.1R-96 Reported by ACI COMMITTE 544. State-of-the-art report on fiber reinforced concrete. Farmington Hills, 1996

AMERICAN CONCRETE INSTITUTE. ACI 408R-03 Reported by ACI COMMITTE 408. Bond and development of straight reinforcing bars in tension. Farmington Hills, 2003.

AMERICAN CONCRETE INSTITUTE. ACI 318:2014 Reported by ACI COMMITTE 318. Building Code Requirements for Structural Concrete. Farmington Hills, 2014.

COMITÉ MERCOSUR DE NORMALIZACION. NM 67: Concreto - Determinação da consistência pelo abatimento do tronco de cone, 1996

ASSOCIAÇÃO BRASILEIRA DE NORMAS TÉCNICAS. NBR 6023: Informação e documentação - Referências -Elaboração. Rio de Janeiro, 2002.

ASSOCIAÇÃO BRASILEIRA DE NORMAS TÉCNICAS. NBR 10520: Informação e documentação - Citações em Documentos -Apresentação. Rio de Janeiro, 2002.

ASSOCIAÇÃO BRASILEIRA DE NORMAS TÉCNICAS. NBR 7222: Concreto e argamassa-Determinação da resistência à tração por compressão diametral de corpos-de-prova cilíndricos. Rio de Janeiro, 2011.

ASSOCIAÇÃO BRASILEIRA DE NORMAS TÉCNICAS. NBR 15530: Fibras de aço para concreto -Especificação. Rio de Janeiro, 2007.

ASSOCIAÇÃO BRASILEIRA DE NORMAS TÉCNICAS. NBR 7480: Aço destinado a armaduras para estruturas de concreto armado-Especificação. Rio de Janeiro, 2007.

ASSOCIAÇÃO BRASILEIRA DE NORMAS TÉCNICAS. NBR ISO 6892-1: Materiais metálicos - Ensaio de Tração Parte 1: Método de ensaio à temperatura ambiente. Rio de Janeiro, 2013.

ASSOCIAÇÃO BRASILEIRA DE NORMAS TÉCNICAS. NBR 5739: Concreto -Ensaio de compressão de corpos-de-prova cilíndricos. Rio de Janeiro, 2007.

ASSOCIAÇÃO BRASILEIRA DE NORMAS TÉCNICAS. NBR 6118: Projeto de estruturas de concreto - Procedimentos. Rio de janeiro, 2014. 
BALAGURU, P. N. e SHAH, S. P. Fiber reinforced cement composites. USA. McGrawHill, 1992.

BARBOSA, M. T. G. Avaliação do comportamento da aderência em concretos de diferentes classes de resistência. 2001. Tese de Doutorado, COPPE - Universidade Federal do Rio de Janeiro, Rio de Janeiro, 2001.

BARBOSA, M.T.G; FILHO, S. S. Investigation of Bond Stress in Pull Out Specimens with High Strength Concrete. Global Journal of Researches in Engineering Civil And Structural Engineering, v. 13, n. 3, p. 54-64, 2013.

CARRAZEDO, R. Mecanismos de confinamento e suas implicações no reforço de pilares de concreto por encamisamento com compósito de fibras de carbono. 2002. Dissertação (Mestrado) - Escola de Engenharia de São Carlos, Universidade de São Paulo, São Carlos, 2002.

CASTRO, C.M. Concreto de alto desempenho: estudo da aderência com a armadura sob ações repetidas. 2002. Dissertação (Mestrado) - Escola de Engenharia de São Carlos, Universidade de São Paulo, São Carlos, 2002.

COMITÉ EURO-INTERNATIONAL DU BÉTON. Bulletin d'Information no. 65: FIB Model Code 2010. Paris, 2012.

CORREIA, V. C. Estudo da influência do uso de fibras de aço e de estribos no comportamento da ancoragem de barras. 2012. Dissertação (Mestrado) - Escola de Engenharia de São Carlos, Universidade de São Paulo, São Carlos, 2012.

COUTO, I.A. Análise teórica e experimental do comportamento da aderência entre o concreto e barras de fibra de vidro impregnada por polímero. 2007. Dissertação (Mestrado) - Escola de Engenharia de São Carlos, Universidade de São Paulo, São Carlos, 2007.

DANIN, A. R. Estudo da aderência entre concreto e armadura: Análise da influência das fibras de aço. 2010. Dissertação (Mestrado) - Universidade Federal de Goiás, Goiânia, 2010.

Dow Corning. Disponível em:

<www.silicon.ind.br/wp-content/uploads/2014/10/FISPQ-DOWNCORNING.pdf>. Acesso em: 10 mar.2018

DUMÊT, T. B. Aderência de cordoalhas em concretos de alta resistência com e sem fibras de aço. 2003. Tese de Doutorado - Escola de Engenharia de São Carlos, Universidade de São Paulo, São Carlos, 2003.

ELIGEHAUSEN, R; POPOV, E. P.; BERTERO, V. V. Local bond stress-slip relationships of deformed bars under generalized excitations. Report No. UCB/EERC-83/23, Earthquake Engineering Research Center, College of Engineering, University of California, Berkeley, California, 1983.

EZELDIN, A. S.; BALAGURU, P. N. Bond Behavior of Normal and High-Strength Fiber Reinforced-Concrete. ACI Materials Journal, v. 86, n. 5, p. 515-524, Sep-Oct, 1989. 
EZELDIN, A S. e BALAGURU, P. N. Normal and high-strength fiber reinforced concrete under compression. Journal of materials in civil engineering, v. 4, n. 4, p.415-429, 1992

FERNANDES, R. M. Influência das ações repetidas na aderência aço-concreto. 2000. Dissertação (Mestrado) - Escola de Engenharia de São Carlos, Universidade de São Paulo, São Carlos, 2000.

FIGUEIREDO, A. D. Concreto com fibras de aço. Boletim Técnico BT/PCC/260 do Departamento de Engenharia de Construção Civil, Escola Politécnica da Universidade de São Paulo, São Paulo, 2000.

FUSCO, P.B. Técnica de armar as estruturas de concreto. São Paulo: Pini, 1995.

GIDRÃO, G.M.S. Propriedades dinâmicas do concreto e relações com sua microestrutura. Dissertação (Mestrado em Engenharia de Estruturas) - Escola de Engenharia de São Carlos, Universidade de São Paulo, São Carlos. 2015.

HARAJLI, M. H.; HOUT, M.; JALKH, W. Local bond stress-slip behavior of reinforced bars embedded in plain and fiber concrete. ACI Materials Journal, v.92, n.4, p.343-354, 1995.

HARAJLI, M. H.; SALLOUKH, K. A. Effect of fibers on development/splice strength of reinforcing bars in tension. ACI Materials Journal, v. 94, n. 4, p. 317-324, Jul-Aug. 1997.

HELENE, P. R. L.; TERZIAN, P. Manual de dosagem e controle do concreto. São Paulo: PINI; Brasília: SENAI, 1992. 349 p.

HOSSEINI, S. J. A.; RAHMAN, A. B. A. Effects of spiral confinement to the bond behavior of deformed reinforcement bars subjected to axial tension. Engineering Structures, v. 112, p. 1-13, Apr. 2016.

HUANG, Z.; ENGSTRON, B.; MAGNUSSON, J. Experimental investigation of the bond and anchorage behavior of deformed bars in high strength concrete. In: $4^{\mathbf{0}}$ International Symposium on Utilization of High-Strength/High Performance Concrete, Paris, v.3, p. 29-31, 1996.

LEITE, A. M. Avaliação do uso da macrofibra polimérica na composição de concreto para fins estruturais. 2018. Dissertação (Mestrado em Engenharia Civil (Estruturas)) Escola de Engenharia de São Carlos, Universidade de São Paulo, São Carlos, 2018.

LEONHARDT, F.; MÖNNIG, E. Construções de concreto: princípios básicos do dimensionamento de estruturas de concreto armado. v.1. Rio de Janeiro: Interciência, 1977.

LEONHARDT, F.; MÖNNIG, E. Construções de concreto: princípios básicos sobre a armação de estruturas de concreto armado. v.3. Rio de Janeiro: Interciência, 1977.

LIN, A.; OSTERTAG, C.P. Multi-Scale Pull-Out Resistance of Steel Reinforcing Bar Embedded in Hybrid Fiber Reinforced Concrete (HYFRC). IOP Conference Series: Materials Science and Engineering, n. 246, 2017. 
LIMA JÚNIOR, H. C; GIONGO, J.S. Modelo teórico para o concreto reforçado com fibras de aço submetido à compressão. Revista IBRACON, São Paulo, v. 10, n.. 30, p. 34-45, jul-set. 2002.

LIMA JÚNIOR, H. C. Avaliação da ductilidade de pilares de concreto armado,submetidos à flexo-compressão reta com e sem adição de fibras metálicas. Tese de doutorado - Escola de Engenharia de São Carlos, Universidade de São Paulo,São Carlos, 2003.

MANDER, J.B.; PRIETSLEY, M.J.N ; PARK, R.J.T. (1988-a). Observed stressstrain behaviour of confined concrete. Journal of Structural Engineering, v. 114, p. 1827-1849.

MANDER, J.B.; PRIETSLEY, M.J.N ; PARK, R.J.T. (1988-b). Theoretical stress strain model for confined concrete. Journal of Structural Engineering, v.114, p.1804-1827.

MEHTA, P.K.; MONTEIRO, P. J. M. Concreto: Estrutura, Propriedades e Materiais.3. ed. New York: McGraw-Hil, 2008.

RAO, G. A. et al. Studies on the pull-out strength of ribbed bars in high-strength concrete. In: 6th International Conference on Fracture Mechanics of Concrete and Concrete Structures, Catania, Italy, p.775-780, Jun 17-22. 2007

REHM, G.; ELIGEHAUSEN, R. Bond of Ribbed Bars under Repeated Loads. German Institute for Reinforced Concrete, Berlin, 1979.

RILEM-CEB-FIP. Bond test for reinforcing steel. 1. Beam test (7-II-28 D). 2. Pull-out Test (7-II-128). Tentative Recommendations. RILEM Journal Materials and Structures, v.6, n.32, p.96-105, 1973

ROSALES, Y. M. Análise Numérico -Experimental do Comportamento da Aderência Aço - Concreto. 2016. Dissertação (Mestrado) - Departamento de Engenharia Civil e Ambiental, Universidade de Brasília, Brasília, 2016.

SANTANA, I. V. Estudo da influência das fibras metálicas no comportamento da aderência entre barras de aço e concretos de diferentes classes de resistência. Dissertação (Mestrado) - Escola de Engenharia de São Carlos, Universidade de São Paulo, São Carlos, 2014.

SILVA, E. D. Desenvolvimento de concreto de alta resistência reforçado com fibras para evitar a ruptura da aderência por fendilhamento. Pesquisa do programa institucional de bolsas de Iniciação científica - PIBIC. São Carlos, 2017

SIMPLÍCIO, M. A. S. Estudo sobre a aderência entre barras de aço e concreto reforçado com fibras. 2008. Tese de Doutorado-Universidade Federal de Pernambuco, Recife, 2008.

ZUO, J.; DARWIN, D. Bond Strength of High Relative Rib Area Reinforcing Bars. SM Report No. 46, University of Kansas Center for Research, Lawrence, Kans., 1998.

ZUO, J.; DARWIN, D. Splice Strength of Conventional and High Relative Rib Area Bars in Normal and High-Strength Concrete. ACI Structural Journal, v. 97, n. 4, p. 630-641, JulyAug, 2000. 


\section{APÊNDICE A-CURVAS DE TENSÃO DE ADERÊNCIA VERSUS DESLIZAMENTO}

\section{ENSAIO PILOTO}

Figura 92- Tensão de aderência versus deslizamento para cada espécime (e sua média) do ensaio piloto com diâmetro de $10 \mathrm{~mm}$ : a) Sem fibra b) Com fibra

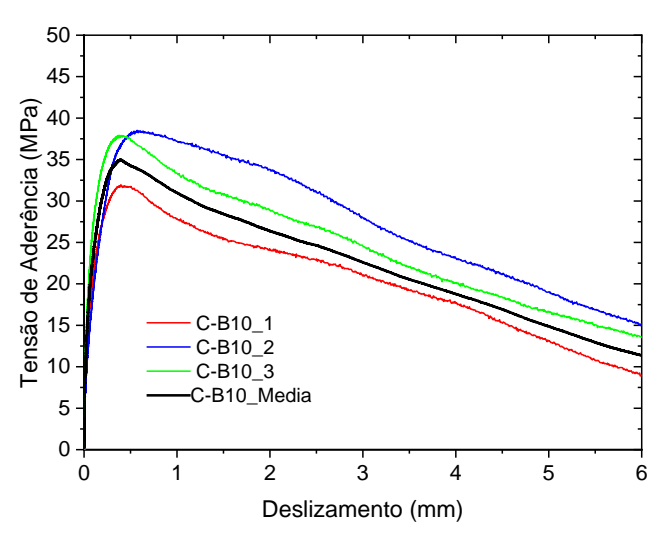

a)

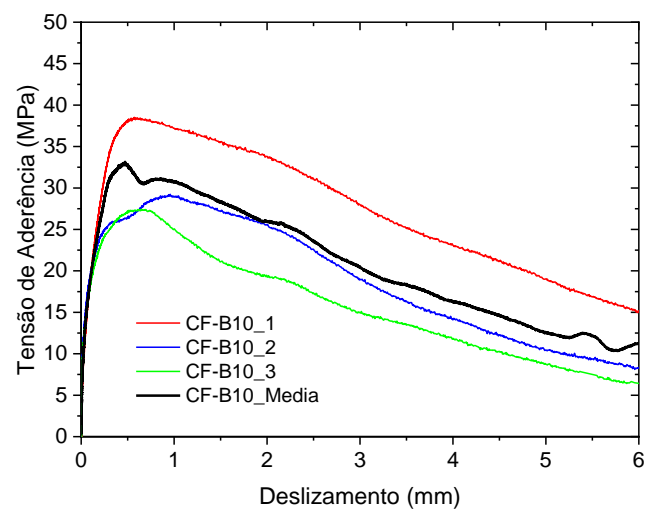

b)

Fonte: Autoria própria

Figura 93-Tensão de aderência versus deslizamento para cada espécime (e sua média) do ensaio piloto com diâmetro de $16 \mathrm{~mm}$ : a) Sem fibra b) Com fibra

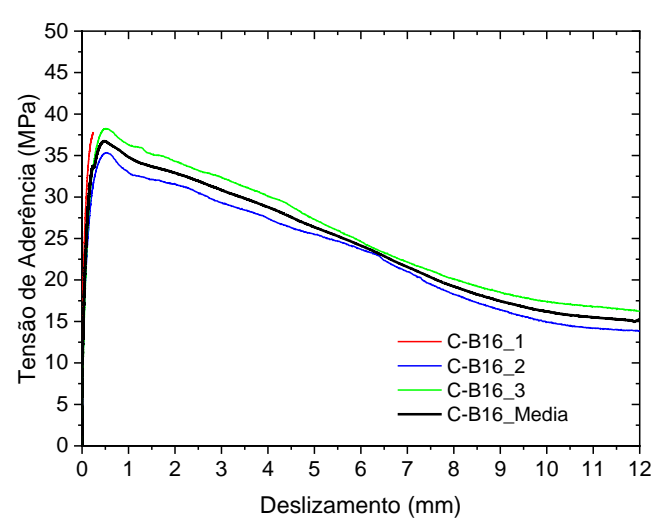

a)

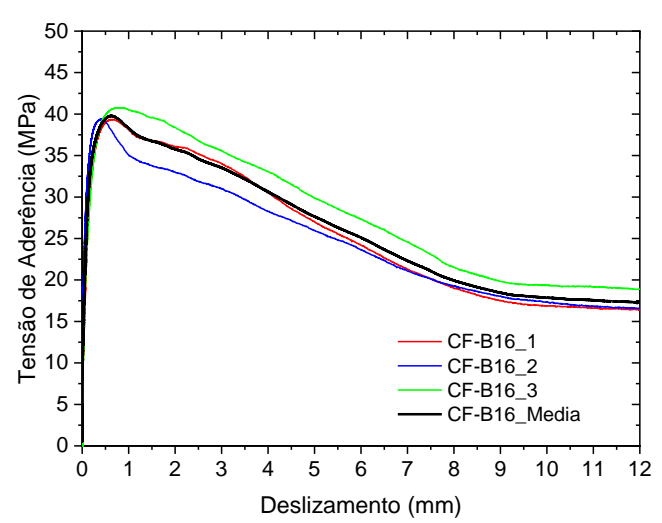

b)

Fonte: Autoria própria 
Figura 94-Tensão de aderência versus deslizamento para cada espécime (e sua média) do ensaio piloto com diâmetro de $20 \mathrm{~mm}$ : a) Sem fibra b) Com fibra

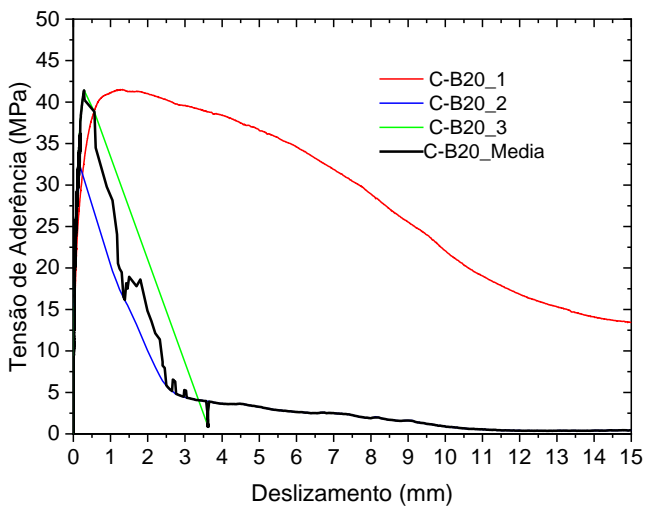

a)

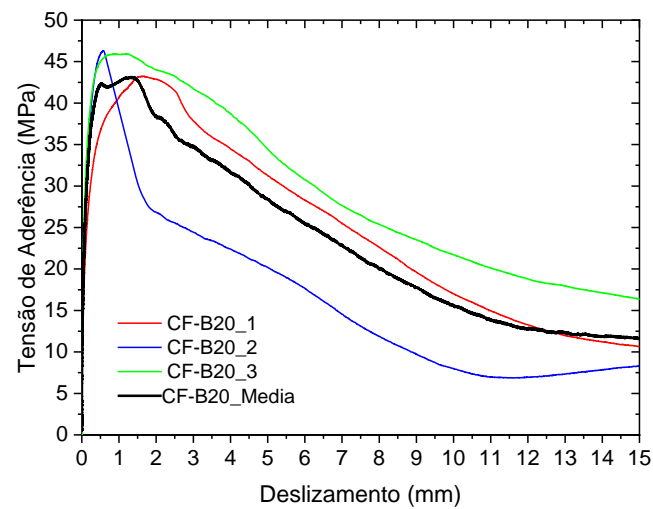

b)

Fonte: Autoria própria

\section{ENSAIO DEFINITIVO}

Figura 95-Tensão de aderência versus deslizamento para cada espécime (e sua média) do ensaio definitivo com $\mathrm{Dc} / \phi=8$ sem fibras: a) Sem estribo b) Com estribo

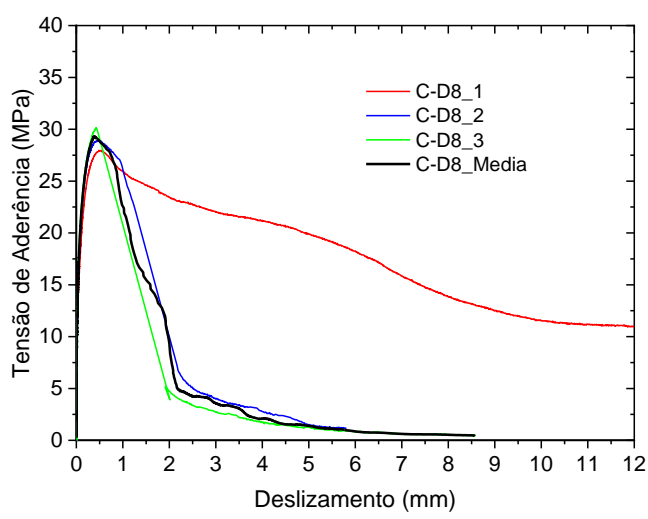

a)

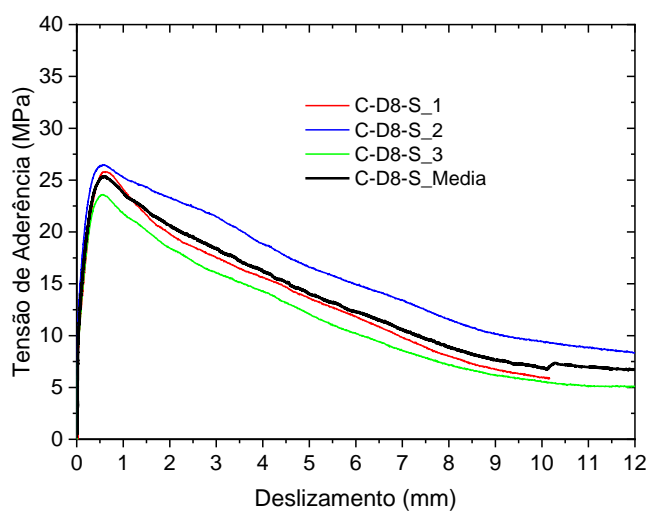

b)

Fonte: Autoria própria 
Figura 96-Tensão de aderência versus deslizamento para cada espécime (e sua média) com Dc/ $\phi=8$ com fibras: a) Sem estribo b) Com estribo

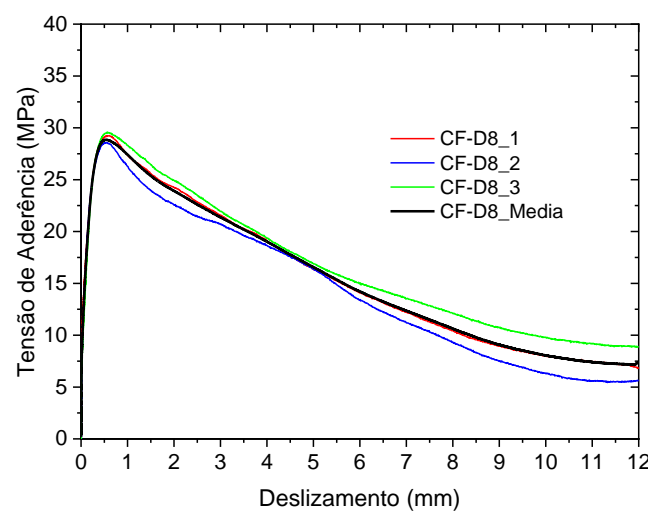

a)

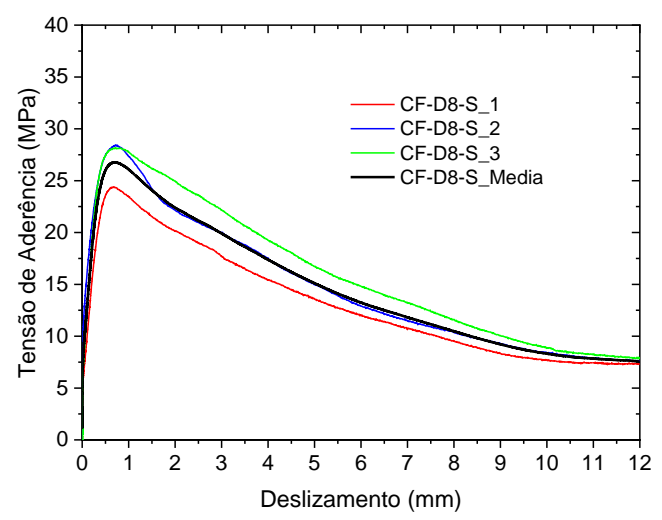

b)

Fonte: Autoria própria

Figura 97-Tensão de aderência versus deslizamento para cada espécime (e sua média) do ensaio definitivo com $\mathrm{Dc} / \phi=9$ sem fibras: a) Sem estribo b) Com estribo

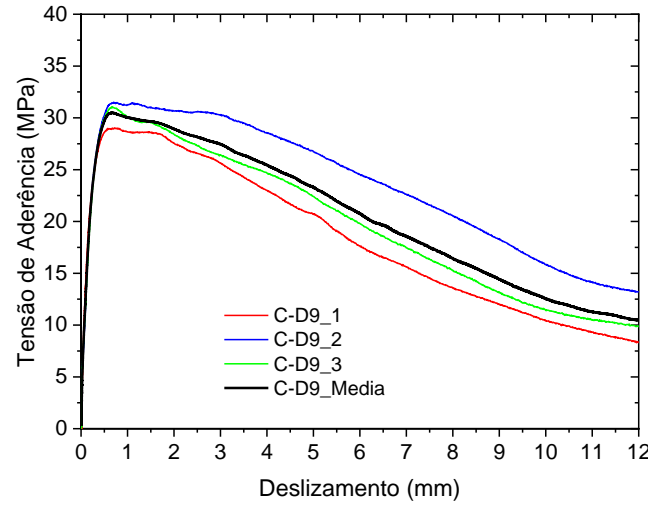

a)

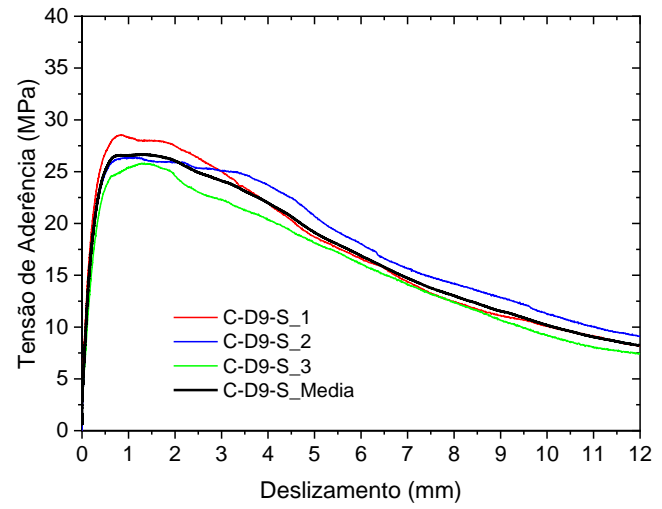

b)

Fonte: Autoria própria 
Figura 98-Tensão de aderência versus deslizamento para cada espécime (e sua média) do ensaio definitivo com $\mathrm{Dc} / \phi=9$ com fibras: a) Sem estribo b) Com estribo

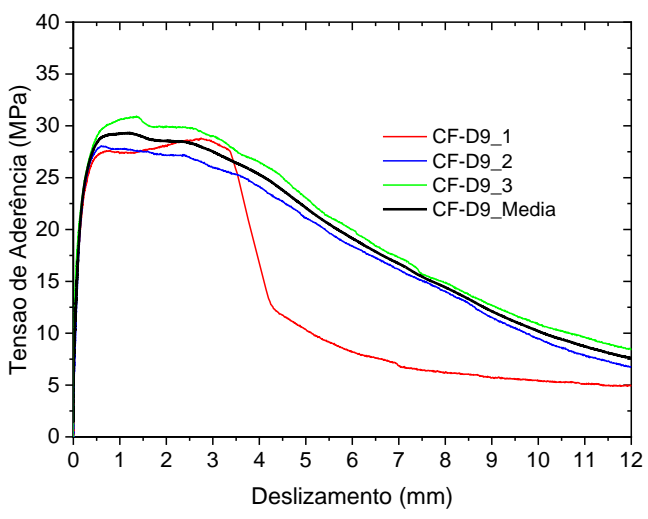

a)

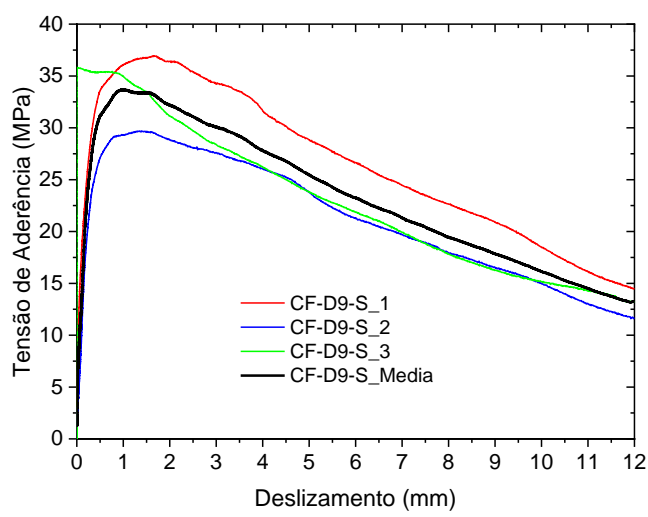

b)

Fonte: Autoria própria

Figura 99-Tensão de aderência versus deslizamento para cada espécime (e sua média) do ensaio definitivo com $\mathrm{Dc} / \phi=15$ sem fibras: a) Sem estribo b) Com estribo

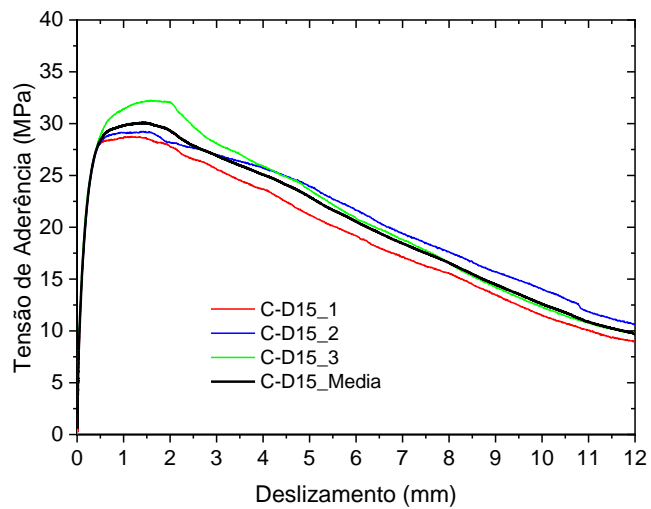

a)

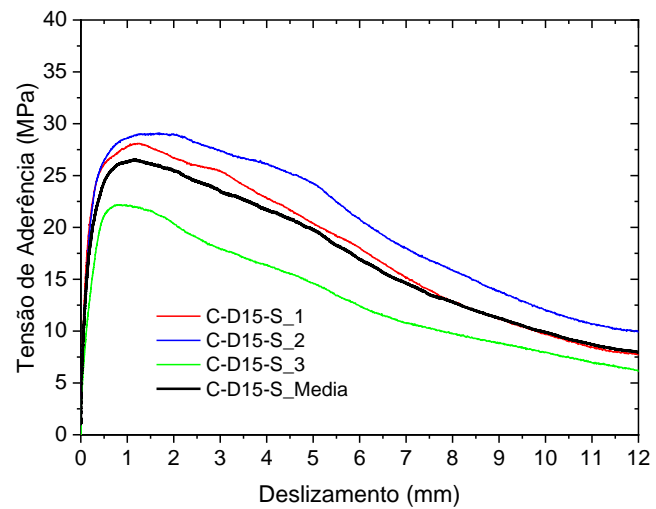

b)

Fonte: Autoria própria 
Figura 100-Tensão de aderência versus deslizamento para cada espécime (e sua média) do ensaio definitivo com Dc/ $\phi=15$ com fibras: a) Sem estribo b) Com estribo

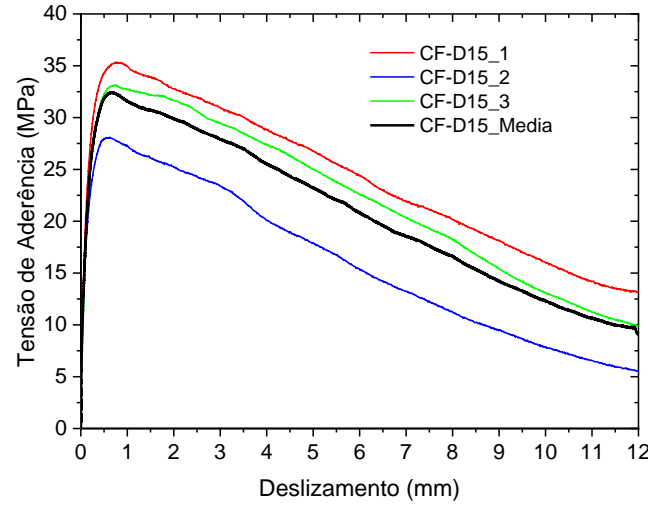

a)

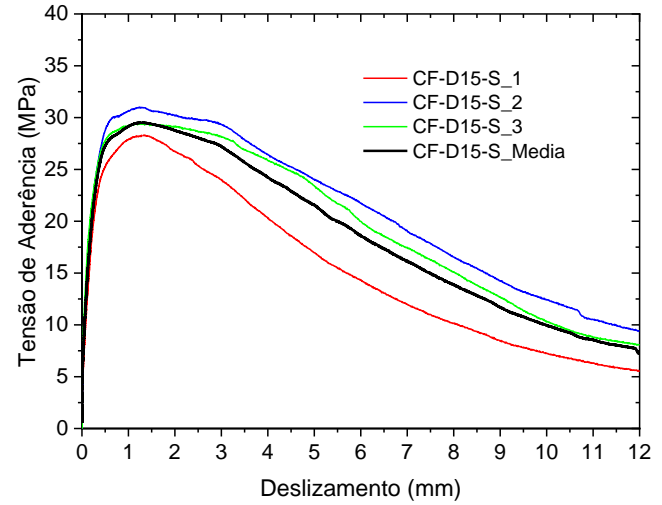

b)

Fonte: Autoria própria 